Florida International University FIU Digital Commons

$12-1989$

\title{
A model of school managerial control : the systematic analysis of managerial behaviors, processes, and indicators
}

Ira Elliot Bogotch

Florida International University

DOI: $10.25148 /$ etd.FI14051180

Follow this and additional works at: https://digitalcommons.fiu.edu/etd

Part of the Educational Leadership Commons

\section{Recommended Citation}

Bogotch, Ira Elliot, "A model of school managerial control : the systematic analysis of managerial behaviors, processes, and indicators" (1989). FIU Electronic Theses and Dissertations. 1769.

https://digitalcommons.fiu.edu/etd/1769

This work is brought to you for free and open access by the University Graduate School at FIU Digital Commons. It has been accepted for inclusion in FIU Electronic Theses and Dissertations by an authorized administrator of FIU Digital Commons. For more information, please contact dcc@fiu.edu. 
A Model of School Managerial Control: The Systematic Analysis of Managerial Behaviors, Processes, and Indicators

Ira Elliot Bogotch College of Education Department of Educational Leadership, Research, and International Development Education Florida International University 
I certify that I have read this study and that in my opinion it conforms to acceptable standards of scholarly presentation and is fully adequate, in scope and quality, as a dissertation for the degree of Doctor of Education.

James A. Hale, Chairperson

Professor of Educational Leadership

Peter J. Cistone

Professor of Educational Leadership

Professor Stephen Loveless

Assistant Professor of Public Administration

December, 1989

Dean of Graduate Studies 


\section{A Model of School Managerial Control}

\section{ABSTRACT}

The theoretical construct of control has been defined as necessary (Etzioni, 1965), ubiquitous (Vickers, 1967), and on-going (E. Langer, 1983). Empirical measures, however, have not adeguately given meaning to this potent construct, especially within complex organizations such as schools. Four stages of theory-development and empirical testing of school building managerial control using principals and teachers working within the nation's fourth largest district are presented in this dissertation as follows: (1) a review and synthesis of social science theories of control across the literatures of organizational theory, political science, sociology, psychology, and philosophy; (2) a systematic analysis of school managerial activities performed at the building level within the context of curricular and instructional tasks; (3) the development of a survey guestionnaire to measure school building managerial control; and (4) initial tests of construct validity including inter-item reliability statistics, principal components analyses, and multivariate tests of significance. The social. science synthesis provided support of four managerial control processes: standards, information, assessment, and incentives. The systematic analysis of school managerial activities led to further categorization between structural freguency of behaviors and discretionary gualities of behaviors across each of the control processes and the curricular and instructional tasks. Teacher survey responses $(\underline{N}=486)$ reported a significant difference between these two dimensions of control, structural frequency and discretionary gualities, for standards, information, and assessments, but not for incentives. The descriptive model of school managerial control suggests that (1) teachers perceive structural and discretionary managerial behaviors under information and incentives more clearly than activities representing standards or assessments, (2) standards are primarily structural while assessments are primarily gualitative, (3) teacher satisfaction is most closely related to the eguitable distribution of incentives, (4) each of the structural managerial behaviors has a qualitative effect on teachers, and that (5) certain gualities of managerial behaviors are perceived by teachers as distinctly discretionary, apart from school structure. The variables of teacher tenure and school effectiveness reported significant effects on school managerial control processes, while instructional levels (elementary, junior, and senior) and individual school differences were not found to be significant for the construct of school managerial control. 
And until the leaders of educational thought in America go beyond gathering statistics and the prosecution of scientific inquiry, however valuable and necessary these undertakings may be, and grapple courageously with this task of analysis and synthesis, the system of education will lack direction and the theory of education will but reflect the drift of the social order.

\section{-George s. Counts The American Road to Culture, 1930}

In dealing with a problematic situation, a decision maker must develop a concept - a representation or a model - of it. He attempts to solve the problem as he conceives it. Thus if his conception is wrong, the solution to the problem as conceived may not solve the problem as it exists. A common example is a formulation of a problem that leads to the suppression of symptoms rather than the removal of the cause of a deficiency that creates the problem. Because of such errors of conceptualization, it has often been observed that we more frequently fail to face the right problem than fail to solve the problem we face.

-Russell L. Ackoff The Art of Problem Solving, 1978 


\section{Acknowledgments}

It gives me great pleasure to present this dissertation to the faculty of Florida International University. The work now assumes a new status: no longer a very private affair, it becomes a public statement, hopefully encouraging discussion and debate.

I especially want to thank some of the people whose direction and patience contributed to the ideas as they evolved over the last three years. Professor James Hale, my doctoral committee advisor, was clearly the gentle, driving force behind this work. He brought his own curiosity, humor, and clarity to the project. He was my mentor in the very best sense.

My thanks also to the two other members of my committee who were there whenever I needed them, as advisors and teachers: Professor of Education, Dr. Peter Cistone and Professor of Public Administration, Dr. Stephen Loveless. The latter introduced me to the field of organizational theory, while Professor cistone encouraged me to confront the political dynamics of school organizations. Both men addressed complexity and change with flexibility and steadfastness; the same kind of behaviors needed to successfully manage people.

The test of any theory, of course, is its practicality. Credit must be given to Dr. Paulette Johnson whose assistance in linking empirical data to the theory of managerial control was essential.

There are two other teachers whose presence I felt every step of the way: Dr. Phyllis Blumenfeld, of the University of Michigan, who offered guidance, structure, and friendship; and Dr. John Fanselow, of Teachers College, who instilled in me the importance of systematic analysis in the search for meaning.

Finally, I want to thank my wife, Rochelle, for tolerating the lost weekends and still loving me. 
TABLE OF CONTENTS

ABSTRACT

iii

ACKNOWLEDGEMENTS

TABLE OF CONTENTS

$\mathrm{vi}$

LIST OF TABLES

$x i$

LIST OF FIGURES

xiv

CHAPTER ONE:

A STUDY OF SCHOOL MANAGERIAL CONTROL

Introduction

The search for Meaning

Managerial Control

Control in organizations

1

2

4

8

Statement of Purpose 15

Research Objectives $\quad 15$

overview of procedures 16

Limitations $\quad 22$

Self-Report Measures 23

Sample size $\quad 25$

$\begin{array}{ll}\text { Significance } & 27\end{array}$

Organization of the Report 31

CHAPTER TWO:

REVIEW OF RELATED LITERATURE: PART I

overview 32

Organizational Theory: Complexity

and Hierarchy 38

problematic Effects of organizational

Complexity

Problematic Effects of Managerial

Complexity

Hierarchical control: Formal.

Authority Variables

School Hierarchical Control.

District-School Control

Principal-Teacher Control 
Table of contents continued

Summary \& Implications of Hierarchical control

\section{REVIEW OF RELATED LITERATURE: PART IT}

Beyond Structure: Disciplines, Theories, and culture

Political control

The Concept of Influence 74

Decision-Making 80

Key Actors \& Groups and Their Linkages 82

Summary \& Implications of Political

Control

Social control

Social control: The concept

Social Control: Processes

Summary \& Implications of Social

control

Psychological control

Behaviorism

Cognitive Theories \& Individual

creativity

Developmental stages

Integrative Theories: Social-

Psychology

Summary \& Implications of

Psychological control

Synthesis of social science control Theories

\section{CHAPTER THREE:}

A PRELIMINARY STUDY OF SCHOOL MANAGERIAL CONTEXT: CURRICULUM AND INSTRUCTION

Introduction

Statement of Purpose

objective

Procedures and Methods

Subjects

Instrument

Data Collection procedures 
Table of contents continued

Data Findings 138

Standards 140

Summary of Standards 1.42

Information 143

Summary of Information $\quad 145$

Assessment $\quad 145$

Summary of Assessment $\quad 148$

Incentives 149

Summary of Incentives $\quad 152$

Conclusions 153

Implications 158

$\begin{array}{ll}\text { Summary } & 161\end{array}$

CHAPTER FOUR:

OPERATIONAL MEASURES OF MANAGERIAL CONTROL

Introduction 163

Dimensions of Managerial Control 163

Philosophical Foundations of Processes

structure and Meaning of Managerial

Behaviors $\quad 173$

The Processes of Managerial control 182

Control of Standards 191

Control of Information 197

Control of Assessment 201

control of Incentives 206

The Indicators of Managerial Control 209

Indicators of Standards 210

Clarity of standards 211

Difficulty of standards 213

Indicators of Information 215

Adequacy of Information 217

Utility of Information $\quad 217$

Indicators of Assessment 218

Worth of Assessment $\quad 219$

Fairness of Assessment 220

Indicators of Incentives 221

Meaningfulness of Incentives 223

Equitable Distribution of Incentives 224

Sumary of Indicators 225

$\begin{array}{ll}\text { Conclusions } & 227\end{array}$ 
Table of contents continued

\section{CHAPTER FIVE:}

PROCEDURES AND METHODS

$\begin{array}{ll}\text { Introduction } & 229\end{array}$

Sample Population $\quad 230$

Instrumentation: Questionnaire 233

Item Construction 234

Pre-Test Procedures $\quad 237$

School Managerial Control Questionnaire 241

Data Collection $\quad 246$

Data Analyses 249

Descriptive statistics 249

Reliabilities and Construct Validation 251

Inferential statistics 252

CHAPTER SIX:

DATA ANALYSIS

Introduction $\quad 255$

Descriptive Statistics

Mean Values and Cumulative Percentages 258

Item Correlations 264

Correlations Between Managerial

Latent Aggregate Variables 269

Model Testing $\quad 277$

Reliabilities $\quad 277$

Principal Components Analysis 283

Revised Model Scale 296

Inferential statistics 304

Structural and Discretionary Managerial
Behaviors

Teacher Tenure and Instructional Levels 307

School Effects 311

School Effectiveness $\quad 314$ 
Table of Contents continued

CHAPTER SEVEN:

SUMMARY, CONCLUSIONS, AND IMPLICATYONS

Summary

Conclusions

standards

Information

Assessment

339

Incentives

340

Implications for Further Research

344

Theory-building

Construct Validation

344

Hypotheses Testing

\section{APPENDIXES}

A. School District Approval to Conduct preliminary study with Curriculumoriented principals and staff

B. Interview Guide Used in the preliminary study

C. School District Approval to Conduct reacher survey study at 14 schools

D. Cover Letter and School Managerial Control Questionnaire (SMCQ)

E. Survey Follow-up Letters and Sample Memos 390 


\section{LIST OF TABLES}

TABLE

Rage

1. Synthesis of social science control theories ......... 224

2. Matrix of academic disciplines and managerial control

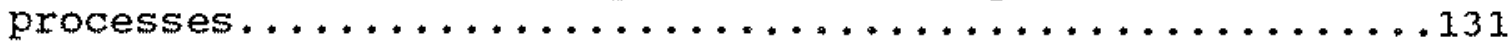

3. School characteristics of sample principal population...135

4. Managerial activities categorized by tasks under the process of standards..................................

5. Managerial activities categorized by tasks under the process of information.......................... 144

6. Managerial activities categorized by tasks under the process of assessment........................... 146

7. Managerial activities categorized by tasks under the process of incentives...................... 150

8. Nominal rank order of managerial activities by control

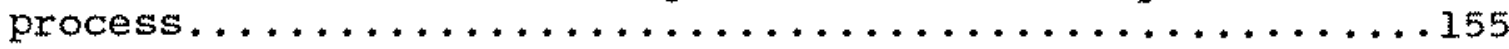

9. Nominal rank order of managerial activities by curricular and instructional tasks............. 156

10. Rank order of managerial activities categorized by

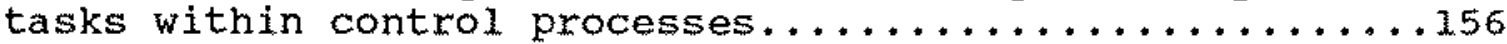

11. Selected differences between the two dimensions of

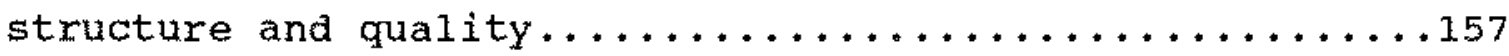

12. Sample Survey Population: Classroom Teachers Per School..232

13. School Managerial Control Variables and Their

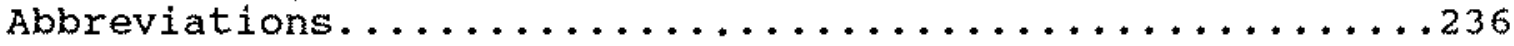

14. Pre-Test statistics on the SMC Questionnaire.........239

15. Items on the School Managerial Control Questionnaire (SMCQ) arranged by aggregate variables............242

16. Teacher Responses to the $\mathrm{SMCQ} \ldots \ldots \ldots \ldots \ldots \ldots \ldots \ldots \ldots \ldots$

17. Top Quartile of Teacher Agreement Responses to Items

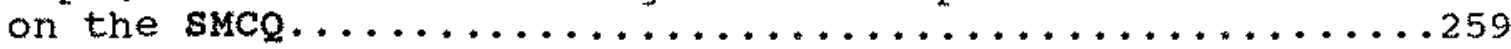




\section{List of rables continued}

18. Bottom Quartile of Teacher Agreement Responses to Items

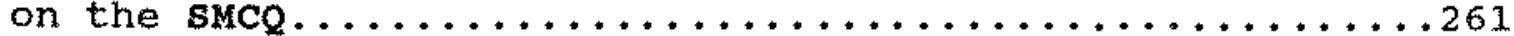

19. Items With Low Teacher Response Rates by Level of

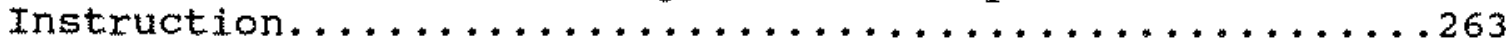

20. Highest Positive Correlations and Commonalities on the

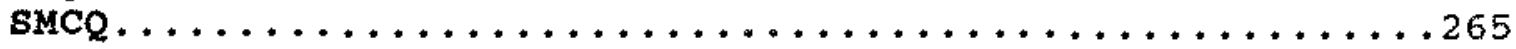

21. Low Item Correlations Between Managerial Control and

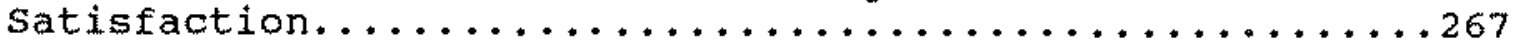

22. Means and Freguencies of Aggregate Managerial Control

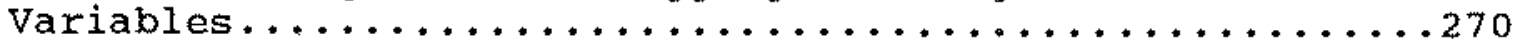

23. Cumulative Percentages of Teacher Agreement on Curricular and Instructional Tasks for standards.......272

24. Cumulative Percentages of Teacher Agreement on Curricular and Instructional Tasks for Information.....273

25. Cumulative Percentages of Teacher Agreement on Curricular and Instructional Tasks for Assessment. . . . . 274

26. Cumulative Percentages of Teacher Agreement on Curricular and Instructional Tasks for Incentives......275

27. Means and Cumulative Percentages of Teacher Agreement of Managerial Control processes.................276

28. Corrected Item-to-Total Correlation Differences Between Aggregate Variables and the overall Model............279

29. Reliability statistics for School Managerial Control....281

30. Factor Loadings From Varimax Rotation of Principal Components on smc Items....................287

31. Varimax Rotation of Principal Components Matrix for

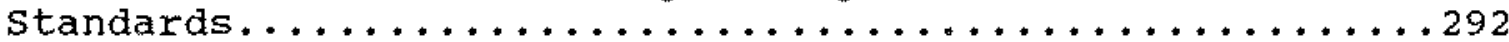

32. Varimax Rotation of Principal Components Matrix for

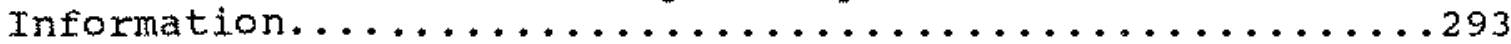

33. Varimax Rotation of Principal Components Matrix for

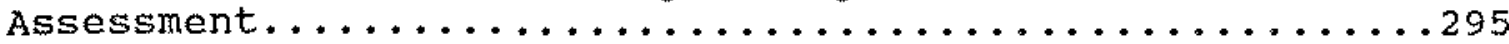

34. Varimax Rotation of Principal Components Matrix for Incentives...............................296 
xiii

List of Tables continued

35. The Revised Scale on the smcQ $\ldots \ldots \ldots \ldots \ldots \ldots \ldots \ldots 298$

36. Varimax Rotation of Principal Components on the

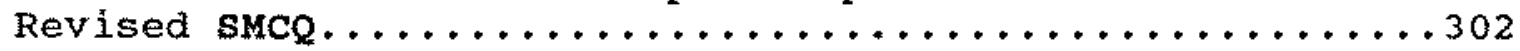

37. The Structural and Discretionary Behaviors of Managerial Control for the Four Managerial Control processes......306

38. Means and Standard Deviations of Teacher Tenure by Level for the Managerial Control Processes............. 309

39. Means and Standard Deviations of Teacher Tenure by the Managerial Control Processes..................... 310

38. Comparison of Merit Versus Matching Schools by Managerial Processes and Behaviors............... 316 


\section{IIST OF FIGURES}

FIGURE

page

1. Curricular and instructional school managerial control

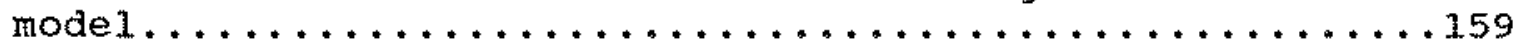

2. Theoretical model of construct validation for managerial concepts.................... 173

3. Reclassification of Lawler and Rhode's behavioral

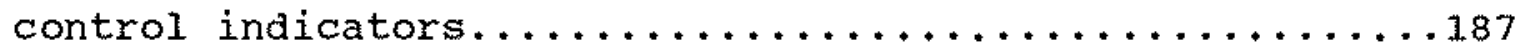

4. The structural and discretionary behaviors for standards

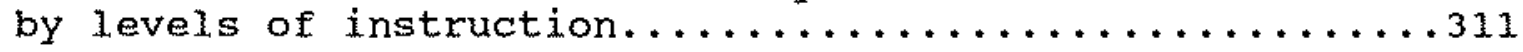

5. Individual school effects for the structural and discretionary behaviors of managerial information......313

6. Interaction effect between experienced and less experienced teachers within merit and matching schools

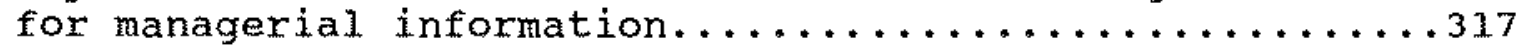

7. Managerial Research Paradigm................. 325

8. Results from aggregate variable testing of school

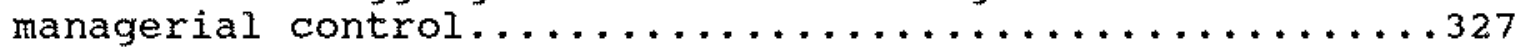

9. Three levels of school managerial control: structural, integrative, and discretionary under the managerial

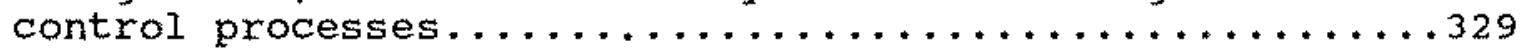




\section{CHAPTER ONE}

\section{A study of School Managerial Control}

\section{Introduction}

There is little agreement among organizational researchers or school administrators as to the meaning and use of the abstract concept organizational control. At one end of the theoretical spectrum, control is considered as a first principle of organizational theory, a key to understanding organizational structure and individual behaviors. Control is portrayed as so potent a concept that it is referred to as the "glue" that holds organizations together (Pfeffer, 1978a). Words that have been used to describe its function range from "necessary" (Etzioni, 1965 ) and "on-going" (E. Langer, 1983) to "ubiquitous" (vickers, 1967). In these instances, it shares equal prominence with the concepts "power" (Etzioni, 1965) and "influence" (Cartwright, 1965; Smith \& Tannenbaum, 1963) such that clear distinctions are difficult to decipher (Meier, 1982).

Yet not all theories hold "control" in such high esteem. In fact, many empirical studies such as Turcotte (1974) measure the negative consequences of organizational control mechanisms. At this opposite end of the theoretical spectrum, control is narrowly defined by formal authority or hierarchical structures. The predominant indicators of its presence are rules and regulations and the frequency of formal, supervisory interactions between individuals within organizations. Unlike the expansive definitions held by some control theorists, the latter empirical 
definitions view control as a matter of constraints and conformity.

\section{The search for Meaning}

The conception of control as managerial activities is largely a matter of choice (Tannenbaum, Kavcic, Rosner, Vianelle, \& Wieser, 1974). It, therefore, involves skills (Koontz, 1971; E. Langer, 1983), processes (Hanson, 1981; Lawler \& Rhode, 1976; Smith \& Tannenbaum, 1963), judgment (Vickers, 1967), and knowledge. Various control typologies have different sets of reference points: written policies and directives (Lang, 1965), organizational structure and size (Blau \& Scott, 1962; Peterson, 1984), politics (Pfeffer, 1978a), professional norms, socialization, and values (Argyris Schon; 1982, Vickers, 1967), external environments (Meyer \& Scott, 1983; Pfeffer, 1978a), public opinion (Bidwell, 1965), and the needs of individuals (E. Langer, 1983). Yet none of these reference points by themselves offers a sufficient yardstick to measure organizational control. It is only when each is measured interactively that the complexity and validity of control emerges.

The position taken in this study is that a synthesis of disciplines, typologies, activities, and needs is both required and possible given (a) the evidence of complexity of school organizations (Astuto \& Clark, 1985; Lortie, 1977; Miles, 1981; Patterson, Purkey, \& Parker, 1986) and (b) social science research methodology and measurement models (Fielding \& Fielding, 
1986; Lennox, 1988; Long, 1983a; 1983b; Hughes, Price, \& Marrs, 1986) which permit the testing of hypotheses that link theoretical constructs to empirical data. others who have attempted similar syntheses have reported the road littered with disagreements, entanglements, and contradictory findings (Cartwright, 1965; Hanson, 1981; Lortie, 1969). There are, however, circumstances today which offer greater opportunities for success through advances in substantive theory in school organizations and in social science research methodology.

Several academic disciplines have had much to say about the meaning of control. Philosophers debate issues of freedom and responsibility, the role of the individual within the state, and ways of knowing which influence and link ideas with actions; organizational theorists study the effects of structures and behaviors on performance; political scientists describe the dynamic struggles for power and influence among key actors and groups, including those outside the organizations' boundaries; sociologists reveal the effects of cultures, roles, and norms on human interaction; and, psychologists report on cognitive processes and the needs people have to be in control. It is not just organizations that suffer when not under control, so, too, do individuals. The emphases and orientations of the disciplines are each different, but the objectives are the same: the search for meaning of the concept of control, how it operates, and what effect it has on organizational effectiveness and the quality of life. Without understanding gained by specific measurable 
indicators, however, the latter issues remain a matter of speculation.

\section{Managerial control}

one focus of this study was to validate the theoretical construct of managerial control. The delimitation of managerial, as opposed to organizational, is significant in that the former permits one to confine the research to building-level variables and participants. The trend in school organizations is towards growth, centralization (Meyer \& Scott, 1983), and standardization (Darling-Hammond \& Wise, 1985). As a result, organizational or institutional control seems more a matter of occurrences outside the school building itself. Not only are the effects of such external efforts inchoate (Fullan, 1982; Mann, 1978; Mclaughlin, 1978), but their legitimacy is suspect (Elmore, 1983; 1987). similarly, recent related areas of empixical research on effective schools (Edmonds, 1979), school improvement (Goodlad, 1987), planned change (Fullan, 1982), and cultural leadership (Sergiovanni, 1987) a11 seem to converge on the building level or what vickers (1967) called the "level of action."

The action domain within schools revolves around the management and implementation of curriculum and instruction at the building level (Bossert, Dwyer, Rowan, \& Lee, 1982; Griffin, 1988; Little \& Bird, 1987). A study of managerial control that is delinited to managerial behaviors associated only with curricular and instructional tasks would seem to have heuristic 
value. Such a specific focus would not deny the influence of either environmental (Rossmiller, 1983) or classroom-level teacher control (Kerr, 1987) on curricular and instructional behaviors. Successful building administrators need to be consciously aware of the restraints imposed by both groups of variables which affect the management and implementation of curriculum and instruction. In fact, administrators, teachers, and the curriculum "must be acceptable to the forces of [extraorganizational] control" (Counts, $1930 / 1971$, p. 23). Nevertheless, managerial control processes have their strongest behavioral impact at the juncture of building-level administrator-teacher relations (Andrews, 1987; Little \& Bird, 1987).

But no matter how narrowly circumscribed is the analysis of managerial control, it remains an abstract, theoretical construct. The concept is abstract in that it is a latent, aggregate variable which has common characteristics across different behaviors and tasks. It would be worthwhile, therefore, to define these common characteristics and to operationalize behaviors so as to provide school builaing administrators with quidelines for improved managerial practice. since the turn of the century, control functions have been consistently listed among the four or five primary areas of administration (Pugh, Hickson, \& Hinings, 1985). Its administrative importance lies not only with fostering organizational stability, but also with developing change 
strategies that improve organizational effectiveness and the quality of organizational life (Koontz, 1971; Lawler \& Rhode, 1976; Patz \& Rowe, 1977; Vickers, 1967). What is still unclear is the meaning and daily operations of control (Bossert, Dwyer, Rowan, \& Lee, 1982; Hanson, 1981; Lortie, 1969; Pfeffer, 1978a). As an abstract concept, it is not simply one thing or a single behavior, the effect of which may be known to us fully and immediately. It exists, in different degrees, in all organizational contexts (Etzioni, 1965; Pfeffer, 1978a). Evidence of its existence is both a priori, in understanding and reason (E. Langer, 1983) as well as in experience (Koontz, 1971). A clearer understanding of the concept of managerial control. and how it is exercised over the dominant technology of schools curriculum and instruction- cannot by itself determine the rightness of any one course or reform. Managerial controls are not ends in themselves, but are instrumental in maintaining organizational health and, when necessary, assisting with change efforts (Bossert, et al, 1982; Patz \& Rowe, 1977). Vision and direction are functions more of organizational leadership than of control (Greenfiela, 1987; R. Harrison, 1985, pp. 133-134); control is largely a matter of managerial skills (E. Langer, 1983), technigues (Koontz, 1971), and processes (Lawler \& Rhode, 1976) which create immediate and reciprocal, looking-glass perceptions among individuals within organizations (Locke, 1977, p. 183).

Managerial controls can signal when the technical behaviors 
are ineffective and help educators to do what they do better. This duality suggests that the elements of control are matters of (1) conformity to known standards (Lawler \& Rhode, 1976; Locke, 1977; Vickers, 1967), (2) information sources and uses (Pfeffer, 1978a; Sproul1, 1981), (3) measures of success (Vickers, 1967), and (4) incentives to planned change strategies (Bossert, et al., 1982; Lawler \& Rhode, 1976, p. 137; Schein, 1972, pp. 76-79). When control is viewed at any one specific point in time, the emphasis is largely on conformity to standards, output measures, and sanctions for deviance (Koontz, 1971. p. 140). But when control is described as a series of processes towards a desired end, then it emerges as a proactive system (Koontz, 1971, p. 141; Patz \& Rowe, 1977, pp. 66-73; Schein, 1972, 76-79), with other attributes.

Based on a synthesis of research findings, the definition of managerial control assumes:

1. that control is a potent theoretical concept that is present in every organization regardless of its formal structure;

2. that control operates, at the building or technical core level, along a series of organizational processes which include standards, information, assessment, and incentives; and

3. that each of the above processes are defined by two dimensions (Ames \& Ames, 1987; Astuto \& Clark, 1985): structural. patterns of frequency, persistence, and regulaxity (Dornbusch \& Scott, 1975, p. 354) and qualitative behaviors measuring the manner in which patterns and technology are operationalized 
(Locke, 1977; Miles \& Vergin, 1966).

It should be noted that any discussion of managerial control is inherently optimistic, for it implies, unlike the 'garbage can' model (Cohen, March, \& Olsen, 1972), that the problems facing organizations are ultimately solvable. Solutions for the problems facing school organizations, however, are neither simple nor straightforward. State legislative policies and district directives are only partial ingredients in the managerial control formula. Their kinds of solutions - rule-making, social

engineering, or rational-structural approaches - ignore the needs and capabilities of people within a specific cultural context. Instead, the real underpinnings of control have as much to do with internal human qualities as with external structure, politics, and social factors. All people share needs to succeed on some leve1. But it is also a basic human need to derive satisfaction from succeeding. Any control system that ignores the latter ingredient cannot succeed over time. Thus, the nature of control mechanisms is not simply technological advances, but rather knowledgeable advances 1 inked to satisfying human needs.

\section{Control in organizations}

Research in organizational theory has identified nonhierarchic and non-bureaucratic mechanisms of control (Lortie, 1969). Included among these non-hierarchic determinants are professionalism (Bidwel1, 1965; Blau \& Scott, 1962), collegiality (Etzioni, 1965; Lortie, 1969), school and community culture 
(Sergiovanni, 1987), trust and confidence (Meyer \& Rowan, 1977), and participation (Hanson, 1981; E. Langer, 1983, p. 83; Smith \& Tannenbaum, 1963). Each of these determinants of control are present, in varying degrees, in schools as well as in other organizational settings. Unfortunately, the interaction among these factors as well as their optimum presence under different conditions is still largely a matter of speculation, particularly in the active task areas of school curriculum and instruction (Dornbusch \& Scott, 1975).

In reporting these non-hierarchic findings, the tendency has been to discard the older, rational, bureaucratic paradigm, replacing it in toto with revised analyses of non-rational explanations (Lincoln, 1985: Patterson, Purkey \& Parker, 1986; Sergiovanni, 1987). Lost in this paradigmatic shift is the explanatory power of structural analyses (Pfeffer, 1978b). This loss seems too high a price to pay, no matter how difficult it may be to integrate measures of the two paradigms. Our preliminary investigation, reported in Chapter Three, caused us to hypothesize that control operates in two interrelated dimensions: a quantitative, structural dimension measured by the frequency and stability of interactions between building-level administrators and teachers, and a qualitative dimension which explores the salient qualities and the behavioral impact of these interactions. The dimensions are to be viewed as complementary, rather than exclusionary.

Because of the necessary relationship between control and 
organizations, it is admittedly difficult to discuss control without referring directly or indirectly to organizational structures, and, hence, by implication, to paradigms (Meyer, Scott, \& Deal, 1983). Yet, it is equally well established that organizations consist of individuals, each having subjective and differing needs and wants, among them the individuals' need to control his or her own environment (E. Langer, 1983).

When organizations are viewed along a structural, quantitative dimension, organizational control has been defined by the patterns of formal authority (Blau \& Scott, 1962), specifically, the chain of command, the organizational technology (Thompson, 1967), and the flow of information (Eisenhardt, 1985). structural analyses of control often avoid looking at processes (Charters, 1981). Their units of analyses are structural variables such as size, organizational levels, and personnel policies, each synonymous with formal hierarchy (Blau \& scott, 1962). Even in more democratic organizations, formal authority and control are still viewed as fundamentally hierarchic (Tannenbaum et al*, 1974). Informal arrangements may also follow clearly identifiable patterns which add to the stability and regularly of the organizations' structure. Thus, structural control measures need not be limited to written rules, job description, and organizational charts.

The control structures assist in aligning idiosyncratic diversity with the organizations' goals and purposes. As organizations grow in size and complexity, the structural control 
systems themselves grow accordingly to encompass related and complex systems of technology, communication, and coordination (Cohen, Deal, Meyer, \& Scott, 1979; Cohen \& Miller, 1980; Lawler \& Rhode, 1976, p. 1976; Wellisch, MacQueen, Carriere, \& Duck, 1978).

In a broader, social context, however, organizational control also contributes to opportunities for individual growth and achievement (Patz \& Rowe, 1977). This aspect of control exists as part of the organizational structure, yet distinct from it as well. Along this other dimension, the needs and qualities of control remain the same regardless of the organizations" structural patterns (E. Langer, 1983). While control is an integral part of organizational life (Etzioni, 1965; Pfeffer, 1978a; Vickers, 1967), it may also be viewed as essential to life itself (E. Langer, 1983; Scott\& Scott, 1971). Somewhat arbitrarily, Heilbroner (1975) refers to man's two underlying personality traits: a "hunger" for political authority and a "fantasy" of political identification (p. 122). Since these needs for control reside within the individual, the discussion of organizational control becomes more than just evidence for any one particular structural entity or framework (Pfeffer, 1978a). Along this so-called qualitative dimension, control occurs as part of the natural phenomenon of human social interaction (Scott \& Scott, 1971). Every interaction involves some measure of control by which individuals are influenced by the manner of that interaction. This suggests that a more comprehensive 
approach to the understanding of control involves an integration of these two dimensions in such a way that the synthesis clarifies the role of both the controller and the controlled (Scott \& Scott, 1971). Both parties become aware of four aspects: themselves, the other, the specific tasks they perform, and managerial control processes. At the core of this synthesis are the perceptions held by the individuals (Andrews, 1987, Argyris \& Schon, 1982; Locke, 1977; vickers, 1967), the organizational processes (Schein, 1972; Smith \& Tannenbaum, 1963), and the techniques and skills employed in exercising control (Koontz, 1971; E. Langer, 1983).

Smith \& Tannenbaum (1963) have defined control as "any process in which a person or group determines or intentionally affects what another person will do." Based on this global definition, Tannenbaum and his associates have reported positive correlations between high "total control" and both organizational effectiveness (Smith \& Tannenbaum, 1963, Tannenbaum, et al., 1974) and expert power (Bachman, et al., 1968). Although these are certainly potent hypotheses, they still leave unexplained the specific daily managerial processes, their interrelationships, and their effects on belief systems and performance unexplained (Bossert et al., 1982; Pfeffer, 1978a; Koontz, 1971).

Recent empirical studies on school organizations have generaliy reported an absence of formal curricular and instructional control mechanisms. The measures used to support these conclusions have been primarily district office-principal 
and principal-teacher interactions (Cohen, et al., 1979; Cohen \& Miller, 1980; Deal \& Cellotti, 1980; Dornbusch \& Scott, 1975, Eye, Netzer, \& Krey, 1971; Fallon, 1979; Hannaway \& Sproull, 1978-79; Martin \& Willower, 1981; Pellicer, 1982; Peterson, 1984). All of these measures have a quantitative bias that stressed perceptions of the presence of formal policies and the frequency of interactions. It is assumed that the higher the frequency, the greater the managerial control.

Not only is it likely that this assumption is erroneous (James, Mulaik, \& Brett, 1982, pp. 51-54; Turcotte, 1974), but the definition of control as formal policy and as interaction frequency is theoretically inadeguate (Bidwe11, 1965; Pfeffer, $1978 \mathrm{a} ; 1978 \mathrm{~b})$. Ironically, when evidence of freguent administrator-teacher interactions has been empirically supported (Ogawa \& Hart, 1985; Peterson, Murphy, \& Hallinger, 1987), it has been suggested elsewhere that their function is not organizational effectiveness, but rather largely symbolic, serving only to legitimize educational institutional status (Meyer \& Rowan, 1977).

The weak empirical findings regarding the presence of school organizational control stand in direct opposition to theoretical views of control which argue that control functions are ubiguitous (Vickers, 1967), on-going (E. Langer, 1983), necessary (Etzioni, 1965; Pfeffer, 1978a), correlated to effectiveness (Smith \& Tannenbaum, 1963) and to the attainment of organizational goals (Koontz, 1971), and, ultimately, serving as 
the 'glue' which holds the organization together (Pfeffer, 1978a). This raises an obvious question: how can such a seemingly potent concept remain hidden to empirical researchers? The answer would appear to lie in the measures used to define control.

Identifying the concept, activities, and measures of school organizational control is a complex undertaking (Cartwright, 1965; Hanson, 1981; Lortie, 1969). When limited to the formal structure and hiexarchy, it tends to explain too much about too little. Multivariate empirical findings on control have begun to peel away normative ideals of how schools ought to be. This Iine of research reports that school organizations have multiple, conflicting, and ambiguous objectives, isolated work arrangements, diverse instructional technologies, infrequent supervision, and limited formal and informal evaluations and incentives (Patterson, Purkey, \& Parker, 1986). There is neither complete information processes nor continuous monitoring and measures of performance. Such a non-rational composite adds complexity to the task of theory building, for it suggests that control activities involve more than top down rules and written regulations. It further implies that there is an art to control that requires measures of artistic appreciation (Vickers, 1967). The task of theory building will take time and sustained effort to decipher and systematize descriptive activities beyond the "vague objectives of managerial work" (Bacharach \& Lawler, 1982; Mintzberg, 1971). The work must proceed in stages: from a 
comprehensive, yet explicit rationale to the identification of discrete behavioral indicators and measures to an auxiliary theory that can be put into practice. There is a need for studies that report on the positive directions taken at each of these stages, along with a need to report on false starts, miscalculations, and errors in juagment so that future efforts may avoid repeating them.

\section{Statement of purpose}

Presently, no adequate definition or typology of control exists which can provide school principals with practical guidelines for curricular and instructional decision-making. The purpose of this study was to increase understanding of the theoretical construct, managerial control, as it relates specifically to building-level, curricular and instructional tasks performed and delegated by school principals. A rationale for a process model of control is needed and construct validation must be supported by data analyses.

As a theoretical study, there was a need to synthesize diverse literatures relevant to the concept of control. As an empirical research design, there was a need to validate the process model of managerial control in order to provide school administrators with specific guidelines for improved practice.

\section{Research objectives}

The research objectives of this study were: 
(1) to develop a process classification model to increase understanding of how school building administrators exercise managerial control over curriculum and instruction at the building-level, and

(2) to test the construct validity of the control process classification model by determining the manner and extent to which principals exercise building-level control over curriculum and instruction.

\section{Overview of Procedures}

The first step in accomplishing objective one, the development of a process model of managerial control, involved the synthesis of research findings from several bodies of literature within the fields of organizational theory, political science, sociology, psychology, and philosophy. The contributions from these disciplines were then integrated into the cultural and contextual framework of public school organizations. This task was accomplished through a literature review of school control mechanisms and through a preliminary research study whose objectives were (a) to identify specific activities of principals as instructional leaders, and (b) to categorize control activities which emerged from the responses of principals' and other building level personnel.

In a preliminary study by this researcher, in-depth interviews were conducted with a small sample of principals who were nominated by their district as effective instructional 
leaders. This investigation generated a comprehensive list of activities often associated with influence-gaining activities in schools (Bossert, et al., 1982) and with school control categories at the state, district, and building levels ( $R$. Campbe11, Cunningham, McPhee, \& Nystrand, 1985; Peterson, 1984; Peterson, Murphy, \& Hallinger, 1987). The literature by itself, however, falls short of providing school principals with specific task and administrative guidelines for improved practice (Duke, 1982 ; Peterson, 1984).

In analyzing both published studies and the interview data, the need for a different classification scheme became apparent. A rationale for process classification was developed based on an interdisciplinary review of literatures on control theories and on the open-ended responses in the preliminary interview study. A theoretical distinction was made between two dimensions found within each of the control processes: a structural dimension comprised of structural patterns, formal as well as informal, and a qualitative dimension which reflects the attitudes, needs, and beliefs associated with managerial control processes and behaviors. Structural control patterns, such as formal control mechanisms and structural constraints, have received primary attention within the research on school control and instructional leadership. These reported findings reveal that structural and formal mechanisms provide only partial explanations of control, regardless of which specific dependent school variable is chosen (Deal \& Cellotti, 1980; Cohen \& Miller, 
$1980)$.

Although the qualitative dimension of theoretical constructs, including control, have been proposed elsewhere (Ames \& Ames, 1987; Astuto \& Clark, 1985; Cartwright, 1965; Turcotte, 1974), its role and treatment to date have been cursory and far less systematic than research using structural variables. Qualitative measures are often excluded from initial hypothesistesting procedures, reported instead as implications (Cohen \& Miller, 1980; Eisenhardt, 1985). It is in establishing behavioral indicators and measures of the gualitative dimension as an integral part of the managerial control concept that present the most challenging and unique aspect of this study. Following the synthesis of literatures, managerial control was hypothesized to be four distinct, yet interrelated control processes involving standards, information, assessment, and incentives; each of which operate along two dimensions: (1) stable and regular building-level, structural patterns, and gualitative administrative behaviors. Under each of the four control processes, which are considered here as aggregate, latent variables, the salient quantitative and gualitative indicators were defined and measured. These indicators emerged from both the literature reviews and the preliminary study. Their content validity, however, has yet to be tested empirically as part of a control model within school organizations. Therefore, at this stage of analysis, they represent assumptions or hypotheses within each of the four school control processes. 
The indicator frequency was used as the dominant measure of administrative-teacher quantitative interactions. The qualitative behavioral indicators describe the manner in which manaqerial control activities are exercised as well as the perceptions they create in teachers. It is assumed that these indicators interact with the structural-frequency indicators of contro1. For example, in the case of standards, qualities of clarity and difficulty complement the frequency measure on which principals and other building level administrators articulate standards. Their combined explanation forms a stronger basis on which to define the school control standards process. Similarly, the combination of frequency and qualitative measures are used for each of the other control processes.

The second research objective links a set of empirical survey data to the theoretical construct of managerial control. In order to test for construct validity, the first step involved the development of a curricular and instructional control instrument. The items on the questionnaire were taken directly from the results of the preliminary interview study. The questionnaire was pretested and then administered to teachers whose perceptions of administrative behaviors have been considered valid measures of control processes (Andrews, 1987; Cohen, et al., 1979). Specific curricular and instructional task contexts were included in each item. The tasks selected were teacher evaluation, staff development, curricular development, and the selection of textbooks and instructional materials 
(Cawelti \& Aakisson, 1986).

The proposed curricular and instructional control model represents a theoretical construct. It is unrealistic to expect a single indicator or entity to describe this complex construct (Hughes, Price, \& Marrs, 1986; Pfeffer, 1978a; Schein, 1972). For this reason, multivariate procedures were used to analyze the interactions among the behavioral indicators as well as among the latent, composite variables. The four processes of control are aggregate or composite variables of both structural and qualitative indicators. It was assumed that although there may be high correlations among the composite variables and observable indicators, they are distinct enough to allow for discussion and analysis.

principal components analysis was used to link the empirical data to the aggregate latent variables. Although the procedure is considered exploratory (Lennox, 1988), the same restrictions for confirmatory factor analysis were enforced, namely, that the model be explicitly identified prior to statistical testing and respecification (Alwin, 1974). Based on the substantive theory, the interrelationships between the variables and behavioral indicators will be stated. It was predicted that the highly correlated variables would form principal components characterized by managerial behaviors of standards, information, assessments, and incentives respectively. It is likely that reformulation or respecification of the measurement model will be necessary since (a) causal relations between the latent variables 
and behavioral indicators are more complex than implied by the basic measurement model which ignores causality (Herting \& Costner, 1985), (b) the data set initially contains responses to indicators which may not be discriminantly valid for a variety of reasons, and (c) a number of the model's assumptions contradict previous findings which hold that control varies according to different technologies (Eisenhardt, 1985; Koontz, 1971; Ouchi, 1978; Thompson, 1967). A fuller discussion of each of these assumptions and limitations is addressed in chapter Five of the study.

Finally, because of the exploratory nature of this study, descriptive statistical data were used to report the frequency and correlations among all the survey items and aggregate variables. Statistical tests of significance were employed to investigate a number of demographic relationships. Of particular interest were the relationships between control processes and dimensions and (a) instructional level, (b) teacher tenure, (c) individual school effects, and (d) school effectiveness. At this stage in theory development, it remains necessary for researchers to lay a stronger foundation for the comparison of research findings across different settings (Hughes, Price \& Marrs, 1986). The purpose for reporting the results of post hoc statistical tests of significance is not to assert causal relationships for even causal direction), but rather to generate specific hypotheses for future research. 


\section{Limitations}

Too often, organizational theorists' concern with matters of theoretical import has led them to overlook the operationalization of social science theories. Heuristic concepts are formulated with little or no consideration given to linkages with empirical findings. The more complex the theoretical model, the greater the difficulty in testing interacting variables. In the case of organizational control, its singular focus upon relationships of structural variables has tended to limit measures to formal authority and hierarchy. When the concept is reformulated to include qualitative variables found within informal patterns, professional, and technological relationships, then the exclusive use of structural variables (e.g., frequency of formal interactions, organizational size, among others) is inadequate. At best, structural evidence can provide partial explanatory support for the complex abstraction. At worst, the reported results are wrong. Usually, the matter is left at a fragmented, incoherent stage which calls for further research.

In order to break out of this unproductive cycle, greater attention must be paid to the validity and reliability of the theoretical constructs offered. Hypotheses based on abstract concepts cannot be tested directly (Sullivan \& Feldman, 1979, p. 10). Therefore, the development of measurable indicators that are valid and reliable is an essential step in theory building. Recent advancements is computer software permit a variety of ways 
to test concepts by linking them to data sets. The task, however, is neither simple nor straightforward since even the use of such rigorous criteria as those of confirmatory factor analysis is largely an exploratory endeavor (Lennox, 1988; Long, 1983b).

One of the primary concerns in establishing the construct validity of managerial control over curriculum and instruction involves the use of self-report, perceptual measures. How valid and reliable are these response indicators? The questions that needed to be answered in this study concerned the convergence of measures into cohesive dimensions and processes, yet at the same time, as measures that were sufficiently distinct to discuss and analyze differences. This objective raised concern about measurement error, inherent in all empirical research. Was it unsystematic, or did it reflect systematic bias or instrument interference such that respondents were not actually addressing the intended variable (Sullivan \& Feldman, 1988, p. 12-13)? Multiple sources and multiple indicators give us more confidence in the results. However, their Iinkages created problems of interpretation (Fielding \& Fielding, 1986). Finally, the validity of the data set may raise questions about the sample size used in the preliminary interview study.

\section{Self-Report Measures}

The decision to develop instrumentation for this study created limitations with respect to the reliance on principal and 
teacher perceptions as the key measure of curricular and instructional control. Based on previous research, self-report perceptions of control processes were assumed to be an accurate measure of building-level control (Dornbusch \& Scott, 1975; Lawler \& Rhode, 1976, p. 80; Locke, 1977; Vickers, 1967) so long as the following criteria were met:

criterion 1: attitudes and perceptions are linked contextually with overt and useful administrative behaviors (Koontz, 1971; Schuman \& Presser, 1981, p.232; Sudman \& Bradburn, 1983);

criterion 2: attitudes and perceptions are taken from different organizational levels so as to reflect both position control and mutual control (Abbott, 1975; Blau \& scott, 1962);

criterion 3: attitudes and perceptions relate to specific technology (Mahoney \& Frost, 1977; Thompson, 1967) and include teachers as a source of data (Andrews, 1987; Cohen, et al., 1979);

criterion 4: attitudes and perceptions reflect both formal structural patterns and constraints as well as the discretionary activities of teachers and administrators (Crowson \& Morris, 1985; Preliminary interview study).

criterion 5: there is little motivation to distort attitudes and perceptions and an assurance of individual anonymity (Lawler \& Rhode, 1976, pp. 166, 169).

Each survey question reflected the teachers' attitudes (criterion 3 ) regarding specific managerial behaviors of building administrators (criterion 1). The wording of the questions were all taken directly from the interview data of principals in the preliminary study so that both building organizational levels would be represented (criterion 2). In order to create managerial process variables (aggregate, latent variables), similar items were asked across four distinct curricular and 
instructional tasks (criterion 3). In addition, under each process as well as under each task, the survey questions included both quantitative frequency perceptions and qualitative behavioral perceptions, some of which reflected informal discretionary actions (criterion 4).

Lastly, ali participants were assured orally and in writing that their participation was completely anonymous (criterion 5). This criterion had even greater applicability to this study than it might another study on a different construct such as leadership. The reason is that the term control itself elicits negative responses and feelings (Converse \& presser, 1986, pp. 13-14). Therefore, the use of the term control was limited to one interview question asked near the end of the interview, and was completely omitted from the survey questionnaire.

\section{Sample size}

Although the concept of control within school settings has been discussed for over twenty years (Bidwell, 1965; Lortie, 1969), there is little understanding or synthesis of the research findings. Research in this area remains at the exploratory stage (Sproul1, 1981; Peterson, 1984), that is, for the purpose of generating hypotheses. Towards this objective, sproull (1981) held that a small sample is justified for this kind of exploratory research effort which is needed to generate hypotheses and increase organizational understanding.

In the preliminary study, twelve respondents from six 
schools were used. Nevertheless, because only those principals who were judged to be knowledgeable curriculum and instruction leaders were selected, a wide, representative range of the managerial activities in this domain was generated. Based on the percentages each principal and informant ascribed to curricular and instructional activities - well over what was reported as levels in the literature - the list of activities compared favorably with larger studies of typical principals.

Somewhat fortuitously, certain circumstances tended to place these principals in situations where the opportunity for curricular and instructional leadership were maximized. In one instance, a principal in a school's first year was using effective school literature findings as the basis for staff development and curricular planning activities; another principal was in the process of converting a regular junior-high school into a midale-school program, which reguired faculty to devote considerable time to learning about middle-school philosophy and practices. Moreover, five of the six principals labelled themselves as innovators and had received district wide, statewide, or private foundation recognition for innovative programs. Sample size is similarly an issue in the analysis of the survey data. A high enough sample was needed for defining each of the factors in the principal components analysis and for subsequent multivariate analyses. Two procedures were used to minimize the loss of data from missing values and aggregated variables: (a) the substitution of mean values by levels of 
instruction for missing values; and (b) the use of a 75 percent teacher response rate for aggregated variables.

\section{Significance}

Although much has been written about the concept of organizational control and the difficulties associated with its implementation (Koontz, 1971), neither the definitions nor measures have proven to be adequate, especially in professional or semi-professional settings (Dornbusch \& Scott, 1975). Ideas about good management practices have not kept pace with research findings related to organizational complexity and environment. Control is still commonly perceived as a matter of rules, regulations, and directives. Conceptually, the managerial functions of control are stuck on planning and monitoring (Duke, 1982; Florida Council on Educational Management, 1984-85). This narrow, closed stance inhibits educators from publicly testing their decisions (Argyris \& Schon, 1982).

The mechanisms and language of control reinforce a closedsystem perception whereby control restraints are emphasized over the managerial activities which give meaning to the restraints. Controls are neither fixed nor immutable, but rather reflect content and values which change over time.

The control indicators offered here represent a syntheses of what various disciplines have reported about organizational, political, social, and psychological control. They reflect the complex reality and open systems' logic of both school 
organizations and individual behavior. The objective is to provide a conceptual framework circumscribing indicators conducive to improving administrative practice. In order to succeed, a climate for re-education must be created. A step in that direction begins with the validation of control mechanisms as reciprocal (teacher-administrator) managerial processes.

As early as 1974, Turcotte reported that the number and frequency of control reports did not improve performance within public organizations. Nevertheless, administrative practice and empirical research continue to count the frequency of control interactions such as supervision and evaluation in the practice and study of managerial control - while concluding that (1) control within school organizations cannot be fully explained by the structural patterns, and (2) that there are other administrative processes and behaviors that explain control which are at least as important as structural patterns (Pfeffer, 1978a; $1978 \mathrm{~b})$. The next step is to explicitly define the specific indicators of the non-structural dimension of control in a manner which is helpful for administrative practice. In research terms, what is needed is to establish the construct validity of managerial control in order to generate hypotheses for empirical testing.

Aside from the enormous theoretical value of construct validity, the results can affect the curricular and instructional policy-making decisions being made nationwide during the present educational reform movement.

A political struggle for control 
over curriculum and instruction is being waged today between state legislative policy-makers and educators. on the one hand, virtually every state legislature has passed laws directing schools to meet minimum standards of performance (M. Cohen, 1985; Doyle \& Hartle, 1985; Odden \& Odden, 1984). On the other hand, there is a growing body of school research which suggests that the critical unit of school improvement is the school building itself (Edmonds, 1979). The research on school effectiveness, teacher effectiveness, and program implementation each concludes that what takes place within schools has a significant effect on the performance and output of teachers and students. The research further suggests that schools are unique and diverse, each with its own culture (Sergiovanni, 1987).

Policy-makers, however, view education from a managerial perspective, amenable to uniform directives, not only in administrative and financial areas, but in curriculum and instruction as well (Darling-Hammond \& Wise, 1985; Elmore, 1983, Wirt \& Kirst, 1982). So, at precisely the same time that educators believe they have a better understanding of learning, teaching, and schooling under diverse circumstances, external policy-makers are directing schools to follow uniform rules and policies which affect curriculum and instruction.

Understanding how control is exercised within school buildings can assist educators and policy-makers in closing the wide gap between policy-making and implementation. The record of successful implementation of externally dixected school 
innovations is disappointing (Fullan, 1982; Mann, 1978). Yet, in spite of this dismal record, educational reforms continue to follow a top-down policy approach (EImore, 1983). This trend has resulted in the growth of centralized school district bureaucracies and the proliferation of laws (Meyer, 1983). But, instead of their being greater educational control and accountability, these actions have had the opposite effect: increased growth and complexity, and decreased control (Elmore, 1983).

School policy reflects how the public views education. state and national reform movements have been critical of school performance. But the top-down approach to school improvement contributes little to the quality of performance since it reflects a poor understanding of how policies are implemented at the builaing-level. Important decisions must be made in restructuring schools, training of administrative personnel, and in the professionalization of teachers. Understanding how managerial control operates and its subsequent effect on learning can contribute to the policy-making debate. A managerial model which gains the confidence of policymakers and improves implementation practices would be welcomed. A valid conceptualization of managerial control will contribute to the accomplishment of these objectives. 
31

Organization of the Report

The following chapter presents a comprehensive review and synthesis of social science and school control theories. In chapter Three, the objectives, procedures, and findings of the preliminary study of school managerial behaviors and context are reported. The proposed model of school managerial control is fully described in chapter Four. chapter Five describes the procedures and methods used to empirically test the model. statistical findings are reported in chapter six. And, the final chapter contains the summary, conclusions, and implications for further research. 


\section{CHAPTER TWO}

\section{Review of ReIated IIterature: Part I overview}

For over 20 years, organizational researchers have been aware of the entangled complexity inherent in organizational. control practices (Cartwright, 1965; Lortie, 1969). The meaning of organizational control is understood as not solely determined by formal authority structures or hierarchy, particulaxly within professional and semi-professional organizations (Bidwell, 1965; Blau Scott, 1962; Etzioni, 1965; Lortie, 1969). It is also understood in theory that the traditional, prescriptive managerial functions expressed by the acronym POSDCORB reflect "vague objectives" (Mintzberg, 1971) that have given way to more empirically diverse descriptions of administrative behaviors and control mechanisms. These revised conceptions acknowledge (a) political processes, (b) professional, social, and cultural norms, and (c) individual characteristics and needs as complementary and competing determinants of organizational control.

Since these determinants of organizational control emerged originally as distinctive findings within several social science disciplines, each with its own models, methods, and measures, published findings have differed. As a result, there is little to link organizational control research findings across disciplines. Moreover, the complexity of the theoretical construct itself has inhibited synthesis research efforts 
(Cartwright, 1965).

Neither theory nor practice of organizational control has progressed much beyond the sociological findings of the $1960^{\circ} \mathrm{s}$ (Bidwe11, 1965: Cartwright, 1965; Etzioni, 1965; Lortie, 1969). In fact, the ten principles of educational theory described by Counts in 1930 may still represent the most systematic account of the underlying concepts related to American educational control. These principles include: faith in education, government responsibility, local initiative, individual success, democracy, national solidarity, social conformity, mechanical efficiency, practical utility, and philosophic uncertainty (1930/1971).

Empirical research on the concept of control is still being conducted at the exploratory stages (Peterson, 1984 ; peterson, Hallinger, Murphy, 1987; Sproul1, 1981). No operational definition of control has been offered which provides managers with quidelines for daily practice (Bossert et al., 1982; Pfeffer, 1978a). The complexities revealed by empirical studies have tended to lead organizational theorists to the conclusion that different circumstances and unique situations most probably account for, if not define, managerial control practices (Hanson, 1979). Yet, contingency theory itself has produced equivocal results (Pfeffer, 1978a; 1978b) due largely to the fact that researchers have chosen single organizational entities on which to base their conclusions. Uncovering complexity of organizational processes and the interactive relationships among individual participants has not as yet been translated into a 
cohesive, theoretical framework.

During the late 1970's and $80^{\prime} \mathrm{s}$, the importance of control as an organizational dynamic has reemerged through the studies conducted by loose coupling theorists. Building on the sociological foundations of Bidwell (1965) and Lortie (1969), and the open systems' logic of Thompson (1967), loose coupling theorists began to identify pervasive, latent, institutional and cultural control variables such as mutuality, trust, good faith, shared beliefs, and confidence (Deal, 1987; Meyer Rowan, 1977; Ouchi, 1978; Scott, 1983; Sergiovanni, 1987; Weick, 1976) as alternative explanations to the traditional, hierarchical control mechanisms of rules, standard operating procedures, close supervision, and formal evaluation.

Nevertheless, the more traditional, hierarchical language of control has recently reappeared under the framework of state and national educational reforms. The present reform movement reflects a shift in political power from local school districts to the state level, whereby most of the educational reforms, including curricular and instructional, now originate within state legislatures (Apple, 1982; Kirst, 1984). This change contrasts sharply with educational policy findings reported only decade ago which rated state political culture "moderate to low" in curricular and instructional areas (Wixt \& Kixst, 1982). Today, there are "strong" state political cultures in the majority of states (Apple, 1982: Doyle \& Hartle, 1985: Mclaughi in, 1983). 
The shift in political power to the states has occurred in spite of evidence offered by effective school researchers who argue that educational differences are more significantly affected by school building-level variables than by external control directives (Edmonds, 1979). This view is further supported by research findings in effective teaching, program implementation, school cultures, and symbolic leadership lodden \& odden, 1984: Sergiovanmi, 1987). Although such findings have been incorporated sporadically into building-level administrative practices, they have not been reported to have measurably influenced the political policy making processes.

The literature reviews of control theories provide a systematic framework for understanding the behavioral impact of managerial tasks related to control. Understanding the effects on individuals who are confronted with specific managerial. control techniques can help to determine the legitimacy, appropriateness, and the relative efficacy of managerial control activities. From these diverse research agendas come a logical framework with a common language in which to analyze the processes of control across different school settings.

From a strict empirical perspective, discrete structures and individual behaviors appear neither systematio nor rational, thus, implying that control may not exist under ali circumstances. This frequent assertion with regard to school organizations may be erroneous however. The alternative explanation may be that control, as a series of processes, occurs 
over time and in relationship to organizational dynamics which are felt as well as observed. Thus, the causal connections or relationships between events are not immediately perceived or determined. Neither curricular nor instructional tasks are reducible to immediate effects nor to formal structure (Dornbusch \& Scott, 1975). Moreover, the sequence of events of tasks do not necessarily follow the same linear pattern (Marzano, et al., 1988). As a result, empirical descriptions based on observation of either formal events, the frequency of interactions, or their perceptions are insufficient measures of organizational control processes (Patz \& Rowe, 1977, p. 72). No matter how accurate are the reported empirical observations of formal structures, they cannot reveal the thoughts, feelings, and beliefs created by administrative behaviors and structural events. control theory, however, necessarily incorporates such thoughts, feelings, and beliefs.

At the root of all measures are two epistemological directions: one observable, the other logical or intuitive. one problem created by this dichotomy is that physical entities change over time, while logical forms do not. Thus, within epistemology there has been a continuing search for the Iinkages between thoughtful, logical categories and empirical happenings. In 1781, Kant wrote in his Critique of Pure Reason that all knowledge is based on experience, but it does not arise from it. With respect to control theory, we need to discover thought processes which unite the many different discrete events involved 
in managerial control. Present day organizational theorists and social science methodologists have already joined in the epistemological search for the links between quantity and quality (Ames Ames, 1987; Astuto and Clark, 1985; Sergiovanni, 1987). control is a function of organizational structure as well as an internal, logical variables. Control theory is part a priori rational categories and part empirical, observable measures. Together they represent structure, stability, action, and motivation. The purpose of this literature review is to describe how the two dimensions, structure and guality, emerged and to explain how they function interactively at the school-building level. The different disciplinemoriented theories of control offer competing, yet complementary explanations which support one or more of the complex administrative options facing school administrators (Clark \& Astuto, 1988; Miles, 1981). Each offers its unique insights that contribute to a more valid, general. theory of curricular and instructional control. organizational structure, politics, sociology, and psychology comprise the practical administrative science of organizational control theory. As a practical science, the level of understanding is necessarily limited and inexact (Mckeon, 1941, pp. xxviff). To counts (1930/1971), "theory which is abstracted from practice is certain to contain numerous contradictions and to lack completeness" (p.7). Therefore, each discipline's theory offers, at best, a partial contribution to our overall understanding of the subject. 
In practical science research, construct validation of concepts should be of the highest priority. Understanding the underlying meaning of control as structure, thoughts, and beliefs is necessary if we are to go beyond discrete events and contingency analyses. Only then can we confidentiy link the madel to empirical findings using multiple sources and statistical measurement theories (Hoy \& Miskel, 1982; Hughes, Price, \& Marrs, 1986).

\section{Organizational Theory: Complexity and Hierarchy.}

Schools axe complex organizations (Astuto \& Clark, 1985; Lortie, 1977; Miles, 1981). A valid theory of control must be able to cope with the realities and dilemmas of organizational and managerial complexity. Sometimes in pursuit of more solid ground, the definitional boundaries of control so tightly circumscribe formal control structures that much of the daily operational processes and interactions have been intentionally excluded from analysis (Charters, 1981). At other times, the pervasiveness of organizational complexity results in a host of alternative explanations and metaphors, many of which contradict rational bureaucratic, and cybernetic models of control (Astuto \& Clark, 1985; Hannaway \& Sproul1, 1978-79: Meyer \& Rowan, 1977). The narrow view addresses managerial activities that are specifically authorized by formal policies and structures, while the broader perspectives encompass all activities not explicitly prohibited by formal policy and structure. Missing is that 
middle ground that systematically incorporates organizational and managerial complexity into the discussion of controlling behaviors.

\section{Problematic efects of organizational complexity.}

Educational organizations have grown from small, selfcontained local school units into large, complex institutions, increasing the bureaucratic centralization of school governance (Meyer, 1983; Scott \& Meyer, 1983, p. 143).

While the size of school organizations tends to correlate positively with bureaucracy and complexity, it also correlates negatively with centralized control (Child, 1977; Elmore, 1983). Increased organizational complexity adds divisional specialization and levels to an organization, requiring added coordination and integration (Blau \& Scott, 1962; pfeffer, 1978b; Thompson, 1967) as well as the need for more information and control systems. Specialization and increased organizational levels bring diversity of goals and expectations (Turcotte, 1974). Consequently, the central organizational processes such as decision-making, implementation, evaluation, and control become problematic rather than formal and rational (Elmore, 1983; rurcotte, 1974). The most persuasive evidence to support this conclusion is found within the disappointing historical record of school program implementation efforts (Fullan, 1982; Fullan \& Pomfret, 1977; Mann, 1978; Molaughlin, 1978; Meyer, 1983). curricular and instructional tasks are assigned to different 
levels and roles within school organizations and environments. since the publications in the early 1980's of the national reforms reports, state legislatures and state departments of education have assumed greater formal authority over curriculum and instruction (Darling-Hammond wise, 1985). Curricular specialists are employed by the state departments' of education to provide state-wide guidelines and directions for local school district use (McDonnell, 1985). At the district level, under the superintendent's authority, there are subject area specialists who provide curricular frameworks and advice to department heads and classroom teachers. And, at the school level, formal responsibility for curriculum and instruction rests with the building principal (Doud \& Montgomery, 1985; Duke, 1982; Rutherford, 1985) who delegates specific tasks to assistant principals, department and grade-level chairpersons, and individual classroom teachers.

No cohesive theory exists which clarifies the interactions among these various levels. Empirical school studies tend to begin and end indiscriminantly. Researchers rely almost as much on accessible subjects and measures as they do on theory. In general, the reported organizational typologies simplify the complex interactions and are usually based on single measures, entities, or concepts applied across the board (Miles, 1981).

Two notable exceptions are the research efforts of Miles (1981) and Clark and Astuto (1988). Determining the nature of organizational complexity of schools is first and foremost an 
empirical question (Miles, 1981, p. 112). Both Miles (1981) and Clark and Astuto (1988) have offered worthwhile maps of common school properties and behaviors. But, what is so unusual about these geographies is their recognition of organizational and managerial dilemmas, i.e*, recognition of two or more contradictory images which emerge from the same terrain. Although Clark and Astuto have expressed the hope that additional vaxiables will, be added to their coupling taxonomy that will lead to greater organizational clarity (see Astuto \& clark, 1985), they acknowledge that the present reality facing school administrators is often two or more alternatively good choices (1988). Miles (1981) had suggested two reasons for the empirical knowledge gap of school organizations: one is the absence of correlational measures between alternative choices (e.g., coordination/flexibility to knowledge use, diversity/uniformity to effectiveness); and the second is the lack of basic understanding as to the nature of organizational concepts, such as teacher autonomy and internal change. Since neither speculative ideas nor prescriptive organizational typologies can contribute to the closing of these knowledge gaps, Miles (1981) recommended descriptive, empirical studies based on contingency, comparative, or experimental analyses. The comparative implementation paradigm proposed by Berman (1981) is an example of just such a descriptive model.

By limiting generalizations, making sensible distinctions among different types of variables, experimenting with time 
- dependent measurements and longitudinal research designs, and structuring analysis in conditional forms, researchers might be able to reduce inconsistency across studies and produce results relevant to policy and practice (Beman, $1981, p, 282$ ).

\section{Problematic effects of managerial complexity.}

Growth and complexity of school organizations have also resulted in changes in the role of school administrators (Bidwell, 1965; Goodlad, 1978). Centralized bureaucratic decision-making limits the ability of school administrators to exercise direct control over all decision-making and implementation processes (Apple, 1982: Fullar, 1982). Other factors identified as limiting the exercise of building-level managerial control incluae the lack of training for school administrators (Fallon, 1979; Pellicer, 1982), the lack of time needed to address non-routine curricular and instructional mattexs (Crowson \& Morxis, 1985), the growing complexity of substantive issues, and technology in public organizations (Ha11, Jx., 1956). The uniformity and standardization of school laws and policies (Darling-Hammond \& Wise, 1985) has resulted in increased prescription of roles, conformity, and caution (child, 1977). The combined effect from these ractors seems to point towards a decrease in discretionary managerial activity.

Yet, it would also appear that the rudimentary nature of school bureaucracies (Bidwe11, 1965) permits discretionary decision-making, especially at the school building level (Eye, et a1., 1971). The interrelationship of federal, state, local 
district, building, and classroom levels makes it doubtful whether school administrators, at any of these levels, could have total control (Bidwell, 1965; Elmore, 1983: Miles, 1981; Meyer, 1983). Thus, in spite of the trend towards bureaucratic centralization and standardization, the levels of school organizations tend to be loosely coupled (Bidwel1, 1965; Weick, $1976 ; 1985)$.

Similarly, technological complexity may foster, rather than inhibit, discretionary decision-making. Curricular and instructional tasks have been categorized as active and nonroutine (Dornbusch \& Scott, $1975, p .348$ ) which are more optimally performed within decentralized decision-making enviromments. Active tasks and non-routine decisions are characteristics of managerial complexity. With the growing inability - and inadvisability - for direct, substantive, or technical controls, administrators must rely more on their skilis and understanding of managerial processes, i.e., how decisions are nade and carried out, rather than on the content or substance of the policies themselves (Ha11, Jr., 1956).

certain hypotheses argue that non-routine decisions and active curricular and instructional tasks do not present clear output standards. To these theorists, performance or behavioral controls are preferable to output controls (Thompson, 1967; Mahoney \& Frost, 1977). Under the same conditions, however, other theorists argue that output controls are necessary precisely because of the non-routine nature of the task (ouchi, 
1978; Eisenhardt, 1985).

What contributes to such contrary viewpoints are the idiosyncratic uses of managerial tems. In one instance, the term behavioral is defined as flexible and subtle (ouchi, 1978); elsewhere, it is used as a human need (Patz \& Rowe, 1977 , pp. 273-274); and in anothex empirical control study, behavioral control is defined by structural rules (Peterson, 1984). Similar conceptual inconsistencies are found throughout the research on controi theory.

overall understanding of managerial complexity has been greatly enhanced by the structured observational methodology developed by Mintzberg (1971). Prior analyses prominent in managerial texts prescribed nomative administrative functions of What good administrators ought to do. This literature offered "vague managerial objectives" (Mintzberg, 1971), acronyms such as POSDCORB, rational assumptions, and theoretical models which have been aptly descxibed as a "senantic jungle" (Koontz, 1978).

Mintzberg's (1971) structured observations of what administrators actually did signaled a significant breakthrough in our knowledge of administrative behaviors. uni ike the rational prototypes of the managerial texts, the evidence Mintzberg reported did not fit accepted nomative prescriptions. He reported that administrators exhibited six nonrational characteristics:

(1) administrators do a great quantity of work at an unrelenting pace;

(2) they do not follow any regular work pattern, instead the 
work is characterized by variety, fragmentation, and brevity;

(3) they prefer current and specific issues which emerge on an ad hoc basis:

(4) they are situated between the organization and a network of contacts, thus receiving far more information than they emit;

(5) they prefer verbal communications; and

(6) they are in control of their own affairs (despite initiating only 32 \% of the verbal contacts).

Most of these adninistrative characteristics have been supported in subsequent school-based studies using Mintzberg's method of structured observation (Martin \& Willower, 1981)* What still remains unclear, however, is the effect these fragmented behaviors have on building level operations, particularly in the areas of curriculum and instruction (Bossert et al., 1982). At one extreme of the loose-coupling paradigin is the assertion that there is no pattern in school decisionmaking. The process is described metaphorically as an "organized anarchy" functioning in a "garbage can" (Cohen, March, \& Olsen, 1972). The empixical literature on instructional leadership suggests that the time devoted to instructional tasks is extremely limited (Hannaway \& Sprou11, 1978-79; Martin \& Willower, 1981; Pellicer, 1982; Rowan, 1982). Indeed, one study reported as little as four minutes a day given to curricular and instructional tasks (Sproul1, 1981).

At the other bureaucratic extreme are tight coupling viewpoints (Hallinger \& Murphy, 1985: 1986) which provide support for strong administrative directives at both the state and building levels. Crowson \& Morris (1985) reported that one-half of the principal's time can be accounted for by formal, 
hierarchical controls (i.e., budget, personnel, scheduling, and pupil behavior). There are numerous studies which indicate that curricular and instructional administrative behaviors play a significant role in schools (Edmonds, 1979; Lightfoot, 1986; Ogawa \& Hart, 1985; Rutherford, 1985).

Within this paradigmatic debate is evidence for a midale ground. "simultaneous loose and tight coupling" (DuFour, 1986) and contingency theories suggest that different controls are appropriate depending on task structures (Eye, et al., 1971; House, 1981; Mahoney \& Frost, 1977; Koontz, 1971; Ouchi, 1978). Unfortunately, most contingency models fall short of their efforts to provide contextual and adaptive strategies for two reasons: (1) they tend to overgeneralize their findings (Berman, 1981), and (2) they ignore the underiying complexity needed for establishing organizational control (Patz \&owe, 1977).

The complexity of strategic, non-routine decisions has ralsed the question of whether there exists an logical underlying structure or pattern (Mintzberg, Raisinghani, sheoret, 1976). According to Mann (1975), policy decision-making divorces mental processes from actions. The mental processes were considered as "calculation" in which demands are recognized, goals identified, alematives weighed and estimated, and a choice of action selected. The latter process, labelled "control, included the action stages of implementation, enforcement, and enactment.

Mintzberg, et a1. (1976) conducted research to see if there was an underlying structure behind "active" tasks. The study 
identified three mental phases: identification, development, and selection. Each mental phase was supported by three empirical roukines: politics, communication, and control. Although the findings Inked the mental processes with the empirical routines, it stopped short of action phases, such as implementation and compliance. The recent literature on program implementation argues persuasively in support of the proposition that decision making per se is not equivalent to implementation processes (Fullan, 1982). In sum, the incorporation of managerial. complexity into the meaning of control strongly suggests that knowledge of how and what people perceive is as vital to understanding control as is subsequent actions.

\section{Hierarchical contro1: Formal authority variables}

In identifying the determinants of control, a logical. starting point is the organization's structure as defined by its formal authority framework. This framework is inevitably hierarchical (Tannenbaum, et a1. 1974) as measured by the number of levels within the organization (Blau \& Scott, 1962), the division of work to be done on each particulax level, and the formal mechanisms which connect vertical and horizontal work arrangements. Not all organizations have the same organizational structure, yet all exhibit a relative degree of hierarchy based on the position level or status role with the organization (Smith Tannenbaum, 1963). Vertically-oriented organizations emphasize the flow of information, generaliy directives, from top 
levels of authority to lower levels. As directives flow downwara, discretionary authority is limited and circumscribed (lang, 1965, p. 852). Roles are prescribed and uniform and there is "no recourse but to obey" (Child, 1977; Lang, 1965). Formal authority ascribes power and rights to certain individuals to make decisions affecting others. At such times, subordinates are asked to suspend their own judgment and to uncritically accept authority (Bacharach \& Lawler, 1982, p. 29).

The pattern is less evident within flatter, horizontallyoriented organizations in which the flow of information increases among employees working within the same level. Subordinates are not expected to suspend their judgment and information is used in a mutually-influencing process. Thus, while authority flows downward, infuence is multidirectional (Bacharach \& Lawler, $1982, p .29)$.

One straightforward measure of organizational hieraxchy is defined as the span of control, that is, the number of subordinates directly under the control of or reporting to an executive or supervisor (Applewhite, 1965: BIau \& Scott, 1962). Applewhite's (1965) review of the literature on the optimum span of control using arithmetic models reported no conclusive findings. There is evidence that under certain conditions, close supervision based on a small span of control is more effective, while under different conditions, close supervision impedes performance (Applewhite, 1965; Blau \& Scott, 1962). Applewhite's review, however, identified other variables which potentially 
mediated the effects of the span of control. Among these mediating variables were (a) staff and line positions, wherein staff positions may exert greater influence than that position would formally indicate; (b) organizational tenure, which may give certain individuals more access and information; and, (c) the number of organizational levels, which affect the management, cooraination, and communication within the organization (Blau \& Scott, 1962).

A more comprehensive hierarchical control variable than span of control is the organizations' technology. Woodward (1970) and Thompson (1967) each proposed technology typologies to analyze organizational structure and behaviors. Woodward's typology, which was based on studies of manufacturing organizations, proposed that technological control operated along two structural continuums: the first continuum measured the degree of personal control versus mechanical control, and the second continuum measured the integration versus fragmentation of control systems. By taking the end points of each continuum, Woodward identified four different control strategies: that is, personal and integrated, personal and fragmented, impersonal and fragmented, and impersonal and integrated.

Just as the studies on span of control had indirectly revealed mediating, non-structural variables, so, too, dia Woodward's typology. From the two structural continuums, Woodward arrived at a number of administrative and political hypotheses to better explain organizational behavior. For 
example, along the first continuum of personal and mechanical control structures, Woodward stated that administrative procedures were needed to link planning with executing. Along the second continuum of integration and fragmentation of control systems, Woodward suggested that the differences in control criteria would lead to political conflict and the need to somehow resolve that conflict. Despite the obvious contextual limitations of manufacturing organizations and the typology's lack of specificity with regard to managerial control mechanisms (Lawler \& Rhode, 1976), Woodward contributed evidence of the relationships between structural variables with administrative procedures and political conflict.

The origins of Thompson's (1967) control typology began with a logic of open systems and a political understanding of the potential for conflict in decision-making. Thompson recognized the incompatibility of direct control within complex organizational structures. Complexity creates not only a limited ability to personally and directly control, but also the inability to comprehend all the possible decisionmaking contingencies. Despite the differences among organizational levels, however, political conflict could be significantiy reduced at the lower, technical core.

Thompson's typology categorized technology in three ways: as sequential relationships, as pooled relationships, and as reciprocal relationships. These relationships hold an organization together by linking individuals to structures. The 
distinguishing feature among these relationships is the degree of dependency needed to perform specific, work tasks. For example, in sequential technology, individuals are dependent upon the completion of some previous task; in pooled technology, only certain aspects of organizational tasks are affected by other tasks; while reciprocal relationships, individuals require the greatest degree of coordination in order to complete a task. These linkages of technology determine (a) to what extent the organizational structure will be vertical or horizontal, and (b) the mechanisms of control: rules and directives for highly dependent tasks, or meetings and committees for more discretionary tasks.

A decade later, Mahoney \& Frost (1977) attempted to operationalize Thompson's typology. They, too, assumed that technology was a causal variable of organizational structure and behaviors. Whereas Thompson had categorized technologies by their dependency, Mahoney \& Frost assigned its opposite, discretion, as their principal measure. With reciprocal technology, they hypothesized that standards are ambiguous, and so, social reference groups with high discretion are used to measure effectiveness; with pooled technology linkages, there is incomplete certainty of cause and effect, and, therefore. instrumental assessments (mediated discretion) are used to measure if goals are achieved; while with sequential technology, the beliefs of cause and effect relationships and outcome preferences are most certain, efficiency tests with no discretion 
are used to assess organizational effectiveness.

Mahoney and Frost (1977) reported finding significant differences in the kinds of controls used for each type of technology relationship. Supervisory control was found most often in sequential technologies and least often in reciprocal technologies; staff development and training were used most often with reciprocal technologies. Although not conclusive, findings were also reported on the relationships of managerial functions and the different technology categories. For example, planning was found to be more important for sequential technology than for reciprocal. In sequential relationships, output results were more significant than in either pooled or reciprocal relationships. While in reciprocal technology, cooperation and staff development made large contributions. Mahoney and Frost (1977) concluded that technology is important, although not fully determinant of organizational structure, behavior, or effectiveness.

In other technology-control typologies, tasks have been commonly distinguished as routine or non-routine (Dornbusch \& Scott, 1975; Eisenhardt, 1985; Ouchi, 1978). Routine tasks are defined as programmable and predictable; non-routine tasks are not programmable and uncertain. Dornbusch and scott (1975) referred to these tasks as "inert" and "active" respectively. The controls over routine tasks are basically standard operating procedures, while control over active, less predictable tasks require sufficient autonomy to respond to uncertainty. According 
to Dornbusch and scott (1975, p. 348), active task controls use fewer xules, less minute specialization of pexsonnel, and less centralized decision-making. These implications axe basically consistent with the hypotheses and indings of whompson (1967) and Mahoney * Frost (1977).

Given the same task distinctions, ouchi (1978) hypothesized and tested a dual control model of behavior controls versus output controls. Behavior controls are flexible and subtle, allowing for local variations; output controls are quantified and used as organization-wide control mechanisms. Both control categories are measurable depending or the intormation characteristics of the tasks (Eisenhardt, 1985).

The ouchi model proposed four measurable hypotheses: (1) if the task can be programmed, the behaviors are easily measured: (2) if the task is not programmed, behaviors are more difficult to measure, therefore, control is measured by outcomes; (3) if the goals are clearly stated, the outcomes can be measured and evaluated: and (4) if both the behaviors and outcomes can be measured, then either control measure, behavior or output, may be used (Eisenhardt, 1985; Ouchi, 1978).

With respect to non-routine tasks, ouchi's second hypothesis departs significantly from Thompson's typology. Accoraing to ouchi, complex, unprogrammable tasks ought to use outcome measures; whereas for Thompson, complex, reciprocal tasks reguire cooperation, meetings, and staff development. It was only for sequential or programmable tasks that Mahoney and Frost (1977) 
found a strong reliance on output results, rather than behavioral measures. Moreover, when the goals of a task are ambiguous, discretion in the use of effectiveness measures (i.e., behavior controls) is more likely than output measures (Thompson, 1967). Eisenhardt (1985) analyzed Ouchi's model and added other variables to performance measures, namely, the effects of rewards, costs, information systems, and environment. Eisenhardt's study concluded that the ouchi framework ignored uncertainty found in the organizational environment and too strictly limited the role of information to tasks. Both criticisms were raised previously by Patz and Rowe (1977) with respect to contingency theory, the framework within which ouchi's model may be said to belong.

Eisenhardt (1985) also noted that both her model and ouchi's deliberately omitted "social control" measures from the analyses. Social controls would be employed to minimize the divergence of preferences and, along with information systems, could compensate for high outcome uncertainty. (Eisenhardt, 1985),

In every instance, the structural-technical control typologies reviewed here noted the effects of a significant number of "mediating" political, social, and psychological variables. It is precisely these residual findings that need further systematic consideration. However, before turning to this task, it is essential to review the literature of school control itself in order to confirm whether similar medating variables also emerged from school structural analyses. 


\section{School Hierarchical control}

\section{District-school control.}

Hannaway \& Sproul1 (1978-79) asked the question, "to what extent is administrative or managerial behavior related to teaching and learning?" In seeking an answer, they assumed that informal verbal communications most accurately reflected the pattern of school influence between the district central office and individual schools (i.e., principals). Based on the frequency of informal verbal communications, Hannaway and sproull found little influence between the two levels, such that "discussions about how well school or classrom units or individual teachers were performing, or how 'production' could be improved, were virtually non-existent."

In 1981, sproull reanalyzed the data reported in his study with Hannaway. Their initial emphasis had been on the communication time devoted solely to curricular matters conly two and one-half percent of the time). Here, sproull examined the total time interaction (20 percent) between managers (principals) and the larger bureaucratic environment (district level). Even with this larger percentage of interaction, sproull noted the inadequacy of the bureaucratic model, particularly: (a) the impracticality of planning, (b) the paradox of supervision (monitoring and evaluating) versus organizational morale, and (c) the mythology of written regulations. Although none of the implications is tested further, sproull suggested that school managers (i.e., principals) should adopt the role of information 
processors, an implication not unlike the mediating variables offered above.

Deal \& Cellotti (1980) also asked, "how much influence do (and can) educational administrators have on classrooms?" Using a panel design over a three year period, superintendents, principals, and teachers were asked to describe their perceptions of how formal policies and administrative practices affect classroom organization and instruction. The authors found a lack of consensus among the three organizational levels which led to the conclusion that "instructional activities do not seem to be effectively coordinated through formal channels."

Meyer, Scott, and Deal (1983) reported findings from survey data that was collected in 1975 from 30 superintendents, 103 elementary school principals, and from 469 teachers in the San Francisco Bay area - a sample similax to the one analyzed by Deal and cellotti (1980). The respondents were asked to what extent they perceived the presence of explicit school-wide policies in several substantive (curricular, administrative, and instructional) areas. The researchers were not interested in the implementation or control of the policies, simply the perceptions of policies. The authors reported finding a "compeling consensus" among superintendents, principals, and teachers concerning the presence and explicit aistinctions of formal policies. The authors proposed two possible explanations for the high level of consensus: (1) close organizational interactions and relationships within schools and districts; or (2) 
institutional or cultural understanding of the roles and norms in education throughout society.

Using tests of analysis of variances, the amount of variance explained by the within organizational interactions was very low in contrast to the percentages of consensus among the 30 districts. Meyer, Scott, and Deal (1983) concluded that school organizations conform, not to formal structural-organizational patterns, but rather to broader institutional rules which define education throughout society.

Rowan's (1982) review of survey and ethnological literature on instructional control also concluded that there was a "weakness of control exercised by administrators (district and school-level) over the teaching and learning process." Rowan tested the loose-coupling model by studying the historical staffing patterns within district administrative staffs. He found that while business management personnel increased dramatically from 10 pexcent in 1930 to 83 percent by 1970 , district curriculum managers increased by only 20 percent, from 10 percent to 30 percent, over the same 40 year period. The percentage increase for district instructional managers was somewhat higher, 37 percent, from 6 percent in 1930 to 43 percent by 1970. Although the study ignored historical changes in school-level roles, Rowan (1982) suggested that with highly uncertain technology, such as curriculum and instruction, control is best in the hands of teachers. While this view presently receives increasing support in the literature (Floden, porter, 
Alford, Freeman, Irwin, Schmidt, \&chwille, 1988; Griffin, 1988; Kerr, 1987) and in collective bargaining negotiations, the empirical data to support this implication is limited.

Each of the school control studies cited so far tends to support the model of loosely coupled educational systems (Weick, $1976 ; 1985)$. Yet, each study raises a question as to the validity of the findings in that in each study only a single measure of control was used to analyze district-school relationships. Deal and Cellotti (1980) limited their investigation to the frequency of formal communications: Meyer, Scott, and Deal (1983) counted the perceptions of formal policies; Rowan (1982) analyzed job titles. Neither regular informal organizational patterns nor the quality of the interactions were included in these analyses.

Similarly, the studies conducted by Hannaway and Sproul 1 (1978-79) and sproul1 (1981), which looked only at the frequency of informal communications, also did not find tight controls. Thus, when control has been defined by a single measure, formal or informal communication frequencies, perceptions of formal policies, or job titles, there is little evidence to support school organizational control.

Yet, each study has offered far-reaching implications based on its limited findings. Given the lack of formal interactions, Deal and cellotti (1980) suggested that informal communications may offer an alternative explanation - a finding not supported by Hannaway and sproull (1978-79). Both sproull (1981) and Meyer, 
Scott, and Deal (1983) rejected the organizational-bureaucratic model. The implication drawn by sproull was that principals should adopt a new role as information processors. The implication drawn by Meyer, Scott, and Deal (1983) is perhaps, the most ambitious of all. The authors reconceptualized organizational control as institutional and cultural influence. What is troubling is that the empirical data on which all of the implications have been based, including the institutional paradigm, are weak. The complexity of organizational interactions need to be identified within a research design using more than a single measure.

The most comprehensive empirical study to date on districtschool-level control was conducted by peterson (1984). The study offers a literature review of organizational control theories and empirical tests for the presence of multiple control mechanisms between districts and schools. The primary objective of the study was to provide rich, descriptive pictures of six administrative control mechanisms by measuring central tendencies and the distribution of the responses from interview data collected from 21 principals and 17 superintendents using closed and open-ended questions.

Peterson (1984) listed four deteminants of organizational control: (1) technology, (2) organizational goals and outputs, (3) organizational environment, and (4) organizational structure. Based primarily on the ideas and findings of Dornbusch \& Scott (1975) and Ouchi (1978), Peterson made the following assumptions: 
that tasks influence the types of control fouchi, 1978: Thompson, 1967): that ambiguous goals need multiple controls; that the environment influences controls (pfeffer, 1978a); and that organizational structure (specifically size) creates a potential for control loss.

Peterson (1984) categorized six control mechanisms under two broad categories: hierarchical and non-hierarchical. We identified four hierarchical control mechanisms: supervision, input control, behavior control, and output control. And, he identified two non-hierarchical control mechanisms" personnel selection and socialization and environmental factors. Work fragmentation of principals and the complexity of school and program goals charactexized hierarchical control. Both tended to reduce the effectiveness of district supervision as a control mechanism. Therefore, the other hierarchical control mechanisms were used to complement or replace close supervision.

Input controls were found to be important particulariy with respect to the administrative use of discretionary and contingency funds. Peterson also reported a relatively 1ow use of behavior control and output controls at the principal 1 evel. one exception was in the area of teacher evaluation where the district instituted strict behavior controls over principals. The low use of output controls was especially true for criterionreferenced tests, although even standardized achievement tests was Iimited to only 50 percent of peterson's sample. The findings related to non-hierarchical control reported 
that most of the principals hired were insiders who conformed to district norms. Environmental controls had to do with the sources of information which have the greatest effect on the superintendent's assessment of principals. The responses placed community views as the most influential control, followed by the superintendents' own views, and then those of teachers, and other central office personnel.

From the empirical data, peterson formulated a number of hypotheses: (a) in considering the multiplicity of controls, peterson suggested that principals spend more time on tasks that are more tightly coupled and more hierarchically controlled and less time on instructional management; (b) considering both organizational and managerial complexity of schools, peterson hypothesized that there are areas or zones of "substantial autonomy" particularly in the instructional domain; (c) the size of the district (structure) had a significant effect on controls; for example, the larger the district, the more hierarchical controls.

Peterson (1984) suggested that further school control research seek to link the concepts of school control with daily behaviors as well as with productivity. The latter issue was addressed subsequently in a study by Peterson, Murphy, \& Hallinger (1987). Using peterson's (1984) control categories to study the presence of control within "effective" districts (N=12), the authors obtained data from open-ended interviews with the superintendents only. The study listed three assumptions: 
(1) multiple controls operate, in combination as a "web" of control, between the district-level and schools, none of which predominate; (2) behavior controls direct instruction, while output controls are used in evaluation: and (3) controls should employ "success criteria."

In contrast to other studies which reported "weak" control between districts and schools, Peterson, Murphy, \& Hallinger (1987) found tight linkages between managerial levels and the technical instructional and curricular core. Seven of the 12 superintendents reported that their districts had long established methods of instruction and numerous mechanisms to insure that the methods were being used in the classroom. Eleven of 12 superintendents reported systematic, district-wide staff development programs. Teacher evaluation was tightiy structured and consistent with state law. on the other hand, a relatively low percentage of districts used student achievement tests (33 percent) and only a third of the districts assisted schools in the dismissal of incompetent teachers. The authors never questioned their sole use of superintendent responses as the measure of hierarchical control. It is likely that superintendents would be inclined to report tighter, more frequent, and substantive interactions with school building administrators.

Generally speaking, at higher levels of school organizations, the tendency has been to centralize policy domains and establish greater uniformity (Darling-Hamond \& Wise, 1985 ; 
Meyer, 1983). Ironically, "the indices of control become less significant and less useful at progressively higher levels" (Vickers, 1967, p. 29). In practice, what this has meant is that (a) one set of criteria (of success) is applied to higher organizational levels than at lower levels (Goldman, 1983, p. 339), (b) higher level "soft" controls and formal policies may not be relevant to lower levels, and (c) control of technology is best addressed at levels below the district-school relationship.

The specific curricular controls reported by Peterson, Murphy, \& Hallinger (1987) included district course guidelines (42 percent), district standards, and textbook adoption laws. On the other hand, no clear control pattern was found in the hiring and transfer of teachers. The authors concluded that there was still a research need to "disentangle the relative importance of the technical and cultural features of these [controly activities and to demonstrate their causal inkages to student performance" (p. 93).

\section{Principal-teacher control.}

The same questions have been asked at the principal-teacher level, namely, which structures ox activities can control teacher behaviors. Wellisch, et al., (1978) reported that there was moxe cooraination between principals and teachers at successful schools than at less successful schools. The independent variables were all managerial processes: (a) how strongly the administration felt about instruction; (b) whether they 
commicated their ideas (coordination); and (c) the extent to which they assumed responsibility for learning (academic standards). Case study principal and survey teacher responses were combined and analyzed. Wellisch, et al. (1978) reported that each of these variables were positively correlated with each other and significant differences were found between successful and non-successful schools. This is essentially the findings supported by effective school research (Edmonds, 1979) and effective school leadership (Andrews, 1987).

Cohen, Deal, Meyer \& Scott (1979) tested the Thompson (1967) hypothesis that complex instructional technology generates complex organizational structures. The evidence found was Iimited specifically to the classroom level, rather than to either the principal or district levels. Thus, the authors concluded that the effects of technology were best studied at the classroom teacher level.

Cohen \&iller (1980) examined the specific nature of organizational and technological complexity. The study did not find that as complexity in classroom technology increased, there was any corresponding increase in coordination or control. In fact, the latter processes were not reported to be even the most important predictors of decision-making effectiveness. Rather, two other "alternative" managerial activities, praise and resource provider, were more closely associated with compliance. Not only did theix findings suggest that a social "exchange process" existed between principals and teachers, but that the 
concepts of control and coordination were really distinct processes. Yet, as with the "mediating' variables reported by organizational theorists, these social control findings were not tested airectiy.

Whereas Anderson and Brown (1971) attributed positive influence directly to the frequency of principal-teacher interactions, Astuto and claxk (1985) argued that frequency may not be the discriminating factor in the relationship. The latter's coupling taxonomy proposed a second, gualitative dimension, in addition to quantitative frequency, in ordex to better explain principal-teacher interactions. The four specific principal activities relating to successful schools offered by Andrews (1987) included aspects of both frequency and social controls. Based on teacher perceptions, Andrews (1987) identified the following principal behaviors: (1) a visible presence, (2) clear communication, (3) resource provision, and (4) instructional leadership. A visible presence is foremost a matter of frequency. The role of communicator encompasses vision, clarity, and consistency (Andrews, 1987; Greenfield, 1987; Hallinger \& Muphy, 1987; Wilson \& Firestone, 1987). Although Bossert (1985) found no evidence in effective school. literature for a single leadership style, he noted two commonalities: (a) systematic visibility and (b) clear articulation (p. 46).

It is difficult to assign valid quantitative measures to qualitative behaviors. Yet, in order to disentangle structural 
variables from social, political, and subjective variables, that is precisely what is needed (Deal, 1987; wilson \& Firestone, 1987). Moreover, Hallinger and Murphy (1987) concluded that context was critical in understanding control since the qualitative behavioral impact of managerial activities - as well as culture (Sergiovanni, 1987) and leadership (Vroom, 1984) differs from organization to organization.

Bossert, et al. (1982) has called attention to the fact that in many previous studies of school principals, somcalled qualitative behaviors have been repeatedly found to be positively associated with effective principal performance. Among the most potent qualitative behaviors were the exchange of information, maintaining good relationships, encouragement, high expectations, and support. The managerial functions which were reported to complement these qualitative behaviors were preparation, goalsetting, and establishing performance standards. Bossert, et al. (1982) concluded that more data on daily managerial processes must be collected and analyzed to learn the impact on instruction.

Bossert, et al. (1982) also pointed to the literature on change and innovation for specific school managerial behaviors as a starting point for further research on coordination and control. In developing their list of behaviors, the following were included:

1. direction of funds associated with instruction

2. control of scheduling staff meetings

3. appointment of staff to specific comittees 
4. public rewards

5. protection of teachers

6. public acceptance of a program

7. control of the flow of program information inside and outside the school

8. limit competition between programs

9. lobbying for administrative support for program

10. promotion of programs outside school

Such a list of daily activities is a significant contribution to the iterature on instructional influencing activities, for it moves beyond the broad conceptual categories and formal bureaucratic policies towards specific, managerial tasks related to curriculum and instruction. Bossert, et al. (1982) further argued that principals should not perform these managerial activities in a random fashion or on an ad hoc basis, but rather in a systematic manner towards a desired goal of improving curriculum and instruction. This suggests that researchers need to analyze both the long and short-term effects of structure on each of these activities.

\section{Summary and Implications of hierarchical control}

The review of the structural analyses has revealed, however unintentionally, alternative managerial processes and qualitative behaviors. Ironically, these untested, "qualitative" influences of specific managerial processes signal the most far-reaching contribution of structural analyses. As yet, none of the findings of "mediating" variables such as tenure (Applewhite, 1965). informal verbal communications (Hannaway \& Sproul1, 1978m 79, Sproul1, 1981), information processors (Sproul1, 1981), the 
institutional model (Meyer, Scott, \& Deal, 1983), "exchange processes" (Cohen \& Miller, 1980), or social control (Eisenhardt, 1985), among others, was found to be empirically tested within school settings. Each of these variables emerged as alternative or complementary explanations after the original hypothesized structure was found to be inadequate. These implied, residual variables were then incorporated into a revised conception, often resulting in a new dichotory between the structural-frequency measures and qualitative variables. In short, the empirical and subjective reality of control, as with organizations themselves, turned out to be far more complex than could be measured by using formal structures alone.

At present, support for qualitative behaviors and their control effect is more intuitive than empirical. Even where empirical evidence has been reported, the linkages between theory and data must be considered weak. Social control is said to minimize preferences among organizational members (Eisenhardt, 1985: Scott \& Scott, 1971). The concept lends support for the institutional paradigr over a managerial model (Meyer, scott \& Deal, 1983). Through social control, organizational merbers cooperate towards achieving organizational goals because they understand and have internalized these goals (Eisenhardt, 1985). According to Crowson \& Morxis (1985) and Tannenbaum, et al., (1974), even hierarchical controls parallel norms of organizational loyalty and identification, placing a premium on rutual trust, individual initiative, and socialization. It is 
this shared belief system as well as the structural relationships Which seem to characterize school controls (Etzioni, 1965; Scott, 1983; Wilson \& Firestone, 1987).

Managerial research strongly suggests that control processes operate on the level of technology as "a guide to action" (Vickers, 1967, p. 29). Support for classroom teacher level data sources was found in many of the studies, particularly in Andrews (1987) and in Cohen, Deal, Meyer, \& Scott (1979). Wellisch, et al. (1978) combined principal with teacher responses. Although the perspectives of superordinates and subordinates differ within organizations (Abbott, 1975; Deal \& Cellotti, 1980; Duke, 1982), the substantive, as well as methodological, issues of combining data sources is unresolved. Nevertheless, more consideration ought to be given to empirical findings which include, rather than ignore, classroom teacher data.

There are some major difficulties in synthesizing control research, particularly the limitations of measures relating performance to both structural and qualitative behaviors, and the idiosynoratic use of organizational process terms. In most of the studies cited, the findings resulted from evidence based on a single structural entity defined as a causal indicator of control. Although these Iimitations are not unique to the concept of control, the close association of control with formal. organizational structures increases the likelihood of further continuing this confusion.

The most frequent request for further investigations echoes 
the need to specify the nature and stxucture of daily managerial processes (Bossert, et a1., 1982; Cawelti, 1987a; 1987b; Ogawa \& Hart, 1985; Pfeffer, 1978a). Koontz (1971) understood this need for specificity. In his managexial control framework, controi mechanisms were to be tailored to jobs, plans, individuals and organizational needs (p. 84). Bossert et al. (1982) concluded that "informal controls by network peers and by the organization's culture as well as incentive systems related to promotions and evaluation can shape principal behavior" (p. 53). In narrowing the scope of control, however, care must be taken not to focus exclusively on those tasks where control can be established, thereby diverting attention away from other important organizational processes (Vickers, 1967, p. 28-29). The effect of this aiversion would linit (1) the behavioral impact of the information on both the decision-makers and other organizational participants, (2) the relative distribution of information, specialization, and expextise within professional organizations, and (3) the interrelationship between control over information and other organizational control mechanisms, such as standards, evaluations, and incentives. Within school buildings, the same individual must often play the roles of both controllex and decision-maker. Thus, the formal separation of control functions from organizational processes is too artificial especially within the active task domain of curriculum and instruction. In short, any narrowing of the technical conception of control would tend to ignore the function of decisionmaking 
as a pragmatic organizational necessity (Hofstede, 1978) and as an individual need (E. Langer, 1983).

Pfeffer (1978a) noted that the structuralists started out with a rational, nomative view of organizational control and with the belief that those organizations which deviated least from the norm were the most effective. What their own research studies found, however, were variations based on size, technology, and stability which contributed to a revised view of organizations as more complex than originally thought. Many organizational researchers have still continued to ignore the implications of complexity by remaining bound to rational prototypes and normative prescriptions (Deal, 1987). Deal (1987) and others have called for the systematic use of nonrational, political, and cultural findings in order to better understand the nature of organizations and organizational behavior (Bolman \& Deal, 1984: Patterson, Purkey, \& Parker, 1986). Before that task can be successfully accomplished, however, a broader review of social science literature is needed to further substantiate the behavioral control indicators which influence school-level performance.

\section{Review of Related Literature: part II}

\section{Beyond structure: Disciplines, Theories, and culture}

From the review of organizational structure, it is evident that the concept of control extends beyond structural variables. Ironically, most of the control factors which are analyzed within social science discussions of control have been reported under 
the conclusions or implications of structural analyses. Unfortunately, the segmenting of control theories across academic disciplines has created substantive and methodological difficulties for a synthesis. No single comprehensive framework emerges. As a result, the various discipline-directed models, based on natural sciences, seem to be evolving into diagnostic (M. Harrison, 1987) and ethnographic descriptions of organizations and organizational behaviors (Lincoln, 1985). In effect, the search for meaning has taken precedence over the reporting of statistical significance (Kirk \& Miller, 1986). Today, organizational research has become both an art form as well as rigorous methodology. New directions are not only derivative of previous investigations, but, in the minds of some, represent a new beginning (Lincoln, 1985). This new cultural and symbolic emphasis has the tone of high drama and adventure with its imaginative metaphors and literary style (Lightfoot, 1986). There has been a perceptible shift in language, tone, and frameworks away from closed systems' models and theories towards increased references to open, institutional frameworks based on subjective, qualitative, and cultural aspects of behavior and thinking (Ames \& Ames, 1987; Astuto \& Clark; 1985, Deal, 1987; Erickson, 1988; M. Harrison, 1987; Sergiovanni, 1987; Wilson \& Firestone, 1987). Rather than predicting outcomes, the focus is on rich descriptions and meanings (Patterson, Purkey, \&arker, 1986). 
The shift from social scientific models to systematic cultural analyses suggests that there exist certain underlying and meaningful qualities, more fundamental than those revealed through structural analysis. The goal, ultimately, is to integrate cultural diversity, nonrational political descriptions, and work fragmentation with practical and specific control indicators in order to improve understanding and managerial performance.

\section{Political control}

Political discussions offer a number of potent alternative explanations which complement the study of power within formal authority structures (Bacharach \& Lawler, 1982; Baldridge, 1971; Dornbusch \& Scott, 1975). Whereas organizational structures tended to foster closed systems thinking, political perspectives impose an open systems' logic (Baldrigde, 1971; R. Campbel1, et al., 1985; Thompson, 1967, Wirt \& Kirst, 1982). "A political. approach to organizations implies a multidirectional image of power, and this means an emphasis on influence apart from, as well as in the context of, the authority structure" (Bacharach \& Lawlex, 1982, p. 42).

R. Campbell, et al., (1985) have developed a complex, political typology to analyze school control. Their framework includes seven interrelated control elements:

(1) demographic control elements which describe the number, character, and cultural values of participants: 
(2) legal control elements that describe the role of state and federal levels:

(3) structural control elements which include the levels of organization and formal roles;

(4) ideation control elements which reflect concepts and purposes;

(5) Knowledge control elements based on information and expertise:

(6) financial control elements which analyze the resources (local, state, and federal); and,

(7) network control elements that discuss the relationships among each of the above elements.

The control elements "reside both in the institution - a school or school district - and in the environment in which the institution exists. The many interactions between institution and envitonment, make the open systems concept a useful one" (pp. 445-446). In particular, network control provides vertical and horizontal perspectives within which all the control elements "evolve into countless combinations and variations" (p. 443). The nature of political control is linked to three expansive dynamics: (1) the concept of influence, (2) incremental decisionmaking, and (3) the interactions among organizational actors and groups. What differentiates these expansive views from the constrained closed systems" perspective is their relationship to the larger institutional environment (R. Campbe11, et al., 1985; Meyer \& Scott, 1983; Pfeffer, 1978a).

\section{The concept of influence.}

The abstract concepts, power and influence, have been of keen interest to observers of organizational behavior (Bacharach \& Lawler, 1982; Cartwright, 1965; Etzioni, 1965; Lexbinger, 1965; 
Pfeffer, 1978a). Unfortunately, the definitions in use of these concepts are so unclear as to preclude valid comparisons across different studies and settings (Cartwright, 1965; Krislov, 1983 , p. 57). In ordinary, comon usage, the distinction between power and influence appears to be quite simple. The former reflects the role or position of an individual in an organization. Thus, holders of public office and those in positions with formal line authority are said to hold power. others who are not in offices with formal authority, but who offer ideas and advice may be said to exert influence. Power is, therefore, directly associated with formal authority structures; influence with other organizational patterns, such as informal structures (Bacharch, 1981, p. 34; Cartwright, 1965; Lerbinger, 1965).

structural analyses focused on formal authority structures. Within this circumscribed, and often normative, framework, power was viewed as a function of the formal organizational hierarchy and unambiguously written into the rules and polices of the organization (Bacharach \& Lawler, 1982, pp. 38-39; Cartwright, $1965, \mathrm{p} .2)$. However, when organizations have been perceived through a political framework, the dynamics of power and influence are considexed more complex than simply formal authority and hierarchy (Bacharach \& Lawler, 1982, p. 7), Within the political framework, the concept of influence emerges as something not found in the rules or directives from superiors (Cartwright, 1965, p. 2).

According to Lerbinger (1965), influence is a better concept 
than power: it is "a powerful sentiment, an icea, a code that is honored and valued; it is an intangible that can result in tangible performance; it is a rich concept invested with a heavy burden" (p. 255). Influence is also persuasive, which implies voluntary submission (Bacharach Lawler, 1982, p. 12). Based on previous studies, Cartwright (1965) reported five types of influence. Of the five, persuasion was ranked highest, followed by manipulation. This peculiar juxtaposition of persuasion and manipulation would seem to highlight much of the confusion associated with the concept of political influence. Namely, unlike pejoratively used terms, such as manipulation or control, persuasion holas a "special moral status" (Burnell \& Reeve. 1984).

Power, of course, has been defined more broadly than just formal authority, hierarchical relationships, and coercion. French \& Raven (1978) defined power in terms of its influence on individual actions or change. Their now classical bases of power identified reward, coercion, legitimacy, reference, and expertise. In empirical studies, French \&aven reported evidence that both reward and coercive power were highly dependent upon others within the organization: rewards tended to increase attraction between individuals on aifferent organizational levels, lowering the resistance to change; coercion had the opposite effects, especially when not perceived as legitimate, that is, it decreased attraction among individuals, increasing the resistance to change. of the five 
bases, referent power, defined as the identification and mutual admiration of individuals on different levels, had the broadest range since it could potentially erase gaps between organizational actors. Alternatively, Bachrnan, et al. (1968) reported that expert power was most positively related to Tannenbaun's global definition of "total control."

A Iimitation of the French \& Raven frarnework was that it delimited the definition of power strictly to forces resulting in change. "By this definition, the influence of o (social agent) does not include $P^{\prime} s$ (person) own forces nor the forces induced by other social agents" (French \& Raven, 1978, p. 199). This not only raises a question of observable change versus psychological change, but it also ignores a tactical problen whereby "the most effective strategy may not always be able to pull the trigger" (Hakel, et al., 1985, p. 46.). Cartwright (1965) described a restricted view of power where one just looks at the effects upon overt behavior while ignoring the effects upon attitudes, beliefs, and motives (p. 24). In contrast, the permissive view not only accomodates overt change, but it also permits analyses of internal and attitudinal preconditions for change.

Bacharach \& Lawler (1982) further criticized French \& Raven's model as being more closely aligned with authority and hierarchy than with the broader, dynamic concept of influence (pp. 36-44). They viewed French \&aven's emphasis to be on intra-organizational dynamics, while totally ignoring influence patterns originating at institutional levels. Even with the 
inclusion of information, as a sixth base of power (Bacharach \& Lawler, 1982, p. 33), the French \&aven analysis of the bases of power was sald to confuse 'causes' of power relationships with characteristics of power holders (Bacharach \& Lawler, 1982, p. 34).

Bacharach \& Lawler (1982) have offered an alternative framework based on four sources of power: office or structural position, personal characteristics (charisma, leadership), expertise, and opportunity (p. 35). In their conception, authority was based solely on position, while influence was to be found within the other three sources (pp. 36-37). In short, the focus of political analyses shifted from closed authority structures to the expansive realm of influence (Bacharach \& Lawler, 1982, p. 44).

A different conceptualization of power was suggested by pfeffer (1978a; 1978b). In his scheme, power was based on (1) the possession of or ability to control critical resources, the control of or access to information and information channels, (3) the ability to cope with uncertainty, and (4) organizational size. Elsewhere, pfeffer (1978b) added comal authority to his 1ist of power determinants (p. 16). Pfeffer also identified internal and external political variables, such as laws, socialization, and selection procedures (Pfeffer, 1978a, $p$. $48 f f)$

Etzioni (1965) offered yet another approach to the conceptions of power and influence. He categorized organizations 
according to three power structures, while viewing structure as a function of control. Thus, within certain organizations, coercive power (i.e., the threat of physical sanctions) predominated; in others, remunerative power (i.e., control of material resources and rewards) predominated; and, in still other organizations, normative power (i.e., control of symbolic rewards and individuals identification with the organization) predominated (p. 651). This typology subsumed formal, authority structures primarily within coercive and remunerative type organizations, whereas influence was most widely utilized within identitive organizations (p. 659). Further, Etzioni's typology Iinked compliance more closely to formal control structure rather than to influence and informal structures. From such linkages, however, it might be implied that compliance ought to occur less often in identitive organizations than in either coercive or remunerative type organizations. What is more likely, however, is that interactive political dynamics (e.g*, compromise, negotiations, and bargaining) are more visible in identitive organizations. Organizational complexity can be seen more clearly in such organizations. Therefore, the use of measures of deviation between standards and performance are less precise and more problematic.

Political analysts explicitly state that limiting the issue to organizational structural components is too simplistic (Baldridge, 1971). Thus, it is through their empirical descriptions that the political analyses have made their major 
contributions to organizational theory. Nevertheless, political scientists offer little empirical data to support their distinctions between power, control, and influence (Krislov, 1983, p. 57). Many political analysts stress the need for clearer understanding and more consistent use of socio-political concepts (Bacharach \& Lawler, 1982; Pfeffer, 1978a). In a recent multi-state study of school control and autonomy, the authors Iinked authority with persuasion, while the definition of power was delimited to only those actions followed by either rewards or punishments (Floden, et al., 1988). Such idiosyncratic definitions make it nearly impossible to judge the validity of research findings.

\section{Decision-making.}

Decision-making has been given special prominence in organizational analyses (Barnard, 1938; Simon, 1957). Empirical research on decision-making revealed a distinction between normative, rational, closed systems models and descriptive processes. There is convincing evidence to support the view that decision-makers rely on incomplete knowledge and information (Lindblom, 1959), rather than on perfect and complete information based on unlimited resources (Dye, 1984, p. 32).

The alternative decisionmaking model has been labelled incrementalism (Lindblom, 1959). The incremental model arises out of confict and the consideration of contingencies, two pivotal political dynamics. Although the distinction between 
mental and action phases (Mann, 1975: Mintzberg, et al., 1976) are still maintained, incremental processes hold that only some, not all, alternatives and consequences need to be considered. Relatively few policy alternatives are outlined. The analytical process of incrementalism is comparative, pragmatic, and systematic, not theoretically dependent. And, instead of making a11 possible comparisons, the incremental model compares alternatives based on past experience before making a selection. Moreover, most social values are disregarded and are not ranked by priority. Lastly, characteristic of all human processes, the incremental model "expects to repeat endlessly the sequence just described" (Linablom, 1959).

Parallel concepts to the increment model may be found within early control theories, particularly frank's (1958-59) analysis of conflicting standards and selective enforcement found within Soviet industry. Frank replaced the notion of formal rationality (i.e., rational calculation) with substantive rationality (i.e.* referring to the achievement of a task, regardless of the means employed). Instead of directives and close supervision, Frank defined control in terms of "sensitivity and responsiveness to superiors" objectives " Similarly, Miles * Vergin (1966) suggested an alternative to the normative, "absolute levels of performance" called variance control, which measured the "variation of performance from period to period." This measure woula permit individuals to gauge performance within an acceptable range, or mean level of performance. It would also 
allow organizational nembers some freedom to set their own performance goals within limits. Control variance further recognized that there are situations beyond one's control for which decisions and judgments are made. This loose coupling measure provided room for a fxeedom to fail (Miles \& Vergin, 1966).

Indeed, within a political framework, all organizational processes are limited by constraints (Katz \& Kahn, 1978) as well as by dynamic factors, such as timing, scheduling, and feedback (Mintzberg, et al., 1976). The ideal, optimum conditions posited by rational theory or sterile conditions created only in laboratory settings cannot be applied with confidence to actual organizational processes. Thus, a valid theory of control cannot be purely rational (i.e., perfect or complete) or purely scientific (i.e., certain and objective). Rather, the theory and practice of control must be based on probability limits (Patz \& Rowe, 1977, p. 269), flexibility (Patz \& Rowe, 1977, pp. 66-73), tentative assumptions (Vickers, 1967) and uncertainty. Ultimately, decision-making is an active process in which "authority, power, and influence interact with the encouragement of dissenting views to achieve the degree of control that is needed" (Clark, 1988, p. 191).

\section{Rey actors and groups and their linkages.}

According to pfeffer (1978a), the study of organizational politics revolves around key actors and their interaction across 
the hierarchy. It is the political framework that directs attention outward from the technical core to encompass the general public, interest groups, political leaders, textbook publishers, standardized test publishers, the media, university professors, professional organizations, school boards and superintendents, as well as school-level administrators and teacher groups (Clark, 1988, 179ff; wirt \& Kirst, 1982; Kirst, 1984).

The identification and description of these key actors occupy a central focus in political analyses. Unfortunately, the description is not a straightforward task since it is difficult to separate objective analysis from a discussion of the relative influence among actors. The very notions of fluid participation (Cohen, March, \& Olsen, 1972) and intra-organizational coalitions (Bacharach \& Lawler, 1982) as well as the more common political concepts of conflict, bargaining, and negotiations (Baldridge, 1971) seem to imply that the descriptions of actors cannot be drawn in fixed, structural terms.

A number of theorists have proposed models of interacting and autonomous zones (Hanson, 1981; Hoy \& Miskel, 1982, p. 280ff; Lortie, 1965). At the school-building level, Hanson (1981) tried to unravel the complexities originally described by Lortie's (1965) interactive school control typology. Hanson's objective was to study the interplay of semi-professional teachers and school bureaucracy. Bidwell (1965), Lortie (1969), Etzioni (1965), and Dornbusch \& Scott (1975) have all agreed that 
teachers are semi-professional in that they are subordinate to the administrative framework and have less autonomy than professionals who participate in deciding entry and selection criteria.

Hanson's (1981) findings of intercomnecting zones were based on a small sample of tive schools in which he compared hierarchical control with collegial control by looking at common school processes. Using intensive interview data, Hanson described a model of interacting spheres among administrators and teachers. In all the schools sampled, he found three zones: an administrative zone, a teachers' zone, and an overlapping contested zone. Within each of the three zones was (a) structured and unstructured controls, (b) formal and informal processes, (c) subcoalitions, and (d) autonomy. Each zone was constrained by externally imposed limits: for example, the administrative zone was constrained by state legislatures, courts, and school boards; the teacher zone was constrained by principals and school rules; while the contested zone was constrained by the interaction of administrators and teachers.

Charters (1981) defined control structure as the relationship between those individuals who have formal authoxity for a decision with those individuals whose behavior is affected by that formal authority. Even though the units of analysis are population groups (input and output populations), the definition of control is fundamentally structural, and not concerned with processes, efficiency, or compliance. When members of the input 
population were also members of the output population, then the decision was participatory; if only teachers were involved with both populations, the decision was collegial. Discretion was not part of control structure since it entalled neither interpersonal processes nor organizational provisions.

Charters (1981) reported that the populations involved in core technology tasks varied by tasks, substantive issues, and time. For example, lesson planning and the cholce of materials were in the hands of teachers: principals determined class grouping; and, school-wide or district-wide personnel selected texts. Over time, Charters found that collegial decisions increased, whereas principal and shared decisions decreased. An exception was that principal decisions were higher at larger schools. Although charters concluded that controls differed by levels (p. 309), the whole system was affected (loosely or otherwise) by the shifts in control populations (, 308$)$.

Some school organizational theorists and political analysts have suggested that building level analysis is the most significant for managerial control (Bossert et al., 1982; Clark, 1988). Hanson (1981) stated that "[t]he principal is the one who usually interprets the directives and constraints coming down from the central office, the state legislature, the community and so on" (p. 255). Moreover, according to Hanson (1981), the principals" use of informal management tactics can enhance the teachers' concept of professionalism since administrators are "keepers of intrinsic rewards" (p. 268). Bacharach (1981) 
defined work processes as "patterns of behavior associated with the conduct of organizational work. Essentialiy work process variables depict behavior of an actor in various aspects of his work" (p. 28)* Bacharach \& Lawler (1982) focused on intraorganizational coalitions as the key unit of political analysis. The description of key actors and groups eventually arrives at the question of their relative influence. "In a very real sense, it makes Iittle difference what the secretary of education says works, what the governor includes in his program, or what the school board adopts for the district administration to implement, If (author's emphasis) none of these actions affects what happens between the teacher and the student" (clark, 1988 , pp. 178-79). "[A]1though the district level of leadership is important for thinking about policy, providing support for curriculum improvement, ensuring material support for school w level work, and monitoring the process of school change, the work of curriculum change is logically the work of teachers and administrators in schools and classrooms (Griffin, 1988, p. 244). The boundaries of organizational influence invariabiy stretch beyond the technical core levels of the organization out to the managerial and institutional levels (Thompson, 1967). By extending the boundaries of organizations, the political opensystems' model increases the complexity (R. Campbe1, et al., 1985) and, invariably, the level of conflict within the organizational enviroment. For some, the conflicts among organizational levels are considered to be irreconcilable 
(Golaman, 1983, p. 337). Most political ideologies, however, accept the dynamics of shared beliefs (Scott, 1983, p. 14), bargaining, and negotiations (Baldridge, 1971) which underlie organizational structures. Meyer, Scott Deal (1983, p. 45) reported high levels of satisfaction among teachers and between teachers and school administrators across districts. The level of satisfaction, however, dropped dramatically with respect to processes of evaluation, instruction, communication, and participation (p. 57)

Principals face an obvious dilemma. Boundary-spanning activities such as information acquisition, physical input control, and interface (Jemison, 1984) increase principals' influence over strategic decisions (Jemison, 1984) and teacher loyalty (Johnston \& Venable, 1986). yet, at the same time, boundary-spanning activities have been found to detract from the managerial functions of principals (Leiter, 1983). Hills (1963) and Leiter (1983) found that principals who represented their schools' interests to higher organizational levels pay a price in terms of their perceived managerial (within-building) performance. What may account for the high correlation with teacher loyalty (Johnston \&enable, 1986) is that in these external interactions, principals are expected and perceived to support and protect teachers and pupils from the environmental network.

Hills (1963) analyzed the representative leadership role using two measures: the procurement of funds and resources from 
above and the disposal of resources. Not surprisingly, the results showed a positive correlation between disposal with total procurement. Hilis then asked how this correlation affected perceptions relating to (a) teacher morale, (b) principal's effectiveness, (c) teacher satisfaction, (d) teacher confidence in leadership of principal, and (e) supervisors rating of principais' effectiveness. Based on a non-random, self-selected sample of 53 principals and 872 elementary school teachers, the results indicated tentative support for the hypothesis that representative functions take away from managerial functions. In a more definitive manner, Leiter (1983) reported that the principal's boundary spanning activities resulted in teacher dissatisfaction and disxuption at the technical core levels. Thus, there are findings of conflict as well as consensus among key school actors which have led theorists to support different organizational paradigms. Whereas Meyer \& Rowan (1977) hypothesized that formal structure and technical core activity were loosely coupled, Leiter (1983) argued that teachers have not sufficiently mastered the technology of teaching to permit solo practice. If the latter view is even partially correct, the need for improving managerial control is essential.

\section{Summary and implications of political control.}

A major debt is owed political theorists for their identification and description of an empirical reality left hidden by normative, rational theories of organizations, 
processes, and participants. Joining the notions of cooperation and harmony are the political dynamics of struggle, conflict, and negotiations (Bacharach \& Lawler, 1982, p. 5). The shift in analyses from formal structures of power to influence dynamics presents an organizational reality that is complex, interactive, non-linear, and multidirectional ( $R$. Campbell, et al., 1985). yet empirical investigations of power and influence are still lacking (Krislov, 1983 ).

Political theorists have offered diverse research units of analysis, ranging from informal groups (Cartwright, 1965) and interest groups, to coalitions (Bacharach \& Lawler, 1982 , Pfeffer, 1978a) and institutional-environmental factors (R. Campbe11, et al., 1985; Meyer \& scott, 1983). Organizational processes such as information, communication, and evaluation (pfeffer, 1978a,b), and incremental decision-making (Lindblom, 1959, Thompson, 1967) have been offered to explain the complexity of the interactions.

The acknowledgement that politics is important, however, does not make everything worthy of political investigation. Typically, complex political typologies leave unresolved the issue of relative influence among the institutional and environmental control elements (R. Campbel1, et al, , 1985, p. 446), particularly at the technical core level on which management functions. The lack of discriminant criteria for inclusion of variables places significant limitations on future theory-building. Multiple, discrete factors are difficult to 
organize and interpret. Moreover, the dynamic processes of political analyses are often too general to apply to specific day to day factors (Pfeffer, 1978a).

The control-autonomy dichotomy itself, an implicit assumption of many control theories, may not be appropriate to curriculum and instruction or instructional leadership (Floden, et al., 1988). That is, the complexity of these technological relationships may preclude either total control or autonomy for either building administrators or teachers. As early as 1971, Eye, Netzer, and Krey had proposed alternative measures of operational patterns (i.e., interpersonal relations). They recognized, as had charters (1981), that pure autonony/discretion was not control, rather that control was one aspect of the larger managerial process. As alternative control measures, Eye, et al. (1971) suggested the following: regular, continuing, systematized, and scheduled scrutiny of curricula (p. 322); standardized procedures for selecting, organizing, and proceeding with known recurring tasks such as textbook selection (p. 323); standard operating procedures for coordinating school and nonschool programs; functional knowledge of instructional aids and materials: evidence of long range plans for evaluation of curricular and design for change ( $D .324)$. These interpersonal characteristics of consistency, regularity, and clarity, however, were presented as alternative mediating variables, and still. await further empirical testing.

Descriptions of complex external phenomena are necessary. 
but do not suffice. Bacharach (1981) has called for the merging of the broader political realm with the more confined organizational or administrative domain. He argued that "we need to examine the mechanisms of linkage between these various levels of government and the processes of policy transference, policy supervision, and the institutionalization of federal and state mandates by $10 \mathrm{cal}$ districts (p. 26) "

This view was advanced further by Bacharach and Lawler (1982) who have taken the political realities of struggle, conflict, and lack of consensus (p. 5) and applied them to a micro-level, intra-organizational analysis. This shift towards micro-level analysis is certainly consistent with numerous other bodies of research on effective schools, implementation theory, and cultural and symbolic leadership.

Descriptive analysis of complex tasks such as curriculum and instruction need to incorporate political personhood. Whereas political analysis has opened the door to non-nomative heuristics, the next step should be to adaress dally managerial interactions and a concern for workers" general well-being (Argyris \& Shon, 1982; Tannenbaum, et al. 1974). organizational work life is not just a matter of lierarchy and authority. Western thought places a high value on the subjective aspect of personal development and growth in the analyses of controls (Myers, 1981; Patz \& Rowe, 1977; Schein, 1972; Scott \& Scott, 1971; skinner, 1966: Vickers, 1967). Thus, from the external realities of politics have come managerial processes 
Miles \& Vergin, 1966), communication and onmgoing assessment (Eye, et al., 1971), and, information and evaluation systems (Pfeffer, 1978a, Sproull, 1981). The investigation can now proceed towards the internalization of social norms (Coser, 1982, p.18) to selfcontrol (E. Langer, 1983) as a completion of the internalization process.

\section{social control}

The concept of social control has its roots in sociological theories emerging at the turn of the century (Coser, 1982). As a normative concept, social control seeks to maintain the structure of society. In this respect, it constitutes conservative mechanisms which a society uses over individuals to enforce conformity to norms and values (Schein, Schneier, \& Barker, 1961; Coser, 1982, p. 13). As sociological analyses have evolved, social controls, such as laws and rules, have shed their Iimited external (i.e., political) status by entering the realm of human nature. The new social control descriptions based on internal, unobservable constructs, however, have been beset by imprecise language, methodological problems, and "unexplained phenomena" (Coser, 1982, p. 14). Nevertheless, through social experiences, a reflexive concept of self has emerged (p. 15) as the external world merges with the human psyche (p. 14) to form a sociom psychological dimension.

The internalization process begins in social expexiences. 
The social context and behaviors of others act as forces of conformity. The strength of social controls varies depending upon many factors, among then formal structures, socialization processes, and rewards and punishments. Each of these factors has the potential to elevate or lower individual performance, depending, in turn, upon the values, ideas, and behaviors of others. Sociologists are then faced with the question of whether the effects of these factors contribute to a normative concept of what ought to be or whether they should simply describe the factors and their effects in ethically neutral terms (Meier, 1982).

In structural analysis, behavior is predominantly a function of the organizations' authority structure. More specifically, it views hierarchy and the demands of technology as the principal causes of behavior. political analysts broadened the causal factors beyond the formal structures and technical core boundaries by identifying institutional processes, key participants, and environmental influences. But neither structural analysis nor the political dynamics were comprehensive enough, if not perhaps always appropriate for educational institutions (Etzioni, 1965; Scott \& Scott, 1971, p. 216). Both formal mechanisms of authority and power relationships excluded references to the internalization processes, viz., social control. Moreover, the structural and political reliance on empirical, observable phenomena prevented them from directly analyzing internal, subjective, and qualitative variables. 
Al social controls have external determinants and, in this sense, are empirical. In organizational settings, the determinants manifest thenselves in collective, group situations that occur within social relationships, customs, work habits, and roles (Scott \& Scott, 1971, pp. 191-224). Their evolvement into social control functions may be linked primarily to two organizational processes: participation (Smith \& Tannenbaum, 1963; Coch \& French, 1978) and interaction (Argyris \& Schon, 1982, pp. 206-207 notes; Bacharach \& Lawler, 1982, p. 16). Both processes can affect behavior: for example, participation is said to lower resistance to change (Coch \& French, 1978), whereas interactions affect perceptions of others, self, and situations (Argyris \& Schon, 1982 , p. 207 note). Participation and interaction have quantitative measures related to their frequency and regularity as well as qualitative measures related to their behavioral impact on attitudes and beliefs. In order to understand the relationship between external and internal determinants of social control, we first need to focus on two issues: (1) the general theory of sociological influence (i.e., the concept of social control itself) and (2) social control processes which contribute to the internalization of externally imposed controls.

\section{Social control: The concept.}

The term social control is often used as a general category in which non-observable, non-structural (Eisenhardt, 1985), non- 
legal (Lortie, 1969), non-genetic (Burnstein, 1982), and other problematic explanations of behavior have all been indistinguishably grouped together. obviously, the greater the internalization, the less observable are its measures (French \& Raven, 1978). Strict empiricists, logical positivists, and behavioral psychologists have all rejected internal constructs which they pejoratively label as "metaphysical" (Ayer, 1952; Ryle, 1969; Skinner, 1966; Quine, 1961). Some sociologists attempt to escape from metaphysics by linking social control only to observable phenomena, such as organizational effectiveness (Meiex, 1982). In so doing, psychological evidence of prior conditions for individual acceptance (Black, 1970; French \& Raven, 1978; Locke, 1977) are ignored.

Although the term social control appears frequently in diverse research Iiteratures, it is often used inconsistently (Coser, 1982) or, simply left undefined (Eisenhardt, 1985). scott and scott (1971) stated that all social control is experienced within social relationships (p. 197). The authors further defined social control as "positive interstimulation" not just a "restriction of action" (p. $x$ ). They traced six sources of social control: (1) political and economic power dynamics, genetics, (3) language, (4) relationships, (5) role differences, and (6) collective roles. Except for genetic factors, such as ability and adaptability, each of these sources emphasized the mutuality inherent in social control (p. 1, 210).

scott and scott (1971) were aware of the limitations of 
their definition, both as a sociological concept apart from psychology, and also as it relates to change and development. For example, they noted that collective roles as a source of social control were less emotionally satisfying than unique roles in meeting an individual's subjective needs ( $p$. 197). As regards to social control as a change strategy, the authors found empirical evidence for generational change which occurs over a long period of time (pp. 205-207) as opposed to short-term changes. Moreover, the mutuality which is central to social control conflicts with the notion of impersonal, organizational control, resulting in a paradox. That is, there is more freedom in impersonal control (e.g., freedom from close supervision) than in mutual control: but, that impersonal controls lead to feelings of alienation and powerlessness (pp. 211-213). Thus, social control raises a practical, administrative problem, namely, how to provide maximum feelings of satisfaction along with maximum effectiveness (p. 215).

An innovation in the conceptual definition of social control was offered by Gibbs (1982). He wrote that "social control is an attempt by one or more individuals (the first party in either case) to manipulate the behavior of one or more other party individuals (the second party in either case) through still another individual or individuals (the third party in either case) by means other than a chain of command" (p.86) * Gibbs" definition excludes direct interactive control and organizational hierarchy from social control. Although the definition seems to 
include intentionality (i.e., manipulate), the issues of overt behavior and change are subsumed under the "attempt."

Gibbs' definition raises a number of other questions pertaining to the means by which social control influence people. The deliberate absence of any reference to standards (p. 88) would seen to permit either coercion or persuasion to be considered as legitimate means of social control. There is also no mention of whether the social control effort must be effective (i.e., successful) or not. The necessary role of a thira paxty further complicates the relationship of social control to cultural norms and deeply held individual values.

In spite of these unxesolved questions, there still appear to be some charactexistics common to most definitions of social. control. First, it is used as a cohesive force that minimizes diverse, political preferences within a system (Eisenhardt, 1985; Gibbs, 1982). Secondly, the mutual aspect of social control tends to steer the concept between the extreme views of total freedom or total control. Total freedom implies no social control whatsoever, while total control eliminates the mutual dependence and interaction between individuals. Thirdly, since norms and values are relatively stable and difficult to change, social control mechanisms are tilted in a conservative direction. Conversely, social control has been thought to have proactive qualities which encourage restructuring, programmatic innovation, political and social dynamics, and personal growth, learning, and development (Black, 1970; Lawler \& Rhode, 1976; Lortie, 1969 ; 
Patz \& Rowe, 1977; Vickers, 1967).

Support for any of these common characteristics of social control has been stronger suppositionally than empirically. In fact, empirical support comes primarily from research studies which have identified the limitations of structural and arganizational explanations and models (Eisenhardt, 1985; Meyer \& Rowan, 1977; Meyer, Scott, \& Deal, 1983). The implications of social control, however, have been based in part on the use of a single factor or variable, such as formal policy in order to explain residual behaviors. Since a single entity cannot fully explain behaviors, cohesive explanations, such as "small societies" (Elmore, 1987), and institutional frameworks (Meyer, Scott, \& Deal, 1983) have been offered, with empirical measurement support originating within group behaviors and norms.

\section{Social control: processes.}

A review of managerial processes associated with social control is obviously hampered by the lack of conceptual specificity. Nonetheless, managerial behaviors which relate to the common characteristics (cohesion, moderation, conservatism, innovation, and personal growth of social control should offer some insight to its operational indicators. What distinguishes social control from either structural or political control is the transformation fxom external mechanisms to internally accepted means of control.

Bidwe11 (1965) noted that in school organizations, 
bureaucratic elements were of a "rudimentary nature" (p. 974) and, hence, provided, at best "a partial solution to the problems of internal coordination." Therefore, he added the concept "control with communication" as a central organizational process (p. 1014). He agreed with Blau \& Scott (1962, pp. 51-56) that professional norms and collegiality conflicted with legalbureaucratic functions of schools (Bidwell, 1965, p. 1012); thus, there was a need to increase professional discretion and judgment, particularly in the non-routine areas of curriculum and instruction (pp. 976, 1004).

Lortie (1969), too, developed a social control typology. Lortie added to the organization's hierarchy both teacher autonomy and collegiality as determinants of behavior. In addition, he considered selection-socialization processes as subtle social control mechanisms used in education (p. 10).

Lortie (1969) distinguished between two kinds of rules, hard and soft. He linked the use of soft rules (e.g. s suggestions, not commands or orders) to the areas of curriculum and instruction. These soft rules would replace close or frequent supervision. Etzioni (1965) found that the more effective socialization and goal congruence, the less need for supervision. Yet the reliance on socialization could be reduced with greater emphasis given to selectivity (pp. 655, 657).

Similax findings had emerged from the structural analysis of technology. Mahoney \& Frost (1977) reported that for reciprocal tasks (i.e., complex, interdependent tasks such as in curriculum 
and instruction) committees and staff development activities were preferable to supervision. Meyer and Rowan (1977) even argued that formal evaluation procedures reduced the trust and confidence of educators, and therefore, did not serve social control purposes at all.

Lortie (1969) also Iinked control to the unique reward system in education wherein neither salaxy nor promotion was controlled by school administrators. Since the social status of educators rests outside the reward system, it is necessary for administrators to understand what rewards teachers do enjoy. Included in this category are work security, a comfortable work schedule, and intrinsic rewards (Lortie, 1969). It is from their students, not administrators, that they derive many of the rewards of the teaching profession (Lortie, 1969). Mitchell's (1987) study of teacher incentives reported that "there is virtually unanimous agreement in the iiterature on rewards that teachers are more powerfully affected by intrinsic rewards, particularly their sense of responsibility for student learning and their enjoyment of warm social relationships" (p. 207).

As a semi-professional field (Etzioni, 1965; Hanson, 1981; Lortie, 1969), education requires a comitment to professional norms; but, it has also tolerated ill-prepared and inept practitioners. Although pre-service training actually begins with one's own classroom education, the in-service socialization mechanisms are not particularly lengthy or very stringent. According to scott \& scott (1971), "educational systems have for 
the most part ineffective means for producing change in codes of behavior, and they are organized in such interlocking ways that it is virtually impossible to produce changes except in a very slow fashion or by setting up entirely new institutions (p. 204). Together with professional discretion and soft rules, the subtle social controls of socialization may, indeed, be inadequate. Bidwell (1965) and Lortie (1969) established the foundation on which Meyer and Rowan (1977) and others have built their institutional and loosely coupled models. Schools are public organizations which must follow state legislative and local school board directives. yet, the political authority frameworks and organization models cannot account for the gap between centralized policy-making and local, managerial implementation. social control provides an alternative explanation to organizational relationships in accounting for the consensus and conformity found within schools (Meyer, scott, \& Deal, 1983). Yet, it also contributes to the problem of measuring accountability, since its mechanisms are slow to take affect, subtie, and often informal. Instead of formal policies, social control measures are found within mutual acceptance (Lawler \& Rhode, 1976, p, 69; Locke, 1977) and belief systems (Mitchell, 1987). Meyer \& Rowan (1977) ascxibed a legitimizing function to bureaucratic, formal mechanisms by which society is able to measure accountability - distinct from the technology and processes which occur daily within schools.

School building managers are continuously faced with the 
choice of whether to address social control processes to groups of individuals (i.e., interest groups, organizational levels, coalitions) on the one hand, or to specific individuals directly. Gibbs' (1982) conceptualization of third party social control simply adds another managerial alternative to consider. Marzano, et al. (1988) noted the difficulty faced by individuals who seek to break away from group norms in order to engage in creative activities. The conservatizing and moderating strength of the group may inhibit much of the dynamic quality of creative actions. Moderation is increased by the control exerted through collective roles, since, as noted above, this dynamic is less emotionally satisfying than when expressed through unique individual needs towards the fulfiliment of whole person (Scott and scott, 1971, p. 197). Dunn (1985) concluded that the most important dependent variable is not instrumental rationality or even collective learning capacities, but enancipation (p. 242). on the other hand, it is from group dynamics that individuals develop feelings of communty spirit, togetherness, and harmony. These feelings strengthen, if not emoble, individual effort, permitting some individuals to perform at levels beyond their individual capacity or motivation. Many of these felt qualities which can result from group effort are not possible from individual actions performed by and for the individual. The community effect is literally more than the sum of its individual parts. "Although power is used by individuals, in the organizational context it is used by individuals as 
members of specific organizational subgroups" (Bacharach \& Lawler, 1982, p.17). Therefore, the individual is not independent of an organization. The subjective needs and wants of individuals (i.e., motivation) as both individuals and as organizational members (e.g., teachers within a system) need to be met (House \& Mitche11, 1974).

One of the responsibilities of school managers is to instill professional standards in teachers and to hold themselves and others accountable for success. Managers do not give up responsibility even when fostering empowerment, autonomy, or teacher professionalism. Given the present structure of socialization and training of teachers, such laissez-faire behavior would be irresponsible (Leiter, 1983). Without a strong knowledge base, individual behaviors rely primarily on past experiences and noms (Argyris \& Schon, 1982). Few believe that teachers, presently, have the knowledge base on which to work independently (Leiter, 1983; Sieber, 1981), or that teachers are willing to manage all functions of schools. Thus, school administrators cannot legally or ethically ignore teachers or even permit them to act as they please, even though, for most of the day, teachers are isolated away from their colleagues and supervisors (Lortie, 1969) and exercise broad discretion within the classroom (Eye, et al., 1971).

\section{Summary and implications of social control.}

The internalization of rules and standards depends more on 
the salient qualities of social control mechanisms, rathex than on organizational structure or power politics. The quality of social control processes, however, are mediated by collective influences, values, and stable norms, thus, creating a conservative environment in which to implement change. once accepted, social control standards may be said to preserve order, not provide a vision of a new order. Standards lay the groundwork for measuring deviance. Without standards, there is no way of knowing about success or failure (Vickers, 1967). According to Meier (1982), the issue of standards in social control is whether they are to be defined normatively or whether the concept is ethically neutral. Trends within the social sciences have favored empirical descriptions, $\dot{i} . e .$, ethical neutrality. Contributing to this view is the assumption that normative ideas are immutable and hold absolute truths. yet, social science standards are more likely to be tentative hypotheses (Argyris \& Schon, 1982; Vickexs, 1967), reguiring repeated testing - not unlike Lindblom's (1959) endless repetition process. The major contribution of social control theory ought to be the recognition of mutualiy interactive standards, not the acceptance or denial of standards based on methodology alone.

Linked to standards is the question of whether social controls can help to support challenging educational standards (e.g., high expectations), or are they limited to collectively acceptable (e.g. minimal standards) mean levels of performance 
(Miles \& Vergin, 1966). Educators need visions and goals if they hope to raise the level of performance (Greenfield, 1987). Yet, collective norms may reduce performance standards and act as negative inducements of social control. Can social control provide individuals with the opportunity to break away from relatively low group norms while also building collective strength to raise the level of individual performance? Presently, social norms by themselves do not ensure the professionalism of teachers. Educational socialization processes are uneven at each level of training and service, from the university classroom to in-school opportunities. Given the total institutional influences within a single school environment (Sergiovanni, 1987), teachers tend to view the world of education from within the school in which they work. Thus, individual building-level social control mechanisms establish standards of their own distinct from larger institutional or societal systems. The professionalism of teachers may be enhanced by the increased knowledge from organizational and management theories. However, Sieber (1981) has noted that the social costs of knowledge utilization presentiy exceeds the benefits (p. 162). Teacher incentives are not based on problem-solving (p. 163). Thus, school organizations permit both principals and teachers to act as if they are not aware of outstanding performance or personnel (see chapter Three). As a result, weak social control mechanisms contribute to the underlying motivations found within individual needs (Mitchel1, 1987; Sieber, 1981, p. 163) 
In sum, intentionality and individual acceptance of standards give meaning to the distribution of incentives. The next stage in the synthesis is a review of conscious thought processes leading to self-control.

\section{Psychological control}

Social control theories focus on conformity to group social values and standards (Burnstein, 1982 , pp.23-24), yet in many of the conceptualizations, social control failed to address individual intentionality (Meier, 1982). It is, therefore, left to psychological control theories to address how values, standards, and rules are internalized to attain a measure of self-control.

In reality, "not all action is "controllable." The more important it is, the less controllable it is likely to be. This is, unhappily, inherent in the nature of control" (Vickers, 1967. p. 30). Experimental evidence has reported finding perceptions of control even in instances wich are uncontrollable (E. Langer, 1983). Thus, "when control is viewed as process, there cannot be a situation in which absolutely no control is available to the person" (p. 20). From the psychological perspective of the actor, there are inner motivational qualities which provide reasons why people hold particulax attitudes (Katz, 1965) and which create illusory control perceptions (E. Langer, 1983; R. Harrison, 1985). Questions persist as to the specific behavioral and cognitive deteminants which create these perceptions - real 
and illusory - of control.

Different orientations in psychology offer competing theories as to how this internalization process actually occurs, whether behaviorally, cognitively, or developmentaliy. In contrast to the contingencies found within structural, political, and social situations, self-control is conceived as a single internal process (E. Langer, 1983) supported either by reinforcement (Skinner, 1966), personal acceptance (Locke, 1977), participation (Coch \& French, 1978), or by effort and commitment (Marzano, Brandt, Hughes, Jones, Presseisen, Rankin, \& Suhor, $1988)$.

The conclusions drawn from psychological and socialpsychological evidence indicated that there are two dynamic processes of managerial control: (1) the internalization of standards, values, and rules, and (2) incentive systems which fuel intentional activities. The control mechanisms varied according to the perceived sources of control: culture and environment as in behaviorism; rational ideas as in cognitive theories, and maturation as in developmental schemes.

There are two obvious responses to the question of internalization. The first is to deny consciousness and mental processes from the analysis of control (Skinnex, 1966). For example, within behaviorism, only verifiable, empirical matters are worthy of concern. The second response is to develop a model which links inner qualities to actions (Bruner, 1962; schein, et a1, 1961; Schein, 1972). These linkages have tended to follow 
one of three paths: (1) a subjective, individualistic path, as in creative thinking (Marzano, et a1., 1988) and subjective motivations (House \& Mitchel1, 1974); (2) a uniform, linear, developmental path as proposed by developmental theorists such as piaget and Kohlberg (Burnstein, 1982), or (3) an integrative path that studies both the individual and the organization (Argyris \& Schon, 1982; Herzberg, 1978; Mintzberg, et al., 1976; Schein, 1972).

A critical point of departure in the analyses of these three paths revolve around the priority ascribed to changing consciousness versus changing situations. Illich's (1973) learning theories suggested that by changing consciousness, real social changes could be achieved. On the other hand, M. Greene (1973) argued that perceptual changes were insufficient; that is, there must be changes in society as wel1. The primary objective in controlling overt behavior, even through a restructuring of social situations as in behavioral psychology, however, is to create a change in the perceptions of man. According to schein, et al. (1961, p. 79), one could dispense with coercive control if one could create a "new man." In this sense, the control of thought is considered by cognitive theorists more fundamental than the control of overt behavior (Schein, et al., 1961, p. 80). The distinct control mechanisms within each branch of psychology differ depending on where and how to channel incentives for change. 


\section{Behaviorism.}

Behaviorism is closely aligned with the physical and cultural environment (Skinmer, 1966, p. 11). Emphasis is placed on observable and manipulable factors rather than on inner qualities (p. 19). Behavioristic control occurs through the structuring of external factors which are manipulated using scientific principals of cultural engineering. It is through the use of external forces ( $\mathrm{pp}$. 13ff.) that man learns to better control himself (p. 11).

According to skinner, behaviorism holds human freedom and democracy in high esteem. Thus, the use of coercive, political power, punishment, or threats is termed "inept control," making "reluctant slaves of those who subnit" (p. 14). Within a democracy, the techniques of control are reciprocal, fostered through education, moral discourse, and persuasion (p. 14).

Each of these techniques, however, is capable of degenerating into its own perversions, such as propaganda, demagoguery, and seduction respectively (p. 14). Thus, behaviorism presents a hierarchy of controls which ascends from threats (e.g., commands and coercion), to "appeals to reason" (self-control), and to "opportunities for action" (disguised control) (pp. 14-15). Democratic systems link ethics and aesthetics to the concept of control (Bruner, 1962). Thus, coercion, brainwashing, and monopolistic control are inconsistent with democratic political systems and with highex levels of human development. Nevertheless, through social 
science research, "control need no longer be imposed. It can be encouraged to come from within" (Baritz, 1974, p. 210). It may not always be so clear, however, if managerial control techniques are exploitative (p, 209).

Skinner (1966) admitted that there is less understanding of the higher levels of control, in part, because both culture and environmental factors determine the type(s) of control techniques (p. 15). By ignoring mental processes as does behaviorism, however, a great deal that cannot be reduced to sensory perceptions and empirical observation including logical forms, value systems (Zaner, 1970, p. 38), and emotion (S. Langer, 1951) cannot be adequately addressed.

\section{Cognitive theories and individual creativity.}

A key concept within the cognitive framework is called "locus of control," which refers to the psychological view in which man can or cannot shape the world around him. Certain individuals are generally inclined to believe in internal causation, while others ascribe causation to external factors (Burnstein, 1982, p. 43). In cognitive psychology, the assumption is made that the thoughts about a task greatly affect how we approach the task. Studies have suggested that this feeling of control often translates into successful perfomance (Berliner, 1984).

In place of cultural engineering, cognitive self-control is driven by a tripartite model of human behavior: attitudes, 
emotions, and actions (Marzano, et al., 1988, p. 10). "People commonly attribute success to one of four causes: abizity, effort, other people, or to luck" (p. 11). Some theorists have stated that the most useful attribution is effort - "the belief that intense, extended effort will generally lead to success" ( $p$. 11). Other theorists specifically identified commitment as a determinant of successful performance. People choose to be comitted to their work, or they choose not to be comitted ( $p$. 10).

The concept of motivation is, obviously, closely related to effort, commitment, and creative behavior. Schein, et al.'s (1961) definition of control stated that a well-motivated worker was one who is obedient, yet "able to apply the party line independently and creatively in new and unanticipated situations" (p. 54) .

Underlying creative people's ability to take risks is trust in their own standards of evaluation. Creative individuals look inwardly to themselves rather than outwardly to their peers to judge the validity of their work. Therefore, the creative person tolerates and often consciously fosters working in isolation, creating a buffer zone that keeps the individual somewhat insulated from standard norms and practices. Not surprisingly, many creative people are not initially well received by their contemporaries (Marzano, et al, p. 25).

Assuming that creativity is a higher order need, motivating factors would center more on intrinsic rewards rather than on extrinsic rewards. Intrinsic motivation manifests specific behaviors and attitudes: avowed dedication, long hours, concern with craft, and involvement with ideas (Marzano, et al., 1988, p. 
25). According to Marzano, et al. (1988), there is considerable evidence to indicate that strong extrinsic motivation undermines intrinsic motivation (p. 25). On the other hand, Burnstein (1982, p. pp. 30-31) and Marzano, et al., (1988) have noted that other studies identified a "resistance to distraction by extrinsic rewards such as higher income for a less creative kind of work (Marzano, et al., p. 25).

"The distinction made between reward and punishment is one of the more important contributions of learning theory to the analysis of control" (Burnstein, 1982, p. 27). This proposition is based on the assumptions that (1) rewards and punishments "cut across all the other conditions" (Schein, et a1., 1961, p.181), and that (2) people strive to maximize rewards and minimize punishment (Katz, 1965, p. 279). As a result, consequences are more salient to learning than the frequency of a purposive act (Burnstein, 1982, p. 27).

It is [also] a well-known principle of learning that the efficacy of reward and punishment decreases as the time lag between the response and the administration of reward or punishment increases" (Schein, et a1., 1961, p. 181). Effectiveness depends on the rapidity with which rewards and punishments are administered (p. 182), and on the clarity, consistency, and nearness of rewards and punishments (Katz, 1965, p. 280). The use of effective information-gathering channels insures a minimum time lag (p. 181), but does not necessarily increase predictability (E. Langer, 1983). "Social psychology is 
replete with examples of how people tend to seek out information that supports their hypotheses" (p. 24).

Conflicting motives may create a cognitive dissonance within an individual (Festinger, 1978). Adams (1978) broadened the potential conflict by replacing cognitions with perceptions, but the theory remained the same, that is, people seek to reduce inequity, real or imagined. The shift from cognitions to perceptions was, of course, significant in that the psychology rested upon an individuals' subjective needs, rather than on a hierarchical model of uniform human needs (Maslow, 1978).

This subjective focus formed the basis for expectancy theory, originally proposed by Vroom (J. Campbell, Dunnette, Lawler, weick, 1978). Individuals have different preferences for a particular outcome and, therefore, pursue that outcome through diverse means. In subsequent, hybrid transformations, the expectancy motivation path has incorporated task goals ( $J$. Campbell, et al., 1978), not unlike the two-factor model proposed by Herzberg (Hexzberg, 1978; May \& Decker, 1988). Yet, prominently lacking in most motivational theories was the ability to predict behavior. Towards that objective, T. Mitchell (1982) identified four variables to predict behavior: (1) knowledge of what is required, (2) the ability to do what is required, motivation, and (4) a suitable work environment. Perry and Porter (1982) identified four similar variables: (1) individual needs, (2) the job tasks, (3) the work environment, and (4) the external environment. These contingency analyses tend to 
overlap, except for the variables of individual ability and the external enviromment. Thus far, the results of experimental psychological studies in motivation have shown highly variable findings (Locke, 1977). What motivational research has identified are instrumental paths and subjective goals and perceptions by which individuals behave differently. At the very least, these findings suggested Iimitations in generalizing results across organizational settings and cultures.

opportunities and exposure to new learning unlocks human capabilities (Bruner, 1962). Deciding whether a rule is good and ought to be followed is a cognitive issue that demands knowledge. Information processing through language, myth, affiliation, and rejection shape our conception of reality and knowledge (Bruner, 1962). According to Black (1970) and E. Langer (1983), rule acceptance is easier if it "seems obvious" or is familiar. "The harder it is to formulate the rule, the more reluctant the agent is to receive it" (Black, 1970, p. 50). Therefore, data must be compressed and structured to be assimilated, remembered as well as used "in practice" (Black, 1970). On the other hand, any actions which are performed automatically, i.e., without thought, are not controlled actions, but mindless and mechanical (E. Langer, $1983, \mathrm{p} .20)$.

Leaxning theory has been described as amorphous and circular (Schein, et ax., 1961) because it tends to explain too little and too much. The same criticism can be made of other control theories as well. Just as decision-making and implementation are 
not synonymous processes (Fullan, 1982), neither is it true that observation and learning of a model means that it will be followed (Burnstein, 1982, p. 30).

\section{Developmental stages.}

Internalization viewed through developmental stages implies that "identification is fostered by the consistent use of psychological or love-miented rearing practices rather than physical reward and punishment" (Burnstein, 1982, p. 26). Bumstein described Kohlberg's model as an example of a moral development model (p. 32) that linked cognitive concepts with behavior. The moral development of man occurs in six stages: the first stage was called heteronomous morality in which compliance is based on power alone; stage two focused on individualism, instrumental purpose, and exchange as man seeks to accomplish personal goals; stage three established mutual interpersonal expectations, relationships, and conformity whereby the group benefits through such feelings as loyalty; with stage four, a social system and conscience emerged wherein individuals seek social approval; stage five was based on a social contract between society and the individual protecting the rights and duties of each; and, finally, in stage six, behavior was based on universal ethical principles (pp * 32-34).

Kohlberg believed that these stages were grounded in empirical reality paralleling the development of moral reasoning skills (Burnstein, 1982, p. 34). Whether they are developmental, 
universal, ox empirical, however, is still to be decided.

\section{Integrative theoxies: social-psychology.}

Bruner (1962) wanted to avoid what he called the "psychological fallacy," $i . e .$, speaking of the psychology of control without reference to its implementation. He, therefore, made the distinction between manifest controls, i.e., deliberate controls manifested by 1 aws and regulations, and latent controls, i.e., "inconspicuous influences" permeating culture through myths and values. The two types of control corresponded to two strategies of control: one based on power and dependency, the other on cognition. The former utilized rewards and punishments (coercion and seduction), while, cognitive control was accomplished by shaping the conception of the world, and then leaving individuals to act or not out of intrinsic, selfcontrol. "It is no exaggeration to say that the role given to each of these forms of control is a hallmark of any political theory of the state and, by the same token, it is the single most telling feature of any psychological theory about the nature of man - whether one envisions man as ultimately captive of the shaping forces of his environment or as competent to shape a world of his own" (Bruner, 1962, p. 133).

control is not a matter of obtaining "maximum or even optimum control of human behavior (Bruner, 1962). Rather, the matter turns, in a democracy, on how to obtain needed control "while preserving the necessary variability that permits change, 
innovation, zest, and a lively sense that the invention of new alternatives is more important than the suppression of ones that may prove ugly" (p. 148). Thus, control techniques go beyond laws and regulations, touching on social, psychological, learning, and behavioral variables, such as language, myth, affiliative pressure, anticipation of rejection and isolation, Iimitation of opportunity, and variable compensation (Bruner, 1962).

Schein (1972) conceived of a "psychological contract" as the mutual interaction between the individual and the organization based on two aspects: (1) a match between the degree to which an individual's expectation of what the organization will provide him and what he owes the organization, and (2) an exchange, e.g., work for money, satisfaction for loyalty, self-actualization for high productivity and creativity. "Most theories of influence Iimit themselves to a consideration of the conditions under which opinion changes will or will not occur.... [I] we are going to consider influence processes which go deeper, ... we must constider not only the conditions of change but also the nature of the new integration which the change produces" (Schein, et a1., 1961, p. 268). Schein's (1972) psychological contract involved a three step process: (1) mutuality, relationality, and interaction, agreement on expectations or standards, and (3) an exchange. The assumption which guided this analysis was the recognition of a complex, interactive man, rather than assumptions of rationaleconomic man, social man, or even self-actualizing man. 
A third social-psychological integration has been proposed by Heilbroner (1975). Psychology explains the subjective foundation for man's behavior $(p, 24)$. There are two traits which dictate social-psychological behavior: (1) the trait of obedience (p, 105), and (2) the capacity for identification (p. 110). According to Heilbroner, obedience was a "latent function" which provides a sense of psychological security arising from the early developmental periods of man's helplessness. Although Heilbroner stressed biopsychological undexpinnings, he did not deny the presence or importance of political elements, such as power (p. 106). But, unlike political theorists who found the bases of power in organizational relationships, Heilbroner saw man's submission to power as having reality within man himself (p. 107) .

The second psychological underpinning identified by Heilbroner was the capacity for identification with others. This identification, however, has cultural initations whereby certain groups were perceived as "within" and others "without" (pp. 110111). Heilbroner held that many of the answers about man's future would be determined by the capacity and willingness of man to form a bond of identity with others, especially those of future generations (p. 115). Two processes were also identified which contributed to the development of these two critical traits: communication and mutually shared concepts (Burnstein, 1982, p. 35; Heilbroner, 1975, p. 162).

However essential the processes of communication and 
mutually shared concepts might be, social-psychologists have struggled to incorporate social and cultural contexts into their theories of control (Schein, et al., 1961). Bruner (1962), Hielbroner (1975), and Bacharach and Lawler (1982) have each attempted to link psychology to the reality and complexity of social organizations. Although the inclusion of cultural contexts into the internalization process appears to be essential, its integration is by no means assured, particularly within democratic systems which strive for a congruency between manifest and latent controls (Bruner, 1962): a congruency between dynamic political and social mechanisms on the one hand and individual psychological determinants on the other. "For the psychologist, the problem of control arises when an individual plan is incompatible with the collective one" (Burnstein, 1982 , p. 23). Whereas organizational, social, and political theories defined control as many things, the psychology of control is viewed as an internal process. Context and culture within the former theories aIways seemed to arrive at situational contingencies. How psychologists intend to avoid this trap and still maintain generalizability remains unclear. Individuals express certain needs that are incongruent with the demands of formal organizations (Argyris, 1978). Nevertheless, there seem to be specific school organizational processes which do contribute to an inner sense of control and greater organizationself integration. Among these processes are participation in decision-making (Ashton, 1984), group support (Lortie, 1975), and 
team organization (Berliner, 1984).

\section{summary and implications of psychological control.}

Psychological control processes seek to gain control over both overt behavior and private beliefs. It is the latter which comprises an individuals' value system (Katz, 1965, p. 277) and which guides people in their daily activities (Bruner, 1962; Heilbroner, 1975, p. 137). There is a need, however, to create a theory based on a wide range of observed data (Schein, 1972, p. 196) that is applicable to diverse social and cultural influences (Schein, et al., 1961) while incorporating internal, socialm psychological dynamics (Coser, 1982, p* 19). Psychological processes appear for the most part as logical, developmental, and uniform, but managerial behaviors are said to be fragmented, irrational, and complex (Mintzberg, 1971).

This descriptive managerial reality does not contradict the view that people "act on the basis of these [stable] expectations, unless and until they are destroyed by further experience. This stability is precondition of effective, collective action over a long span of time" (Vickers, 1967, p. 39). Evidence that control is stable or not emanates from the focus of one's perspective, reference points, and the measures used in analyzing the construct (E. Langer, 1983, p. 26). One dimensional explanations are important for specificity, but insufficient (Katz, 1965, p. 278; pfeffer, 1978a; Schein, et al., 1961, p. 196). 
There are psychological consequences of regular activities, even if some of these consequences are not well understood (Bruner, 1962; Skinner, 1966). Even structural variables have subjective consequences. In an area so richly studied as technology, Dornbusch \& Scott (1975) have identified the significant differences among tasks as "subjective beliefs of participants rather than on the objective characteristics of the tasks themselves" (p. 348 ).

choices of action lead to a self-monitoring system based on an individual's own standards (Burnstein, 1982, p. 31). Yet, standards are reinforced by other significant individuals and groups (p. 31). If control standards are not a question of maximum or optimum performance (Bruner, 1962), but reflect processes of change and creativity, then ownexship of standards is needed to overcome resistance (Lawler \& Rhode, 1976, p. 101) and incorporate implementation. Another way to persuade people to change is "to make the new more familiar and to increase involvement and participation" (E. Langer, 1983, p. 87). E. Langer (1983) recognized that these processes had already been identified within organizational research. What was new, however, was the findings that perceptions of control did not depend upon "distributing real control" but, rather, from "inducing an illusion of control through the introduction of control-related but outcome-independent factors" (p. 87). These factors included (a) skill in making choices, (b) thinking about. tasks and strategies, (c) effort exerted, (d) familiarization 
with materials and responses, and (e) competition with others (p. 45).

The critical link to self-control is the relationship between cultural standards and individual, subjective incentives. within schools, intrinsic motivation is generally seen as more highly valued than extrinsic rewards (D. Mitche11, 1987; D. Mitchell \& Peters, 1988). This occurrence is particularly relevant to building managers who must integrate external policy directives and community expectations into school-level standards of performance despite their lacking structural mechanisms to control three dominant motivating factors: pay, promotion, and student learning (Bidwell, 1965; Lawler \& Rhode, 1976; Lortie, 1969). School building administrators do, however, exercise incentive control with the distribution of discretionary funds, staff development opportunities, and praise (Bossext, et al., 1982; Cohen \& Miller, 1980). In terms of importance, Lawler and Rhodes (1976) ranked pay, promotion, and dismissal as higher extrinsic motivating factors than praise, in non-school settings. Since the cost of praise is very low, it is used far more frequently than either promotion or dismissal (p. 59). Therefore, the theory of managerial control is concerned not only with the intrinsic qualitative values, but also with the stability, regularity, and frequency of behaviors - which have both structural and gualitative meanings for individuals. 


\section{synthesis of social science control Theories}

Within the different social science literatures, much attention has been focused on the meaning of control. yet, even within disciplines, the definitions of control are clearly idiosyncratic, offering, at best, incomplete explanations of the concept of control. In a global terms, control was defined as any process which influences behaviors (Smith Tannenbaum, 1963). In reviewing the related literatures on control theory literatures, the most significant differences refer to theix units of analyses.

Table 1 highlights the distinctions among concepts, units of analyses, and variables. The predominant model in classical organizational theory has been rational, bureaucracy. The unit of structural analysis is the organization, more specifically the variables of size, levels, and technology. From the political concept of control, two theories predominate: the process of incremental decision-making and the descriptive organizational metaphor of loose coupling. Political control extends the unit of analyses to interactions between organizations, members, and their environments. Societal institutions are even broader organizational conceptualizations within which social control influences behaviors. The primary unit of analysis is the group (e.g., peers, society) which establishes values, norms, and culture that may be internalized by individuals. In psychology, competing theories explain the processes by which control is completely internalized by the individual. 
Table 1

synthesis of social science control Theories

\begin{tabular}{|c|c|c|c|c|}
\hline Concept: & $\begin{array}{l}\text { Organizational } \\
\text { Control. }\end{array}$ & $\begin{array}{l}\text { Political } \\
\text { Control }\end{array}$ & $\begin{array}{l}\text { Social } \\
\text { Control }\end{array}$ & $\begin{array}{l}\text { Self- } \\
\text { Control }\end{array}$ \\
\hline Model: & $\begin{array}{c}\text { Rational } \\
\text { Bureaucracy }\end{array}$ & $\begin{array}{l}\quad \text { Loose Inst } \\
\text { Coupling } \\
\text { Incrementalism }\end{array}$ & titutions & $\begin{array}{l}\text { Behaviorism } \\
\text { Cognitive } \\
\text { Developmental }\end{array}$ \\
\hline $\begin{array}{l}\text { Unit of } \\
\text { Analyses: }\end{array}$ & organization & $\begin{array}{l}\text { Environment } \\
\text { Power/Influence } \\
\text { Key Actors }\end{array}$ & $e^{\text {Groups }}$ & Individual. \\
\hline Variables: & $\begin{array}{l}\text { Structure: } \\
\text { size, levels, } \\
\text { \& technology }\end{array}$ & $\begin{array}{l}\text { Interactions: } \\
\text { uncertainty : } \\
\text { multidirections }\end{array}$ & $\begin{array}{l}\text { Values, } \\
\text { norms \& } \\
\text { culture }\end{array}$ & $\begin{array}{l}\text { Internali } \\
\text { ization s } \\
\text { motivation }\end{array}$ \\
\hline
\end{tabular}

The study of managerial control makes two assumptions based on a synthesis of social science literatures: (1) that aspects from each of the disciplinary theories presented must be incorporated into a general theory of managerial control, and (2) that the concepts and variables presented by discipline-oriented research need to be operationalized within a contextual managerial setting and, then, empirically tested.

Although aspects of rational bureaucracy continue to influence organizational thinking (Johnston, 1985), there is increasing evidence to support other organizational and behavioral explanations. From the structural analyses, we concluded that structural bureaucratic processes such as supervising, directing, 
and evaluating were weak or inappropriate, especially within school organizations. The conclusions reached from single entity, quantitative measures, ironicaliy, redirected attention away from the organization itself towards a broader institutional- environmental framework with cultural implications (Meyer, Scott, \& Deal, 1983). Unfortunately, the residual

findings from structural analyses offered administrators few, if any, guidelines for managing organizations (Bossert, et al., 1982; Fullan, 1982: Fullan \& Pomfret, 1977; Pfeffer, 1978a). The alternative explanations, such as politics, information, communication, coordination, participation, collegiality, and shared decision-making were variously suggested in order to extend the meanings of control.

Education is largely a public, institutional system with environmental influences which affect the behaviors of individuals working at all levels of the organization (Bidwell, 1965). To some extent the technical core within the organization can be protected from the other institutional levels (Thompson, 1967), but never fully (Pfeffer, 1978a). Cultural factors, such as social and professional values, influence managerial control processes, permeate schools, and establish standards by which success is measured (e.g., organizational effectiveness). But, the literature clearly reports that standards differ from culture to culture (Tamnenbaum, et al., 1974) and from school to school (Sergiovanni, 1987).

This variability raises a research question as to the choice 
of dependent variables, particularly the meaning of curricular and instructional effectiveness. Even if organizational or educational theorists could agree on a suitable definition of effectiveness (Cameron \& Whetton, 1983), there would stili be left unresolved the question of causal direction between control and effectiveness (Staw, 1975). Organization theory employs hypothesized variables which can be either independent variables of performance, dependent variables of effects, covariates of third variables, or elements in a web of mutual causality (staw, 1975).

The most often repeated research finding was that managerial activities and individual behaviors were mediated by structural, political, social, and psychological factors. The results indicated that activities and behaviors were influenced by "something else" not directly studied or being measured. The issue no longer was whether the bureaucratic structural model was adequate to explain the complex dynamios and determinants of control. It is not. Whereas authority is static, "influence is the fulcrum of change" (Bacharach \& Lawlex, 1982, p. 42). Lorange \& Morton (1977) summarized the contributions of structural analysis into three emerging issues: organizational complexity, (2) non-measurable dependent variables and (3) the linkages between planning and control. Bacharach \& Lawler (1982) agreed that "objective conditions of dependence have subjective meaning to parties in a conflict setting" (p. 23). 
Under the political framework, a wider range of variables were analyzed, thus, providing greater descriptive validity. The political model was thus born as a open system in which all organizational dynamics and processes could be described as political. The political units of analyses broadened the search for key behavioral variables beyond the technical core and managerial relationships. The external focus of the political analyses, however, created a gap between environmental influences and intra-organizational behaviors. Moreover, the headlong rush for empirical validity tended towards a somewhat indiscriminant acceptance of descriptive data.

sociological studies directed attention back to influential interactions among individuals within organizations. Yet similar to the political models' concept of multidirectionality, sociological approaches analyzed influential diversity of cultures and roles. This approach, too, failed to provide a comprehensive organizational framework by which variables of interest could be ranked in order of theix relative influence. The place of social standards was taken by a position of ethical neutrality.

Psychological research of control revealed a paradox between subjective individual idiosyncracy and common, basic human needs. Whereas the former requires managerial activities to acknowledge the subjective needs of each individual, common, basic needs of individuals are viewed as so fundamental that they underlie all social and political activities. 
As a result of these inconclusive and inconsistent aisciplinary findings, confidence in their definitions of control is understandably weak. Therefore, a new integrative perspective is needed, one that is significantly different from merely applying the different disciplinary frameworks successively to a given situation (Bolman \& Deal, 1984). Ultimately, understanding behavior is not a matter of alternating lenses which reveal different perspectives, but rather of integrating perspectives.

The question is how to achieve this synthesis at the managerial action level on which control operates, while still maintaining institutional, cultural, subjective, and epistemological truths. The task involves reorganizing quantitative and qualitative measures along managerial control processes. It is principally a matter of identifying common technological characteristics which operate across diverse, problematic, cultural circumstances. The central question of this investigation is, thus, how to reconcile a uniform, systematic framework with the empirical findings of organizational complexity, fragmentation of activities, and nonrational behaviors. 


\section{CHAPTER TKRER}

\section{A preliminary study \\ of school Managerial context: \\ Curxiculum and Instruction}

Introduction

Empirical data should be anchored in an organization"s context in order to validate the meanings of managerial concepts (Hughes, Price, Marrs, 1986). This is particularly true for the concept of managerial control which operates on the "level where action is taken" (Vickers, 1967, p. 29). Yet, a synthesis of control theories within social science literatures offered surprisingly little data about the managerial context. The conceptualizations of control which emerged were theoretically abstract, such that the terms power, authority, influence, and social control were difficult to distinguish and often used idiosyncratically. As a result, generalized findings from control theory research have been inconsistent and incorrect.

Nonetheless, the different social science disciplines have contributed unique findings which may be integrated into a more general, valid theory of managerial control. From structural analyses of organizations, the most conclusive finding was that single structural variables offered only partial explanations for individual behaviors. Thus, researchers variously implied that political, social, and psychological processes need further direct empirical consideration (Cohen Miller, 1980: Eisenhardt, 1985; Woodward, 1970). 
political dynamics have suggested that information and evaluation systems may be as important, if not more so, than structural explanations (Pfeffer, 1978a). Social control studies have also dismissed structural-organizational explanations (Meyer \& Rowan, 1977; Meyer, Scott, \& Deal, 1983), replacing organizational variables with institutional and professional norms and values as standards of performance. Psychological research has focused on the notion of self-control which in certain theories are independent of external contingencies ( $E$. Langer, 1983). Although there are organizational and individual factors that influence the internalization of self-control behavior, the postulating of a subjective, internal reality suggested that behaviors were governed by internal standards, perceptions of rewards and punishments, and their distribution systen. Only when viewed integratively do the social science disciplines offer a heuristic framework within which to categorize contextual data.

The four logical processes to have emerged from the social science theories of control reflect a complex reality of managerial standards, information, assessment, and incentives. Table 2 depicts the matrix between disciplinary conceptions of control and managerial control processes, along with their mediating factors. 
$\operatorname{Tab} x=2$

Matrix of Academic olsciplines and Managerial control processes

Academic Disciplines: Political Science Sociology Psychology

organizational

Dynamics:
Interactions $\begin{array}{ll}\text { Group values, } & \text { Internali- } \\ \text { norms, } & \text { zation \& } \\ \text { culture } & \text { motivation }\end{array}$

Standards

Standards Incentives
Managerial Control Processes:
Information

Assessments

As a preliminary step towards the validation of a school managerial control model, empirical data about what school building administrators actually do within the domain of curriculum and instruction are needed (Bossert, et al, 1982 ). Because context and culture are so critical to school managerial. control (Hallingex \& Murphy, 1987), data from non-school organizational studies or even from external building levels are 111-suited for practical managerial purposes.

Unfortunately, there are no simple, straightforward measures by which contextual analyses, especially within complex organizations such as schools, are revealed (Bacharach \& Lawlex. 1982: Miles, 1981). In complex settings, rich descriptions convey many meanings because highly abstract words are used to designate both entities and qualities (Huxley, 1971, p. 161). The qualitative dimension of organizational control theory has had strong support for over twenty-five years (Astuto \& Clark. 
1985; Etzioni, 1965; Frank, 1958-59; Koontz, 1971; Miles \& Vergin, 1966; Patz \& Rowe, 1977; Tannenbaum, et a1., 1974; Turcotte, 1974: vickers, 1967). Yet, its direct empirical study has been anything but systematic.

The qualitative dimension is not the only conceptual and measurement obstacle confronting educational researchers. There are at least two other concerns which must be addressed: (a) determining the appropriate cultural unit of analyses, whether societal institutions, school districts, schools, or individual classrooms (Sergiovanni, 1987; Stephenson \& Levine, 1987), and (b) grasping the reality that school administrators are often faced with the dilemmas of having "a choice between two goods" (Miles, 1981; Clark \& Astuto, 1988). There exist within school contextual settings empirical evidence to support contrary findings (e.g., diversity versus uniformity, coordination versus flexibility, centralized authority versus shared influence, and change versus stability).

School-level managerial activities involve specific expertise of curricular and instructional technology (Cawelti. $1987 \mathrm{a}, 1987 \mathrm{~b}$ ), but are not limited to it (Grifin, 1988; Sergiovanni, 1984). There are managerial processes, behaviors. and skills which control these curricular and instructional activities across diverse tasks (Apple, 1982; Hall, Jr., 1956). It is towards a better understanding of these managerial processes within school buildings that this preliminary study was directed. 


\section{Statement of Purpose}

There were two purposes for conducting the preliminary study: (1) to describe systematically the context of schoollevel managerial control processes for curricular and instructional tasks, and (2) to use the findings in the development of a valid instrument to measure school-building control.

\section{Objective}

The primary objective was to categorize school administrative behaviors related to curriculum and instruction under each of the four managerial control processes: standards, information, assessment, and incentives.

\section{Procedures and Methods}

\section{Subjects}

At the school-builaing level, principals have been judged to be the key actor in terms of managerial control activities. "The standaras place the principal squarely in charge of the effectiveness of his/her school, and demand that the principal assume responsibility for instructional leadership at the building level" (Doud \& Montgomery, 1985). "In fact, they were frequently the only individuals within the school who had the overall perspective to enable them to [have an institutional focus]" (Martin \& Willower, 1981). 
A small number of principals was nominated by their district's central office supervisors as being curriculumoriented or instructional leaders (Appendix A). From these nominations, six principals, representing two elementary schools, two junior-high/middle schools, and two senior-high schools were selected. When one senior high school principal declined to participate, an alternative senior high school principal was selected from the nomination list. Table 3 presents characteristics of the six schools in the preliminary study.

AlI of the principals had experience in at least two schools, with total tenure ranging from six and one-half years to fourteen years.

At the same time that each principal was initially contacted, he or she was asked to designate an individual at his or her school who would also be interviewed regarding curricular and instructional control at the school. The purposes of having informant responses at the school level were to provide a second viewpoint on school curricular and instructional control from a different organizational level and to elicit specific managerial behaviors. 
$\mathrm{Table}$

school Characteristics of Principal sample population

\begin{tabular}{ccccc}
\hline Interview & Level & $\begin{array}{c}\text { No of Assistant } \\
\text { Principals }\end{array}$ & $\begin{array}{c}\text { No. of } \\
\text { Faculty }\end{array}$ & $\begin{array}{c}\text { Student } \\
\text { Enroliment }\end{array}$ \\
\hline 1 & Elementary & 1 & 32 & 689 \\
2 & Elementary & 1 & 42 & 934 \\
3 & Junior & 3 & 65 & 1609 \\
4 & Middle & 3 & 62 & 1307 \\
5 & Senior & 4 & 115 & 2444 \\
6 & Senior & 3 & 134 & 2808
\end{tabular}

\section{Instrument}

A standardized interview guide was used for all interviews of principals and informants (Appendix B). An initial format was pre-tested with a volunteer principal. Under each of the four managerial control processes, the principal was asked to discuss how the tasks of teacher evaluation, staff development, curricular development, and selection of textbooks and instructional materials were managed. During this pre-testing, general open-ended questions were asked about the principal's activities. This format tended to elicit only vague, nonspecific responses without further prompting. The interview format was, therefore, revised so that principals were prompted to discuss managerial activities under each of the four hypothesized managerial control processes for each task separately. The order of the questions followed a logical progression beginning with goals and objectives (standards and information) and proceeded to implementation processes (evaluation and incentives). 


\section{Data collection procedures}

Al1 school principal and infomant interviews were conducted in private at the six school-sites and lasted from 45 minutes to over one hour. The first 45 minutes were audio cape recorded. After 45 minutes, hand written notes were taken. Both the tapes and notes were transcribed and summaxized.

\section{Limitations}

The study's small sample size, the reliance on selfreporting measures, and the lack of dependent variables might all be viewed as limitations. There is ample evidence, however, to demonstrate that none of these factors has invalidated the reported findings.

The six principals interviewed were selected specifically for their career long involvement in curricular and instructional affairs. In fact, their own perceptions of the time allocated to curricular and instructional activities were much higher than what has been reported in the literature on instructional leadership. The mean average pexcentage of time devoted to curricular and instructional activities reported by this sample was approximately 45 percent (versus, for example, 17.4 percent measured by Martin \& Willower, 1981); the remaining time was ascribed to administrative areas. The list of managerial activities compiled here is quite comprenensive and compares favorably with other similax school management studies (Bossext, et a1., 1982). The systematic analysis of these managerial 
activities into the four hypothesized managerial control processes does not, in any way, delimit other conceptualizations of managerial control. Rather, to establish validity of any managerial control process requires the systematic analysis of specific behaviors within a particular task context.

In any empirical study, the use of self-report data is not without limitations and bias; however, the recognition of qualitative attributes of managerial concepts and tasks (Dornbusch \& Scott, 1975, p. 348; Lawlex \& Rhode, 1976, p. 169) suggests that the "only reality is perceived reality" (Andrews, 1987, p. 10). "[I]n the last analyses the content of a particular individual"s goals and intentions must be inferred from his verbal report (based on his introspection)" (Locke, $1977, \mathrm{p}, 183)$. The consistency of the interview format and administration, along with the inclusion of informants contribute to the confidence in the principals ${ }^{3}$ responses.

The nature of managerial control research, from Dormbusch \& Scott (1975) to Sproull (1981) to Peterson (1984), has been exploratory, that is, the reporting of findings and statistics rather than testing hypotheses. There are severe measurement problems Iinked with control studies (Koontz, 1971; Lorange \& Morton, 1977), such that many of the independent and dependent variables are not meaningful to participants or clearly defined. Although a number of studies have measured the influence of instructional leadership (Ogawa \& Hart, 1985), the evidence has hardiy been persuasive. With respect to dependent variables, 
"the standardized achievement tests generally used as criteria for nultivariate school effectiveness studies provide only a crude and often misleading measure of learning in classrooms" (Stephenson \& Levine, 1987, p. 33). As for independent variables, Martin and Willower (1981) reported that "[principals"] instructional leadership role component did not include active instructional or curricular involvement. Although the principals retained final authority over these matters, they chose to exercise it in a passive fashion" (author's emphasis). Thus, the research has yet to adequately operationalize these passive activities or independent variables. The purpose of this study is to collect and categorize data of managerial control activities as measured by nominal data, with no implication as to their effect on a dependent variable, such as achievement. The testing of that hypothesis cannot be derived solely from selfreport data from principals (Andrews, 1987).

\section{Data Findings}

The reported managerial behaviors were elicited from the principals [and informants] during the interview sessions. The behaviors have been categorized under each of the four managerial control processes: standards, information, assessment, and incentives. Although the assumption regarding managerial control is that the processes and behaviors are similar for distinct. tasks within a domain such as curriculum and instruction, the purpose of contextual analyses is always to present the data in 
their most discrete setting. Therefore the data have been further categorized under the distinct curricular and instructional tasks of teacher evaluation, staff development, curriculum development, and the selection of textbooks and instructional materials (Cawelti \& Adkisson, 1986; Cawelti, 1987a).

In some cases, judgment as to the placement of a managexial behavior might appear arbitrary in that the behavior fits as well elsewhere. Given the interrelationship among the four processes as part of a larger, single construct, i.e., managerial control, such redundancy is to be expected. Neither the control process categories nor the curricular and instructional tasks are mutually exclusive or unique.

The rather long list of curricular and instructional managerial behaviors, over one hundred and fifty reported here (Tables 4 through 7), suggests that, for some principals at least, curricular and instructional activities are an important part of their responsibilities and that the curricular and instructional role itsels is extremely complex. On the other hand, neither the number nor diversity of these managerial control behaviors indicates the frequency or competency with which these managerial tasks are performed. Those particular questions will be explored in the subsequent chapters.

The discussion of each managerial control process begins with the objectives of the interview questions concerning that process. Following some of the managerial behaviors, there is a 
number in parenthesis which refers to a specific principal's unique response not echoed by the other respondents. If no number is indicated, it means that a majority of the respondents expressed similar views. Lastly, the managerial behaviors have been separated by a broken line, indicating the distinction between the formal structural behaviors and the principals: discretionary actions.

\section{Standards}

The specific questions on standards attempted to elicit the principals" views concerning state, district, and school policies, goals, and procedures for four different curxicular and instructional tasks: teacher evaluation, staff development, curriculum development, and the selection of textbooks and instructional materials. The principals were asked whether they also attempted to exceed formal policies and procedures, and if so, how. The managerial activities relating to standards and reported by principals and informants are categorized by tasks in Table 4. 
Table

Managerial Activities categorized by Tasks under the Process of

Standaras

Teacher Evaluation stanaards

1. Formal district instrument

2. Straightforward, impersonal, and clear

3. Specitic teaching behaviors

4. A helping instrument for improving instruction

5. Collective bargaining contract requires that principals obsexve beginning and annual contract teachers

6. Optimum performance (5)

7. New teachers know when they wi1l be obsexved: so they can be at their best (2)

8. Prioxities assigned to the teaching behaviors

9. A classroom where children are happy and free to lean (1)

10. Would I want my child sitting there? (3)

11. We try to exceed the minimum requirements

12. Work with all students in the class (5)

13. Hixing and stafing criteria within centralized

staff Development standards district procedures $(2,4,6)$

1. District workshops and district priorities

2. Redress prescriptions from classrom observations

3. Collective bargaining contract constraints on the number of monthly staff meetings

4. Limited budget for outwof-town conferences (6)

$-\ldots-\ldots-\ldots-\ldots-\ldots$

5. Voluntary participation

6. School-designed workshops: school priorities $(1,2,4,5)$

7. A "we can improve" attitude (1)

8. Assignments of assistant principals and department heads $(3,5,6)$

\section{Curricular Development standards}

1. District/state objectives [to do more and nore $(2,5,6)]$ and testing (6)

2. A balanced curriculum $(1,2)$

3. We give everybody the same thing: classic mistake (5) 
Table continued

4. Legitimate and reasonable (3)

5. Our job is to put students in the right place in order to help them learn (1)

6. School innovations: on the cutting edge of curriculum $(4,5)$

7. Redesign on the bases of readability, scope and sequence (5)

Selection of Texts and Instructional Materials" standards

1. State/District 1ists of textbooks and schedule of adoptions

2. Budget allows limited flexibility $(4,5)$

- - . . - . . . . . . - . . -

3. Grade leve1/departmental consensus $(2,4,6)$

4. Teacher-developed materials (5)

5. Readability $(3,5)$ and published tests (2)

6. Pride and professionalism of faculty (2), department heads (6), and assistant principals $(1,2,4,5)$

\section{Summary of standards}

Principals" responses on curricular and instructional

standards appeared to fall into two distinct categories: (a) the clear, yet perhaps minimal standards that are part of the formal directive, rules, procedures, schedules, and instruments, and (b) the personal or intangible qualities, not stated or directed by policjes or measured by an instrument, that principals want to have in their schools. The latter reflected the individual school's unique mission or cultural standards and the discretionary managerial behaviors reserved to school building administrators.

Principals expressed curricular and instructional standaras in general, expressive terms: "school is a place of learning" (2), and often used the vocabulary of the effective school itterature, e.g., high expectations. Although each principal 
stated that he/she strictly followed Board policies when it came to the formal state and district procedures, they did not limit their comments to the formal procedures or scheduled requirements. For each task, they offered unique, discretionary, and informal standards. The principals sought the most appropriate use of the discretionary latitude they all felt they had within each task.

\section{Information}

The questions relating to the information system referred to the flow of communications from administrators downward in sharing information among the instructional staff, and the transmittal and use of information from teachers to administrators. The principals were asked about the structural channels for communications and the informal, qualitative sharing of information. Managerial activities relating to information are categorized by tasks in Table 5 . 
Tabie 5

Managerial Activities categorized by Tasks under the process of Information

Teacher Evaluation Information

1. Annual oxientation workshop

2. Consistency checks with assistant principal (s)

3. Schedule of observations

4. Collective bargaining schedule

5. Pre and post observation conferences

6. Formal observation as a basis for discussion (5); a point of departure (2)

7. Informal walks through the classrooms (2)

8. We talk about what is expected, about what a good lesson should look like (2)

9. Not just one meeting, but a number of meetings

10. No written negatives: face to face for negative comments

11. Prioritize deficiencies

12. Faith in the ability of other administrators to see what teachers are doing in the classroom $(2,4)$

B. Staff Development Information

1. District schedule posted in each school: no in-school schedule $(1,3,5)$

2. Teacher representative to district

3. Administrative announcements (4),

4. At faculty meetings, so it becomes compulsory

5. Block grade-level planning meetings $(1,2)$

6. Department meetings with department heads $(3,6)$

7. Physical structure: office and classrooms of a department are located nearby (5)

8. weekly bulletin (2).

9. curriculum council (6)

10. Evolves as the year progresses $(1,5)$

11. Invite others to work with faculty: district curriculum specialists, university professors, publishing house representatives

12. Encourage sharing, not required, (e.9., happens naturally): no formal mechanism

13. Voluntary basis: emphasize need for it (4)

14. "I think this would be good for you" (6)

15. "mhose that need infomation, seek it" (5)

16. visits to other schools 


\section{Table 5 continued}

\section{Cuxxicular Development Information}

1. State directives and district guidelines

2. Build a process and provide access (5)

3. Delegation of responsibility to department. heads and/or teacher(s)

4. Scope and sequence development $(2,3)$

5. Cabinet meetings among trusted aides

6. Brainstorming around ideas and faculty interests (encourage innovations)

7. Provide baseline data and organize a system

8. Keep results in front of teachers: "you are part of a good school" (4)

9. "Beg, borrow, steal, find and bring it together and unify it to make it uniform so that everyone uses it" (5)

D. Selection of Texts and Instructional Materials" Infor mation

1. State textbook adoption list

$\ldots \ldots \ldots \ldots$

2. Grade level consensus on instructional goals

3. Publishers' visits

4. Faculty meetings

5. No records on instructional materials in stock

\section{Sumary of Information}

The flow of information reflects both formal state and district-school communications as well as specific intraschoollevel policies instituted by principals. A large amount of information appears to be free-flowing and based on the trust of certain individuals with the hope and expectation that the information will be professionally used and shared.

\section{Assessment}

Principals were asked whether formal evaluations were conducted for each of the curricular and instructional tasks. 
The principals were also asked to explain their own criteria of assessment in addition to formal policies and procedures. Their responses are categorized in Table 6.

Table 6

Managerial Activities Categorized by Tasks under the Process of Assessment

Teacher Evaluation Assessment

1. Compliance with state, district, and collective bargaining agreement contract

2. consistency check and philosophical agreement with assistant principals $(1,2,3)$ (see Information)

3. Fair and impersonai (3)

4. To improve instruction (see standards)

5. Prescriptions, resources, further diagnoses: follow-up through observations (5)

6. Summative decision-making: prescription and termination (6) (see Incentives)

7. "I do not use formal observations first" (I); sit down informaliy and say, "Tell me what's happening" (1)

8. Talk about positive things and the things that need improvement: on-going (2)

9. Positive is very, very important (2) (see Incentives)

10. Optimum performance from each teachex (5)

11. "I think generally you know who the better teachers are" (5): "but I am not sure I know who all of my bettex teachers are" (6)

12. "Look for what we think the problem is and then we prioritize and work on one or two aspects" (5); "I think [the instrument] leaves us some discretion" (2)

13. Negatives are better to say face to face because [teachers] read into something negative that maybe is not there (2)

14. Union contract protects incompetent people (6) 


\section{Table 6 continued}

Stati Development Assessment

1. No procedures or records kept except with regard to district workshops in which faculty earn credits

2. Department heads ill out a form about what they would Iike to accomplish (6)

3. Need to develop pride and professionalism (2)

4. Teachers who need information, will seek it (5)

\section{Curricular Development Assessment}

1. Test scores: nationally normed and state assessments

2. Use project managers from the district area office to help ne objectively look at what's going on (3)

3. Periodically attend grade level meetings (2)

4. Review mid-period reports and seek samples of pupi1"s work (2)

5. No formal evaluations; not worth the time to do pre -post tests (5)

6. RE: Reading: Ilsten to children read, see how often they pick up a book, see if it is fun (1)

7. RE: Reading and Math: Along more traditional Iines: we're using MacMillan Reading tests and Harcourt Brace math tests (2)

8. RE: Humanities: everyone seems to like it; if we have a demand for it next year, it is successful (3)

9. RE: Computers: initial feedback from the students and teachers has been very positive (4)

10. RE: Media Center: students not sitting idle, programming, not playing games, log of classes that use centex (6)

11. RE: Magnet Program: formal evaluation, which was not done by the aistrict, to find out how we were doing; we pulled together a committee of people from the university and specialists to review our curriculum (4) 


\section{rable 6 continued}

\section{Selection of Textbooks and Instructional Materials Assessment}

1. State adopted textbook list

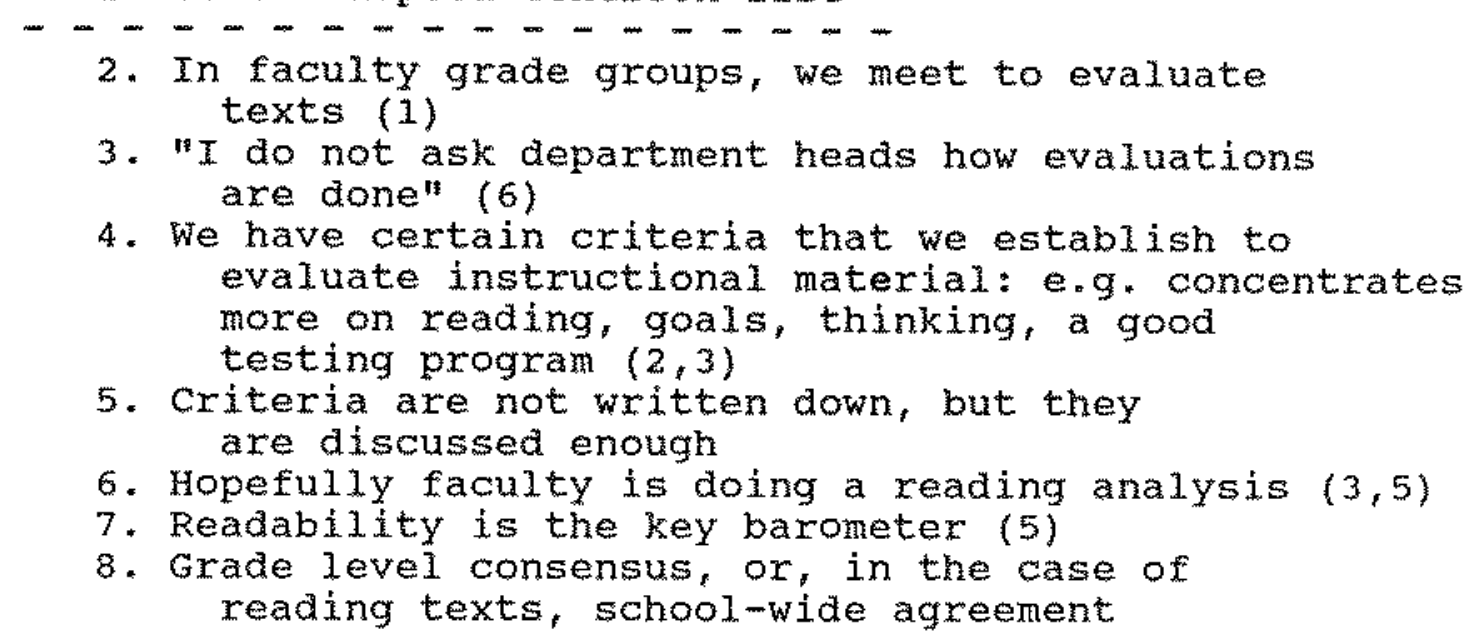

\section{Summary of Assessment}

The assessment of curricular and instructional tasks seems to follow the same formal-informal dichotomy noted above, whereby formal assessments are prescribed by the state or district or collective bargaining contract and informal evaluations reflect the perceptions, judgment, and managerial discretion of principals. The line between the two dimensions is often blurred as principals are able to "piggy-back" idiosyncratic criteria and goals onto the formal assessment procedures. For example, with the use of the teacher evaluation instrument or in curricular assessments, principals have their own lists of meaningful, priorities and criteria for judgment. At times, the formal and informal mechanisms are at odds: formative improvement of teaching and innovative programs versus sumative decisionmaking: professional development as measured by specific needs of faculty versus earning credits for certification. 
Sole reliance on formal mechanisms such as test scores was not evident. "Teachers can become complacent when they don't have a right to be and others could become very upset, when perhaps they have been doing an excellent job teaching, but for some reason the scores at that level do not reflect what has actually gone on" (1). Ironically, the evaluative school-level criteria employed by principals are very explicit and easily measured: yet, they have not received sufficient organizational support to establish their legitimacy or public testing.

\section{Incentives}

Incentives are the planned and controlled distribution of rewards (Mitche11, 2987; Mitchell \& Peters, 1988). Schoo1builaing administrators face a unique organizational situation whereby the most meaningful rewards to teachers do not come from principals. The emphasis on intrinsic rewards distinguishes school organizations from most other capitalistic/profit making enterprises (Gevirtz, 1984). Intrinsic rewards are derived from teaching students and in sharing with teacher colleagues. Moreover, building administrators play almost no role in the extrinsic rewards defined by salary and promotions (Bidwell, 1965; Lortie, 1969; MitchelI, 1987).

In the interviews, principals were asked about the kinds of rewaras, recognition, and negative sanctions, as well as the way in which rewards, if any, were distributed. Their responses are categorized in Table 7 . 
Table 7

Managerial Activities categorized by Tasks Under the process of

\section{Incentives}

\section{Teacher Evaluation Incentives}

1. Teachers rated as "acceptable" or "unacceptable" on formal instrument

2. On formal instrument, little room for comments (3)

3. Follow-up conference with teachers

4. Formal prescriptive procedures

5. Pressure to retire (6)

6. Transferring of teachers

7. Texmination: "I have no teachers on prescription right now. Last year, maybe one to three" (6); fox the last two years, no teachers have been judged "unacceptable" (I)

8. No tangible rewards

9. Pat on back (6): verbal "I like what you are doing"

10. Note or meno in teacher's mailbox or in stapf bulletin

11. Positive is very, very important (2); encouragement (6)

12. Annual letters (4)

13. Teacher of the year (4)

14. "Let"s sit down and talk [informally] about [a problem\}" (3)

15. Let teachers [who need help] observe others, use video equipment for self-improvement (1)

16. Give attention to teachers who are in need of help (4)

\section{Staff Development Incentives}

1. Academic or certification credit for staff development

2. Self improvement is a reward in itself $(1,6)$

3. Collective bargaining contract limits the number of staff meetings

4. Use of staff meeting time or workday for credit

5. Released time and class coverage with substitutes

6. Teachers help plan workshops (5)

7 . Workshops on specific teacher needs, not just: generic skilis (5)

8. Spend money out of school's budget

9. Schedule of staff development negotiated with faculty: "knowing that [a workshop] will take more 
mable 7 continued

than an hour, I would say, 'there will be no other meetings this month' (4)

10. Positive feedback if I see something from a workshop implemented

11. Letters in personnel file

12. Attend out-of-buliding workshop or conference

Curricular Development Incentives

1. State is requiring a lot more curricular objectives

without giving budgetary support $(1,2,5,6)$

2. Encourage faculty interest

3. Use of released time and substitutes for teachers and department heads: to wite scope and sequence; to plan new courses; to visit other schools (3)

4. Send teachers to conferences

5. Use in-house, school resources (5)

6. Cautious not to reward or recognize an individual, department or grade level over another

7. Publicize test scores for each class (1)

8. "I don't see programs as being less or more successful: I see certain teachers, certain grade levels, certain students, but I don't see a whole program in my school as unsuccessfui" (1)

9. "I think that each of the individual teachers, where they are being successful, know they're successful; and those who are not as successful, know that we are trying to help them" (4)

Selection of Textbooks and Instructional Matexials Incentives

1. A small school hurts for money for materials; a large school has greater opportunities $(1,2,3)$

2. Assign responsibility to teachers

3. "Nobody is given a budget. You turn in what you need. What are your requests? I figure it is my responsibility to meet those requests. I've always been able to get people what they wanted" (3)

4. "If something is not on the state adoption list and we want it, I'II purchase it some other way, rather than go through textbook monies" (6)

5. "I use [our two xerox machines] all day long and all night long for runing off instructional materials" (5)

6. "I don't think I have said no to a teacher for anything" (5) 


\section{Summary of Incentives}

The formal structure for the distribution of rewards minimized opportunities for principals to recognize outstanding performance within their schools. In teacher evaluation, an "acceptable" rating was the highest recognition on the formal instrument. Principals, therefore, found ways to acknowledge good work through written and verbal announcements and informal pats-on-the-back. Negative sanctions are, indeed, rare - with few teachers on prescription to improve a particular skill and hardly anyone terminated for lack of competency.

The incentives for staff development were restricted primarily by the responsibilities of classroom teaching. Principals negotiated with faculty to use workday time and staff meetings for workshops as well as buy released time and classroom substitutes. With little or no formal requirements, other than for prescriptive mode teachers, or records, principals relied on persuasive techniques to encourage staff development.

state and aistrict course requirements severely limited school-level innovations. New programs were developed primarily through mutual principal-teacher initiatives. Yet principals seemed overly concerned about distributing recognition equitably across grades and departments.

In the area of instructional materials, principals stated that they went out of their way to say yes to teacher requests. At the same time, with textbooks, they required a faculty 
consensus before taking action.

In sum, principals distributed praise, facilitate professional credit for maintenance or advancement, tempered internal competition, buffered external criticisms, and provided resources through regular budgeted or discretionary funds.

\section{Conclusions}

For each of the four managerial control processes, principals carefully followed externally prescribed policies, guidelines, and structural arrangements. This so-called structural dimension established constraints on their managerial activities, yet it was also seen by principals as points of departure and a basis on which to go beyond the structures. While many of the informal managerial activities have been so routinized as to be indistinguishable from structural constraints (Crowson \& Morris, 1985), there was clearly a category of managerial activities that reflected opportunities for discretionary behavior (Morris, crowson, Porter-Guthrie, \& Hurwitz, 1984). The latter dimension is predicated on the individual principal's views concerning education in general and the unique circumstances of their schools in particulax.

Through the words spoken here, each principal exercised a wide range of discretionary managerial behaviors which defined the schools' criteria for standards, information, assessments, and incentives, all within the framework of prescribed practice. Although the principals publicly espoused school-wide goals, they 
placed a great deal of emphasis on trusting certain individuals to professionally perform their curricular and instructional. tasks. This trust was translated into mutual activities and school policies regarding good teaching, programmatic innovations, staff development opportunities, and teacher resources. Neither the criteria nor the practice in this dimension were formally expressed, yet principals based their judgments in teacher evaluation, curriculum, and instructional materials on this personal, school-level criteria, rather than on formal procedures and evaluations. Within this qualitative managerial dimension, school-level priorities were established. As a result, many school-level priorities and whatever risks of decision-making they entail, specificaliy in programmatic innovations, were protected from public scrutiny. In addition, principals proceeded with caution when it came to setting instrumental standards, evaluating teachers, and distributing rewards and sanctions.

It is from the collective voices of our sample principal population that data have been analyzed. In addition, the use of a standard interview guideline permits the collection and tally of nominal data as broad parameters of managerial behaviors. Thus, we can summarize the diversity of responses under standards, information, assessments, and incentives and for the different curricular and instructional tasks. Again, these data make no reference to the frequency or efficacy of the managerial behaviors. 
From the sumary of interview transcripts, a total of 156 managerial behaviors were recorded: 53 behaviors were defined as formally prescribed or structurally determined; 103 defined as discretionary or qualitative behaviors.

Table 8 shows the nominal rank order of all managerial behaviors, both structural and qualitative. Incentives ranked just ahead of information, with assessments and standards having the least number of activities.

\section{$\mathrm{Table}$}

\section{Nominal Rank order of Managerial Activities by control process}

\begin{tabular}{lr}
\hline Control Process & $\begin{array}{r}\text { Numbe } \\
\text { Activi }\end{array}$ \\
Incentives & 43 \\
Information & 42 \\
Assessments & 37 \\
Standards & 34
\end{tabular}

Tota1: $\quad 156$

In Table 9 , the responses were categorized by tasks across all four control processes. The number of managerial teacher evaluation activities were more than double the textbook and instructional materials" selection behaviors, indicating that principals exercised a wider variety of activities in teacher evaluation than in the other curricular and instructional tasks. Given contractual responsibilities for annual teacher evaluation observations, the high rank might suggest the influence of external directives on in-school managerial behaviors. 


\section{Table 9}

Nominal Rank order of Managerial Activities oy curxicular and Instructional Tasks

\begin{tabular}{lr}
\hline Curricular and & Number \\
Instructional Tasks & Activit \\
& \\
Teacher Evaluation & 55 \\
Staff Development & 40 \\
Curriculum Development & 36 \\
Selection of Texts & 25
\end{tabular}

Lota1: $\quad 156$

Table 10 presents the number of activities of tasks by control processes. Teacher evaluation incentives and staff development information ranked highest followed by teacher evaluation assessments and standards.

Table 10

Rank order of Managerial Aetivities Categorized by Task Within Control processes

\begin{tabular}{lr}
\hline Tasks/Process & $\begin{array}{c}\text { Number } \\
\text { Activi }\end{array}$ \\
Teacher Evaluation Incentives & 16 \\
Staft Development Information & 16 \\
Teacher Evaluation Assessments & 14 \\
Teacher Evaluation Standards & 13
\end{tabular}

Tota1: $\quad 59$

Table 11 indicates the numerical aifferences between the structurally required tasks and discretionary or qualitative 
managerial activities. The data support the view that there are a wider variety of discretionary activities within curxiculum and instruction than formal mechanisms available to school administrators, especially when it comes to assessments and incentives. With respect to assessments, principals articulated their own criteria of success, particularly for teacher evaluation and curriculum development. Regarding incentives, the difference is more Iikely to be attributable to the limited formal or extrinsic incentives provided by school-level administrators to teachers. What may account for the large difference in textbook selection and staff development is the relatively few formal procedures pertaining to curriculum and instruction established either at the state, district, or school levels (Tulley \& Farr, 1985).

Table 12

Selected Differences Between the two Dimensions of structure and Discretion Curriculum Development Incentives Selection of Texts Assessments Staff Development Incentives

$\begin{array}{ll}2 & 9 \\ 1 & 8 \\ 1 & 7 \\ 3 & 9\end{array}$




\section{Implications}

There are basically two ways to approach the implications from a preliminary study such as this. The first approach is to use the data in order to further test (i.e., validate) the original findings concerning school managerial control processes. The data provide specific behaviors in which to establish the meaning of the four control processes as they relate to schoollevel management of curriculum and instruction.

The second direction is to examine the data and generate a list of hypotheses about managexial control of curriculax and instructional tasks.

The findings in general confirm that principals and schoolbuilding administrators are engaged in managerial activities related to curriculum and instruction across diverse tasks and along four control processes. These managerial activities are further categorized by structural constraints and discretionary or qualitative behaviors. Thus, a conceptual model of curricular and instructional school managerial control is offered in Figure 1 as follows: 
Figure 1. Curricular and instructional school managerial control model

MANAGERIAIS BEHAVIORS

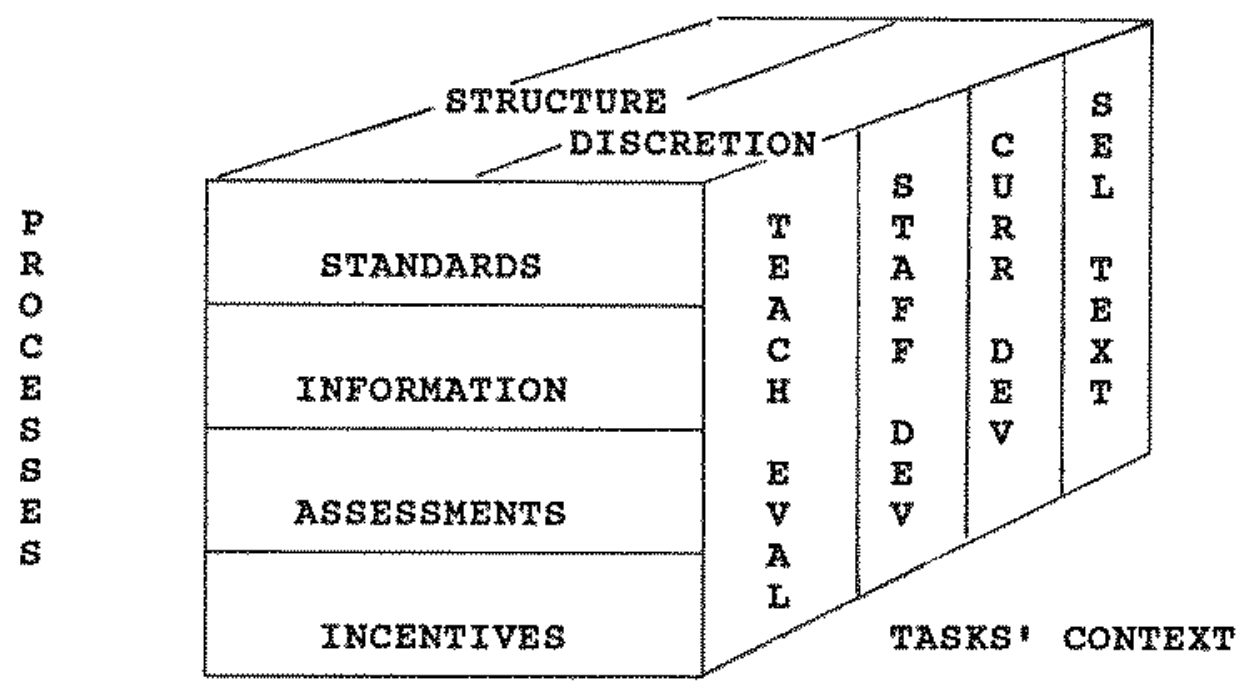

The construct validation path is not well travelled within the literature of educational administration. Nevertheless, it is critical to the advancement in the understanding of complex managerial activities within complex organizations (Hughes, Price, Marrs, 1986). At the same time, the advancement of knowledge is also served by hypothesizing and hypothesis testing. This preliminary study may also be helpful along these lines as well.

There are numerous hypotheses (or characteristics) suggested by the interview data from these curriculum-oriented principals. Several are listed here in no particular order of priority. 
1. Curriculum-oriented principals tend to estimate their percentage involvement with curricular and instructional tasks higher than do typical principals as reported in the literature on principals.

a. They tend to use language from effective school research, particularly high expectations and time on task.

b. They have had principaling experience at a least one previous school.

2. Curriculum-oriented principals are aware of their school's unique character and specific needs.

a. They initiate or support innovative projects which they publicly label "successful."

3. Curriculum-oriented principals go beyond the parameters of externally directed policies (formal stxuctures), yet are careful to denonstrate that policies are followed.

a. They are "critically accepting" of external policies and formal structures. (e.g., the formal teacher evaluation instrument, state legislation and directives, collective bargaining contract, district staff development priorities).

b. They tend to believe that the criteria used in their own evaluations have less to do with formal performance appraisal systems than with other principal behaviors (i.e., community

support, school climate, and problem-solving ability); they defined accountability in terms of their clients and themselves, rather than for their area director.

c. They tend to rely initially on informal. structure and behaviors before proceeding to formal structures and policies, but utilize both in completing tasks.

d. They all have faith and confidence in the performance of certain members of their immediate staff (assistant principals, department heads, or trusted teachers).

e. They all articulate good teaching criteria above and beyond the formal instrument for evaluating teachers.

f. They all exercise extreme care and caution when it comes to rewards and recognition of individual teachers and instructional programs.

g. They minimize the role of formal evaluation of programs, hardware, and materials in favor of personal school-building objectives.

4. Curriculum-oriented principals utilize formal structures 
to facilitate and encourage communication and professionalism among teachers and staff $(e .9 .$, planning by grade levels in the elementary school, scheduling inservice and staff development at faculty meetings).

a. They devise strategies to overcome constraints of policy, budget, and contract le.g., use of discretionary budget account and

negotiating

with faculty over the schedule of staf meetings).

5. Curriculum-oriented principals readily acknowledge that teachers play a major role, if not the major role, in the implementation of curriculum and in the selection of instructional materials.

a. They rank affective classroom or organizational qualities higher than subject area knowledge in selecting teachers.

b. They are aware of their limitations in contralling instruction and, therefore, come to rely on selling ideas and beliefs, increasing participation, and demonstrating administrative care.

6. The behaviors described by curriculum-oriented principals do not confirm the validity of standards, information, assessment, or incentives. other systematic frameworks for analysis need to be hypothesized and tested.

\section{Summary}

To give meaning and contextual understanding to the four managerial control processes identified by social science research, in-depth interviews were conducted with six curriculumoriented school principals. The large number of responses suggested that the curricular and instructional role of principals was complex. In order to analyze the data, the responses were categorized under each control process across diverse curricular and instructional tasks. A managerial control model was presented, reflecting both structural and discretionary managerial activities. As a preliminary study, the data from the 
interviews were used to further test and measure the model in a subsequent study. In addition, the data were quantified in order to indicate broad parameters of school-building managerial behaviors and to generate a number of hypotheses for further empirical testing.

The next steps in the construct validation process call for operationalizing the definitions of the managerial control processes, which are themselves abstract concepts. A clearer description of the interrelationship between the three hypothesized dimensions (see Figure 1) is presented along with literature references to support the choices of salient, observable indicators. Together with the findings from the preliminary study, the indicators were used to develop survey items for further data collection and analyses. 


\section{CHAPTER FOUR}

\section{operational Measures of Managerial control}

\section{Introduction}

An explicit description of the managexial control process model is a necessary step in theory development. From the literature reviews of social science control theories (chapter Two) emerged the four managerial processes: standards, information, assessments, and incentives. These managerial control processes were then placed within the context of school building managerial activities inside the domain of curricular and instructional tasks. The preliminary empirical study (Chapter Three) suggested that each of these rational control processes had, at least, two dimensions of behavioral indicators for managerial control behaviors: structural and discretionary. The next step in articulating the model is to operationalize and measure both the processes and their behavioral indicators. Towards that end, the entire chapter is devoted to operational definitions and to the identification of salient, observable indicators.

\section{Dimensions of Managerial Control}

The topic of dimensionality is relevant to both substantive as well as statistical analyses (Kruskal \& wish, 1978, p. 48). Technically, dimensionality refers to "the number of coordinate values used to locate a point in the space. This is basically the same notion as the number of factors in factor analysis" (p. 
48). Other meanings of the term refer to a direction of particular interest or an underlying characteristic of an object under study (p. 48). Statistical analyses, however, may not always reveal direction or characteristics; thus, dimensionality is ultimately a matter of interpretation.

Philosophical Foundations of processes and Behavioral Indicators

Although the social science literature reviews have contributed to an understanding of control as a practical administrative science, they do not offer a comprehensive framework for understanding the theoretical construct. Still lacking are the categories [logical, empirical, or symbolic] in which to confidently organize empirical data.

In traditional Western philosophy, there have been two paths by which epistemological confidence has been attained: along the first path, knowledge proceeds directly through intuition and logical categories of judgment to understanding; along the second path, knowledge begins in experience before arriving at an understanding of physical reality. Despite intellectual efforts to reconcile these two paths, epistemology has remained a matter of drawing a line between logical judgments and the physical reality of things.

Aristotle was the first Western philosopher to attempt to combine logical form with physical natter by giving material meaning to ideal (i.e., platonic) forms and by establishing formal, logical rules to underlie changing circumstances and 
situations (McKeon, 1970, pp. 7ff.). Form and matter could be united through the essential attribute(s) of things (p. 9).

Aristotle constructed a model of logical categories underlying matter and experience (pp. 15-28). The model consisted of three logical categories: quantity, relative, and quality. Quantity was defined as discrete or continuous, divisible in number, and existing in time and space. When something is defined as quantitative, it is known "only by reference to something external" (p. 16).

The second logical category, relative, comes into existence simultaneously, that is, "it is impossible to know that a thing is relative, unless we know that to which it is relative" (p. 4).

The third logical category is called quality, "in virtue of which people [or things] are said to be such and such" (p. 23). Qualitative aspects include habits, customs, and dispositions. Today, the term organizational culture has been affixed to this logical category. Most qualities have contraxies and can have varying degrees. Hence, there are cultural differences.

The 18th century empiricist, Hume, took exception to Aristotle's model of logical categories. Hume held that there can be "no idea of substance [i.e., essential attributes] apart from a collection of particular qualities" (copleston, 1964, p. 71). Two significant implications emerged from the empirical framework: (1) that causality was nothing more than the continuous association of "simple ideas" which occur immediately to us over time and space, and (2) that learning was not a matter 
of definitions or words alone, but rather of providing impressions or empirical examples.

These empirical implications, in turn, deeply troubled Immanuel Kant, an 18th century rationalist, since Hume's empiricism would seem to limit all knowledge to experience (Smith, 1965, p. 127) and rule out the possibility of there being certain knowledge of physical things. Kant opened his renowned critique of Pure Reason with the statement that, "[t]here can be no doubt that al1 knowledge begins with experience" (p. 41). Yet, while "all our knowledge begins with experience, it does not follow that it all arises out of experience" (p. 41). Thus, Kant, as had Aristotle before him, sought to link the two paths of human knowledge: sensibility and understanding (p. 61).

The Kantian model assumed that objects must conform to our knowledge; i.e., "determining something in regard to them prior to their being given" (p. 22). Kant reduced human understanding to the concept of judgments (p. 106) through two taxonomies: one of judgments, and a second, arising from the first, of intuition. It was this derived relationship between the judgment and intuition which, according to Kant, distinguished his complete system from Aristotle's "haphazard search" (p. 114). Both Kantian taxonomies contained four categories of knowledge: quantity, quality, relation, and, a new category, called modality. Modality was derined as having three logical [not objective] functions: problematic [the possible], assertoric [the real or true], and apodeictic [the necessary].

"I] nasmuch as we 
first judge something problematically, then maintain its truth assertorically, and finally affirm it as inseparably united with the understanding, that is, as necessary and apodeictic - we are justified in regarding these three functions of modality as so many moments of thought" $(\mathrm{p}, 110)$.

In the derived Table of Intuition (p. 113) all four categories of knowledge are included. Yet, it is the interrelationship of the categories which is important. To know a physical entity is to know each of its essential aspects, i.e., its quantity, quality, relation, and modality; for, separate and apart, the categories offer only incomplete explanations.

To Hegel, who dominated rational philosophy in the 19th century, the definitions and labels of the logical categories were of no real concern (Bailile, 1967). Instead, Hegel focused on the method and unity of reason, a totality so all encompassing and absolute that plurality, endless and finite variations, and individuality were part of the system (pp. 45-47). The unifying principle of subject and object was thought (p.48). The higher the level of awareness, the more unified the relationship ( $p$. 48). Yet, even at the pinnacle of rational knowledge, experience was still considered the raw material of knowledge. Experience and history needed to be understood through logical categories, but not as isolated incidents and details (p. 57).

In the pragmaticism espoused by James (1968), the criteria for how and where to draw the line between knowledge of physical objects and understanding, between matter and form, and between 
experience and reason became an issue of human temperament ( $p$. 7). In philosophical pragmaticism, the tough-minded empiricist and the tender-minded rationalist (p. 9) can walk down the path of knowledge together. "[T] he one thing that has counted so far in philosophy is that a man should see things, see them straight in his own peculiar way, and be dissatisfied with any opposite way of seeing them" (author's emphasis, p. 7). The focus of attention is on practical consequences, not on alternative explanations. Instead of looking at categories and principles, the pragmatist looks at facts and consequences (p. 27). "The pragmatist clings to facts and concreteness, observes truth at its work in particular cases, and generalizes" (p. 33). Whatever: hypothesis proves itself to be good, no matter the source, rational or empirical, is accepted as true (pp. 37-38). The pragmatic method can thus be applied to questions of substance, categories, attributes, unity, and plurality asking always for the practical consequences of alternative views.

The pragmatic solution, of course, did not satisfy everyone. Modern philosophers have continued the debate between rational and empirical traditions. For example, Russell (1970) agreed with Kant vis a vis the priority of a theory $\left[i, e_{*}\right.$, necessary truths grasped by the mind of knowledge (pp. 82-90). On the other hand, Russell held that laws of thought were beliefs about things, not just about thoughts. They are "fact[s] concerning the things in the world" (author's emphasis, p. 89). Ayer (1952) divided propositions into two classes: ideas and matters of fact 
(p. 31). He believed that metaphysical statements concerning consciousness were nonsense. To Quine (1961), the distinction between analytic and synthetic was imaginary. All things are matters of fact; the only differences are in degree (pp. 44-46).

Although the philosophy of phenomenology accepted empiricism as its starting point, holding that direct encounters are better than no contact or indirect contact (zaner, 1970, p. 37), it distinguishes itself from empiricism in stating that the problem of knowing is more complex than observing sense objects (p. 38) and having perceptions based on these objects. That is, "...our experience is fax xicher than empiricism could admit" (p. 38). "Not only are there different ways of experiencing the same thing - sense perceptually (in different modes), remembering, imagining, depicting, expecting, and still others - but some things are not at all accessible or reducible to sensory perception for example, one's own mind and mental processes..." (p. 38). Phenomenology, therefore, resurtected essences and universals given in puxe intuition [i.e., direct awareness]: reducing objects to their universals.

Husserl, a central figure in 20 th century phenomenology, was interested in processes, not in the existence or non-existence of objects (Nakhnikian, 1964, p. xiii). The world is constituted by the intentional acts of the transcendental ego. Intentionality characterizes judgments, beliefs, meanings, values, and desires. Phenomenology accepts the relativism of individuals and cultures by acknowledging the problematic character of philosophy (zaner, 
1970, p. 22). The philosophic method is to look for the best obtainable evidence (p. 39).

An alternative view of knowledge was offered by $S$. Langer (1952). She wrote that one result of a two dimensional approach to knowledge $\dot{i} . e .$, rationalism and empiricism, is a "peculiar hybrid of concept and precept, the given "fact" (p. 231). "A philosophy that knows only deductive or inductive logic as reason, and classes all other human functions as 'emotive, irrational, and animalian, can see only regression to a prelogical state in the present passionate and unscientific ideologies.... They are residues, emotional disturbances,.... But a theory of mind whose keynote is the symbolic function,... is not obliged to draw that bifurcating line between science and folly" (p. 246). "New conceptual forms are crowding out the traditional empirical-rational duality, but these conceptions are themselves just only at the mythological phase..." (p. 246).

The recent emergence of organizational and leadership culture (Deal, 1987: Sergiovanni, 1987) and the symbolic framework (Bolman \& Deal, 1984) may be understood within both $S$. Langer's symbolic transformation as well as in the problematic methods of phenomenology. The acceptance that real meanings lie within residual concepts has given rise to cultural and qualitative explanations within social scientific hypotheses. The residual findings reported by structural analysts support $s$. Langer's (1952) view that epistemology is not "discursive reasoning about wel1-conceived problems" (p. 246). Political, 
social, and psychological dynamics express the need to organize and decipher interactive data into meaning (Bacharach \& Lawler, 1982).

"The problem caused by the intrusion of subjective values into its inquiries has always troubled social science, which has struggled, without too much success, to attain the presumed "value-free' objectivity of the natural sciences" (Heilbroner, 1975, p. 22). The challenge rightly falls to philosophy to frame the parameters of this new journey which travels beyond social scientific restrictions. Of all the academic disciplines, only philosophy, with its intentional skepticism and critical attitude, seems prepared to withstand being shipwrecked on the shoals of non-reason or non-empiricism (Jaspers, 1955, p. 119). Neither empirical evidence nor proposed a priori definitions have been able to prove that the thing itself - e.g." the construct of managerial control - existed. It is fitting that Aristotle provided the most heuristic guidelines for estabishing construct valialty: "In establishing a definition by division, one should keep three objects in view: (1) the admission only of elements in the definable form, (2) the arrangement of these in the right order, (3) the omission of no such elements" (Mckeon, 1970, pp. $175 f$ f.).

The concept of managerial control is a charged linguistic symbol: neithex purely technical, nor purely utilitaxian. It has multiple meanings, some of which are beyond empirical interactions or purposive acts. "Our perception organizes it, 
giving it an individual definite Gestalt" (S. Langer, 1952, p. 240). "... W]e control each other's merely incipient behavior with fantasies of force. We employ sanctions, threaten vague penalties, and try to forestall offenses by merely exhibiting the symbols of their consequences....(T) he power of symbols enables us not only to limit each other's actions, but to command them; not only to restrain one another, but to constrain" (author's emphasis, p. 241).

Clearly, the qualitative, cultural, and symbolic metaphors have emerged to challenge the rational-empirical dichotomy in organizational analyses. These concepts represent a new beginning; but the failure of structural analyses to produce a comprehensive theory with descriptive validity does not justify total disbandonment. The logical categories dexived from philosophical analyses represent different dimensions of knowledge. Kant and Arististole offered us quantity, quality, and relativity. The fourth logical category, modality, is a process, perhaps Hegelian, or pragmatic, or phenomenological, or even symbolic. The categories and processes are inextricably linked such that analyses of only one aspect at a time cannot solve the problems of knowledge.

The model of managexial control proposed at the conclusion of chapter Three (see Figure 1) can be redrawn in philosophical terms. Thus, Figure 2 below depicts the modality of processes, the managerial behaviors of quantity and quality, and the relational context. Alternative explanations for the meanings of 
each philosophic term have been of fered. Processes may be rational, pragmatic, or even symbolic (Meyer \& Rowan, 1977); likewise, the tasks by which context is fully known are a combination of objective technology and subjective beliefs (Dornbusch \& Scott, 1971). Moreover, both logical categories of managerial behaviors, quantity (e.g., structure) as well as quality (e.g., discretion and culture) must be part of the measurement construct.

Figure 2. Theoretical model of construct validation for managerial concepts

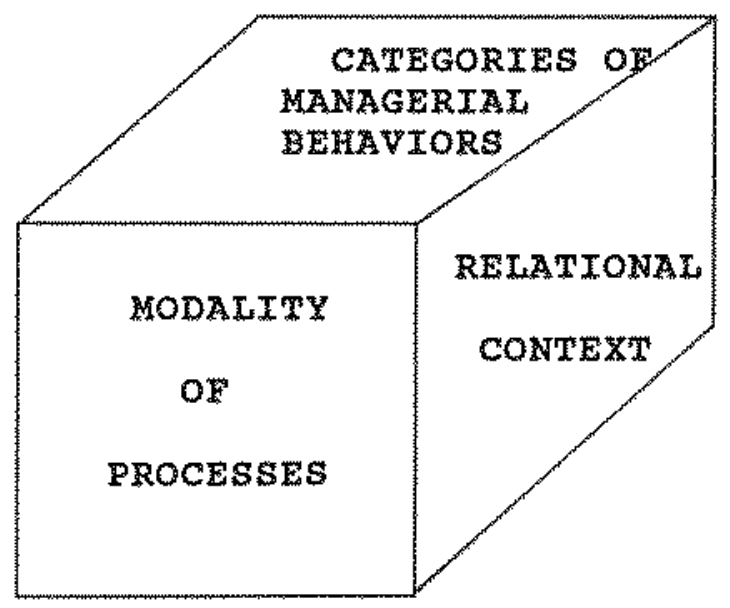

\section{Structure and Meaning of Managerial Behaviors}

organizationaliy, there is a structure within which regular patterns of observable managerial behaviors operate. It is known to us by reference to something external, whether formal or 
informal. From the literature reviews came numerous examples of the quantitative-structural referents:

1. formal authority structure (Lang)

a. organizational levels (Blau \& Scott)

b. supervisory control (Duke; Mahoney \& Frost: Turcotte)

c. prescribed roles (Child; Rowan; Scott \& Scott)

d. legitimate power (French \& Raven; Pfeffer)

e. size (Applewhite: Child; Elmore; Peterson)

2. technology and work processes (Bacharach; Cohen \&

Miller; Dornbusch \& Scott; Eisenhardt;

Koontz; Mahoney \& Frost; Ouchi; Pfeffer; Thompson)

3. tenure (Applewhite; Etzioni)

4. standards (Koontz; Mahoney \& Frost)

a. organizational goals (Peterson; Bossert)

b. performance standards (Bossert; Doud \&

Montgomery; Koontz; Ouchi; Vickers)

5. information (Applewhite; Bacharach \& Lawler;

Pfeffer; sproull)

a. information systems (Eisenharat; pfeffer;

Schein)

b. information processors (Sprouli)

c. exchange of information (Bossert; cohen \& Milier)

d. control of flow (Bossert)

e. expextise (French \& Raven)

f. staff development (Mahoney \& Frost)

h. comittees (Mahoney \& Frost)

6. planning and preparation (Bossert: FCEM: Mahoney \& Frost)

7. output results (Blau \& Scott; Manoney \& Frost; Ouchi; Peterson)

a. evaluation systems (Dornbusch scott; Duke; Ellett; pfeffer)

b. material rewards (Etzioni; Lawier \& Rhode)

8. Costs (Eisenhardt; Katz \& Kahn)

9. scheduling (Bossert)

10. appointments (Bossert)

11. lobbying for administrative support (Bossert)

12. selection (Etzioni; Peterson)

Likewise, organizationally, quality conveys meanings which are associated with structure or behaviors, affecting attitudes, beliefs, or even subsequent behaviors. Attitudes involve evaluative judgments (i.e., beliefs). "When specific attitudes 
are organized into a hierarchical structure, they comprise value systems" (author"s emphasis) (Katz, 1965, p.277). Here, too, the social science literature offered numerous qualitativediscretionary, managerial referents:

1. influence (Bacharach \& Lawler; Lerbinger)

a. environmental interdependence ( $R$. Campbell, et al.: Eisenharat; peterson; Pfeffer)

b. processes (Bossert; Pfeffer; Wellisch)

c. ideas and advice (Cartwright)

d. informal structure (Bacharach; Cartwright; Lerbinger)

e. sentiment (Lerbinger)

f. attitudes, beliefs, and motives (Cartwright; Katz)

9. more than rules and directives (Cartwright)

h. inconspicuous (Bruner)

i. language, myths, stories (Bruner; Meyer \& Rowan)

j. ideology (Johnston)

2 . beliefs and preferences (Thompson)

a. self-interests (Deal: House \& Mitchell)

b. illusion of control (E. Langer: R. Harrison)

3. discretion and choice (Mahoney Erost; Thompson)

a. variance control (Miles \& Vergin)

b. probability limits (Patz \& Rowe)

c. discretionary use of funds (Bossert)

a. exchange process (Cohen \& Miller)

e. freedom to fail (Miles vergin; Myers)

4. internalization of standards (BIack; Locke)

a. individuals' subjective needs (J. Campbell, et al.; Mitchell)

b. intelligibility and clarity (Bruner)

c. confusion (Elmore; Frank)

d. identitive organizations (Etzioni)

5. task conceptions i.e., beliefs (Dornbusch \& Scott)

6. cooperation (Floden, et al.; Mahoney \& Frost)

a. limit competition between programs (Bossert)

b. understanding and social control (Eisenhardt; scott \& Scott)

c. identification and mutual admiration of

individuals on different levels i.e., referent

leadership (French \& Raven)

d. individuals' identification (Burnstein;

Etzioni: Heilbroner)

e. affiliative trait (Bruner; Heilbroner)

7. intrinsic rewards (Eisenhardt: French \& Raven; 


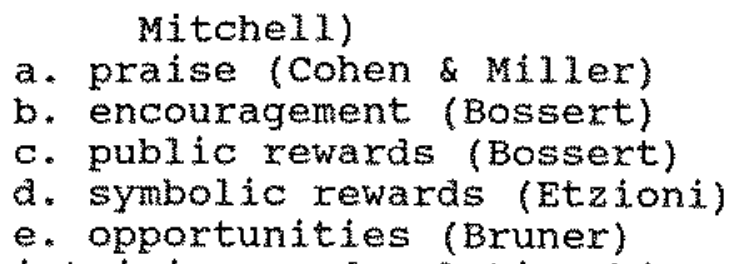

8. maintaining good relationships (Bossert)

a. protection of teachers (Bossert; Leiter; Thompson)

b. risk propensity (Marzano, et al.)

9. high expectations (Bossert: Edmonds; Little \& Bird)

a. public acceptance of a program (Bossert)

b. promote programs outside school (Bossert)

c. moral discourse (Burneli \& Reeve; Skinner)

10. manipulation, coercion, and physical sanctions

11. favoritism (Blase) (Etzioni; Gibbs; Skinner)

12. persuasiveness (Bacharach \& Lawler; Burne11 \& Reeve; Cartwright; skinner)

a. voluntary submission (Bacharach)

b. commitment (Marzano, et al.)

13. satisfaction (C. Greene; Hoy \& Miskel)

This conceptual duality of quantity and quality within organizational structure and behaviors is certainly not novel. Researchers have tested the strength, interaction effects, and causality of all of the variables listed above. In the majority of these studies, the qualitative variables emerged as residual findings from structural analyses. These non-structural findings have subsequently become the bases for political, sociological, and psychological studies (Ames \& Ames, 1987; Pfeffer, 1978a: Scott \& Scott, 1971), as well as alternative models of organizational analyses (Astuto \& Clark, 1985; M. Harrison, 1987).

Until recently, the dominant organizational paradigm has been rational bureaucracy. Within this model, the organization has been portrayed metaphorically as a machine. "Control 
procedures are designed to monitor the machine's performance along a number of dimensions and to dispatch various reports to upper level officials. Management in this model stands at the 'control panel,' alert to evidence of negative deviation from the pre-established standards and procedures and ready to pull switches and twist dials to enforce compliance at any point at Which deviation may occur" (Miles \& Vergin, 1966). The impersonal control mechanisms in a modern bureaucracy are (1) rules, (2) computer mechanization, (3) performance records, (4) recruitment and training and (5) incentives (Blau \& Scott, 1962, p. 185). Although under certain conditions or for routine tasks, the machine metaphor may be appropriate (Hofstede, 1978), the complexities of organizations revealed a multiplicity of control functions as well as the necessity for overall control (Lorange \& Morton, 1977).

Cybernetic theory is related to the mechanistic model (Hofstede, 1978), but with one significant difference: the concept of self-regulation. Narrowly defined, the term cybernetics refers to any self-regulating system that is amenable to mathematical formalization; however, in its broadest, holistic sense, cybernetics is "the general science of the control over complex systems, information, and communications" (Dechert, 1969 , p. 70). When cybernetics incorporated social systems, both man and society were viewed as self-regulating. The implication from a managerial perspective was that self-regulation resulted from sensitivity and learning, guided by perceptions of the future. 
Koontz (1971) related control systems to cybernetic theory through: (1) the identification of deviations or the difference between desixed performance and actual performance; (2) the analysis of the deviations, (3) a program of corrective action, and (4) the implementation of corrections (p. 140). In order to have such a rational process system, koontz reasoned that it would be necessary to teach the nature and philosophy of the system. As a conceptual tool, cybernetics relates perceptions to values, and values are a matter of culture (Dechert, 1969). In practice, however, control is "largely a matter of techniques" (Koontz, 1971, P. 140). Thus, one must study the adequacy of the perceptions within a specific culture or context in order to discover whether the techniques of managerial control can evoke self-regulating responses.

In Ames and Ames (1987), the contrast between quantitative measures and qualitative measures of motivation was made clear. The former describes the activity, energy, and persistence inferred from achievement levels. On the other hand, the qualitative definition of motivation is related to the different values or goal orientations, the different ways of processing or attending to information, and the different cognitions (perceptions and interpretations) about performance. Their research findings on how specific goals and values affected students and teacher perceptions, attributes, self-evaluations, and beliefs about strategies of action reported differences of perceptions based on the beliefs and values of the subjects. 
A qualitative perspective focuses on the beliefs of the perceiver. Thus, understanding behavior is not simply a matter of hypotheses-testing about rational information-processing systems or issuing nomative prescriptions. The reasons why people hold particular attitudes goes to the level of psychological motivations, a level distinct from external events and situations (Katz, 1965, p. 279). Consequently, Ames and Ames (1987) and Mitchell (1987) have concluded that principals needed to be more aware of teacher belief systems.

Astuto and clark (1985) developed an organizational taxonomy of coupling relationships based on the distinction between quantity and quality within structures and behaviors. The authors used their taxonomy to conduct a meta-analysis of case studies of effective schools to determine whether administrativeteacher relationships supported strong bureaucratic or loosely coupled assumptions. Fifty-nine case studies were "interviewed" using closed-ended questions adapted from the Rand corporation comparative case survey technique. The measure used to determine structure or quantitative interactions was frequency, while the qualitative interactions were measured by the degree of reliability, responsiveness, harmony, and dependence. Astuto and clark (1985) defined reliability as consistency and stability; responsiveness as "the extent to which one (organizational) element adjusts quickly to altered conditions of another element." The authors further described reciprocity, haxmony, rapidity, dependence - relational interactions within the 
qualitative dimension.

The language used by Astuto and clark (1985) to describe qualitative interactions had already been part of the expansive language previousiy used to discuss organizational control. (Frank, 1958-59; Lawler \& Rhode, 1976; Patz \& Rowe, 1977; Turcotte 1974; Vickers, 1967). Each of these control theorists found structural language too restrictive (i.e., homeostatic) and, therefore, expressed the need to substitute expansive language incorporating growth and maturity into the discussion.

There has not always been a clear delineation between quantity and quality. For example, under reliability, a qualitative measure, Astuto \& Clark (1985) have grouped the following managexial behaviors: regularly scheduled inservice, coordination, series of information-sharing meetings, weekly calendar, regular monitoring throughout the year with feedback, ongoing interaction - each of which seems to be, in this reviewer's judgment, a structural variable - with qualitative variables such as (a) comitment to all teachers and (b) a sense of order. The latter are beliefs and attitudes which may result from the structural managerial activities listed above.

Astuto and clark (1985) reported that consistency levels under the reliability variable were high, suggesting to the authors that principals invested schools with a sense of order, predictability, and purpose; they also found that systematic mechanisms were in place to facilitate effective comunication. Although the authors stated that as the coupling taxonomy was 
refined, more variables would provide more precision in the analysis. Nevertheless, the definitions offered and their implications are certainly worth pursuing further.

One of the major weaknesses of control systems is that measures of qualitative factors and individual development are more difficult to ascertain than structural mechanisms since qualitative measures vary in completeness, objectivity, and difficulty of influence (Lawler \& Rhode, 1976, pp.42-45). for example, reqardless of the amount of feedback given employees, it is how much they perceive they have that affects their reactions to their jobs. (p. 80). Dornbusch and scott (1975) reported a similar finding with respect to technology. Theix definition of "task conceptions" was based not on the objective characteristics of a task, but rather on subjective perceptions (p. 348). Control systems, in general, tend to appraise performance only and ignore quality factors (Koontz, 1971). They also tend to overlook individual development (Patz \& Rowe, 1977). It is, therefore, important to develop measures of quality which complement structural measures and reporting systems (Lawler \& Rhode, 1976, p. 94).

Astuto and clark (1985) reported that the frequency of interactions were disjointed and variable, rather than absolute or constant. They further reported that low interactions were rare. others have reported that frequencies of interactions differ since the time span should reflect the schedule needed to complete a specific job (Koontz, 1971; Lawler \& Rhode, 1976). 
What appears to be constant is the perception that frequency is a valid control measure (Anderson \& Brown, 1971; Hoy \& Miskel, 1982 , p. 308; Lawler \& Rhode, 1976, p. 182), thereby, supporting the view that principals are visible (Andrews, 1987) and active. The evidence is unclear whether the freguency of interactions is or is not a discriminating factor in leadership. Anderson and Brown (1971, p. 197) along with Andrews (1987) have suggested that it is, whereas Astuto and clark (1985) implied otherwise. unlike other structural models, however, the coupling taxonomy specified gualitative relationships within schools, and quite predictably found evidence of their influence. Nonetheless, as an exploratory investigation, Astuto \& clark (1985) understandably stopped short of identifying patterns of coupling that enhanced or impeded effectiveness.

\section{The processes of Managerial control}

The evidence from social science control theory research strongly suggests that managerial control is defined by several dynamic organizational processes, rather than as a single formal or informal entity. Multidirectional political dynamics highlighted the need for information and assessment systems in the service of managerial control; social control established norms of performance and standards as a managerial control process; and, psychological control identified the system of incentives and internalized standards as control processes. viewed as a whole, these processes freed one from the ilmitations 
of (a) organizational structure, (b) single discipline orientations, and (c) objective characteristics of specific work tasks *

Conceptually, a process analysis is rational. That is, processes describe common characteristics of behaviors in a logical, although not necessarily sequential linear, progression (Anderson, 1982). Given the complexity of school organizations and the effects of situational and cultural differences on learning, it may be considered impractical to hypothesize a unified system of control processes across diverse tasks and organizational cultures; but, that is precisely what is suggested here, at least within a single domain of tasks such as curriculum and instruction.

The claim that there are common characteristics of control seemingly contradicts previous findings that controls ought to be tailored to tasks and individuals (Chaxters, 1981: Koontz, 1971), and that control differs among cultures (Tamnenbaum, et al., 1974). Since a process analysis embodies a rational perspective, it further raises the question of whether this framework contradicts managerial complexity (Mintzberg, 1971), or the nonrationality of school organizations (Patterson, Purkey, \& Parker, 1986; Sergiovanni, 1987), or the non-sequential logic of organizational processes (Cohen, March, \& Olsen, 1972), or the weak school organizational incentives of problem-solving motivation (Sieber, 1981) - findings which have al1 been supported by empirical evidence. 
In contrast, a unified model of managerial control suggests that underlying observable differences in tasks, settings, and cultures have common, essential attributes (i.e., processes and dimensions) of control which can be identified and measured. A unified model makes no absolute clains of a one best control system, yet it can document discipline and order by relying on logical categories and the qualities of human character, such as freedom, and individual responsibility (Buber, 1967, p. 116).

Control is, fundamentally, a rational and sensible concept. Logically, its contrary is defined as "out of control" (E. Langer, 1986), random behavior, or, in Hobbesian terms, "a state of war" (Hobbes, 1651/1958). These contrary positions are irrational in that none is willingly chosen. What accounts for differences in control definitions are the cultural and structural differences in organizations (Vroom, 1984), idiosyncratic a priori definitions, or the empixical measures used to study control. Yet, within any single organizational context, there exists a valid theory of control which identifies the underlying unity of the concept.

The rational control processes identified here have been defined as latent variables comprised of multiple factors. The empirical findings of weak school control mechanisms reported in Chapter Two, however, were not based on multiple measures. In their designs, they also overlooked the strength of psychosocial evidence as measured by qualitative indicators which could identify a subjective reality underlying control systems. 
Attitudes originate at the psychological level, distinct from "the accidents of external events and circumstances" (Katz, 1965, p. 279). Individuals have basic needs (a) for perceiving rational processes (Ames \& Ames, 1987), (b) for perceiving theix being in control (Katz, 1965; Langer, 1983; Vickers, 1967) regardess of empixical situations, and (c) for obeying authority (Heilbroner, 1975).

The dichotomy between a diverse, nonrational world and the needs for internal rationality can be reconciled through the study of interactions between the quantitative and qualitative measures of control along the hypothesized managerial control processes. It is precisely this level of contextual analysis which provides valid descriptions of organizational structure linked with specific managerial behaviors and their associated beliefs, attitudes, and perceptions. A logical process analysis supported by empixical data can ultimately provide managers with a guide to action when confronted by organizational complexity or contradictions.

Lawler \& Rhode (1976) developed a process classification model based on common characteristics of control systems: (1) similar structures to (a) collect, (b) store, and (c) transmit information in a particular form and with specific frequency (pp. 5-6); (2) similar purposes to (a) influence behavior and (b) govern human behavior towards a predictable action. How information is collected, stored, and transmitted can affect attitudes and behaviors which influence, if not govern, behavior. 
Thus, the Lawlex and Rhode model incorporated both quantitative and qualitative meanings of structure and behaviors.

Their hypothesized measures of control varied in completeness, objectivity, influence, difficulty, immediacy, continuity, and importance. Each of these measures has been linked to a specific control process. For example, under the first process, the nature of standards, not only is it necessary to identify who sets the standards, but it is also important to measure the perceived difficulty of the standards (pp. 45; 98). If the standard is perceived as unreasonably difficult, lawler and Rhode (1976) predicted rigid bureaucratic behaviors, invalia data, and resistance $(p, 98)$. Increased participation, adequate flow of information, and the utilization of data were al1 managerial strategies suggested to overcome any dysfunctional behaviors associated with the nature of standards ( $p .101$ ).

Communication processes are conceived as two-way channels among individuals at different levels of the organization. Therefore, perceptions of meaning and worth are enhanced by the utilization and feedback of information based on the speed and frequency of communications. Even assessments, referred to as discrimination, is viewed as a mutual process. These activities must be perceived as important and linked to a source of individual motivation, intrinsic or extrinsic. Figure 3 describes the Lawler \& Rhode (1976) process classification system in terms of the four processes of managerial control proposed in this study. 
Figure 3: Reclassification of Lawler and Rhode (1976)* behavioral control indicators

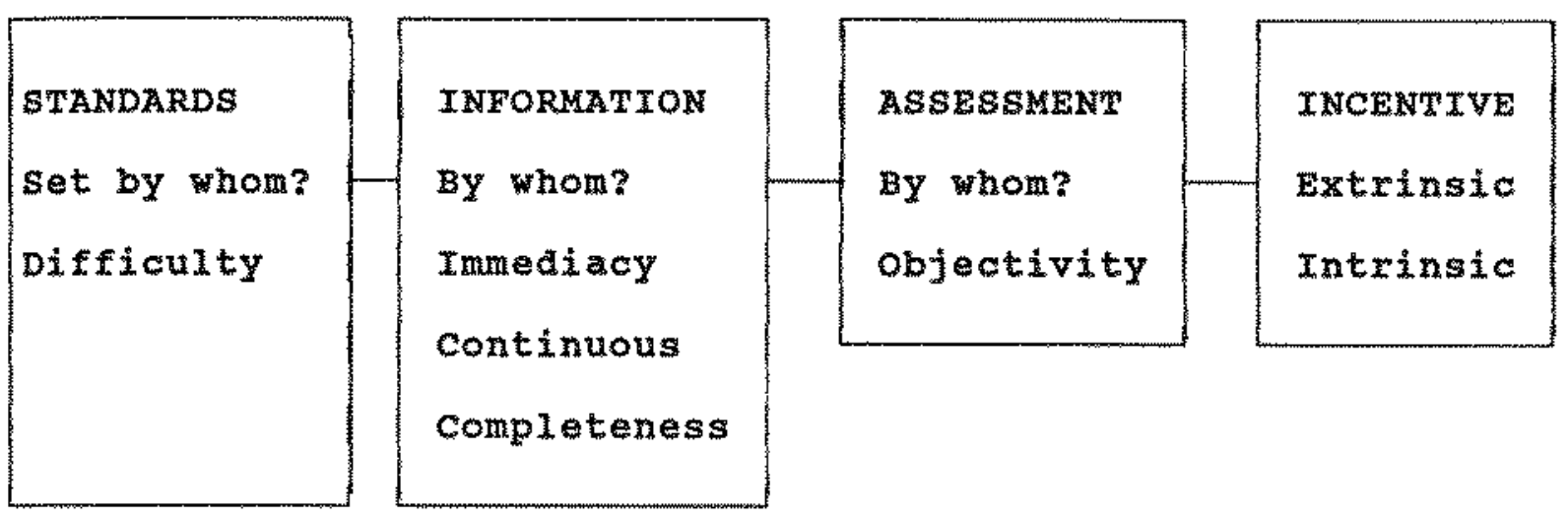

* See: Lawler Rhode, 1976, p. 4.

Lawler and Rhode (1976) included two other very important measures in their classification system: influence and importance. The first measure assumes that each of the behavioral indicators has a varying degree of influence upon individuals. The second measure relates to the type of activity and its perceived importance. Managers will encounter situations in which certain tasks are easier to control than others. Some of these tasks, however, are of less importance to performance than are other tasks which may be more difficult to control. A question raised by Lawler and Rhode (1976), and others (Counts, 1930/1971; Koontz, 1971; Ouchi, 1978; Peterson, 1984) is related to the managerial decision to control less important, but easily controllable tasks, as opposed to the control of important, but more difficult to control tasks. 
Within the most comprehensive descriptions of control, the discussions eventually include the topic of processes. Koontz (1971) concluded from his management studies that the processes of control (a) required time, (b) were linked to work-related operations, (c) have qualities that were clear and objective, and (d) were related to meaningful incentives (Chapter 7). It is a system that must be learned. Thus, control has been described as a function of learning theory (Bruner, 1962; schein, et al., 1961; Skinner, 1966) which implies metacognitive control over a process, whereby one "must know what facts and concepts are necessary for the task; which strategies, heuristics, or procedures are appropriate (conditional knowledge); and how to apply the selected strategy, procedure, or heuristic" (authors" emphasis. Marzano, et al., 1988, p. 14).

Following the metacognitive stage, Marzano, et al. (1988) defined "executive control" of the process, involving evaluation, planning, and regulation. They write:

Evaluation occurs throughout an entire process and is both the beginning and the end point for a task. It also includes assessing whether we have the resources needed for the task.... [E]valuation includes assessing task goals and subgoals....

Planning involves deliberately selecting strategies to fulfill specific goals... [Planning occurs before the concrete operational stage.] Regulation involves checking our progress toward the goals and subgoals identified... From this perspective, regulation is the process of continually assessing how close to our goal or subgoal we are.... Then, carrying out appropriate revisions is critical (Marzano, et al., 1988, p. 15).

The inclusion of a metacognitive stage of control necessitates the presence of self-control as part of the control 
processes. It implies that self-control can supplement the roles of supervisor, disciplinarian, and authoritarian leader. Work may be accomplished autonomously and effectively, but with others in different and difficult situations (Marzano, et al., 1988, p. 16).

People interactions are dynamic and changing within the workplace. From a managerial perspective, daily interactions may best be viewed as occurring de novo in that the potential is always there to either enhance or unhinge a previously existing relationship. Although people who work together genexally develop a stable pattern of behavior based on previous interactions (Baumeister Jones, 1978) - i.e., a workplace interpersonal history - that relationship is extremely fragile. In a single instance, a perceived inequity can affect the relationship negatively and permanently. Interpersonal work relationships are continuously being evaluated on the quality of immediate interactions (Argyris schon, 1982, p. 206-207 note).

Marzano, et al., (1988) also made the distinction between skills and processes. The former are simpler cognitive operations (e.g., oral and written communication), while the latter are broader in scope, more macro and take a longer time to complete $(p, 32)$. This distinction reflects two perspectives: technological versus managerial. Whereas the relationship between technology and people usually reaches an objective balance which can be measured by performance, i.e., behaviors or outcomes, (Ouchi, 1978), managerial relationships depend on less 
substantive issues. Although managerial processes involve both technology as well as substantive issues (Caewiti, 1987a; Sergiovanni, 1984), managerial interactions are different (Hall, Jr., 1956). Within schools - as professional or semiprofessional organizations (Lortie, 1969) - principals are relatively familiar with school curricular and instructional technologies; yet, they manage not only as technology experts (Cawelti, 1987a), but in other, perhaps more appropriate, roles (Deal, 1987; Sergiovanni, 1987). Both of these aspects of control, however, technical and managerial, are essential parameters of school managerial control (Apple, 1982, p. 141164). The interdisciplinary perspective of organizations necessitates a rethinking of control functions which go beyond words and actions such as monitoring, verifying, correcting, inspecting, adjusting, repairing, auditing, etc. (Myers, 1981, p. $98,106-7)$. Within public schools, managerial control processes have short and long term behavioral and relational effects on others. Almost 60 years ago, Counts (1971/1930) wrote, "in education there can never be the separation of process and product which is characteristic of manufacturing enterprise" (p. 149)

Despite the widespread use of the terms standards, information, assessment, and incentives to describe the managerial processes, there are stili viewpoints which argue against their inclusion in organizational analyses in general. Hofstede (1978) has argued that standards may not exist, 
accomplishment may not be measurable, and feedback information cannot be used. Other objections raised suggest that control standards are difficult to implement or ineffective. vickers (1967) and Koontz (1971) have noted that (a) goals are difficult to set, (b) goals tend to be short term, (c) goals tend to focus attention too narrowly on fields where control can easily be established and away from important fields where action may not be controllable. Nevertheless, the most persuasive evidence supports the view that in order to increase our understanding of school managerial control, the analysis must identify general social processes which can be described and analyzed on the level of action (Blalock, 1984, p. 164; Koontz, 1971; Vickers, 1967) through the study of control process relationships (Dornbusch \& Scott, $1975, p$, ix), specifically with teachers perceptions (Andrews, 1987: Cohen, et a1., 1979; Kerr, 1987).

From both a rational and empirical perspective, the investigation begins with standards. According to Argyxis and Schon (1982), individuals rely on past experiences and group norms when standards or knowledge is 1 imited. Since professionalization (Lortie, 1969) and the professional norm system for teachers are still presently weak (Leiter, 1983), there is a definite need to initiate control through the process of standards.

\section{Control of standards}

In a rational order, there exists a prescribed relationship 
between the behavior of individuals, their productivity and the standards or goals of the organization. standards based on a rational decision-making process act as a guide to appropriate behaviors and outputs (Koontz, 1971, p. 140). In this sense, the primary criterion of success is measured by the conformity to a given standard (Vickers, 1967, p. 27). Standards state the expectations of what ought to occur, an "ought-to-be" (vickers, 1967, p. 111). Under the control of standards, whenever a standard is communicated and operationalized, there is a signal for a process to select and initiate an apt response (Vickers, 1967. p. 113). Not only do standards initiate control processes by acting as "a guide to action" (Vickers, 1967, p. 29), they also serve as measures against which actions and outcomes are judged to be successful or deficient. The normative assumption within this model is that "those organizations which deviate least from the optimum structure will be the most effective" (Pfeffer, 1978a).

As rules, policies, or established patterns of behavior, the standard is defined as structural. Rules and policies attain legitimacy through the hierarchy in which communication flows downward through a chain of command. The rules and policies serve directive and regulatory functions (charters, 1981) for both behaviors and outcomes.

yet, rules and policies are not the only determining factors of performance standards. People assume standards and values of their affiliated group members (Bruner, 1962; Heilbroner, 1975; 
Katz, 1965, p. 302). If a standard is based on the performance of others or on an individuals' ow criteria, then control of standards is often derived from social control or self-control dynamics. In either instance, control of standards encompasses political, social, and psychological aspects of organizational processes outside organizational structure. These dynamics might include negotiated standards, socialization, selection, and professional standards, and/or personal, subjective, motivational standards.

The sequential order of standaras as the first control process is important not only because a known standard is needed for intrinsic motivation (tawler \& Rhode, 1976, p. 75), but, also, because standards are needed to perform the other managerial control processes. For example, "(control) is singularly dependent on plans since there is no possible way a person can know whether he is going where he wants to go - the job of control - unless some planning was done by some one to show where it was intended to go" (Koontz, 1971, p. 140). Likewise, incentives are a function of the goals that individuals set in response to them: that is, goals mediate the effects of incentives on behaviors (Locke, 1977). Both assessment and incentives are dependent upon standards (perry \& porter, 1982). If goals are clearly stated, then outcomes can be measured and evaluated (Dornbusch \& Scott, 1975: Eisenhardt, 1985).

The inkages among standards and the other manageriai control processes do not necessarily mean that a single standara 
is needed to trigger action. Standards may have variable and flexible meanings (Miles and Vergin, 1966), or be a mattex of choice (Tannenbaum, et al., 1974). Standards can reflect the external environment, local cultures, ideology, or intrinsic motivations (Hannaway \& Sproull, 1978-79; Sergiovanni, 1987; Tannenbaum et a1., 1974).

Empirical organizational studies have revealed the problematic nature of standards, Among the characteristics identified have been (a) conflicting standards which leave the criteria for evaluation unclear (Frank, 1958-59), (b) selective enforcement of standards which may pose a continual threat to subordinates (Frank, 1958-59), and (c) the possibility that an individual may meet or miss a goal through no fault of his own, and, therefore, may not really show performance (Koontz, 1971). Conflicting standards may result either from ambiguous goals or from incomplete knowledge or limited communication channels (Frank, 1958-59). Since conflicting standards ensure that subordinates will always fail to meet one of the selectively enforced standards (Frank, 3958-59), it keeps a continual threat on subordinates. Frank reported that such conflicts generated three specific managerial responses: (1) creating margins of safety by stockpiling materials or understating or overstating capacity or needs, (2) fudging perfomance records, and (3) using personal influence to obtain favors.

Many solutions have been offered to overcome such dysfunctional organizational behaviors. Frank (1958-59) offered 
a substantively rational solution: i.e., managers ought to focus on the achievement of the task regardless of the means employed. He also suggested decentralizing decisions, enhancing flexibility, and for subordinates to become acquainted with superior's objectives. He introduced such qualitative terms as, sensitivity and responsiveness to control theory.

Brown (1969, p. 84) advised managers to focus on the human side of control. Miles \& Vergin (1966) suggested a managerial response to variable standards called "variance controls: i.e., "total pattern of performance rather than some preset absolute standard...the distribution of performance measurements around the average (mean) level of performance" (1966). Similarly, Patz \& Rowe (1977) expressed their sensitivity to change in discussing control by setting measures attuned to "probability Iimits" wherein goals are defined as hypotheses (p. 269). In line with Lindblom's (1956) theory of incrementalism, Sprould. and Zubrow's (1981) Pexformance Information system measured performance against a standard "within an acceptable range." Patz and Rowe (1977) even argued that getting close to an objective was preferable to exactly meeting it since the former involved less time, effort, and data (pp. 267ff.).

Miles and Vergin (1966) found that standards were understood and accepted... through participation and with a "freedom to fail." The approach was not viewed as a panacea, for they foresaw problems in defining and measuring performance. still, the advantage of such managerial responses was that it removed 
close and intensive supervision, and broadened the base of selfcontrol. Studies of control in public organizations supported these expansive views on managerial control processes (Hall, Jr., 1956; Lawlex \& Rhode, 1976; Turcotte, 1974). Mahoney and Frost (1977) suggested that staff development and committee meetings were alternatives to close supervisory activities for reciprocal tasks. Etzioni (1965, p. 655) recommended screening admission, on-the-job training, and social controls through work groups. And, more recently, Ouchi (1978) and Eisenhardt (1985) distinguished between behavior and outcome control mechanisms. Despite the empirical findings of conflict, multiplicity, and difficulty in determining standards and their measurement, the control of standards process provides a logical starting point for the analysis of managerial control. The results of oux preliminary study found that school principals (a) stressed school goals over individual goals and (b) used expressive, rather than instrumental language in articulating school goals. For each and every curricular and instructional task, principals offered a list of behaviors which went beyond the formal policies and prescribed patterns of behaviors. Even within mandated policies and directive checklists, principals considered certain behaviors more important than others. Their discretionary ideas and actions, however, in no way took issue with either district or state directives, even when the latter were viewed as being marginal or misguided. Nevertheless, they believed that school standards were not synonymous with those of the district or 
state. In some instances, principals labelled school standards as being higher than mandated requirements or frameworks; in other instances, the standards were simply viewed as different, often reflecting specific student needs and commity influences.

\section{Control of Information}

Ideally, control is mediated by the information (vickers, 1967, p. 20) transversing an organization through communication channels. Communication theorists have suggested that these channels are capable of influencing the distributions of beliefs, values, and behaviors of people within organizations (Krippendorff, 1986, p. 19). As such, information is inked to the concept of power. Bacharach and Lawler (1982) noted that later versions of the French Raven power bases model, in fact, included information as the sixth basis of power (p. 33). In an organization, it is both the structural characteristics of communication channels and the psycho-social-political dynamics of information which influence behaviors.

Koontz (1971) stated that "[0]ne of the frustrating problems in effective controls is to know what things to watch and how to select those critical factors in any situation that the manager must watch if he is to be assured that his actions are conforming to plans (p. 84). Frank (1958-59) argued that to enhance control there needed to be open communication channels. Yet, an open circuit is only one of many characteristics of communication channels within organizations (Katz \& Kahn, 1978, Chapter 14). 
Within cybernetic theory, information refers specificaliy to feedback information. The characteristics of a cybernetic control system is that it (a) detects critical information, (b) evaluates information (c) regulates and corrects behaviors, (d) is simple and quick, and (e) is on-going (MoManama, 1971). The key concept of cybernetics is self-regulation. Hence, information acts as a "mis-match" signal that sets-off the control process (Vickers, 1967). In order to activate the systern, however, the feedback response has to get back to the controller to serve as a basis for further action.

Research findings in communications' theory, political science, and social psychology provided numerous examples of breakdowns in cybernetic theory (Hofstede, 1978). A descriptive political framework depicts the uncertainty of information, complexity of issues in policy-making (Lindblom, 1959), and the participation of numerous key actors or groups, resulting in a non-rational theory of decision-making (Cohen, March, \& olsen, 1972). Among the more persuasive criticisms of purely rational frameworks are: (a) entropy of messages whereby information may be transmitted with unequal frequency or probability (Krippendorff, 1986, p. 15); (b) difficulty of selecting, detecting, or correcting information (Koontz, 1971); (c) evaluation of information, since standards are cultural or matters of choice (Hoy \& Miskel, 1982, p. 359; Sergiovanni, 1987; Tannenbaum, et al., 1974); (d) complexity and slowness of feedback (Claxk \& Astuto, 1988): (e) bogus or inadequate feedback 
(Patz \& Rowe, 1977), errox, and omissions (Katz \& Kahn, 1978), and, (e) difficulty of detecting or measuring information - even if it is on-going (Cohen \& Miller, 1980; Kippendorff, 1986, $p$. 16).

As a political mechanism, information is used in bargating, negotiating, and decisionmaking processes. As such, information and commication variables may be as important as rules and position (pfeffer, 1978a). Organizations can compensate for decreased task programmability and outcome measurability by increasing information systems (Eisenhardt, 1985). Thus, in complex organizations with complex technologies, information can play an important role in maintaining behavior control as an alternative to outcome control (Eisenhardt, 1985).

Ironically, "communication and information subsystems are often located disadvantageously in organizations" (Katz \& Kahn. 1978, p. 473). Turcotte (1974) reported that the amount of information, for the wrong reasons does not improve performance. Lawler \&hode (1976) found that not all information related to behaviors. Katz \& Kahn (1978) also disputed the Idea that the amount of information per se was a problem. In fact, shrode \& Brown (1977) found that managers spent an excessive amount of time on information-oriented decisions as opposed to eithex taskoriented or people oxiented decisions. Typical of statistical and control reports is that they "do not inform managers of what they need to know in order to control their operations (Koontz, 1971, p. 84). Rapoport (1965) found that "far less infomation 
is required to describe an orderly axrangement...than a disorderly one" (p. 236).

social psychology research has also provided examples of how people tend to seek out information that supports their own hypotheses, "while innocently ignoring disconfirming evidence... [People] typically select information to enhance their perception of control" (E. Langer, 1983). Selective infomation along with other communication breakdowns, therefore, have rendered rational theories, such as cybernetics and the thermostat model as inadequate (Hofstede, 1978; Sproul1, 1981).

Understanding the problems inherent in organizational. comunication is related to problems of measurement. The characteristics of communication channels are structural. Within this dimension, quantitative data, such as the frequency, redundancy, variety, and probability of interactions provide insights into organizational structure and patterns of behavior. Essentially, we can measure, non-parametrically, contentless frequencies. Yet, neither the organizational structure nor the frequency of communication interactions is a reliable single measure of information processes. "The "quantity of information' as a measure ...has no necessary (author's emphasis) relationship to the anount of semantic information conveyed by a statement" (Dechert, 1969, p. 70). As Rapoport (1965) succinctly stated, the quantity of information is a "big idea" (p. 226).

on the other hand, information may also be measured by qualitative data, such as the meaning, content, and utility, 
which cannot be understood solely through statistical analyses (Krippendroff, 1986). The ideas and concepts surrounding the studies of information and communication theories have become complex. This complexity is expressed by new technical terms used to describe communications. For example, the term, entropy, is used to measure diversity and variety of information (Krippendorff, 1986, p. 15). Specifically, entropy is a measure that removes uncertainty. Regulating uncertainty is essential to the health of an organization. Krippendorff (1986) in quoting Ashby's law of requisite variety, i.e. "only variety can destroy variety," held that "the survival of a system depends on its ability to generate at least as much variety within its boundaries as exits in the form of threatening disturbances from its environment" (p. 19). Support for this view extends to even the individual, whereby communication strategies are used to reduce uncertainty so that rules and goals can be internalized and accepted as a prexequisite for changing behaviors (Black, 1970; E. Langer, 1983).

\section{Control of Assessment}

The variables of organizational structure (e.g., size, levels, and technology) sinultaneously emphasize and constrain such managerial behaviors as rule-making, supervising, directing, and coordinating. At the center of these managerial behaviors is the process of evaluation. "In a rational system, evaluation is an indispensable process controlling task performances" 
(Dornsbusch \& scott, 1975, viii). What determines rationality is the effect that higher evaluations ought to reflect better performance and better effort (pp. 340ff). Evaluation is a "fundamental process to all human interaction and specifically in the operation of authority systems in organizations. Much that is right and much that is wrong in current organizations can be explained in terms of evaluation processes" (p.358). Accordingly, Dormbusch \& scott concluded that knowledge of evaluation must be applied and extended in order to "control the organizations that so often control us" (p. 358).

"The managerial function of control involves measuring and correcting actions to assure that plans are actualiy being achieved. It is the means by which the loop is closed in managing" (Koontz, 1971, p. 140). Action should be controlled by the observed difference between what is and what ought to be (Vickers, 1967), Nevo (1983) reported, however, that there was no agreement on any single best evaluation process. Evaluations can be made on numerous variables: definition, function, process, method, criteria, participants, among others (Nevo, 1983).

Most empirical studies of school evaluation processes seem to agree that structural, formal, bureaucratic evaluative features are weak or non-existent (Dornbusch \& Scott, 1975; Meyer \& Rowan, 1977). Under an institutional model of schools (Meyer \& Rowan, 1977; Meyer, Scott, \& Deal, 1983), a weak role for evaluation actually enhances professional trust and the "logic of confidence" within schools. Formal evaluations, on the other 
hand, serve only an externally directed, legitimating function. Given the central theoretical importance that Dornbusch \& Scott (1975) have attributed to evaluation processes, on the one hand, and the Iimited organizational role it plays in reality (Meyer \& Rowan, 1977), serious efforts to reformulate educational assessments have been proposed (The Joint committee on standards for Educational Evaluation, 1981). Dornbusch scott (1975), however, have noted research limitations when attention was restricted to a single task; therefore, in their own subsequent studies, they, too, have looked at multiple tasks and focused on the "generalized right to evaluate organizational performance." other alternatively proposed evaluative variables have been formative evaluation, goal-free evaluation, process evaluation, informal evaluation, and soft criteria of evaluation (Morris \& Taylor Fitz-Gibbon, 1978; Goldman, 1983). Much effort and resources have been expended to instill the goal of improved performance as the primary purpose of evaluation (Morris \& Taylor Fitz-Gibbon, 1978). Even formal instruments used in comprehensive teacher evaluation are designed to serve two functions: formative and sumative (Eliet, 1987). Yet, in spite of these proposed alternative theoretical efforts, and the almost inconsequential results of sumative evaluations - e.g., relatively few teachers are placed on prescription or judged unacceptable, the formative-improvement function has not generated formative-success measures that have been publicly tested. Perhaps vickers $(1967, \mathrm{p}$. 127) was correct in stating 
that it is seldom possible to make one set of standards serve both positive and negative control purposes.

Nevertheless, teachex evaluation systems "represent the largest investment. . that have direct implications for the instructional supervision role of school principals" (Ellett, 1987, p. 304). The teacher evaluation model adopted by Dade county, Florida schools follows a comprehensive system including orientations with performance expectations, pre-observation conferences, classroom observations, post-observation conferences, and follow-up prescriptions for teachers if needed (p. 320). No formal, district-wide system, however, has been implemented for the evaluation of any of the other curricular or instructional tasks. What appears to exist, however, are written procedures, state directives, and frameworks to guide practice along with informal systems developed at the school-building level for curriculum development and the selection of textbooks and instructional materials.

Even within the formal procedures of evaluation, there are two systens of personnel evaluation at the school level, one for managexs and another for teachers. In Dade county, Florida, performance appraisal systems are used for principals, while a behavioral checklist, the Teacher Assessment and Development System (TADS), is used for teachers. The former is indicative of the "soft" criteria for managerial evaluation which may include interpersonal style, whereas the latter, the "hard" assessment of "worker productivity generaliy focuses on clear easily measurable 
output" (Goldman, 1983, p. 339). A hard-soft metaphor has also been applied to school rules in general. Lortie (1969) noted that "soft" rules were used in formulating instructional policy, while "hard" rules were found in more easily codified areas. It may be thought somewhat misguided that managerial performance, instruction, and curriculum are evaluated softiy, whereas teachers who operationalize instruction and curriculum are directed and evaluated by hard criteria.

The irony is extended by vickers (1967) who stated that "generally speaking, the indices of control become less significant and less useful at progressively higher levels" (p. 29). In practice, this hypothesis reveals that there is less precision used to judge pexformance of those at managerial levels than for their subordinate workers. Likewise, the dominant technologies within schools, curriculum and instruction, are also guided by "soft" criteria. It is evident that a structural bias at the subordinate teacher level has contributed to this situation. Most certainly, the continued lack of clarity in managerial terminology and models has fostered idiosyncratic definitions of control, such that measures of behavior, performance, output, and results remain confusing (Bidwel1, 1965; Cartwright, 1965; Eisenhardt, 1985; Goldman, 1983; Ouchi, 1978, Peterson, 1984; Peterson, Murphy, Hallinger, 1987). The solution proposed here is to systematically integrate structural measures with qualitative measures of behavior and to reconceptualize managerial control as a dyadic concept apart from 
the central role of task supervision (Cohen \& Miller, 1980 ; Katz \& Kahn, 1978; Mahoney \& Frost, 1977; Miles \& Vergin, 1966; Patz \& Rowe, 1977; Turcotte, 1974).

\section{Control of Incentives}

According to Etzioni (1965), "organizational control structure is a distribution of means used by an organization to elicit the performances it needs and to check whether the quantities of such performances are in accord with organizational specifications" (p. 650). In theory, oxganizations must distribute sanctions on the basis of evaluations (Dornbusch \& Scott, 1975). The social-psychological assumption implied by this relationship is that an organization's participants must care about the rewards and punishments which are distributed. Both the theory and assumption of incentives, however, must be tested empirically within any organization, including public schools.

Teachers are salaried employees, with their salaries determined by seniority rather than by effort, outputs, or administrative evaluations of performance (Dombusch \& Scott, 1975, p. 336; Lortie, 1969). Throughout society, in fact, only 28 percent of all U.S. workers see a direct link between job performance and salaries (Kleiman, 1988). Nonetheless, Dornbusch \& scott (1975) included public schools under theix theoretical framework of evaluation (p. 336), primarily because of the role of intrinsic incentives in education - a process which Bossert. 
et al. (1982) have also identified as significant. Lortie (1969), however, admitted that data are not available on what principals actually do with respect to the reward system (p. 37). There is virtually unanimous agreement in the iiterature on rewards that teachers are more powerfully affected by intrinsic rewards - particulariy their sense of responsibility for student learning and their enjoyment of various social relationships (Mitchel1, 1987; Mitche11 \& Peters, 1988). The subjective rewards from students may quite likely have a greater effect on teachers than school-level administrative rewards (Lortie, 1969). Hanson (1981) reported that "administrators generaliy were 'keepers of intrinsic rewards.' By selectively praising some teachers in open gatherings..., the administrators were frequently able to direct others seeking such rewards in a desired direction" (p. 268).

Mitchell (1987) has made important distinctions among three concepts: motivation, rewards, and incentives. He has defined the latter system as the "planned and controlled distribution of rewards." The proper focus of control should be on the incentive system in ordex to study managerial activities and their effects. Thus, what is critical for a better understanding of what principals do is to measure the incentive distribution system and the meaningfulness of the specific rewards, such as praise and discretionary funds (Bossert, et aI., 1982; Cohen \& Miller, 1980) to teachers.

vickers (1967, p. 129) has stated that there is not one best 
pattern of rewards. Yet, "the use of rewards and punishments cuts across all the other conditions ffor change]" (Katz, 1965, p. 290). These two views are not at all contradictory. on the one hand, expectancy theory confirms that rewards, intrinsic and extrinsic, vary from individual to individual and from culture to culture; on the other hand, the distribution of organizational rewards, that is the control system of incentives has common attributes which affect attitudes and behaviors. people "strive to maximize the rewards in their extexnal environment and to minimize the penalties" (Katz, 1965. p. 279). "The clarity, consistency and nearness of rewards and punishments, as they relate to individual activities and goals, are important factors in the acquisition of... [new] attitudes" (p. 280), regardless of whether the sources are identified as human needs or job factors. 


\section{Indicators of Managerial Control Behaviors}

Quantitative and qualitative aspects of managerial behavioxs as well as processes of managerial control represent latent, aggregate variables which can only be measured indirectiy. on the other hand, observable indicators of managerial control behaviors can be measured directly within school contexts. It is upon this empixical foundation of observable indicators that the validity of theoretical constructs must be based.

within organizational theory, there are a number of empirical indicators which purportedly measure organizational structure. Meyer, scott, and Deal (1983) used individual perceptions of formal policies for a variety of tasks to demonstrate support for their hypothesized institutional model of educational organizations. Astuto and Clark (1985) counted the frequency of interactions as their sole measure of the quantity or structural interactions within their organizational coupling taxonomy. Other researches have measured structure by the frequency of interactions with respect to formal policies (Deal \& Cellotti, 1980) or informal policies (Hannaway \& Sproull, 197879). Still, others have ignored process measures completely and have simply looked at participants in decision-making (charters, 1971) or administrative roles (Rowan, 1982).

In each of the above instances, a single measure was used to define organizational structure. Although this study, too, limits organizational structure to a single measure, it does so in conjunction with other qualitative variables in order to more 
accurately depict organizational dynamics. The single measure which seems most applicable in defining the structure of schoollevel organizations is the frequency of formal and/or informal interactions within contextual managerial situations. In our judgment, the distinction between formal and informal managerial activities has not been supported by empirical findings here or elsewhere in the literature. Katz \& Kahn (1978) have reported positive correlations between informal and formal communication channels during normal operations. When used, the distinction has reflected a structural bias in research designs. To avoid this bias, the perceptual indicator of frequency or regularity of both formal and informal activities was used to measure the structural dimension.

In contrast to organizational structure, multiple qualitative indicators were needed for each managerial control process. As qualitative properties of distinct processes, the indicators differ from process to process. Thus, qualitative indicators for standards are different from those of information as well as for assessments and incentives. Essentially, the choice of the most salient behavioral indicators within the qualitative dimension is a continuing search for meaning.

\section{Indicators of standards}

Standards emerged as one of the managerial control processes primarily from sociological and psychological reseaxch studies. Group behaviors and professional roles establish norms or 
standards of performance. "By each interaction,...teachers and administrators confirm or erode the set of professional norms..." (Little \& Bird, 1987, p. 127). The hiring or selection process and socialization efforts tend to also influence standards (Etzioni, 1965). Yet, within this total social context, individuals have idiosyncratio, subjective goals. According to Katz (1965, p. 306), the idiosyncracy of standards makes [organizational] attitudinal change so difficult.

At the school builaing-level, the pxincipal plays the dominant role in the control of standards across all curricular and instructional tasks. Under the Dade County, Florida collective bargaining contract, the principal implements the district's formal teacher evaluation system. The individual school's curricular innovation efforts are either initiated or supported by the principal. The school administration schedules faculty meetings at which in-school staff development activities for teachers are fostered or ignored. And, while the state directs school districts to adopt state-approved textbooks, the curricular and instructional criteria for specific selection have been left to the individual schools, which may supplement statem approved texts and instructional materials.

\section{Clarity of standards.}

Clarity is both perceptual and qualitative, rather than quantitative. That is, it is logically distinct from quantitative attributes, such as multiplicity and diversity which 
may or may not be evident in school standards. Thus, the conditions for there being clarity of standards can still be met. even while pointing out ambiguity (The Joint comittee, 1981, p. 38) and acknowledging differences. Whis aistinction between logical dimensions of quantity and quality is particularly relevant in interpreting political and sociological findings of organizational conflict, diverse preferences, or multiple goals (Bidwe11, 1965; Cohen, March \& Olsen, 1972). These reported findings may be descriptively accurate (Charters, 1981; Miles \& Virgen, 1966; Frank, 1958-59; Hills, 1963; Hanson, 1981; Lortie, 1977), but they beg the question of clarity as it relates to managerial control.

Dornbusch and scott (1975) identified clarity of standards as one of the qualities of tasks. "clarity refers to the extent to which the instructional process is understood and can be specified" (Hallinger \& Murphy, 1987, pp. 179-203). Clear standards axe a prerequisite for deliberate action and are the minimum prior condition for successful implementation (Elmore, 1983). Only when standards are understood and considered legitimate do individuals voluntarily unleash creativity and energy (Miles \& Vergin, 1966). Clarity is essential for audience understanding, and provides for credibility and application (The Joint committee, 1981, p. 37). The specificity of a goal has been found to lead to a higher level of performance than do goals urging another to "do your best" (Locke, 1977).

clarity is sometimes related to adequacy of contextual 
information (Rapoport, 1965, p. 230; The Joint Comittee, 1981, p. 37). On the other hand, technical terms may devolve into statements that are empty of meaning or be so vague as not to have a contextual meaning. Linguistically, explicit and unencumbered statements, characterized by conciseness, logical development, well-defined technical terms may all be indicators of clarity (p. 37).

Context is deemed critical for control (Hallinger Murphy, 1987, pp. 179-203). Clarity is particularly needed in school management. Without precise knowledge, behavioraI norms and past experience tend to be substituted as the basis for action (Argyris \& Schon, 1982) - certainly not an optimum situation since the socialization of teachers as professionals have never been viewed as strong (Bidwell, 1965; Leiter, 1983; Lortie, 1969).

\section{Difficulty of standards.}

Under the nature of standards, the qualitative indicator of difficulty ranges from very difficult to very easy (Lawler \& Rhode, 1976). "[W]hen dealing with objects as complex and autonomous as persons, control is reduced to presenting a challenge so structured that it evokes the desired response" (Dechert, 1969, p. 77). Higher levels of performance have been unequivocally attributed to moderately difficult goals as opposed to easy goals (Locke, 1977).

It is not completely clear just what level of goal difficulty is optimal with respect to motivation. As far as 
intrinsic motivation, moderately difficult goals seem optimal.... In terms of extrinsic motivation, it is easiest to motivate achievement of easy goals because when goals are easy expectancy and the relationship between effort and performance] beliefs are high and this means that motivation will be high if rewards are tied to good performance (Lawler \& Rhode, 1976, p. 180, 20).

If the goal is unreasonably difficult, it will lead to rigid bureaucratic behavior, invalid data and resistance (Frank, 195859; Lawler \& Rhode, 1976, p. 98). Moreover, a history of failure has also been negatively associated with pexformance (Locke, 1977; Mann, 1978; McLaughlin, 1978).

A prerequisite to optimum performance is that the goals themselves are accepted as legitimate and some degree of internalization (i.e., ownership) has already taken place. Thus, it should not be surprising that top down directives, close supervision and monitoring, and "error avoldance" control strategies have not been generally successful within public organizations and schools. Turcotte (1974) reported that "error avoliance" mechanisms led to lower performance levels than did the use of higher expectations.

In line with these findings is one of the predominant characteristics of effective school reform, that is, high expectations of students by their teachers (Edmonds, 1979). If the characteristic of higher expectations is propitious for student learning, it would make sense that its efficacy would also be potent in teacher development and in the management of schools. Griffin (1988) summarized Rosenholtz' findings that teachers at the most effective schools perceived that teacher 
learning was a continuous process, whereas those teachers at less effective schools believed one could become a good teacher in just a few short years. Similarly, Little and Bird (1987) found that teachers gave their highest approval to observation and evaluation systems that were extensive and demanding, rather than to systems that sought to detect and correct performance.

\section{Indicators of Information}

Information is the medium of communicative exchange. Its preeminence emerged primarily from research findings of organizational complexity and political dynamics. pfeffer (1978a) viewed information to be as important as either structure or rules.

Katz (1965, p. 275) and E. Langer (1983) both reported that simply increasing the flow of information did not necessarily increase knowledge gained by information. "[N] information will not modify old attitudes unless there is some inadequacy or incompleteness or inconsistency in the existing attitude structure as it relations to the perceptions of new structures" (Katz, 1965, p. 284). In fact, "to increase the order of anything means to make it describable with less information" (Rapoport, 1965, p. 237). Thus, information systems cannot solely be measured by structural-frequency variables.

The two qualitative indicators of information, adequacy and utility, correspond to the sender-receiver relationship in comnunication theory. Adequacy of information measured 
subordinates' beliefs as to the quality of information across curricular and instructional tasks. Utility of information measured subordinates' perception of the use made of the information which they provided to school administrators across curricular and instructional tasks.

Miles and Vergin (1966) and Koontz (1971) have described the need for quick feedback given simply and visibly in a common language, understandable to those who take action (Koontz, 1971, p. 142). Similarly, Black (1970) and E. Langex (1983) called for Ianguage to be compressed and digestible. Lawler \& Rhode (1976) reported that individuals with higher order needs, those most influenced by intrinsic motivation, needed feedback (p. 73), but that "supervisors tended] to be poor and unreliable givers of feedback" (p. 74).

Within schools, there are numerous opportunities for information to be conveyed from the principal to teachexs: an annual orientation to explain the school's goals, staff meetings devoted to improving curriculum and instruction, an annual review of the formal teacher evaluation system, grade-level and department meetings, the posting of schedules for in-service training sessions, informal hallway meetings, a principal's open door policy, public address announcements, and, arranging for experts to inform the faculty in diverse axeas from curricular innovation to new textbook publications. The reciprocal process of information from teachers to principals includes many of the above forums as well as reporting documentation (e.g., student 
progress reports) and private meetings initiated by faculty to make curricular proposals and recommendations of textbooks and instructional materials.

\section{Adequacy of information.}

Complete information was held to be a requirement of the rational decision-making model (Dye, 1984). Under the political analysis of decision-making, the emphasis shifted from rational certainty to empirical or pragmatic uncertainty. The qualitative indicator, adequacy, reflects this transition from rationalism to incrementalism (Lindblom, 1959) and "satisficing" (Simon, 1957). While the content of the information is still considered rational, the process relies on getting adequate, rather than complete information, to people (Katz, 1965, p. 274.).

A problem with information is not that there is not enough information (Katz \& Kahn, 1978); on the contrary, there is usually an overload which needs to be avoided (Lawler \& Rhode, 1976). Putting information within a context may help in its interpretation (The Joint Committee, 1981, p. 104).

\section{Utility of information.}

"Most individuals who maintain information and control systems like to believe that the reports they prepared are useful for decision-making by managers and external parties" (lawler \& Rhode, 1976, p. 137). But, in fact some reports are prepared only for legal reasons, and are not used. 
In a variety of organizational settings, Lawler and Rhode (1976) and Masland (1984), among others, have recognized a need to motivate decision-makers to use information. certain characteristics of information seen to increase its chances for utilization. A short list suggests that it should be understandable, objective, timely, practical, beneficial, and persuasive (Lawler \& Rhode, 1976; The Joint Comittee, 1981, p. 13, p. 156). of course, there is empirical evidence indicating that informational data are not always valid (Frank, 1968-59) or heard (E. Langer, 1983). In order to overcome these situations, managerial control of information must rely on other control processes, especially the assessment and incentive processes which have relational (i.e., interpersonal) as well as contextual (i.e., task) attributes. Although Shrode and Brown (1977) found that lower-level managers [in business] often spent too much time on information-oriented decisions, they would also spend insufficient time on peoplemoriented decisions. The utility of an information indicator is as much a people-oriented activity as it is information-oriented.

\section{Indicators of Assessment}

The costs of implementing managerial control systems are high, particularly it seems when it comes to evaluation and incentive processes. Not only are formal teacher evaluation programs the most expensive in terms of a dollar investment with respect to principals' supervisory duties (Ellett, 1987), but the 
systematic assessment of all other curricular and instructional tasks would involve substantial dollar costs as well as enormous time and effort commitments throughout the school organization. Regardless of the actual costs, there is a general lack of formal evaluations conducted for curriculum development, staff development, and school building-level selection of texts and instructional materials. What ittle formal evaluation which does take place has been generally described as superficial (see Chapter Three).

\section{Worth or assessment.}

Evaluation has been considered a fundamental process of organizations (Dornbusch \& Scott, 1975, p. 358) and central to the distribution of sanctions (p. 337). "people in all fields make choices, and it is inconceivable that they should do so without assessing the worth of or merit of options" (The Joint Comittee, 1981, p. 5)。

From The Joint Comittee Report, three criteria were expressed to support a judgement of worth: (1) that the evaluation must be comprehensive enough (p. 27); (2) that the evaluation procedures must be practical and not just a theoretical concept (p. 52); and, (3) that the evaluation results would be of "Iittle interest or use if it [were] not intexpreted against some pertinent and defensible idea of what is good and what is bad" (p. 32).

The sentiment among the sample of school principals in the 
preliminary study seemed to be that formal evaluations were not worth the time and effort since they would not provide the kind of information useful to school practitioners. Eliciting teacher judgments as to the worth of evaluations would obviously be limited in the absence of any formal evaluation procedures or an awareness by teachers of the criteria of evaluation. Nevertheless, the qualitative beliefs of teachers as to the worth of evaluations may have valid measures across even those curricular and instructional tasks which lack formal evaluation procedures.

\section{Fairness of assessment.}

Blase (1988) has reported on the negative effects among teachers resulting from the perception of favoritism. Among the results were lower motivation, a feeling of a loss of control, and a reduction in effort. In Dade county, Florida, the primary concerns of the teacher's union before it could support a comprehensive teacher assessment and development system, TADS, were (a) objectivity, (b) standardization, (c) fairness and equity, and (d) due process (E1lett, 1987).

The rational bases for evaluation is the predictability of the relation between task procedures and outcomes and the belief that better performance will receive higher evaluations (Dornbusch Scott, 1975). Moreover, legitimate authority systems are considered more proper than an unauthorized system of power (Dornbusch \& Scott, 1975). Thus, the qualitative indicator 
of fairness favors rational and formal authority structure.

Two other qualities related to faimess are impersonality and objectivity. Both can be met through a fair or balanced "presentation of strengths and weaknesses... so that strengths can be built upon and problem areas [can be] addressed" (The Joint comittee, 1981, p. 90). Fairness does not imply, however, an equal number of strengths and weaknesses. Therefore, qualitative data other than frequency counts are necessary to measure the perceptions of fairness.

The only empirical Dade County, Florida data concerning fairness of assessments come from teacher ratings of TADS in which 93 percent of the teachers rated the comprehensive teacher evaluation system as fair; 65 percent thought it would improve quality of instruction (Ellett, 1987, p. 315).

\section{Indicators of Incentives}

support for the inclusion of incentives as an essential managerial control process was found primarily within the literature of psychology. The emphases, however, were placed on the theories of motivation and the role of xewards (Mitchell \& Peters, 1988). The distribution of rewards, or incentives, is a managerial function. The formal system of incentives within schools is decidedy non-individualistic. That is, the extrinsic rewards of salary, for example, are distributed on the basis of seniority and roles rather than on individual performance. In Dade county, Florida, there is a district-wide merit-school 
program, but no merit-teacher program.

Measuring educational rewards and the system of incentives is somewhat problematic. Dornbusch and scott (1975) have included educational organizations in their theory of evaluation based on findings that other, intrinsic, rewards played a big role in the performance of educators (p. 336). Griffin (1988) has described educational rewards as both tangible and intangible. The former range from stipends for assuming extra responsibility to access to resources to released time from classroom teaching (pp. 253-255). Intangible, symbolic rewards, however, are "remarkedly barren" (p. 254). "[W] here are the celebrations of outstanding professional behavior and consequences of that behavior? Where are the recognition points in a teacher's career?" (p. 254). Sieber (1981) found that professional knowledge utilization efforts offered teachers compensatory incentives only under special conditions, and that the social costs of such efforts tended to exceed the perceived benefits (p. 162).

The managerial control process of incentives measures how rewards are procedurally distributed as well as their subjective valences. The qualitative indicator for implementation is equitable distribution. The gualitative indicator measuring the "reward-value" or the amount of satisfaction, pleasure, fulfillment (or their opposites) that the rewards are capable of producing is the meaningfulness of the rewards themselves. Within the context of school building-level organizations, 
there are limited resources. To a large extent, it is left to the managerial skills of principals to respond positively to teachers" requests. Whereas discretionary actions characterize the educational reward system, formal procedural guidelines and policies seem to most often govern negative sanctions. Consequently, more school building-level reward activities are found within the discretionary or informal sphere than within the formal structure.

\section{Meaningfulness of incentives.}

The litexature on motivation theory has been subdivided between (a) the needs of individuals (e.g., Maslow, Mccelland) and (b) the subjective values which individuals ascribe to rewards and punishments (e.g., vroom). It is primarily through the latter framework of expectancy theories that the meaningfulness of rewards is essentialiy defined as independent of objective reality. That is, the value placed on any reward or punishment is an individual, subjective determination. Rewards can be meaningful regardless of their extrinsic or intrinsic origin (Lawler Rhode, 1976, p. 59), and regardless of how they may be classified, hygienic or motivational (Herzberg, 1978). Yet, for the evaluation process to function rationally and predictably, the rewards and penalties must be meaningful to the organizational participants (Dormbusch \& Scott, 1975, p. 336) as a whole, not just to individuals.

Under extrinsic motivational factors, salary, promotion, 
dismissal, and interesting work rate high on importance (Lawlex \& Rhode, 1976, p. 59). Praise is viewed as moderately important and incurring low costs, while intrinsic motivation relates to most closely to individuals with high order needs (p. 66). As for the difference between rewards and punishments, both demonstrate highly variable results, but praise has been generally shown to be more effective (Locke, 1977).

Central to intrinsic motivation is that the job must be meaningful and worthwile to the individual (Lawler Rhode, 1976, pp. 78-80). Ames \& Ames (1987) found that teachers have a high intrinsic motivation rewards system, rating high the importance of teaching as a work activity, their beliefs as to the importance of teacher competency, their enjoyment of teaching, and the time spent with students. These high scores indicated that teachers took more responsibility for outcomes and had a strong belief in effort-outcome correlation.

\section{Equitable distribution of incentives.}

"It is a well known principle of learning that the efficacy of reward and punishment decreases as the time lag between the response and the administration of reward and punishment increases" (Schein, et a1., 1961. p. 182). In addition, "[c]onsistency of reward and punishment also contributes to the clarity of the instrumental object for goal attainment" (Katz, 1965, p. 280). Thus, as a general ruie, the control of incentives ought to be applied quickly and consistently (Katz, 
1965, p. 302) in order to establish a perception of equitable distribution.

The implementation procedures of an incentive system, therefore, evoke significant qualitative variables independent of the content or meaning of rewards and punishments (Nacoste, 1985). Since individual teachers ascribe subjective meanings to rewaxds, an incentive system which focuses on individuals is likely to have unreliable measures and cause alienation and favoritism (Blase, 1988; Mitche11 \& Peters, 1988). On the other hand, if the emphasis of the school reward system focuses on aggregate groups, such as programs and departments as well as whole schools, the perception of an equitable distribution of rewards creates a positive climate, a necessary attribute of good schools (Mitchell Peters, 1988). Thus, the indicator of equitable distribution of rewards may be the foremost procedural quality of incentives.

\section{Summary of Indicators}

There are phenomenological indicators belonging to each of the managerial control processes wich influence "cognitive, affective, and behavioral aspects of the work situation" (Blase, 1988, p. 174). Although there is a conspicuous lack of data describing daily school-level managerial activities, each of the indicators selected have been anchored in specific managerial behaviors. Moreover, these phenomenological influences extend even to implementation procedures (Nacoste, 1985): that is, 
structural procedures which themselves influence a variety of individual responses.

The appropriate evidential support for understanding managerial processes and behaviors must rely upon teacher beliefs (Andrews, 1987; Ames \& Ames, 1987; Mitchell, 1987, p. 226)

inferred directly from verbal reports (Locke, 1977, p. 183). The importance of the qualitative aspects have been summed up by Landy, Zedeck \& Cleveland (1983) who wrote that "[a]n organization with a positive climate and employees with strong commitment can replace a performance-appraisal system that monitors and controls employee performance."

To summarize, the phenomenological aspects of qualitative indicators used as measures of managerial control processes are as follows:

clarity: a cognitive pexception related to the administrators' skill in communication of standards

Difficulty: a cognitive and affective perception of task standards

Adequacy: a cognitive perception related to the administrators' skili in communication of useful information

Utility: an relational perception related to the belief that information is used in managerial decision making

Fairness: an affective and proceduxal indicator related to the balanced use (e.g., objectivity) of assessment measures

Worth: a cognitive perception related to the organizational effort needed to conduct systematic evaluations; and, an affective indicator reiated to individual effort as well

Meaningfulness: an affective indicator of individual needs related to the rewards and penalties of an 
organization

Equitable Distribution: a procedural indicator related to the implementation of rewards and punishments

\section{Conclusions}

The aiscussion of managerial control processes and behavioral indicators fulfills the first research objective of the study. The literature reviews presented numerous suppositional and empirical definitions ascribed to the concept of control. Although no comprehensive framework emerged from the social science disciplines, there were key signposts indicating which next steps needed to be taken. It was evident across empirical studies that control mechanisms varied according to organizational settings; therefore, a study of school building control activities was needed as a preliminary step in order to test for the presence of school managexial control.

It was also evident across studies that the language of control needed to be systematized. The aims of such an effort would be threefold: (1) a more precise statement of theory; (2) better empirical indicators of managerial control activities; and (3) improved communication and generalizability (Hughes, Price, \& Marrs, 1986). In Chapter Four, the latent, aggregate concepts have been explicitly stated. A logical process model provided the framework within which specific managerial activities could be categorized. At the empirical level of measurable indicators, specific managerial activities were categorized by quantity and quality, the former indicative of structure, whereas the latter 
characterizes managerial discretion.

The study now proceeds towards the development of a valid and reliable scale of school managerial control based on the hypothesized model. 


\section{CHAPTER FIVE}

\section{Procedures and Methods}

\section{Introduction}

Most discussions of organizational dynamics remain at abstract and theoretical levels because the concepts used have not been empirically established. This is as true for managerial processes as it is for organizational paradigms. The terms standards, information, assessment, and incentives - activities which are performed at the work level - are themselves latent variables comprised of multiple factors. Each factor, therefore, needs to be uniformly measured in order to unify and validate the meaning of the theoretical construct of managexial control.

Measurement involves the systematic identification of observable indicators. Based on logical categories of judgment, the indicators have been categorized into quantitative, qualitative, and relational items anchored in the unique contextual configuration of the particular organization being studied. The lack of progress made in defining school managerial control is directly attributable to the absence of measurable, behavioral indicators for each of the managerial processes.

The apparent simplicity of school organizations contrasts sharply with the documented complexity (Lortie, 1977), such that neither formal institutional descriptions (Dye, 1984), bureaucratic characteristics, nor single entity neasures provide adequate explanations to undexstand school organizations and behaviors. It is becoming more evident that the so-called 
dysfunctional aspects of school organizations are, in fact, prototypical of other complex organizations (Weick, 1985, p. 115), and that the logic of open systems analyses is compelling (M. Harrison, 1987; Thompson, 1967).

The primary objectives of this research have been to establish empirical indicators of managerial control and to test their theoretical validity and statistical reliability within school organizations. Despite the exploratory nature of the study, the spirit of the analysis was confimatory in that it sought to test specific hypotheses about the construct of managerial control which were dexived from published social science literatures and the empirical study conducted preliminarily for this research (see chapter three).

\section{Sample population}

The subjects in this study were pubiic school teachers (Nw48) working within Dade County, Florida, the largest of sixty-seven school districts in the state of florida and the fourth largest school district nationally. The teachers were all employed at one of fourteen (14) schools which were selected on the following sampling criteria:

- Principal Tenure: In each of the fourteen schools, the principal had been in office for at least three consecutive years at the same school.

- Meritorious Recognition: Seven schools were selected because they had received meritorious recognition by the county at least two times during the first three years that the nerit school program was established. The district's designation for a merit school was based on improvement in reading and mathematics on stanford 
Achievement Tests, participation in a physical fitness program, and school-wide projects. Students' scores were statistically compared with similar students by grade leve1, sex, ethnic group, income group, and prior scores.

The seven mexit-schools selected were then matched with other schools having similar racial and ethnic backgrounds and where the principal also had at least three years tenure. Two of the schools in this matching group had actually received a second level designation of merit-school for one year under broader criteria of recognition.

- Instructional Leve1: each instructional level was represented in the sample as follows: four high schools, four junior high schools, and six elementary schools. The two additional elementary schools were included because of their smaller faculty size in contrast to junior and senior high schools.

The sample population permitted some exploratory testing of statistical differences among (a) schools (P. Blumenfeld, personal communication, January 1, 1989), (b) levels of instruction (Corcoran, 1985), (d) size (Peterson, 1984), (e) tenure (Applewhite, 1965), and (f) school effectiveness (Peterson, Hallinger, \& Murphy, 1987; Wellisch, et al., 1978). In order to conduct a large scale survey of teachers, approval for the study was received from the school district's central office. The granting of approval was made contingent upon agreement from individual school principals to conduct the study at their schools (Appendix C). Pxincipals of the fourteen schools were mailed a letter describing the purpose of the study and requesting the school's participation and assistance in the dissemination and collection of the questionnaire. Out of the fourteen schools originally chosen for participation, only one school principal, at the high school level, refused to 
participate. That school was replaced with a two-tire merit winner.

The sample survey population of classroom teachers is presented in Table 12. Of the 907 teachers surveyed, 523 were employed at the four senior high schools (S1 to S4), 182 at the four junior high schools ( $\mathbb{1} 1$ to $J 4$ ), and 202 at the six elementary schools (EI to E6). The symbol (M) after the school abbreviation designates a district merit school.

Table 12

Sample Survey Population: Classroom Teachers per school

Elementary

Schools

EIM 47

E2 36

E3M 39

E4 28

E5 35

E6M 17

Elementary School

Total 202

Merit School Total:

Matching School Tota1: 431

Grand Total: 907
Senior High Schools High Schools

S1 $\quad 122$

S2M 152

\$3M 122

S4 127
Senior High

Total 523 


\section{Instrumentation: Questionnaire}

The decision to develop a survey questionnaire to measure the theoretical construct managerial control - as opposed to using an existing standardized instrument - was based on the needs (1) to study building-level processes unique to school curricular and instructional tasks, and (2) to establish a basis for the construct validity of the concept of managerial control within school organizations. No standardized questionnaire has been designed to meet either of these primary objectives.

All of the standardized questionnaires on organizational attitudes and behaviors lack school contextual situations, particularly with regard to curriculum and instruction. The Michigan Organizational Assessment questionnaire (MOAO), the Organizational Assessment Inventory COAI, and the Survey of organizations [which has not been updated since 1972], (M. Harrison, 1987, p.140) all provide technical information on scale development and have validity and reliability measures. Both the MOAQ and OAI reflect muli-organizational perspectives which incorporate environmental, tasks, technology, personnel, history, and organizational size variables (M. Harrison, 1987, p. 65-66).

The disadvantages inherent in adapting a standardized instruments were persuasive. While it is possible to draft situation-specific questions to be included within the standardized instruments (M. Haxrison, 1987, pp.63-66), Converse and Presser (1986, p. 51) and Schuman and Presser (1981) have warned of the negative effects on validity and reliability as a 
result of borrowing questions and creating a new question order and context. Furthemore, most of the shorter organizational. instruments (a) do not provide any technical data, (b) were designed for workshops and training, or (c) were not developed specifically for school organizations (M, Harrison, 1987, pp.14014I). Only the Job Diagnostic survey (developed by Hackman \& oldham, 1980) seemed potentially useful since it focused on job characteristics that affect motivation.

\section{Item construction}

In the preliminary study, principals and informants were asked about the goals of each of the four instructional tasks, how those goals were communicated and implemented, the criteria and assessment behaviors used to distinguish success or deviance from the goals, and what recognition and sanctions were used. The interview questions were task specific, yet allowed for openended responses and for follow up clarification. other questions referred to the organizational framework used in each task and envirommental impact on curriculum and instruction, i.e., state and district mandates, the collective bargaining contract, and parent-community partioipation.

The findings from the principals" interview study (see Chapter Three) were used to develop the teacher survey questionnaire. To a large extent, linking data from different sources is an interpretative process requiring judgment and choice (Fielding \& Fielding, 1986, p. 5). However, others, such 
as wellisch, et al. (1978) have combined case study data from principals with survey data from teachers.

The managerial control questionnaire is made up of fortyeight questions in which four curricular and instructional tasks are measured under the four managerial control processes. The four control processes are standards, information, assessment, and incentives - each measured by twelve items the terms items and indicators are used interchangeably (stevens, 1986, p. 337); variables refer to the aggregation of items] representing specific curricular or instructional tasks: teacher evaluation, staff development, curricular development, and the selection of textbooks and instructional materials. Based on the interview findings, the questions were also designed to differentiate formal and regular structural behaviors from discretionary aspects of managerial activities. Thus, sixteen items contained a frequency measure of building administrator-teacher interactions (defined as structure); while, thirty-two items measure discretionary qualities of managerial behaviors (defined as discretion). Two additional questions were added to the questionnaire to measure teacher satisfaction with (a) their own job and with (b) their current building administrators.

The questionnaire instrument developed for managerial control employs unidimensional scaling of teacher responses. At this stage of analysis, to hypothesize multidimensions of managerial control without first measuring how teachers respond to a particular attribute of managerial control would be 
theoretically unwise (Mcrver \& Camines, 1981, p. 14).

The sixteen frequency indicators measure school structure, stability, and regularity; the thirty-two discretionary indicators measure salient behavioral qualities for each of the control processes. Table 13 provides a listing of abbreviations for the specific indicators.

Table 13

School Managerial control Variables and Their Abbreviations

Curricular and Instructional Tasks

Teacher Evaluation TE

Stafe Development SD

Curriculum Development $\mathrm{CD}$

Selection of Textbooks and Instructional Materials ST

Contro1 processes and variables

standards $\mathrm{s}$

Frequency

Clarity $c$

Difficulty $D$

Information I

Frequency $\mathrm{F}$

Adequacy a

Utility U

Assessment $A$

Frequency $\mathrm{F}$

Fairness

Worth W

Incentives I'

Frequency $F$

Meaningfulness M

Equitable Distribution 
Multiple questions for each variable are used to avoid overgeneralizations caused by single item responses to global questions (Schuman \& Presser, 1981, p. 313). This procedure is usually more reliable than single-item measures (McIver \& Carmines, 1981, p.15). Each question contains a concrete situational reference to aid recal1 (Sudman Bradburn, 1983, pp. $72-73$ ) and to link teacher responses to overt behaviors (Schuman \& Presser, 1981, p. 243). Jastly, question order was randomized to avoid any sequencing effects (Schuman \& Presser, 1981, p. 54).

\section{Pre-Test procedures}

Pre-testing of the survey instrument was conducted in two stages on a sample population similar to the study population (Coverse \& Pressex, 1986, p.68). The first pre-test objective was to claxify the meaning of each of the questions. In extended discussions of 1 to 2 hours each, a small sample ( $N=5$ ) of Dade County, Florida public school teachers at the three levels of instruction reviewed and discussed the questions, offering suggestions on language to bring greater clarity to each question. The first session was held with only one teacher, while the subsequent two sessions used pairs of teachers. After each pre-test session, the questionnaire was revised to incorporate the suggestions offered. With each session, there were progressively more items on which both the teacher and researcher could agree. Initial response agreements reached on the meaning of each question progressed from 13 questions at the 
initial session to 28 questions and ultimately to 34 questions out of 48 items. Disagreements generally focused on the specific use of a technical tem found within the school district or the state education department or concerning the source of control. Question stems which included only the principal were adjusted to include the phrase "or other school administrators" so that the questionnaire would have greater content validity for junior and senior high schools which employ assistant principals.

The second stage of the pre-test procedures involved recording responses to the questionnaire in order to (a) measure response variability and internal consistency of the items, finalize the order of presentation, and (c) establish time parameters (Converse \& Presser, 1986, pp. 54-55). Twenty-one completed questionnaires [out of 27 administered] were judged suitable for response analysis. The teacher-subjects were all graduate students in education at a nearby state university campus. They were asked to respond to managerial behaviors by choosing one of four responses: strongly agree, agree, disagree, and strongly disagree. The responses identify whether teachers believe the task specific managerial behavior occur within their own schools and strength of that belief. Means, standard deviations, cronbach Alpha coefficients, and corrected iten-tom total correlations were analyzed. The stems of the items with low corrected item-to-total correlations $(<, 40)$ and low squared multiple correlations [not shown in Table 141 were revised to be more syntacticaliy consistent with those items in the composite variable that had higher correlations. Table 14 provides a 
statistical sumary of the pre-tests results. Similar data on the final version of the smce have been reported in chaptex six to facilitate comparisons with the pre-tested instrument.

Table 14

pre-Test statistics on the sMC Questionnaire

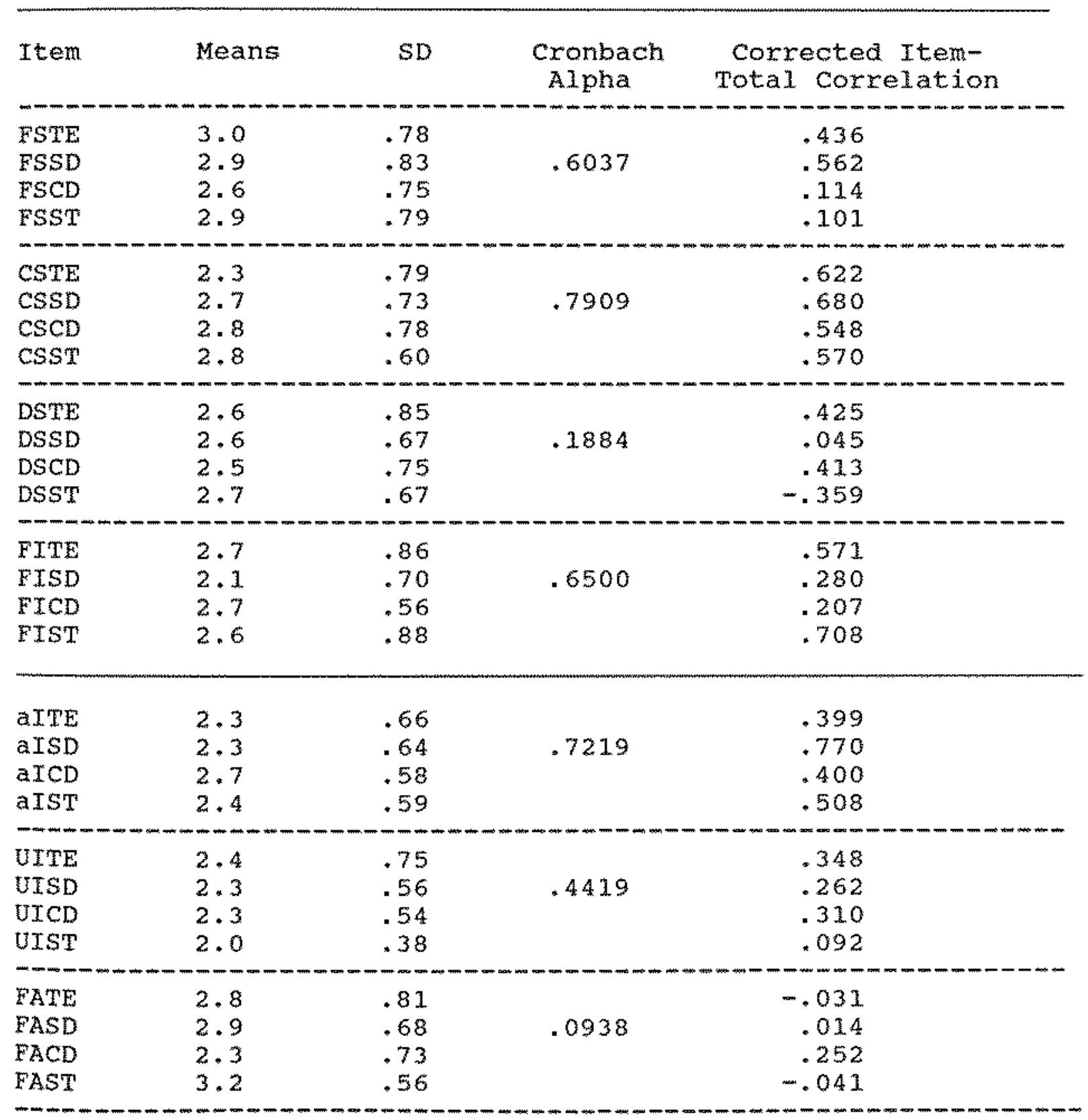




\section{Table 14 continued}

$\begin{array}{lllll}\text { EATE } & 2.1 & .54 & & .325 \\ \text { fASD } & 2.6 & .74 & .5938 & .587 \\ \text { FACD } & 2.4 & .67 & & .379 \\ \text { fAST } & 2.4 & .60 & & .234\end{array}$

$\begin{array}{lllll}\text { WATE } & 2.5 & .83 & & .653 \\ \text { WASD } & 2.5 & .76 & .7142 & .421 \\ \text { WACD } & 2.3 & .86 & & .721 \\ \text { WAST } & 2.0 & .56 & & .246\end{array}$

\begin{tabular}{|c|c|c|c|c|}
\hline $\begin{array}{l}\text { FI'TE } \\
\text { FI'SD } \\
\text { FI'CD } \\
\text { FI'ST }^{\prime} \mathrm{CD}\end{array}$ & $\begin{array}{l}2.5 \\
2.3 \\
2.6 \\
2.3\end{array}$ & $\begin{array}{r}.87 \\
.85 \\
.68 \\
.44\end{array}$ & .6773 & $\begin{array}{l}.482 \\
.619 \\
.409 \\
.384\end{array}$ \\
\hline $\begin{array}{l}M I I^{\prime} T \\
M I^{\prime} \mathrm{SD} \\
M I^{\prime} \mathrm{CD} \\
M I^{\prime} S T\end{array}$ & $\begin{array}{l}2.4 \\
2.1 \\
2.0 \\
2.0\end{array}$ & $\begin{array}{r}.81 \\
.73 \\
.89 \\
.59\end{array}$ & .5280 & $\begin{array}{r}.111 \\
.547 \\
.400 \\
.279\end{array}$ \\
\hline $\begin{array}{l}\text { EI'TE } \\
\text { EI'SD } \\
\text { EI'CD } \\
\text { ET'ST }\end{array}$ & $\begin{array}{l}2.7 \\
3.0 \\
2.4 \\
2.2\end{array}$ & $\begin{array}{l}.85 \\
.76 \\
.59 \\
.94\end{array}$ & .6395 & $\begin{array}{l}.306 \\
.567 \\
.518 \\
.362\end{array}$ \\
\hline
\end{tabular}

Overall Alpha $=.8658$

In addition to item revisions, the response options on the sMce were increased from four to six (B. Greenberg, personal communication, February, 1, 1988; P. Johnson, personal communication, February, 4, 1988). At the request of the Dade County Public school Research Review Committee, a seventh Don't Know option was added. Further changes regarding item language and demographic infomation (B. Greenberg, personal communication, February, 1, 1988) were also made before the final version of the questionnaire was administered to the sample survey population. 


\section{School Managerial Control Questionnaire (SMCQ)}

Teacher survey responses to the individual items were measured along a 6 point Likert-type scale: For example, item 10 reads:

All grade levels, departments and programs at my school are evaluated on an equitable basis

Strongly Disagree (6), (5), Disagree (4), Agree (3), (2), Strongly Agree (1).

The Don't Know (DK) option was given a value of 0 . Likert scaling employs a single stimulus and a single type of response on which to scale subjects (McIver \& Carmines, 1981, p. 9).

All of the questions reflected a positive bias. The response order, however, began with the negative choice "strongly disagree" in order to counter both a primacy effect which generally occurs by the response order (Schuman \& Presser, 1981) and an agreement response bias $(p, 177)$. In order to force value and attitude choices (p. 313) as well as increase the number of usable responses, there was no midale alternative. According to Schuman and presser (1981, p. 301) approximately 25 percent of the sample may be affected by the Don't know response, although the distribution of responses is not likely to be noticeable.

The items on the SMC questionnaire were placed in a random order. To assist in data analyses, however, the items on the questionnaire are presented in Table 15 by their aggregate variables beginning first with the frequency of standards items. The abbreviations follow the outline presented in Table 13 . In the parenthesis after the written item, the actual placement on the SMCQ has been indicated. 
Table 15

Items on the school Managefial control questionnaire (BMCQL

Arranged by Aggregate Variables

Standards

FSTE: The principal or other school administrator frequenty reviews good teaching practices with teachers (item 6)

FSSD: Each year, the principal or other school administrator sets in-service and professional growth guidelines for me and the other teachers (item 33)

FSCD: The principal or other school administrator frequently communicates schoolwide objectives for meeting state and county curricular goals (item 16)

FSST: Whenever I am selecting textbooks and instructional materials for my classes, my school administration reviews the criteria for selection to be used (item 45)

CSTE: In my opinion, the principal or other school administrator states cleariy the classroom teaching behaviors that she/he values most (item 11)

CSSD: The principal or other school administrator makes it clear how inservice workshops and staff development opportunities offered at my school relate to my classroom teaching (item 22)

CSCD: The principal or other school administrator makes it clear how state and county curricular requirements are to apply to my school, my students, and to the courses I teach (item 5)

CSST: criteria for selecting textbooks and instructional materials established by my school administration are clear (item 50)

DSTE: The teaching behaviors that my principal would most like to see in the classroom are more difficult than those in TADS (item 31) 


\section{Table 15 continued}

DSSD: The principal keeps raising the standard of performance expected of me as a teacher (item 24)

DSCD: The principal expects the academic course requirements for my students to be higher than state and county standards (iten 32)

DSST: The principal expects me to find the best available materials even if I have to go outside the list of state adopted textbooks (item 46)

\section{Information}

FTTE: The principal of other school administrator frequently provides me and the other teachers with information about TADS and other effective teaching behaviors (item 41)

FISD: My school administration frequentiy sends me information regarding staff development opportunities and activities (item 37)

FICD: MY school administration frequentIy sends me information on new ideas in curriculum and instruction (item 49)

FIST: Information is regularly available to me at my school regarding the publication of new textbooks and instructional materials (item 34)

aITE: I consider the information I receive from my school administrators regarding teacher evaluation to be adequate (item 7)

aISD: The information I obtain from staff meetings and inservice activities held at my school give me an adequate understanding of how to do my job well (item 8)

aICD: My school administration provides me with adequate information to participate in curxicular planning and innovative projects (item 28 )

aIST: The information I receive through my school administration regarding published material is adequate for deciding on texts and instructional materials (item 39)

UITE: The principal uses the information from classroom observations to generally improve the caliber of teaching at my school (item 38) 


\section{Tab1 15 continued}

UTSD: The school administration keeps records of the participation and progress of teachers engaged in staff development (item 44 )

UTCD: My school administration uses teachers ideas in developing and/ox implementing curmiculum (iwem 47)

UTST: My school administration accepts teachers" input on which instructional materials to use in the classroom (item 48)

\section{Assessment}

FATE: The process of evaluating teachers occurs at my school more otten than just: when $I$ am being observed for TADS (item 4)

FASD: The school administration evaluates each staff development workshop or TC inservice session offered at my school (item 43)

FACD: The principal and the school administration regularly monitor what I an teaching through a variety of ways (e.g., the lesson plans and objectives, class visits, etc.) (item 26)

FAST: My school evaluates textbooks and instructional materials more requentiy than the time-tables established by the state or county (item 42)

EATE: The criteria used by the principal and other school administrators to evaluate classroom teachers are fai (itern 40 )

EASD: I would say that the principal and administrative staff have an accurate assessment of the professional needs of teachers (item 21)

fACD: All grade levels, departments and programs at my school are evaluated on an equitable basis (item 10)

fAST: The procedures used at my school for selecting textbooks and instructional materials give a fair assessment to the alternative choices (item 13)

WATE: Time and effort devoted to classroom observations, both formal and informal, have been worthwile to me as a teacher (1tem 29) 


\section{Table 15 continued}

WASD: Time and effort devoted to the evaluation of inservice staff development and training workshops given at my school are worthwhile (item 15)

WACD: The formal and informal assessments by my school administrators of the courses I teach have been worthwhile both for me and for my students (iter 30 )

WAST: The efforts taken at my school to evaluate textbook and other instructional matexials make a difference in how well my students learn (itern 23)

\section{Incentives}

FI'TE: The principal and other school administrators frequentiy recognize my strengths as a classroom teacher, and, when needed, offer to get me help in areas in which I could improve (item 20)

FI'SD: After I attend a staff development workshop or training session, the principal or other school administrator will frequentiy support my efforts to incorporate new ideas into my classes (item 19)

FICD: The principal or administrative staff frequently responds to ry ideas for curricular improvenent (item 3 )

FI'ST: The principal frequent1y finds ways to meet my requests for more materials and books (item 12)

MI'TE: Classroom observation comments from school administrators about my teaching motivate me to incorporate new teaching behaviors and ideas into my classes (item 1)

MI'SD: MY principal's efforts to encourage my continued growth as a teaching professional (e.g., master plan credits, finding substitutes to cover my classes) are meaning ful (item 17)

MI'CD: Providing me with released time and hiring substitutes to cover classes are meaningful ways in which my school adninistration shows its support of my efforts to improve my courses (item 9)

MI'ST: The school administration has shown its support and trust of my efforts to get the best materials for my students by delegating authority to select textbooks and instructional materials to grade levels and departments or by using discretionary funds (item 18) 
Table 15 continued

EImE: In my opinion, the principal equitably rewards teachers whose performance is well-above-average and treats falry teachers whose pexformance need improvement (iten 35)

EI'SD: All teachers who participate in staff development activities receive similar kinds of recognition and rewards from the principal and other school administrators (item 36)

EI'CD: The principal does not favor one grade level or department over another when it comes to distributing resources and money for program development and curricular improvement (item 27)

EI'ST: The principal does not favor one grade level or department over another when it comes to distributing resources and money for textbooks and materials (item 2)

TOTAL 48 questions

\section{Data Collection}

Data collection procedures at 12 of the 14 schools were similar. A school building administrator, either the principal or an assistant principal, was hand-delivered a questionnaire packet for distribution to each classroom teacher on stafi. Attached to the questionnaire was an envelope and a cover letter explaining the purposes of the study and instructions for retuming the questionnaire to a central location at the school (Appendix D). In a few instances, the builaing administrator attached a memo to the teachers requesting their voluntary participation *

At two elementary schools, E2 and E3M, different procedures were followed: E2 permitted the researcher to administer the questionnaire at a faculty meeting and collect it immediately 
upon completion; the principal at E3M requested that teachers be given a stamped self-addressed envelope for return by mail, which was done.

After approximately one week, follow-up procedures were initiated at all of the schools. The follow-up included announcements by building administrators and a memorandum thanking participants and granting other teachers an additional week to complete the questionnaire. Follow-up memos were given to grade-level and department chairpersons to be posted in the teachers' lounge and/or placed in teachers' mailboxes. In order to increase the response rate at $\$ 4$, the researcher was permitted to collect follow-up questionnaires by sitting in the faculty lounge for a complete day. Two public address announcements were made to encourage teachers on a voluntary basis to come to the faculty lounge. In informal conversations with the teachers who came by, they noted how busy they were particularly around graduation time. Despite the low response rate, the completed questionnaires did not indicate any unique systematic bias and, therefore, were used in the data analyses.

Table 16 summarizes the teacher responses by school. Overa11, 54 percent of the teachers in the survey population completed the smce. The highest response rate came from elementary school teachers, 76 percent, as compared to 63 percent and 41 percent from junior high and senior high school teachers respectively. The effect of the alternative data collection procedures at E2 and E3M was negligible, except to note that on- 
site administration of the sMcQ had the highest return rate of all schools, 97 percent. The return rate from teachers at merit schools was 59 percent, while teachers at the matching schools had a somewhat lower return rate of 47 percent. In addition, of the 486 respondents, 472 indicated their level of teaching experience. One-third had taught for three years or less; twothixds had four years or more teaching experience.

Table 16

\section{Teacher Responses to the sMCQ}

\begin{tabular}{|c|c|c|c|c|c|}
\hline School & $\begin{array}{l}\text { Classroom } \\
\text { Teachers }\end{array}$ & $\begin{array}{l}\text { First } \\
\text { Return }\end{array}$ & $\begin{array}{c}\text { Follow up } \\
\text { Return }\end{array}$ & $\begin{array}{l}\text { Total } \\
\text { Return }\end{array}$ & Percen \\
\hline EIM & 47 & 37 & 3 & 40 & 85 \\
\hline $\mathrm{E} 2$ & 36 & 35 & 0 & 35 & 97 \\
\hline E3M & 39 & 29 & 2 & 31 & 79 \\
\hline E4 & 28 & 14 & 7 & 21 & 75 \\
\hline$E 5$ & 35 & 14 & 0 & 14 & 40 \\
\hline $\mathrm{E} 6 \mathrm{M}$ & 17 & 13 & 0 & 13 & 76 \\
\hline
\end{tabular}

\begin{tabular}{|c|c|c|c|c|c|}
\hline SubtotaIs & 202 & 142 & 12 & 154 & $76 \%$ \\
\hline J.M & 54 & 29 & 5 & 34 & $63 \%$ \\
\hline$J 2 M$ & 45 & 31 & 0 & 31 & $69 \%$ \\
\hline 33 & 29 & 11 & 5 & 16 & $55 \%$ \\
\hline$J 4$ & 54 & 26 & 8 & 34 & $63 \%$ \\
\hline
\end{tabular}

\begin{tabular}{|c|c|c|c|c|c|}
\hline Subtotals & 282 & 97 & 18 & 115 & $63 \%$ \\
\hline$S 1$ & 122 & 55 & 1 & 56 & $46 \%$ \\
\hline$S 2 M$ & 152 & 80 & 2 & 82 & $54 \%$ \\
\hline S3M & 122 & 45 & 7 & 52 & $43 \%$ \\
\hline S4 & 127 & 22 & 5 & 27 & $21 \%$ \\
\hline
\end{tabular}

Subtotals $\underline{523} \quad \underline{202} \quad \underline{15} \quad \underline{217} \quad \underline{19}$

Totals: 907 


\section{Data Analyses}

The teacher data responses from the questionnaire were all reviewed for accuracy. Variable codes were entered by the researcher on a micro-computer using a word processing program for later transfer as an ASCII file to a mainframe computer.

Missing values and Don't know responses were each coded separately in order to analyze these independent responses. In understanding building-level control, these responses might indicate (a) that teachers do not know what the school administration is doing within a particular task or, perhaps,

that teachers have been given discretion to act autonomously on a specific task relatively independent from close administrative supervision.

The data were subsequently analyzed [more accurately, operationalized] in three stages: descriptive statistics, reliability and construction validation procedures, and post hoc tests of significance.

\section{Descriptive statistics}

Means, percentage frequencies, and correlations were calculated for each item in the scale as well as for latent, composite variables. These statistics were empirically analyzed as part of the initial decision-making process of validation and reliability testing for each item. Mean values were calculated both conservatively, i.e., by requiring that each item be answered under each task, and more liberaliy, i.e., by 
substituting mean averages by instructional levels for all missing values and by accepting 75 percent responses per variable (P. Johnson, personal communication, october, 21, 1988). The only purpose for using the more liberal mean values was to assure a sufficiently large enough sample size for valid reliabilities and principal components analyses.

The mean statistics on the Likert-type scale offered an indication of the strength or intensity of the teacher's agreement that the task specific managerial behavior occurs within theix school (Converse \& Presser, 3986, p. 37). The lower the mean, the stronger was the teacher's perception that the specific administrative control behavior occurred at the school building-level.

The interpretation of descriptive statistics dexived from a nonstandardized instrument led to a particular concern with identifying method interference. Such instances may have occurred due to (1) items which may have been misinterpreted by teachers to mean what building administrators ought to do rather than what current building administrators wexe actually doing (see item 9); (2) items which night be confused with another item because of (a) consecutive placement (see e.g., items 7 and 8,31 and 32,38 and $39,42,43$, and 44 , and 47 and 48 ) or (b) syntax similarities, (see e.g., itens 2 and 27 or items 15 and 29): and, (3) missing and DK responses which ultimately may have affected either the content validity of the item or its reliability. 


\section{Reliabilities and construct Validation}

The primary objective of the study was to increase our understanding of the meaning of managerial control. In order to support school managerial control as a construct, three criteria needed to be met: (1) establishing the uniqueness of the two dimensions of managerial control and the four managerial control processes; (2) obtaining consistent measures across a variety of curricular and instructional tasks; and (3) distinguishing managerial control from other managerial concepts in general and from the concept of job satisfaction in particular. Construct validity is a necessary precondition for theory development (Hughes, Price \& Marrs, 1986). The major obstacle in ascertaining validity is that the hypothetical constructs are not directly observable, but rather exist as part of theory (Hoyle, in press).

Looking at the inter-item correlations is the first "objective check" (McIver \& Carmines, 1981, p. 24) of the reliability of each item. Three other rellability measures have been used to interpret the correlations: (1) Cronbach Alpha coefficients, (2) corrected item-to-total correlations, and (3) squared multiple correlation coefficient in which each item is regressed on the remaining items. Each of these analyses were performed on both the total items in the managexial control scale and on the hypothesized latent variables.

The development of a construct scale necessitates the identification of underlying concepts which explain the 
relationship within a group of variables. In most instances, the number of underlying concepts are less than the number of items in the scale. In order to test the underlying aspects of the school managerial control model, principal components analyses were performed on all 50 items on the smco as well as on the latent families of items. Based, in part, on the results of these reliability tests, decisions were made to retain or reject specific items in the scale. These calculations and interpretations may be considered confirmatory in that they were conducted within the theoretical parameters of the model proposed in Chapter Four. In social science research, an emerging method used to test hypothetical factors and model parameters is confirmatory factor analysis (Dunteman, 1989, p. 59; Hughes, Price, Marrs, 1986). The confirmatory factor model not only specifies the number of common factors and observed variables to be analyzed, but also imposes substantive constraints on the data by stating specific relationships among latent and observable variables (Long, 1983a, p. 12). Under the conditions present within this study, e.g., high communalities of the variables and a large number of variables, both principal components and factor analysis are likely to give similar results (Dunteman, 1989, p. 60: Stevens, 1986).

\section{Inferential statistics}

Empirical studies of organizational control have been labelled exploratory (Peterson, 1984; Sproull, 1981). Therefore, 
they have tended to describe their findings and report statistics rather than test specific hypotheses (Dornbusch \& Scott, 1975; Hanson, 1981; Peterson, 1984). Even when the samples have included schools from each of the three levels of education, elementary through high school, researchers have not analyzed differences among the instructional levels (Hanson, 1981).

The aim of construct validation procedures is to establish a unique solution of the hypothetical model. Meaningfulness, however, is dependent upon substantive theory. Statistically significant differences, in fact, may not be appropriate to concepts originating from common factors. Nevertheless, the value of a measurement model ultimately rests with its practical implications. Therefore, a number of univariate and multivariate inferential tests of significance using the actual mean value data was reported independently of the reliability findings reported in the previous section.

In the managerial control model, standards, information, assessments, and incentives are defined as latent variables which can be viewed as responses or dependent variables. Since the effects of schools (Blumenfeld, personal communication, January 1, 1989), instructional levels (Corcoran, 1985; Dornbusch \& Scott, 1975; Rowan, 1985), size (Peterson, 1984), tenure (Applewhite, 1965; Etzioni, 1965) and effectiveness (Hallingex \& Murphy, 1985; Peterson, Hallinger, \& Murphy, 1987; Wellisch, et al, 1978) have been associated with other control studies, post hoc univariate, repeated measures, and MANOVA's were conducted to 
determine the interactive effects with the managerial control processes of standards, information, assessment, and incentives. In exploratory research, "both (author's emphasis) the univariate and multivariate tests [for repeated measures are] routinely used because they may differ in the treatment effects that they discern (Stevens, $1986, p .414$ ). Considering the complexity of variables involved with managerial control, there is a need to study their interaction effects. Although the mathematical basis for applying MANOVA is generally accepted, there is considexable debate as to its proper use (Bray \& Maxwel1, 1985). Thus, these tests will rely on good judgment and interpretation. Where statistical significance is observed, further analyses may need to be conducted to isolate the specific effects. Since none of the inferential tests of significance was part of an expeximental research design, the results simply suggest to researchers specific avenues of study that may offer insights regarding these relationships as well as alternative paths of investigation. 


\section{CHAPTER SIX}

\section{Data Analysis}

\section{Introduction}

In order to test the validity and reliability of the measures of the school managerial control model, data from the School Managerial Control Questionnaire (SMCQ) were analyzed at various levels of aggregation. Although vickers (1967) warned that with every aggregation, the "indices of control become less significant" (p. 29-30), the definition of managerial control must reflect the complexity of school organizations and underlying conceptual relationships. Statistically, aggregations are more sensitive to systematic bias (Blalock, 1985), and, as a rule, yield higher $R$ squared statistics than do individual level data (Kenny, 1979, p. 262). Nevertheless, the evidence from social science literatures on organizational control makes it clear that multiple items are needed to measure that complexity (Morris \& Fitz-Gibbon, 1978, pp. 14-29; Pfeffer, 1978a; Schein, et al., 1961). The aggregation of the multiple items reflect latent variables or theoretical constructs supported by empirical data (James, et al., 1982, pp. 104-105). Each of the items on the sMce is a descriptive, observable indicator relating to a specific task context as well as to the latent variables of managerial control. While confirmatory analyses begins with observable indicators, it must also extend beyond descriptive statistics.

The fact that there is so little published empirical support 
for specific managerial behaviors which influence school control (Bossert, et al., 1982; Duke, 1982), careful attention must be paid to descriptive responses reported by school teachers. The descriptive data analyses proceeded from the specific items through the levels of aggregation hypothesized by the school managerial control model. The actual mean values were reported, since any missing values or teacher Don't know responses were considered important data findings.

In addition to reporting means, frequencies, and correlations for individual items, unidimensional scaling, reliability tests, and principal components analysis procedures were conducted as described in the previous chapter. The purpose of these statistical tests was to explore the underlying factors of teacher perceptions of managerial control and to guide further construct validity testing of the proposed model. In order to maximize the sample size for reliability tests and principal components analyses, mean values by instructional levels were substituted for all missing values and Don't Know responses. Because of the limitations of a single study, only initial results of construct validation testing results can be reported here.

Finally, given the descriptive and exploratory nature of this study, findings from a number of post hoc tests of significance regarding the effects of schools, levels of instruction, tenure, and school effectiveness were also reported. Here, again, the actual mean data were used to limit the 
systematic bias of aggregation. These statistical results may suggest a number of hypotheses leading to future research on school managerial control.

Although a complete description of the smce instrument is found in chapter Five, a review here of item abbreviations should facilitate their quick and accurate reading. The items on the sMCQ measure the attributes of two dimensions: structuralfrequency (F) and discretionary-quality of the four managerial control processes, i.e., standards (S), information (I). assessment (A), and incentives (I\%). The qualitative indicators under each managerial control process vary and are abbreviated as follows:

claxity of standards (C) difficulty of standards (D) adequacy of information (a) utility of information (u) fairness of assessment (t) worth of assessment (w) meaning fulness of incentives $(M)$ equitable distribution of incentives (E)

Each item is also Inked contextually to a specific curxicular and instructional task: teacher evaluation (TE), staff development (SD), curriculum development (CD), and selection of textbooks and instructional materials (ST).

In reading an item abbreviation, the first letter refers to the measure of managerial behaviors, either frequency or a quality; the second letter refers to the managerial control process: while, the last two letters refer to the specific task. For example, the item abbreviated as csme reads: clarity of standards for teacher evaluation. 
The abbreviation $M I \cdot S D$ reads:

meaningfulness of incentives in staff development.

\section{Descriptive statistics}

\section{Mean Values and cumulative Percentages}

on the SMCQ, teacher responses $(\underline{N}=486)$ on a likert-type scale ranged from one, representing "Strongly Agree" to six, representing "Strongly Disagree." Therefore, the lower the mean value, the stronger the teacher perception that the specific managerial behavior occurs within the school-builaing. In Table 17, the top 12 items with the lowest mean values have been reported along with their standard deviations and the cumulative percentage of teacher agreement. The latter statistic is the percentage of teacher responses from one "Strongly Agree" to three "Agree" on the Likert-type scale. The column labelled "number of responses" excluded two distinct categories: (a) teachers who stated that they Don't know (DK) whether that managerial behavior occurs with respect to one of the behavioral indicators, and (b) missing values, i.e., items left blank. Teachers chose the DK response fax more often than omitting a response (see Table 19 ).

Eleven of the 12 items receiving the strongest teacher perceptions of school managerial behavior reported in Table 17 belonged to the hypothesized dimension of discretionary behavior. of the qualitative indicators, teacher input [utility of information 1 in the selection of textbooks and instructional materials (UIST) ranked first, followed by another information 
item, adequacy of information in teacher evaluation (artw). A third information process indicator made the top quartile, the utility of information for staff development (UISD). However, the low number of responses $(n=208)$ to this item indicated that a majority of the teachers responding (57.2\%) did not necessarily agree that this managerial behavior was present in schools.

sable 17

Top Quartile of Teacher Agreement Responses to Items on the sMco

\begin{tabular}{lcccc}
\hline Item & $\begin{array}{c}\text { Number of } \\
\text { Responses }\end{array}$ & Mean & $\begin{array}{c}\text { Standard } \\
\text { Deviation }\end{array}$ & $\begin{array}{c}\text { Cumulative } \\
\text { Percentage of } \\
\text { Agreement }\end{array}$ \\
\hline UIST & 445 & 2.39 & 1.15 & 90.6 \\
aITE & 477 & 2.45 & 1.16 & 88.1 \\
EATE & 456 & 2.45 & 1.17 & 90.6 \\
fAST & 408 & 2.48 & 1.32 & 82.1 \\
MI'ST & 437 & 2.49 & 1.37 & 82.2 \\
EI'ST & 431 & 2.52 & 1.59 & 75.9 \\
FI'SD & 407 & 2.54 & 1.26 & 83.5 \\
MI'CD & 450 & 2.56 & 1.50 & 78.0 \\
CSCD & 472 & 2.57 & 1.33 & 82.6 \\
FASD & 457 & 2.57 & 1.32 & 80.5 \\
CSTE & 467 & 2.59 & 1.29 & 80.3 \\
UISD & 208 & 2.60 & 1.29 & 83.7
\end{tabular}

The managerial process with the most items was incentives, with four, one more than either information or assessment. The multiple items indicating fairness of assessment in (a) teacher evaluation, (b) selection of texts, and (c) staff development also had strong teacher agreement. The managerial process with the least items in Table 17 was standards, which included only items pertaining to clarity, more specifically the clarity of standards for curriculum development (CSCD) and the clarity of 
standards for teacher evaluation (CSTE). In Dade county. Florida, formal standards for both of these tasks originated above the individual school-level.

All four curricular and instructional tasks were represented within the managerial processes. The selection of texts and instructional materials ranked first in teacher agreement with four items, followed in order by teacher evaluation and staff development with three items, and curriculum development with two items.

In Table 18, the bottom quartile is shown, representing the 12 items with the lowest levels of teacher agreement; although, here, too, a majority of the teachers were generally in agreement with the behavioral impact of the managerial activities. Unlike the preponderance of discretionary qualities appeaxing in Table 17. eight out of the bottom 12 indicators belonged to the structural-frequency dimension. Three of the items referred to the frequency of standards, while three others referred to the frequency of assessments.

Seven of the 12 item in Table 18 referred to the managerial control of standards. A.1 four of the items having to do with the difficulty of standaras were included, along with three out of the four structural-frequency indicators of standards. The managerial process which appeared next most often was assessment with three items, all pertaining to the structura-frequency of assessments. Interestingly, the tasks Iisted under the structural-frequency dimension of standards and assessments were 
the same: teacher evaluation, staff development, and selection of textbooks and instructional materials. The singular exception under the structural-frequency of standards and assessments was the task of curriculum development, which received relatively high levels of agreement $(79.2 \%$ and 75.2 respectively).

\section{Table 18}

Botton ouartile of Teacher Agreement Responses to Items on the SMCO

\begin{tabular}{lcccc}
\hline & $\begin{array}{c}\text { Number of } \\
\text { Responses }\end{array}$ & Mean & $\begin{array}{c}\text { Standard } \\
\text { Deviation }\end{array}$ & $\begin{array}{c}\text { Cumulative } \\
\text { Percentage of } \\
\text { Atgreement }\end{array}$ \\
DSTE & 392 & 3.69 & 1.30 & 32.7 \\
FSSD & 394 & 3.50 & 1.34 & 47.7 \\
FAST & 276 & 3.30 & 1.37 & 54.7 \\
FSST & 339 & 3.27 & 1.40 & 59.9 \\
DSCD & 428 & 3.19 & 1.38 & 58.2 \\
FSTE & 459 & 3.09 & 1.40 & 63.6 \\
FATE & 446 & 3.08 & 1.51 & 67.3 \\
FASD & 222 & 3.08 & 1.45 & 67.1 \\
DSSD & 439 & 3.05 & 1.32 & 63.3 \\
FICD & 459 & 2.99 & 1.38 & 68.4 \\
DSST & 367 & 2.94 & 1.43 & 69.8 \\
FI CD & 423 & 2.92 & 1.38 &
\end{tabular}

In general, the number of responses per item were lower for the bottom quartile of teacher agreement. Particularly low response rates were given to the frequency of assessments for selecting texts and instructional materials (FAST) (n 276 ) and to the frequency of assessment for staff development (FASD) ( $\underline{n}=222)$. obviously mean values were higher in rable 18 , but so also were 
standard deviations. The frequency of agreement ranged from a low of 32.7 percent for difficulty of standards in teacher evaluation (DSTE) to a high of 69.5 percent for the frequency of incentives for curriculum development (FI'CD).

In both Tables 17 and 18 , missing values and teacher ok responses were excluded. As stated previously, these two responses highlighted specific school building managerial behaviors of which teachers admitted they were not aware. In Table 19, a majority of the teachers surveyed indicated that they did not know whether their input was used in developing a staff development program at their school (UISD) or whether school administrators evaluated staff development programs (FASD). Over 40 percent of the teachers were not aware of the frequency of assessment of textbooks and instructional materials (FAST). Over 30 percent were not aware of the frequency of standards for the selection of textbooks and instructional materials (FSST). Other items which received high DK responses were the equitable distribution of incentives for staff development (EI'SD) and the difficulty of standards in the selection of textbooks and instructional materials (DSST). When these responses were calculated for each of the three levels of instruction, the percentage of elementary school teachers who indicated Don"t know for these items was lower than for teachers at the jumior high or senior high school levels. This was particularly true for the frequency of assessment for 
textbooks, the equitable distribution of incentives for staff development, and the difficulty of standards for the selection of textbooks. Conversely, junior high school teachers registered the highest percentages of $\mathrm{DK}$ and missing values among the three levels of instruction.

\section{Table 39}

\section{Items With Low Teacher Response Rates By Instructional Levels}

\begin{tabular}{|c|c|c|c|c|c|c|}
\hline \multirow[b]{3}{*}{ Item } & \multirow[b]{3}{*}{$\begin{array}{c}\text { Missing } \\
8\end{array}$} & \multirow[b]{3}{*}{ 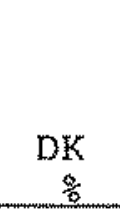 } & \multirow[b]{3}{*}{$\begin{array}{c}\text { Total } \\
8 \\
\end{array}$} & \multicolumn{3}{|c|}{ Instructional Levels } \\
\hline & & & & Elementary & Junior & Senior \\
\hline & & & & $\begin{array}{c}(n=154) \\
8 \\
0\end{array}$ & $\left(\frac{n}{2}=115\right)$ & $\begin{array}{c}(n=217) \\
\frac{0}{5}\end{array}$ \\
\hline UTSD & 1.6 & 55.6 & $57 \cdot 2$ & 55 & 60 & 58 \\
\hline FASD & 2.1 & 52.3 & $54 \cdot 4$ & 47 & 54 & 59 \\
\hline FAST & 1.4 & 41.8 & 43.2 & 35 & 52 & 44 \\
\hline FSST & $2 \cdot 3$ & 28.0 & 30.3 & 26 & 33 & 32 \\
\hline$E I ' S D$ & 2.9 & 23.0 & 25.9 & 18 & 32 & 29 \\
\hline DSST & 2.5 & 22.0 & $24: 5$ & 20 & 30 & 24 \\
\hline
\end{tabular}

Three of the top four items in table 19 were structuralfrequency indicators. Only two of the four curricular and instructional tasks were found to have a high number of teacher DR responses: staff development and the selection of textbooks and instructional materials.

Two items [not shown in Table 19] were left blank by teachers far more often than any of the other 48 items. They were frequency of assessment in teacher evaluation (11.1.0) and the equitable distribution of incentives for the selection of textbooks and instructional materials $(7.2 \%)$. The actual mean values for the former item were over 3.0 , indicating teacher 
disagreement that "the process of evaluating teachers occurs at my school more often than just when I am being fformally observed]." With respect to the equitable distribution of incentives for selecting texts and instructional materials, those who responded [over $80 \%$ ] agreed that this managerial behavior was practiced.

\section{Item Correlations}

Correlational analyses based on actual mean values were performed for each of the 50 items on the sMcQ. As behavioral indicators of specific tasks and processes which have all been hypothesized as relating to the domain of managerial control, the inter-item correlations were predictably high and positive. Nevertheless, with the large number of variables in the matrix, it was unrealistic to comprehensively describe the inter-item correlations. "The goal of principal components analysis is to decompose the correlation matrix... variables that correlate highly with a particular principal component give meaning to the component" (Dunteman, 1989, p. 21). Since greater theoretical significance is attached to the meanings of aggregate variables, only the highest correlations might be of interest at this time (Table 20). Most of these individual item pairings wili anticipate latent variable relationships.

In judging the correlation between two items, four factors seemed to be associated with the high correlations: (1) consecutive placement on the sMco, (2) similar structure or 
quality, (3) similar process, or (4) similar task. Although the items on the smce were ordered on a random basis, in some instances, items measuring the same managerial behavior were consecutively placed. These pairings tended to result in the highest positive correlations among the 48 managerial control items (Table 20). Yet, in only one instance was consecutive placement the single commonality between the items.

\section{Table 20}

Highest positive correlations and commonalites on the sMco

$\begin{array}{lccl}\text { First } & \begin{array}{c}\text { Correlational } \\ \text { Coefficient }\end{array} & \begin{array}{l}\text { Second } \\ \text { Item }\end{array} & \text { Commonalities } \\ \text { Iten } & .86 & \text { WACD } & \text { (placement, process, behavior) } \\ \text { WATE } & .77 & \text { UIST } & \text { (placement, process, behavior) } \\ \text { UICD } & .77 & \text { UISD } & \text { (task) } \\ \text { FASD } & .74 & \text { aIST } & \text { (process, task) } \\ \text { FIST } & .71 & \text { CSST (placement) } \\ \text { FICD } & .71 & \text { aIST (task) } \\ \text { CSST } & .71 & \text { UITE (task) } \\ \text { WATE } & .70 & \text { FASD (dimension) } \\ \text { FSST } & .70 & \text { UICD (process, behavior) } \\ \text { UISD } & .70 & \text { aIST (process) } & \end{array}$

An additional pair of items with a high positive correlation fell outside of the four primary influence factors: fairness of assessment in staff development (fASD) correlated positively, .73, with satisfaction of school administrator performance. The influence of teacher satisfaction on managerial control is important in order to identify processes and specific managerial behaviors which correlate with both concepts. The effects of teacher satisfaction are present within each of the item's measures. 


\section{Correlations between managerial control and satistaction.}

Correlations were calculated between the forty-eight managerial control items and two satisfaction indicators. Bachman \& Tannenbaum (1968, Chapter 16), C. Greene (1981, pp. 218-230), Locke (1977) and Tuxcotte (1974) have all demonstrated a somewhat variable, but positive correlation between pexformance and satisfaction. C. Greene (1981) reported that recent motivation research seemed to reject the view that satisfaction causes perfomance, yet only moderately supports the view that performance causes satisfaction. Two intervening variables identified in the literature have been rewards and effort. It is important, therefore, to establish the relationship between satisfaction and the processes and tasks of managerial control.

Two items on the sMCQ, numbers 14 and 25 , sought to measure different aspects of teacher satisfaction. Item 14 read:

I am satisfied with the job my school administration is doing.

Item 25 read:

I ar generaliy satisfied working at my school.

The former referred to satisfaction with the performance of the administration, wile the latter with personal job satisfaction.

Practically all 998 percent] the teachers in the sample responded to these two satisfaction items. on the basis of mean values, personal job satisfaction (item 25) ranked first with the nighest level of teacher agreement $(2,03)$. That is, teachers reported a highex level of satisfaction with their jobs than with any of the 48 managerial control benaviors. High school teachers reported to be the most satisied with their jobs as well as with their school administrators. Junior high school teachers were 
the least satisfied with the performance of their school administrators (mean value of 2.8 ).

The two satisfaction items, however, exhibited a number of pairwise correlations with the managerial control items that were lower than those found among the managerial control variables themselves.

At the level of curricular and instructional tasks, the low correlations between satisfaction and managexial control were even clearer, although the relationship is certainly complex. The lowest correlations between satisfaction items and managerial control items reported in rable 21 included variables related to the lack of meaningful incentives or managerial effort as measured by frequency of interactions and difficulty of standards.

Table 21

Low Iten Correlations Between Managerial control and satisfaction

School Administration Item FSSD Satisfaction

Job

Satisfaction

.40

DSTE

.25

.23 comments

Less teacher job satisfaction with the infrequent setting of personal in service goals

Less overall teacher satisfaction with the level of difficulty in standards expected in teaching 
Table 21 continued

$\operatorname{DSCD}$

.33

FAST

$M I^{\prime} \mathrm{CD}$

.34
.30
Less overall

teacher satisfaction with the level of difficulty in curriculur development standards

Less teacher job satisfaction with the regular procedures for assessing wexts or othex materials

Less teacher job satisfaction with the incentives to develop curriculum

The low correlations between satisfaction and specific managerial control items were also supported by the high mean value scores of each control item, except the meaningful incentives for curriculum development. In fact, the means scores indicated some degree of teacher disagreement, ranging from 3.19 to 3.69. As for the meaningful incentives for curriculum development, (MI'CD), it might have been that teachers misinterpreted the written item as a behavior that school administrators ought to do, rather than answering the guestion based on the behavioral impact of providing released time and hiring substitutes. possibly, these behaviors were not regular, on-going managerial activities at some schools in the sample. 
The data on inter-item reliabilities, however, presented a somewhat different picture of the relationship between managerial control and satisfaction. Here, it was not job satisfaction which influenced teacher pexceptions of managerial control, but rather satisfaction with the performance of school

administrators. Both the corrected item-to-total correlation and the squared multiple correlation were very high 1.783 and .731 respectively), and if satisfaction with school administration was deleted from the statistical analysis, the overall Alpha Coefficient would be lowered from .9747 to .9738 .

Thus, while there is some correlational evidence to support the distinction between managerial control and teacher job satisfaction, the concepts of managerial control and satisfaction with administrative performance were clearly interrelated.

\section{Latent Aggregate Variables}

The first level of aggregation above individual items combined indicators of structural-frequency and discretionaryquality for each task under one of the four managerial control processes. Thus, the four frequency items pertaining to standards were combined as were the frequency items under information, assessments, and incentives. Likewise, all of the salient qualitative items were combined under their respective managerial control process. Table 22 indicates the number of teacher responses, actual mean values for the first-level aggregation, and the cumulative percentage of teacher agreement 
for each managerial variable. The loss of responses from the original $\mathbb{N}=486$ occurred because data was quantified oniy from those teachers who responded to all four items comprising that variable. The most severe losses were reported for the frequency of assessments $(n=168)$ and the utility of information $(n=190)$.

\section{Table 22}

Means and Frequencies of Aggregate Managerial Control Variables

\begin{tabular}{lccc}
\hline Variable & $\begin{array}{c}\text { Number of } \\
\text { Responses }\end{array}$ & $\begin{array}{c}\text { Cumulative } \\
\text { Means }\end{array}$ & $\begin{array}{c}\text { Frequencies of } \\
\text { Aqreenent( })\end{array}$ \\
\hline Frequency/Standards & 278 & 3.11 & 52.2 \\
Clarity/Standards & 368 & 2.67 & 69.8 \\
Difficulty/Standards & 294 & 3.20 & 44.9 \\
Frequency/Information & 412 & 2.77 & 64.8 \\
Adequacy/Information & 398 & 2.65 & 71.1 \\
Utility/Information & 190 & 2.48 & 76.8 \\
Frequency/Assessment & 168 & 2.98 & 57.7 \\
Fairness/Assessment & 333 & 2.47 & 74.8 \\
Worth/Assessment & 346 & 2.75 & 65.9 \\
& & & \\
Frequency/Incentive & 343 & 2.65 & 68.8 \\
Meaning/Incentive & 394 & 2.62 & 71.1 \\
Equity/Incentive & 297 & 2.69 & 68.7
\end{tabular}

Within the managerial control process labelled standards, 69.8 percent of the teachers agreed that clarity of standards existed within their schools, while structural-frequency and difficulty of standaxds were the least evident. The latter variables had mean values over 3.0 , also suggesting some teacher disagreement with these managerial activities. Their cumulative percentage of teacher agreement was the lowest reported for alI 
of the aggregated variables, 52.2 percent and 44.9 percent respectively.

With respect to information, both of the qualitative variables, adequacy and utility, received higher teacher agreement than the structural-srequency of information. Sinilarly, the data reported for assessments indicated that the structural-frequency of assessments had a lower level of teacher agreenent than either of the two qualitative variables.

only under the managerial control process of incentives did the data demonstrate that structural-frequency was evident to the same extent as the qualitative variables of incentives.

Although some task differences were evident in Tables 23 through 26, the impact of school managerial control behaviors were found across the different curricular and instructional tasks. For example, within the task of teacher evaluation, the cumulative percentages of teacher agreement for clarity of standards, adequacy of information, and faimess of assessments were all high. Within the process of standards, frequency and difficulty were consistently lower than clarity for all four curricular and instructional tasks. Likewise, all three indicators under the process of assessment demonstrated a consistency across the curricular and instructional tasks.

When the items on the smco were aggregated by curricular and instructional tasks under the managerial control process of standards (Table 23), the percentages of teacher agreement were lower for the structural-frequency of standards in staff 
development and selection of textbooks and instructional

materials than for teacher evaluation and curriculum development. overall, the clarity of standards by tasks was high, although it, too, followed the same task pattern as structural-frequency. In contrast, teachers reported low agreement about the presence of difficulty of standards, especially for the task of teacher evaluation. Thus, for example, teachers viewed standards for teacher evaluation to be clear, somewhat frequent, although not difficult.

Table 23

cumulative Percentages of Teacher Agreement on curricular and Instructional Tasks for standards

\begin{tabular}{lcccc}
\hline & $\begin{array}{c}\text { Teacher } \\
\text { Evaluation }\end{array}$ & $\begin{array}{c}\text { Staff } \\
\text { Development }\end{array}$ & $\begin{array}{c}\text { Curriculum } \\
\text { Development }\end{array}$ & $\begin{array}{c}\text { Selection } \\
\text { Texts }\end{array}$ \\
\hline Standards & & & & \\
Frequency & 63.6 & 47.7 & 79.2 & 59.9 \\
Clarity & 80.3 & 73.6 & 82.6 & 73.7 \\
Dificulty & 32.7 & 63.3 & 58.2 & 67.8
\end{tabular}

on the sMcQ, teachers registered consistentiy high agreement about information managerial behaviors for each of the four curricular and instructional tasks (Table 24). of the three behavioral indicators, utility of information in the selection of textbooks and instructional materials ranked highest overall with 90.6 percent, followed by the adequacy of information for teacher evaluation with 88.1 percent. 
able 24

Cumulative Percentages of teachex Agreement on curricular and

Instructional wask for Information

\begin{tabular}{ccccc}
\hline & $\begin{array}{c}\text { Teacher } \\
\text { Evaluation }\end{array}$ & $\begin{array}{c}\text { Staff } \\
\text { Development }\end{array}$ & $\begin{array}{c}\text { Curxiculum } \\
\text { Development }\end{array}$ & $\begin{array}{c}\text { Selection } \\
\text { Texts }\end{array}$ \\
\hline Information & 72.9 & 81.8 & 68.4 & 77.6 \\
Frequency & 88.1 & 78.8 & 77.7 & 78.1 \\
Adequacy & 77.4 & 83.7 & 81.7 & 90.6 \\
Utility & &
\end{tabular}

Utility of information was defined as the teachers' perception that their feedback information and suggestions were used by school administrators. The two tasks in wich utility was ranked highest were the selection of texts and instructional materials and in staff development. Teacher evaluation and curricular development ranked somewhat lower in terms of utility of information. The adequacy of information ranked highest (88.1\%) for the task of teacher evaluation. Under the structural-frequency of information, teachers agreed most on staff behaviors, with selection of texts second, followed by teacher evaluation, and curriculum development.

The data reported in Table 25 indicate that the structura1frequency of assessments across three of the four curricular and instructional tasks received less teacher agreement than did almost all the discretionary, qualitative assessment behaviors. OnIy 54.7 percent of the teachers reported agreement with the structural-frequency of assessments of textbooks and 
instructional materials. Along the structural-frequency dimension, teachers reported highest agreement for the task of curricular development assessment.

The highest percentage of agreement among teachers was for the fairness of assessments with respect to teacher evaluation. Teacher judgment as to the worth of assessments was consistent, varying only 4 percent across all tasks.

\section{Tabl 25}

Cumulative Percentages of Teacher Agreenent on curricular and Instructional Tasks for Assessments

\begin{tabular}{lcccc}
\hline & $\begin{array}{c}\text { Teacher } \\
\text { Evaluation }\end{array}$ & $\begin{array}{c}\text { Stafi } \\
\text { Development }\end{array}$ & $\begin{array}{c}\text { Curriculum } \\
\text { Development }\end{array}$ & $\begin{array}{c}\text { Selection } \\
\text { Texts }\end{array}$ \\
\hline Assessments & & & & \\
Frequency & 67.3 & 67.1 & 75.2 & 54.7 \\
Worth & 72.5 & 76.5 & 72.5 & 75.1 \\
Fair & 90.6 & 80.5 & 80.5 & 82.1
\end{tabular}

The data presented for the managerial process of incentives in Table 26 indicate a somewhat different pattern of teacher agreement of managerial activities than found in the other managerial processes. Incentives were the only managerial control process in which the structural-frequency measures were congruent with the discretionary, qualitative indicators of meaningfulness and equitable distribution. only under information did teachers also report such high levels of agreement for structural-frequency activities. 
The two highest percentages of teacher agreement for incentives were reported for the structural-frequency of staff development $(83,5 \%)$ and for the meaningfulness of incentives for selection of textbooks and instructional materials $(82.2 \%)$. Teacher response rates to the indicators of meaningfulness were higher than for either the indicators of structural-frequency or equitable distribution. For meaningfulness in curriculum development, 450 teachers responded, while 437 teachers responded to the meaningfulness in the selection of textbooks and instructional materials. Interestingly, the level of teacher agreement about equitable distribution of incentives was lower across all tasks in comparison to either frequency or meaningfulness indicators.

\section{Table 26}

Cumulative percentages of Teacher Agreement on curricular and Instructional Tasks for Incentives

\begin{tabular}{lcccc}
\hline & $\begin{array}{c}\text { Teacher } \\
\text { Evaluation }\end{array}$ & $\begin{array}{c}\text { Staff } \\
\text { Development }\end{array}$ & $\begin{array}{c}\text { Curriculum } \\
\text { Development }\end{array}$ & $\begin{array}{c}\text { Selection } \\
\text { Texts }\end{array}$ \\
\hline Incentives & & & & \\
Frequency & 76.7 & 83.5 & 69.5 & 76.1 \\
Meaningfulness 76.4 & 77.3 & 78.0 & 82.2 \\
Equity & 71.7 & 74.2 & 72.6 & 75.9
\end{tabular}

The second level of aggregation combined both the structural-frequency items across all four tasks with the indicators of discretionary quality under each of the four 
managerial control processes. In Table 27, teachers reported highest agreement about managerial behaviors pertaining to information and the lowest agreement on managerial behaviors related to standards. The reduced sample sizes occurred because data was tabulated only from those teachers who answered every item [12] within the aggregation.

\section{Table 27}

Means and cumulative Percentages of Teachex Agreement of Managerial Control processes

\begin{tabular}{lccc}
\hline Process & N & Neans & $\begin{array}{c}\text { Cumulative } \\
\text { Percentages of } \\
\text { Agreement }(\%)\end{array}$ \\
Standards & 202 & 2.94 & 54.5 \\
Information & 166 & 2.49 & 75.3 \\
Assessments & 143 & 2.59 & 69.2 \\
Incentives & 232 & 2.53 & 70.7
\end{tabular}

of the teachers who responded to all twelve indicators of information, 75 percent agreed that school administrators managed curriculum and instruction through information systems. In contrast, only a little over one half of the teachers agreed that school building administrators actively managed standards for curricular and instructional tasks. Both incentives and assessments fell between the other two managerial processes. Although the mean values and percentage frequency of agreement for incentives and assessments were similar, there was a 
considerable difference in the number of teacher responses to the respective twelve indicators for each process. Almost an additional one hundred teachers responded fully to managerial activities related to incentives as opposed to assessments.

\section{Model Testing}

The proposed model of managerial control is a theoretical construct made up of latent variables, with explicitly stated relationships among the items on the sMce. The objective of construct valiation is to arrive at a unique model solution which is explained by the data. At this stage of theory development, however, with only one sample population, the initial objective is to make intelligent decisions on whether to accept or reject specific items for inclusion in a scale of school managerial control.

since the hypothesized elements and relationships comprising the model of school managerial control were proposed as necessary attributes, decisions to reject specific items were guided not only by empirical data, but by social science control theory as well. In fact, there are no purely statistical procedures which identify latent variables or guarantee theoretical validity (Heise, 1974, p. 9).

\section{Reliabilities}

The initial statistical reliability techniques for unidimensional scaling measured both the corrected item-to-total 
correlations and cronbach Alpha coefficients which assess the internal consistency of items and serve as the basis for creating factor scores (Armor, 1974; Heise, 1985). Since iten-tomtotal correlations are biased because each item contributes to the total scale score, thexeby inflating the correlation coefficient, corrected item-to-total correlations wexe computed to eliminate that item's variance. (McIver \& Carmines, 1987). Aggregate variable correlation matrices and squared multiple correlation statistics were also used to determine the reliability for each item.

Most reliability measures are affected by the number of items in the scale. When the 48 items on the suco were analyzed [the two satisfaction items were excluded here], the cronbach Alpha coeficient was $\$ 732$ [compared with the cronbach Alpha coefficient on the prewtested scale of .8658 [See Table 141. The coefficient is an estimated average of each inter-item correlation (Ammor, 1974, p. 19). The corrected inter-item correlations for each of the managerial control items also established a measure of item discrimination; that is, ideally, correlations among items of the same latent variable should have higher coeficients than with the overall model.

Twelve items explicitly met the ideal discrimination criterion (Table 28). That is, their latent aggregate variable corrected item-to-total correlation was higher than their correlation to the overall model, excluding the two satisfaction items. Since many factors infuence the correlations, e.g., the 
number of items, the amount of variance of each item, and the existence and relative size of the aggregated itens, the calculated differences cannot be considered conclusive in determining reliability.

Table 28

Corrected Item-to-Total Correlation Differences Between Aggregate Variables and the overall Model

$\begin{array}{cc}\text { Corrected Item-to- } & \text { Corrected Item-to- } \\ \text { Total Aggregate } & \text { Total overail } \\ \text { Variable Correlations Model correlations Difference }\end{array}$

$\begin{array}{llll}\text { DSSD } & .452 & .282 & .17 \\ \text { DSCD } & .519 & .415 & .10 \\ \text { EI'CD } & .681 & .614 & .07 \\ \text { EI'ST } & .573 & .515 & .06 \\ \text { WACD } & .776 & .731 & .05 \\ \text { WATE } & .750 & .708 & .04 \\ \text { UICD } & .776 & .750 & .03 \\ \text { UIST } & .702 & .679 & .02 \\ \text { MICD } & .554 & .533 & .02 \\ \text { FSSD } & .659 & .645 & .01 \\ \text { aISD } & .640 & .628 & .01 \\ \text { FICD } & .758 & .758 & -01\end{array}$

Ten of the twelve items in Table 28 identified discretionary behaviors. Given the difference between the number of items in the model versus the aggregate variables (48 versus 4 ), even items which did not meet this criterion may be considered to discriminate. certain items had low corrected iter-to-total correlations with the overall model. These included difficulty 
of standards for the selection of textbooks and instructional. materials, the utility of information in staff development, the frequency of assessment for the selection of textbooks and instructional materials, and the meaningful incentives for teacher evaluation. Each of the four processes were represented along with three different tasks.

At the other extreme, certain items had high overall model corrected item-to-total correlations. These included the fairness of assessment for staff development, the adequacy of infomation for curriculum development, the frequency of information for curriculum development, and the clarity of standards for stafi development. Three processes and only two tasks were represented in this grouping of items.

Pre-test reliability statistics have been reported in Table 14. The same analyses were repeated on the revised items used in the survey study (Table 29). The cronbach hlpha coefficients on a11 twelve aggregate variables were higher on the revised survey itens. The highest cronbach Alpha coeficient belonged to the aggregate variable labelled frequency of information, while the lowest Alpha coefficients were found in the difficulty of standaras and the frequency of assessments.

A comparison of corrected itenuto-total correlations with coefficients on the correlational matrix provided two method evidence for deciaing whether to retain or reject specific items (McIver \& Camines, 1987). Low correlations indicated a weakness in that item. The weakest items appeared to be the task of 
selecting of textbooks and instructional materials as it related to the managerial process of standards, the utility of information pertaining to staff development, the frequency of assessments, fairness and worth of assessment as it related to textbook selection, and the meaningfulness of incentives as it related to teacher evaluation.

\section{Table 29}

Reliability statistios for school Managerial control

\begin{tabular}{|c|c|c|c|c|c|c|}
\hline \multirow[t]{2}{*}{ Item } & \multirow[t]{2}{*}{$\begin{array}{l}\text { Corrected } \\
\text { Item-Total } \\
\text { correlation }\end{array}$} & \multirow[t]{2}{*}{$\begin{array}{c}\text { Crombach } \\
\text { Alpha }\end{array}$} & \multicolumn{3}{|c|}{$\begin{array}{c}\text { Correlation } \\
\text { Matrix }\end{array}$} & \\
\hline & & & $T E$ & SD & $\mathrm{CD}$ & $\mathrm{ST}$ \\
\hline FS & & .8062 & & & & \\
\hline FSTE & .618 & & 1.000 & & & \\
\hline FSSD & .659 & & .516 & 1.000 & & \\
\hline FSCD & .636 & & .572 & .524 & 1.000 & \\
\hline FSST & .581 & & .432 & .570 & .456 & 1.000 \\
\hline $\mathrm{CS}$ & & .8094 & & & & \\
\hline CSTE & .603 & & & & & \\
\hline $\operatorname{CSSD}$ & .645 & & .497 & & & \\
\hline $\operatorname{CSCD}$ & .647 & & .526 & .550 & & \\
\hline CSST & .615 & & .477 & .539 & .512 & \\
\hline DS & & .6838 & & & & \\
\hline DSTE & .452 & & & & & \\
\hline DSSD & .488 & & .312 & & & \\
\hline DSCD & .519 & & .453 & .405 & & \\
\hline ossT & .399 & & .255 & .372 & .295 & \\
\hline FI & & .8544 & & & & \\
\hline FITE & .662 & & & & & \\
\hline FISD & .704 & & .550 & & & \\
\hline FICD & .758 & & .635 & .663 & & \\
\hline FIST & .665 & & .527 & .585 & .608 & \\
\hline
\end{tabular}


Table 29 continued

TE $S D \quad C D \quad S T$

aI

\begin{tabular}{ll} 
AITE & .610 \\
AISD & .640 \\
aICD & .652 \\
aIST & .618 \\
\hdashline & \\
UI & \\
UITE & .599 \\
UISD & .523 \\
UICD & .776 \\
UIST & .702
\end{tabular}

.8119

640

618

.562

$.502 \quad .520$

$\begin{array}{llll}.453 & .498 & .579 & 1.000\end{array}$

.8194

599

523

.416

$.866 \quad .514$

$.689 \quad .433 \quad .745$

FA

FATE

494

FASD $\quad .540$

FACD $\quad .583$

FAST $\quad .491$

.7252

$\begin{array}{ll}\mathrm{IA} & .8110\end{array}$

IATE $\quad .630$

CASD $\quad .719$

IACD $\quad .617$

AAST $\quad .555$

.638

$.501 \quad .566$

$.411 .526 \quad .462$

WA $\quad .8192$

$\begin{array}{ll}\text { WATE } & .750 \\ \text { WASD } & .565 \\ \text { WACD } & .776 \\ \text { WAST } & .490\end{array}$

.330

$.497 \quad .444$

$.311 .515 \quad .379$

.495

$.850 \quad .525$

$.424 .412 \quad .438$

FI

FI:TE

.621

.7992

FI'SD .634

FI'CD $\quad .620$

FI'ST .580

.574

$.489 \quad .514$

$.465 \quad .456 \quad .515$

$M I^{\prime}$

MITE $\quad .376$

$\mathrm{MI}^{1} \mathrm{SD} \quad .683$

$M I$ "CD $\quad .554$

MIST $\quad .573$

.7474
.372
.248
$.323 .559 \quad .451$ 
Table 29 continued

$\mathrm{EI}$

$\mathrm{E}+\mathrm{TE}$

ET:SD

$E I^{\prime} \mathrm{CD}$

EI ST
.581

.586

.681

.573
.7921

.666

$.445 \quad .441$

$.354 \quad .341 \quad .709$

The corrected item-to-total correlations consistently showed that the items for the task of selecting textbooks and instructional materials were the weakest variable under the managerial control process of standards. Low squared multiple correlations between the items and the total also supported this conclusion. The multiple $\mathrm{R}$ squared coefficients for the selection of textbooks and instructional materials were .368 (FSST), .383 (CSST), and .172 (DSST), which accounted for only a small amount of the variance. Similarly, the multiple $R$ squared coefficients for the selection of textbooks and instructional materials under the process of assessment were also low: .301 (FAST), .319 (fAST), and .244 (WAST).

Based on the data in Table 27, the selection of textbooks and instructional materials under the managerial control processes of standards and assessment appeared to be among the weakest items. Other items must also be considered questionable based on these internal reliability statistics. Yet, there is still the question of whether these data identified single weak. items or clusters of items. In order to provide more evidence of the underlying relationships between items, principal components analyses were conducted. 


\section{Erincipal Components Analysis}

Principal components analyses were pexformed on the overall model as well as on latent, aggregate variables. Principal components analysis may yield as many components as there are indicators; thus, the pivotal question raised by this procedure is, how many hypothetical factors have substantive meanings (Heise, 1974, p. 9). The factor loadings or coefficients offer a broad numerical solution as to the underlying dimensions of the items which may then be interpreted for substantive relationships.

Principal components analysis partitions the total variance of all the items (Stevens, 1986, p. 338). Statistically, factor scores are pearson $\mathrm{r}^{\prime} \mathrm{s}$. The first principal component explains the highest percentage of the total variance. The second component is the linear combination of items which are uncorrelated with the first principal component. It explains the next highest percentage of the total variance [after the variance attributed to the first component has been removed].

Principal components analysis provides a matrix between the itens and the derived factors or components. There are a number of methods used to guide the analyses of the factors (Dunteman, 1989, pp. 22-23; Stevens, 1986, pp. 340-343): (a) Kaiser's criterion of retaining factors with eigenvalues greater than one; (b) Jolliffe's criterion of retaining factors with an eigenvalue cutoff of $0.7 ;$ (c) the retention of factors which explain up to 70 percent of the total variance; (d) a scree graph which plots 
the steep drop of elgenvalues; and, (e) the calculation of a $Q / P$ ratio $<.30$ (where $Q$ is the number of factors and $P$ is the number of variables). The interpretation of the retention criteria, however, is not straightforwara, especially if there are particular items with high coefficients in factors with low a amount of variance. Moreover, the relationship between the sample size, number of variables, and mean communality the portion of the total variance that is shared with the remaining $\mathrm{p}^{-1}$ variables (Dunteman, 1989, p. 55) l determine the accuracy of the above methods. In general, for $\mathbb{N}>250$ and a mean commality $\geq .60$ [i.e. for each factor], the kaiser or scree criteria have been shown to be accurate (stevens, 1986, p. 341-m 342).

The coefficients under each factor correspond to the largest associated variance, often referred to as an eigenvalue. Hence, there is another decision which must be made regarding the meaningfulness of coefficients. "certainly any loading which is going to be used to interpret a factor should be statistically significant at a minimum" (p. 343). Since measurement errox or chance may be prevalent in principal components analysis, stevens has recommended taking sample size into account in calculating significance $[\mathrm{p}>.01$, two-tailed test] $(\mathrm{p} .344)$. The critical value of $N=500$, is .117. Therefore, as a rough estimate, by doubling the critical value, only factor loadings $>2(.117)=$ .234 in absolute value would be statistically significant. A more conservative estimate would, of course, explain more of the 
variance and be of greater practical significance. Thus, factor loadings between 4 and .5 would be minimally acceptable for purposes of this study (Armor, 1974, p. 35; Dembo \& Gibson, 1984).

In order to facilitate the interpretation of principal components analysis, Kaiser developed a varimax rotated analysis of factor scores resulting in higher loadings on a smaller number of items (Stevens, 1986, p. 343) and communality coefficients of less than one. The varimax rotation maximizes the sum of the variances of the squared factor loadings within each colum and offers a unique solution (Dunteman, 1989, p. 49), The tables and interpretations used here were all varimax rotations.

The initial statistics in the principal components analysis of all 50 items on the sMCQ resulted in six factors with eigenvalues greater than one, which explained 60.9 percent of the total variance. However, in order to broaden the analysis and explain at least 70 percent of the total variance, twelve principal components were extracted. The first principal component explained 45.7 percent of the total variance. The second, uncorrelated component explained 3.9 percent, while the remaining factors had associated variances of 3.6 to 1.6. Each principal component had mean communalities greater than .64 on the final statistics and varimax rotation.

The results of a varimax rotation of the individual principal components are reported in rable 30. Those items with the highest factor loadings were listed under each of the twelve 
factors. In six of the factors, an interpretation of the practical significance was readily apparent and may be considered meaningful to the construct of school managerial control.

Table 30

Factor Loadings From Varimax Rotation of Principal componants on suco Items

\begin{tabular}{|c|c|c|c|c|c|c|}
\hline $\begin{array}{l}\text { Factor } \\
\text { one }\end{array}$ & $\begin{array}{l}\text { Factor } \\
\text { Two }\end{array}$ & $\begin{array}{l}\text { Factor } \\
\text { Three }\end{array}$ & $\begin{array}{l}\text { Factor } \\
\text { Four }\end{array}$ & $\begin{array}{l}\text { Factor } \\
\text { Five }\end{array}$ & $\begin{array}{l}\text { Factor } \\
\text { Six }\end{array}$ & $\begin{array}{l}\text { Factor } \\
\text { Seven }\end{array}$ \\
\hline $\begin{array}{l}\text { EI 'TE } \\
(.674)\end{array}$ & $\begin{array}{l}\text { FIST } \\
(.693)\end{array}$ & $\begin{array}{c}\text { CsT } \\
(.643)\end{array}$ & $\begin{array}{l}\text { WACD } \\
(.743)\end{array}$ & $\begin{array}{c}\text { FASD } \\
(.742)\end{array}$ & $\begin{array}{c}\text { EI ST } \\
(.833)\end{array}$ & $\begin{array}{l}M I ' S T \\
(.603)\end{array}$ \\
\hline $\begin{array}{l}\text { Job Sat. } \\
(.657)\end{array}$ & $\begin{array}{c}\mathrm{FTSD} \\
(.683)\end{array}$ & $\begin{array}{c}\operatorname{CscD} \\
(.602)\end{array}$ & $\begin{array}{l}\text { WATE } \\
(.735)\end{array}$ & $\begin{array}{c}\text { UTSD } \\
(.683)\end{array}$ & $\begin{array}{l}E T^{\circ} \mathrm{CD} \\
(.772)\end{array}$ & $\begin{array}{l}\text { WAST } \\
(.500)\end{array}$ \\
\hline $\begin{array}{l}\operatorname{Sch} . \text { Adn . } \\
\text { Sat. } \\
(.620)\end{array}$ & $\begin{array}{c}\text { aIst } \\
(.646)\end{array}$ & $\begin{array}{l}\text { FATE } \\
(.598)\end{array}$ & $\begin{array}{l}\text { MI TE } \\
(.601)\end{array}$ & $\begin{array}{l}\text { FAST } \\
(.640)\end{array}$ & $\begin{array}{l}\text { FI'ST } \\
(.495)\end{array}$ & $\begin{array}{c}\text { fAST } \\
(.498)\end{array}$ \\
\hline $\begin{array}{l}F^{\prime} S \mathrm{SD} \\
(.556)\end{array}$ & $\begin{array}{c}\text { FCD } \\
(.617)\end{array}$ & $\begin{array}{c}\text { FSTE } \\
(.593)\end{array}$ & $\begin{array}{c}\text { EATE } \\
(.422)\end{array}$ & $\begin{array}{c}\text { FSST } \\
(.433)\end{array}$ & $\begin{array}{c}\text { (ACD } \\
(.444)\end{array}$ & \\
\hline $\begin{array}{l}\text { (ASD } \\
(.522)\end{array}$ & $\begin{array}{c}\operatorname{cssT} \\
(.509)\end{array}$ & $\begin{array}{c}\text { aITE } \\
(.532)\end{array}$ & $\begin{array}{c}\text { aITE } \\
(.411)\end{array}$ & & & \\
\hline $\begin{array}{l}E x \cdot S D \\
(.501)\end{array}$ & & $\begin{array}{c}\text { FSCD } \\
(.510)\end{array}$ & & & & \\
\hline $\begin{array}{l}\text { Factor } \\
\text { Eight }\end{array}$ & $\begin{array}{l}\text { Factor } \\
\text { Nine }\end{array}$ & $\begin{array}{l}\text { Factor } \\
\text { Ten }\end{array}$ & $\begin{array}{l}\text { Factor } \\
\text { Eleven }\end{array}$ & $\begin{array}{l}\text { Factor } \\
\text { Twelve }\end{array}$ & & \\
\hline $\begin{array}{l}\mathrm{MI} \mathrm{CD} \\
(.802)\end{array}$ & $\begin{array}{l}\text { DSTE } \\
(.853)\end{array}$ & $\begin{array}{l}\operatorname{FsD} \\
(.485)\end{array}$ & $\begin{array}{l}F I T E \\
(.476)\end{array}$ & $\begin{array}{l}\text { WASD } \\
(.515)\end{array}$ & & \\
\hline $\begin{array}{l}M I^{2} \mathrm{SD} \\
(.626)\end{array}$ & $\begin{array}{c}\text { DSCO } \\
(.735)\end{array}$ & $\begin{array}{l}\text { FSST } \\
(.428)\end{array}$ & $\begin{array}{l}M I T E \\
(.431)\end{array}$ & $\begin{array}{c}\text { aISD } \\
(.440)\end{array}$ & & \\
\hline & & & $\begin{array}{l}\text { DSST } \\
(.405)\end{array}$ & & & \\
\hline
\end{tabular}


The first principal component explaining the highest percentage of total variance was dominated by the two satisfaction items and those managerial control behaviors which were associated with incentives. Thus, equitable distribution and frequency of incentives and fairness of assessments in staff development and teacher evaluation correlated most highly with satisfaction. Moreover, three out of the top four managerial control items referred to the task of staff development. The next five highest factor scores $(>.4)$ in the first principal component, however, included two other tasks, curriculum development and teacher evaluation. Although only one item measuring utility of information appeared in Table 30 in factor five, two utility of information items had statistically significant factor scores greater than .4 in factor one. Consistent with reliability results, the highest proportion of variance [ 68 percent] of all the items in the first seven principal components was found in the item measuring teacher satisfaction with the performance of the school administration $[i . e .$, based on the sum of the squares of the loadings for each row of the principal components matxix (Dunteman, 1989, p.39)). The second principal component or factor clearly identified the managerial control process of information. The specific indicators with the highest factor scores focused on the structural-frequency of information rather than on the qualitative indicators. Three additional information indicators had factor scores greater than 4 in factor two. 
The items which correlated highly in the third principal component belonged primarily to the managerial process of standards, including both structural and qualitative indicators. The frequency of assessment in teacher evaluation was one of four items pertaining to directly to the task of teacher evaluation in factor three. The other predominant task in the thira principal component was curriculum development. Not listed was the item of FACD, with a factor score of .470 .

The fourth principal component identified the indicator of worth of assessments for teacher evaluation and curriculum development. In fact, teacher evaluation was clearly the dominant task in this principal component. Thus, teachers associated meaningfulness of incentives, worth and fairness of assessments, and the adequacy of information with teacher evaluation.

Each of the four items isted under the fith principal component also appeaxed in Table 19. Recall that these were items with high teacher Don't know responses, and for FSST, FAST, and FASD, the mean values were above 3.0, indicating apparent teacher disagreement about these managerial behaviors. Therefore, this principal component may indicate behaviors not part of the construct of school managerial control, and, for that reason, correlate highly.

Two equitable distribution of incentive behaviors were associated with satisfaction in the first principal component. In the sixth principal component, the other two equitable 
distribution of incentive behaviors dominated, selection of texts and curriculum development. The items supporting this factor were faimess of assessment in curriculum development and the frequency of incentives for the selection of textbooks and instructional materials.

In the seventh principal component, the qualitative indicators of worth, meaning, and fairness were all associated with the task of selecting textbooks and instructional materials. No other curricular and instructional tasks were reported here.

For factors seven through twelve, the practical significance was limited to just two or three items per factor. Nevertheless, the correlations Iinked similar managerial processes, behavioral indicators, and/or tasks. In the eighth principal component, meaningfulness of incentives were identified. In the ninth principal component, two difficulty of standards loaded highly. The tenth principal component included two frequency of standards indicators, although the factor loadings were less than .5 . The eleventh factor matched both incentives and teacher evaluations [again the factor loadings were less than .5]. Included here, too, however, was the item of difficulty of standards for the selection of textbooks and instructional materials. In the twelfth principal component, two qualitative indicators of the task of staff development were statistically correlated. Finally, two items on the sMco had no practically significant correlations with any of the twelve factors. They were CSSD and DSSD. 
The results of principal components analysis on the overall model in the SMCQ identified factors in which three out of the four managerial processes predominated: information (factor two), standards (factor three), and incentives (factors one, six, eight, and eleven). The other managerial control process, assessment, was identified primarily as a qualitative vaxiable in factors one, four, six, seven, and twelve. Within the six meaningful principal components, four factors tended to focus, although not exclusively, on specific tasks: factor one (staff development), factor two (the selection of textbooks and instructional materials), factor three (teacher evaluation and curriculum development), factor four (teacher evaluation), and factor seven (the selection of textbooks and instructional materials).

While the principal components analysis on the total model revealed meaningful factors across the managerial processes as well as across specific curricular and instructional tasks, a closer perspective was afforded by principal components analyses of each of the four managerial processes themselves again substituting mean values by instructional levels. Although the number of items was reduced from 50 in the overall model to 12 for the aggregate variables, the same criteria for retaining factor loadings were applied $(i . e,>, 4)$. In order to facilitate initial interpretations, varimax rotations extracted three principal components for each aggregate variable.

Tables 31 through 34 report data from the varimax rotation of 
the principal components analysis for each of the four latent managexial process. The rotated factor loadings are followed by eigenvalues, percent of variance, cumulative percentages, and the communality estimate of the factors. None of these statistics were affected by the varimax rotation (Dunteman, 1989).

In Table 31, the first principal component within the managerial process of standards combined the structuralfrequency dimension with the qualitative indicator clarity of standards. The specific task of the selection of textbooks and instructional materials formed its own factor, loading high on each of its three items in the second principal component. The thixd principal component referred to the perception of difficulty of standards.

Table 31

Vaximax Rotation of Principal components Matrix for standards

\begin{tabular}{lccc}
\hline & \multicolumn{3}{c}{ Principal Components } \\
Item & 1 & 2 & 3 \\
FSTE & .787 & .102 & .144 \\
FSSD & .586 & .305 & .388 \\
FSCD & .817 & .178 & .070 \\
FSST & .501 & .49 & .218 \\
CSTE & .755 & .141 & .162 \\
CSSD & .662 & .428 & .060 \\
CSCD & .730 & .219 & .082 \\
CSST & .511 & .626 & .104 \\
DSTE & .038 & .105 & .848 \\
DSSD & .598 & .252 & .418 \\
DSCD & .215 & .141 & .773 \\
DSST & .116 & .878 & .186 \\
& & & .831 \\
Eigenvalue & 5.696 & 1.253 & 6.9 \\
Percent Variance & 47.5 & 10.4 & .404 \\
Cumulative Percent & 47.5 & 57.9 & 64.8 \\
Communality & .651 & .587 & .704
\end{tabular}


The principal components analysis of items under the managerial control process of information resulted in three factors with eigenvalues greater than .8 , which explained almost 70 percent of the total variance (Table 32). The first principal component measured the structural-frequency of information supported by two adequacy indicators for curriculum development and the selection of textbooks and instructional materials. The second principal component identified all four utility of information items, supported by two frequency behaviors. The third principal component identified the other qualitative behavior of adequacy. Four of the twelve information items contributed to more than one principal component, suggesting that the items are interrelated.

\section{Table 32}

Varimax Rotation of Principal Components Matrix for Information

\begin{tabular}{|c|c|c|c|}
\hline Item & $\begin{array}{l}\text { Principal } \\
1 \\
\end{array}$ & $\begin{array}{r}\operatorname{comp} \\
2 \\
\end{array}$ & $\mathrm{~s}$ \\
\hline FTTE & .70 & . 87 & .347 \\
\hline FISD & .752 & .336 & .186 \\
\hline FICD & .666 & .49 & .244 \\
\hline FIST & .823 & .185 & .198 \\
\hline aITE & .161 & .306 & .820 \\
\hline AISD & .355 & .073 & .783 \\
\hline $\mathrm{aICD}$ & .595 & .346 & .408 \\
\hline aIST & .771 & .269 & .257 \\
\hline UITE & .358 & .526 & .423 \\
\hline UISD & .217 & .783 & -.005 \\
\hline UICD & .314 & .730 & .360 \\
\hline UIST & .322 & .683 & .320 \\
\hline
\end{tabular}


Table 32 continued

Eigenvalue Percent Variance Cumulative Percent Communality

$$
6.656
$$

55.5

55.5

.579

$\begin{array}{cc}.854 & .823 \\ 7.1 & 6.9 \\ 62.6 & 69.4 \\ .713 & .704\end{array}$

The principal components analysis of assessments resulted in three factors with eigenvalues greater than 9 , which explained almost 66 percent of the total variance (Table 33 ). The first principal component was dominated by all four faimess items, joined by two indicators of worth. The structural-frequency dimension of assessments separated into two principal components: teacher evaluation and curriculum development were part of the second principal component, while the items indicating regular assessments of staff development and selection of textbooks formed their own factor. In both instances, the structuralfrequency items were linked with judgments as to the worth of assessments. In fact, in each of the three pxincipal components, teacher perceptions of the worth of assessment was present. 
Tabla 33

Varimax Rotation of Principal Components Matrix of Assessments

\begin{tabular}{|c|c|c|c|}
\hline Item & ${ }^{P}$ & Principal components & 3 \\
\hline FATE & .082 & .691 & .261 \\
\hline FASD & .140 & .352 & .723 \\
\hline FACD & .260 & .671 & .320 \\
\hline FAST & .193 & .190 & .814 \\
\hline AATE & .708 & .388 & .037 \\
\hline IASD & .697 & .445 & .179 \\
\hline $\mathrm{AACD}$ & .706 & .276 & .106 \\
\hline EAST & .714 & .033 & .361 \\
\hline WATE & .391 & .796 & .106 \\
\hline WASD & .533 & .406 & .207 \\
\hline WACD & .385 & .785 & .160 \\
\hline WAST & .584 & $* 121$ & .543 \\
\hline Eigenvalue & 5.913 & 1.025 & .962 \\
\hline Percent variance & 49.3 & 8.5 & 8.0 \\
\hline $\begin{array}{l}\text { Cumulative Percent } \\
\text { Communality }\end{array}$ & $\begin{array}{l}49.3 \\
.552\end{array}$ & $\begin{aligned} & 57 . .8 \\
& .666\end{aligned}$ & $\begin{aligned} 65.8 \\
.620\end{aligned}$ \\
\hline
\end{tabular}

The principal components analysis on the fourth managerial process of incentives also resulted in three factors explaining 67 percent of the total variance (Table 34). The mean communalities for the factors were somewhat lower, suggesting the interrelatedness of the items, particularly the structuralfrequency of incentives which were found in each of the three principal components.

The first principal component linked the meaningfulness of incentives with two structural-frequency items, while principal components two and three each had two items measuring the equitable aistribution of incentives. In the second principal component, the frequency, meaning, and equity of teacher evaluation were highly correlated. While, in the third principal component, the frequency and equitable distribution for the 
selection of textbooks had high factor loadings.

Table 34

Varimax Rotation of principal Components Matrix of Incentives

Principal components

Item 1 2 3

FI'TE

FI'SD

$F^{\prime} \mathrm{CD}$

FI'ST

MI TE

$M I: S D$

MI ${ }^{\prime} \mathrm{CD}$

MI'ST

EI'TE

EI'SD

EI CD

EI'ST

Eigenvalue

Pexcent Variance

Cumulative Pexcent

communality
.536

.564

.339

.400

$-.002$

.769

.805

.616

.393

.391

.250

.066

5.961

49.7

49.7

.607
.551

.496

.637

.315

.819

.333

.063

.300

.620

.628

.170

.197

1.186

9.9

59.6

.597
.128

.180

.230

.630

.156

.154

.171

.395

.274

.231

.847

.889

.871

7.3

66.8

.574

\section{Revised Model Scale}

The descriptive statistics, the measures of internal consistency, and the principal components analyses provided empirical evidence to interpret the reliability of specific items on the SMCQ and the practical significance of the aggregate variables. Of the original 48 managerial control indicators, there was evidence to support the retention of 35 items. For five other items, the evidence was less clear in deciding whether to retain or reject. While for eight items, as presently written, the decision to reject them was obvious. Table 35 presents the revised scale of school managerial control. 
Seven of the 13 managerial control items that were rejected or categorized as questionable belonged to the specific task of selecting textbooks and instructional materials. Of the five items rejected or questioned which pertained to structuralfrequency, three were from the frequency of assessment. In all, six of the rejected or questioned items were associated with the managerial control process of assessments, including items from the two qualitative indicators of worth and fairness. Likewise, each of the three indicators under the managerial control process of incentives had one item rejected or questioned. While for standards, frequency and difficulty relating to the task of textbook selection were rejected as were two utility of information items associated with the tasks of teacher evaluation and staff development. 
Table 35

The Revised scale on the sMce

Items Retained

Questionable Items

Items Rejected

FSTE

FSST

FSSD

FSCD

CSTE

CSSD

CSCD

CSST

DSTE

DSST

DSSD

DSCD

FTTE

FISD

FICD

FIST

AITE

aISD

aICD

aIST

UICD

UIST

FACD

fATE

fASD

IACD

WATE

WACD

FI'TE

FI'SD

EI'CD

$M I{ }^{*} \mathrm{CD}$

MI'TE

MI'SD

MI'ST

EI'TE

EI'SD

UITE

UISD

FATE

FASD

EAST

EI'CD

fAST

WASD

WAST

FI'ST

$E^{\prime} I^{\prime} S T$ 
The decisions to reject or question specific items wexe based primarily on the empirical data reported in this chapter. The item FSST reported high teacher disagreement (Table 18) along with high DK responses (Table 19). In addition, the corrected item-to-total correlation was lower for FSST than for the other frequency of standards itens (Table 29). Similar evidence was found to reject DSST. Thus, if these items were deleted, the Cronbach Alpha coefficient for their aggregate variables would be higher.

UITE was rejected based on the reliability data which indicated a low corrected item-to-total correlation (Table 29). Here, too, the Alpha coefficient of utility would be higher if the item were deleted. The decision on UISD was based on reliability data (Table 29) as well as on the low $n$ and high teacher DK responses (Table 19).

Three frequency of assessment items, FATE, FASD, and FAST, were rejected or questioned based on teachex disagreements about the occurrence of these managerial behaviors (Table 18). FATE was categorized as only questionable since it correlated highly with strong items in factor three of the overall model principal components (Table 30); yet, reliability data predicted that the Alpha coefficient would be raised if it were deleted from the aggregate variable. FASD was rejected because of its low $n$ (Table 19) and high correlations with many of the other rejected items (Tables 20 and 30 ), The evidence to reject FAST included all of the above statistics as well as low inter-item 
correlations (Table 29).

The other three assessment indicators were qualitative, fAST, WAST, and WASD. The deletion of each item would raise the Cronbach Alpha coefficient of the aggregate variables as indicated by their low correlations and corrected item-to-total correlations (Table 29). In addition, the factor loading for WASD on Factor Twelve in Table 30 , dia not indicate practical significance.

The last three items which were either rejected or questioned were related to the managerial control process of incentives. The decision to question FI'ST was based primaxily on the reliability data in Table 29. Moreover, both FI'ST and EI'ST loaded onto Factor Six in the principal components analysis of the model (Table 30). On the other hand, in support of EI'ST, it had a higher corrected item-to-total correlation on its aggregate variable than on the overall model (Table 28). Thus, the evidence against these items cannot be considered conclusive. In the case of MI'TE, this itern had a low corrected item-to-total correlation with low correlations and multiple $\mathrm{R}$ squared.

The same statistical interpretations were used to justify the retention of the remaining 35 items. The evidence to support these items, however, varied significantly. That is, while certain indicators of behaviors and processes aggregated within factors precisely as originally hypothesized, other indicators were empirically linked to items outside of its aggregate variable. As a result, alternative meanings must be considered 
as to how school managerial control actually operates. For example, under the managerial process labelled standards, frequency and clarity loaded onto the same factor (Table 31), while a unique factor was created by the indicators pertaining to the selection of textbooks and instructional materials.

Under the managerial process of information, frequency and adequacy were not clearly distinguishable from the present set of items (Table 32). Utility, on the other hand, formed its own unique factor in Table 32, although it was not strongly supported within the overall principal components model (Table 30).

The structural-frequency of assessments appeared to reflect curricular and instructional tasks aifferences. In addition, the perception of the indicator of worth was possibly not so clear since factor scores were not consistent within any one category (Tables 30 and 32 ).

The evidence to support the structural-frequency of incentives seemed to confirm the blurred ine between structural and discretionary behaviors (Tables 22,26 , and 34). However, the statistical differences among the indicators of equitable distribution seemed to reflect task distinctions (Tables 30 and 34).

The statistical measure of the revised scale of the 35 iten model resulted in an overall Alpha coefficient of .9675 [somewhat lower than the 48 item Alpha coeficient] and eight principal components with eigenvalues greater than .75 , explaining 69.4 percent of the total variance. The mean communality of each of 
the elght factors was greater than .6. Table 36 summarizes the substantive results from the varimax rotation of the principal components. The items undex each factor were 1 isted in descending order, beginning with the highest factor scores. only the last three items in factor seven had factor scores less than 4.

Table 36

Varimax Rotation of Principal components on the Revised $5 M c 0$

\begin{tabular}{|c|c|c|c|c|c|c|c|}
\hline $\begin{array}{l}\text { Factor } \\
\text { one }\end{array}$ & $\begin{array}{c}\text { Factor } \\
\text { Two }\end{array}$ & $\begin{array}{l}\text { Factor } \\
\text { Three }\end{array}$ & $\begin{array}{c}\text { Factor } \\
\text { Four }\end{array}$ & $\begin{array}{c}\text { Factor } \\
\text { Five }\end{array}$ & $\begin{array}{c}\text { Factor } \\
\text { Six }\end{array}$ & $\begin{array}{l}\text { Factor } \\
\text { Seven }\end{array}$ & $\begin{array}{l}\text { Factor } \\
\text { Eight }\end{array}$ \\
\hline aIST & EITE & FSSD & aISD & WATE & $M I \cdot S D$ & $\mathrm{E} T \mathrm{CD}$ & DSTE \\
\hline EIST & Job/Sat & DSSD & aITE & WACD & $M T^{\prime} \mathrm{CD}$ & $\mathrm{AACD}$ & DSCD \\
\hline FTSD & $\mathrm{FI}^{\prime} \mathrm{CD}$ & FACD & $\mathrm{CSCD}$ & fatr & $\mathrm{MI} S \mathrm{ST}$ & $\mathrm{SAT} / \mathrm{SCH}$ & \\
\hline FTCD & Sch Adm & FSCD & CSTE & aIrs & & ADM & \\
\hline $\operatorname{cssi}$ & Sat & FITE & FSTE & & & fASD & \\
\hline UIST & UICD & FSTE & & & & & \\
\hline $\mathrm{aICD}$ & $F^{\prime} T^{\prime} S D$ & & & & & & \\
\hline FITE & $E^{\prime} I^{\prime} S D$ & & & & & & \\
\hline
\end{tabular}

The results of the principal components on the revised sucQ closely reflect the hypothesized model of school managerial control. All four managerial processes were identified: information in factors one and four, incentives in factors two, six, and seven, standards in factors three, four, and eight, and assessment in factor five. Two task differences were also reflected in certain factors: selection of textbooks and instructional materials in factor one, and teacher evaluation in factors four and five.

In the first principal component, the managerial process of 
information dominated. Three of the items with factor scores between .67 and .70 pertained to the frequency of information. Four of the eight items pertained to the selection of textbooks and instructional materials, although the other curricular and instructional tasks were also present within the managerial activities of information. The frequency of information was supported by three qualitative indicators: adequacy of information, clarity of standards, and the utility of information. The relationship between adequacy and clarity was further demonstrated in factor four.

The second principal component related teacher satisfaction With equitable distribution and frequency measures of incentives. The factor scores ranged from .63 to .50 . Three out of the four curricular and instructional tasks were present in this factor. one other managerial activity, the utility of information in curriculum development also seemed to correlate with teacher satisfaction and the incentives" process.

The thira principal component included all three of the remaining frequency of standards items along with two other structural-frequency items for information and assessment. This factor, therefore, seemed to reflect structural-frequency as a dimension of managerial control.

As was noted above, the fouxth factor linked managerial activities related to adequacy of information with the clarity of standards. Three of the four curricular and instructional tasks were present in this factor. Missing was the selection of 
textbooks and instructional materials.

The fifth principal component identified the managerial process of assessment along the discretionary, qualitative dimension. Indicators of worth and faimess had the highest factor scores ranging from .75 to .53 . Only two tasks were present here, teacher evaluation and curxiculum development.

Meaningful incentives across three tasks fomed a unique principal component in factor six. Equity and fairness in factor seven were again linkea to teacher satisfaction with the performance of school administrators as in factor two. Finally, the last principal component included only two items, both related to the difficulty of standaras.

As in the initial principal components analysis of the overal1 model (Table 30 ), the item CSSD again aid not load highly within any one particular factor. The validity of this item, therefore, should be considered questionable.

\section{Inferential statistics}

The decisions leading to the practical significance of latent, aggregate variables are matters of juagment and interpretation. Item reliabilities and principal components analyses were performed on each of the items on the sMco as well as on the latent, aggregate variables in the hypothesized model of school managerial control. There already appears to be consiaerable evidence to support the categories of managerial behaviors and processes of managerial control. More definitive answers 
necessitate many other confirmatory factor analyses with many different samples, which are not possible within a single study (Armor, 1974, p. 35). Further heuristic evidence relating to the substantive meaning of managerial control may be gained, however, through the use of univariate, repeated measures, and multivariate statistical tests of significance.

In heeding Vickers' (1967) earliex warning concerning aggregations (pp. $29-30)$, the tests of significance were conducted on the data with actual mean values, rather than with mean substitutions or with factor scores (stevens, 1986, p. 362). For some tests, in order to limit the reduction in sample size, which occurred with aggregations in Table 21 , a response criterion of 75 percent was established. That is, actual means were analyzed from those respondents who answered 75 percent of the items within a process (i.e., 9 out of 12 items per managerial process).

The interactive effects which have been of particular interest measure the relationships between managerial control on teacher tenure, levels of instruction, schools, and school effectiveness. A1l of these data were collected from the demographic questions on the sMce or from published school district profiles. The district's own definition of merit- schools (QuIIP) was used to group the sample of schools (see chapter five). 


\section{Structural and Discretionary Managerial Behaviors}

The proposed model of school managerial control hypothesized the presence of two measurable dimensions, structural and discretionary behaviors, for each of the managerial control processes. The differences between these dimensions were measured by within-subject effects in a repeated measures design. statistically significant differences were found between structure and discretionary behaviors for three of the managerial control processes, standards, information, and assessments (Table 37). Only under the managerial control process of incentives were no behavioral differences perceived by teachers.

\section{Table 37}

structural and Discretionary Behaviors of Managexial control for the Four Managerial processes

\begin{tabular}{|c|c|c|c|c|c|c|}
\hline $\begin{array}{l}\text { Processes/ } \\
\text { Behaviors }\end{array}$ & $\begin{array}{c}\text { Number of } \\
\text { Respondents } \\
(\mathrm{N}=486)\end{array}$ & $\begin{array}{c}\text { Percent } \\
\text { Total }\end{array}$ & of Mean & SD & $F$ & $\mathrm{p}$ \\
\hline \multicolumn{7}{|l|}{ Standards } \\
\hline Struct. & 415 & $85 \%$ & 3.12 & 1.13 & 1245 & 001 \\
\hline Discret. & 414 & & & & 12.45 & .001 \\
\hline \multicolumn{7}{|l|}{ Information } \\
\hline struct. & 452 & $93 \%$ & 2.78 & 1.14 & & \\
\hline Discret. & 416 & $85 \%$ & 2.60 & .97 & 7.98 & .005 \\
\hline \multicolumn{7}{|l|}{ Assessment } \\
\hline struct. & 298 & $61 \%$ & 3.03 & $1+18$ & & \\
\hline Discret. & 415 & $85 \%$ & 2.66 & 1.03 & 54.67 & .001 \\
\hline \multicolumn{7}{|l|}{ Incentives } \\
\hline struct. & 423 & $87 \%$ & 2.72 & 1.12 & & \\
\hline Discret. & 408 & $84 \%$ & 2.66 & 2.07 & 0.17 & .680 \\
\hline
\end{tabular}


All of the processes reflected stronger teacher agreement for the discretionary qualities of managerial behaviors of control. The low $\mathrm{n}$ and high mean for the structural dimension of assessments indicated the sharpest contrast between the two categories of managerial behaviors.

\section{Teacher Tenure and Instructional Levels}

A cross-sectional study of control is limited to the specific time interval when data are collected. There may be time intervals in which managerial actions influence satisfaction which, in turn, may influence behaviors (c. Greene, 1981, pp. 218-230), but which do not necessarily influence control (James, et a1., 1982, p. 51). In order to approach some kind of equilibrium ( $p .52)$, the variable of tenure is important.

One criterion in the selection of schools in the sample was whether the principal had been at that particular school a minimum of three years. On the $\mathrm{sMc}$, teachers were requested to state the number of years of teaching experience. Five choices were offered: (a) 1 year or less, (b) 2 to 3 years, (c) 4 to 6 years, (d) 7 to 10 years, and (e) more than 10 years. The response choices "a" and "b" were combined to create a group of "less experienced" teachers, while the combination of choices "c" through " $e$ " formed a group of "experienced" teachers.

Instructional levels were categorized by elementary, junior high, and senior high schools. Thus, differences between subjects could be measured for six categories (2 tenure 
categories $x 3$ instructional levels) against the dependent variables of managerial control. In Tables 38 and 39 , means and standard deviations are reported for the tenure labbreviated as inexperienced and experienced and instructional level

independent variables. In every instance, the mean values for experienced teachers were higher than the mean values for less experienced teachers, reflecting decreased agreement about the presence and quality of managerial control activities with increased experience, Mean values greater than 3.0 would indicate teacher disagreement that these managerial activities are practiced. Experienced teachers at the junior high school level had the highest levels of disagreements among all categories and levels of teachers. Elementary school teachers appeared to be most in agreement with perceptions of managerial control activities. 
Table 38

Means and standard Deviations of reacher Tenure by Level for

the Managerial control processeg

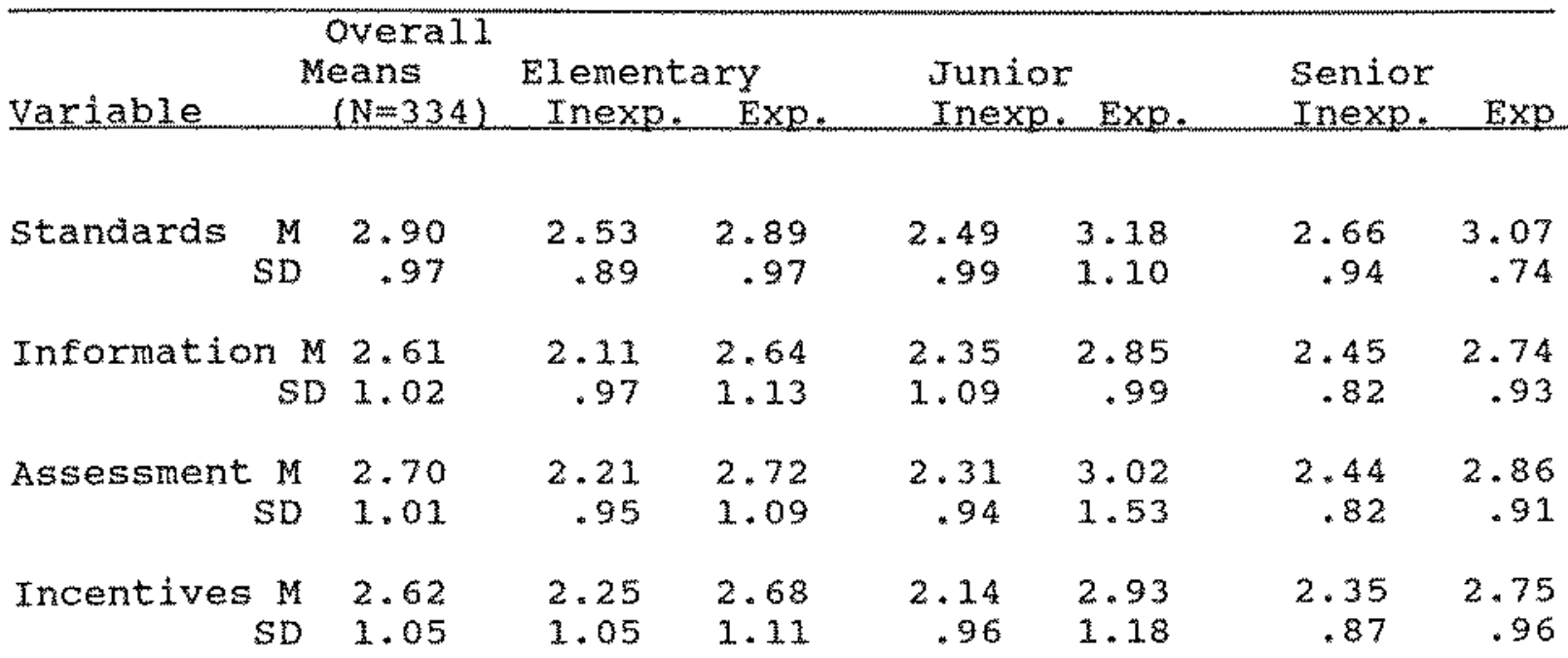

When MANOVA tests of significance were conducted, however, there were no significant interactive effects of teacher tenure by level on the sum of the means of the managerial processes (Wilks' Lambda $=1.26, d f=8,650, \mathrm{p}=.259$ )

subsequent multivariate tests of significance to determine the independent effects of teacher tenure or instructional levels on managerial control resulted in statistically significant differences for teacher tenure $(F=5.61$, df $=4,325, p<.001)$, but not for instructional levels.

To determine which of the variables contributed to the overall significant aifference, post hoc univariate tests (F) at the .05 level $[\mathrm{d} f=1,328$ ) were conducted (Stevens, 1986, p. 122) on the means reported in Table 39. Univariate E-tests indicated significant tenure effects for standards, information, 
assessments, and incentives.

\section{rable 39}

Means and standard Deviations of Teacher Tenure by Manageria1

\section{Control Processes}

\begin{tabular}{|c|c|c|c|c|c|c|c|}
\hline \multirow[b]{2}{*}{ Variable } & \multicolumn{2}{|c|}{$\begin{array}{r}\text { Experienced } \\
\text { Teachers }\end{array}$} & \multirow[t]{2}{*}{ Less } & \multicolumn{2}{|c|}{$\begin{array}{l}\text { Experienced } \\
\text { Teachers }\end{array}$} & \multirow[b]{2}{*}{$\mathrm{F}$} & \multirow[b]{2}{*}{$\mathrm{p}$} \\
\hline & Mean & $\mathrm{SD}$ & & Mean & SD & & \\
\hline standards & 3.07 & .97 & & 2.81 & .93 & 16.297 & .001 \\
\hline Information & 2.73 & 1.01 & & 2.49 & .94 & 11.703 & .001 \\
\hline Assessment & 2.83 & 1.01 & & 2.51 & .96 & 18.484 & .001 \\
\hline Incentives & 2.79 & 1.07 & & 2.43 & .95 & 16.893 & .001 \\
\hline
\end{tabular}

Given the statistical differences between structural and discretionary behaviors in three out of the four managerial processes (Table 37), tests for significant differences between effects of teacher tenure and level of instruction were recalculated in a repeated measures design. Repeated measures, or within-subject designs, reduced the error variance or chance differences, thereby providing a more powerful test of the hypothesized differences than did MANOvA tests of significance (Bray \& Maxwe11, 1988). At the $\mathrm{p}<.05$ level, there was only one significant within-subject result: level of instruction by behavioral dimension for standaras $[E(2,378)=4.38, p<.013]$.

In order to see at what level of instruction the behavioral difference in standards was significantiy different, the data are 
shown in a graph in Figure 4. The overall standard means for the two behavioral dimensions are plotted against the three levels of instruction. Based on the differences between overall means, the significant difference between the behavioral dimensions for standards appears to be at the high school level $[0,3>0.1]$.

Figure 4. The structural and discretionary behaviors for standards by levels of instruction

overall

Means

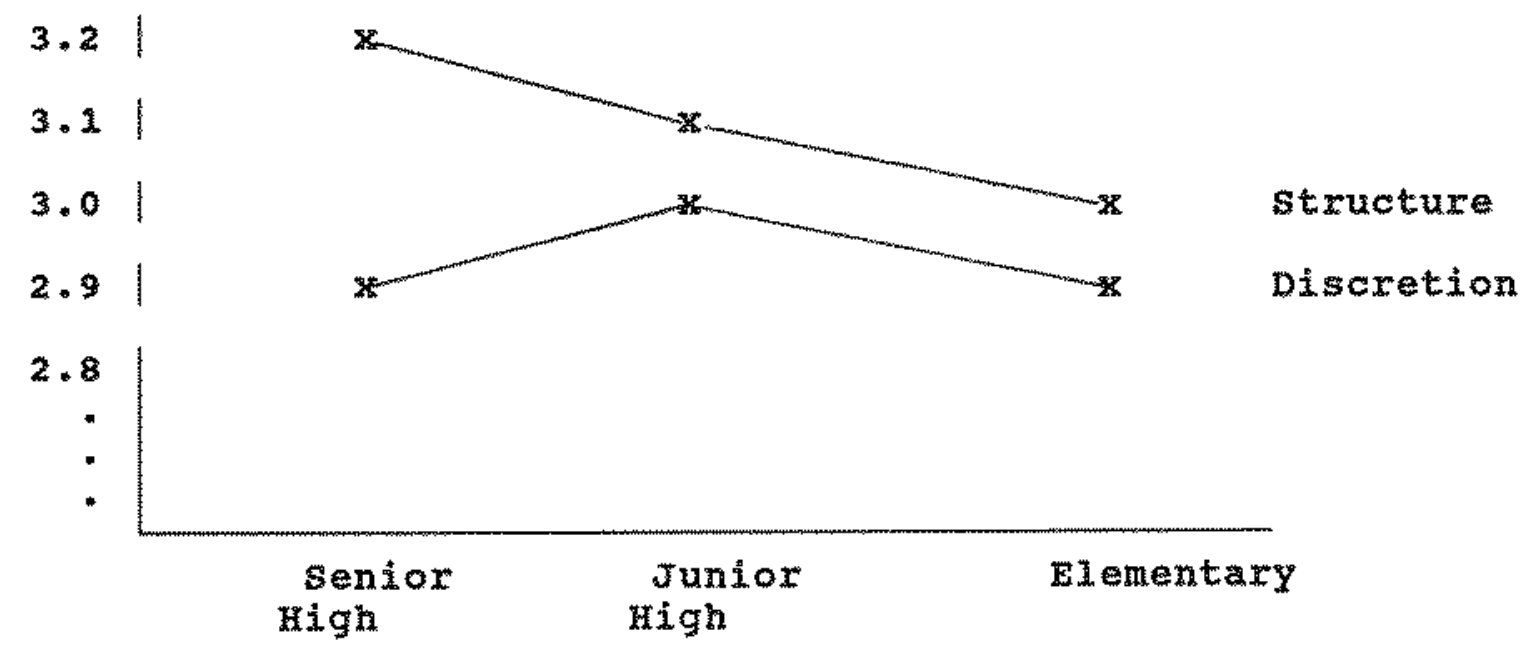

\section{School Efects}

The unit of analysis for the construct validation has been the individual teacher. But, the question may be legitimately raised as to the effect that individual schools have on teachers. Social control theorists and cultural analyses have demonstrated that individuals are influenced by peers and social systems. Perhaps managerial control processes and/or managerial behaviors 
in the sample population can be attributed to differences between schools? School effects were, therefore, tested using repeated measures. The results indicate that a significant betweenschool difference was present for each of the managerial processes: standards $[E=2.39, \mathrm{df}=13,470, \mathrm{p}=.004]$, information $[E=1.98, \mathrm{df}=13,467, \mathrm{~g}=.021]$, assessment $[F=1.85, \mathrm{df}=13,470$, $p=.033]$, and incentives $[F=1.74, \mathrm{~d} f=13,467, \mathrm{p}=.05]$. However, those differences resulted from only one of the fourteen schools within the sample. For each managerial process, the elementary school, E5, had significantly higher mean values for both structural and discretionary behaviors. In other words, the teachers working at $\mathrm{E} 5$ were in greater disagreement about school managerial activities than at the other schools, suggesting that this school's results were anomalous.

In addition, one significant within-school effect was found for schools and managerial information $[\underline{F}=2.03, \mathrm{~d} f=1,13, \mathrm{p}$ $<.017]$. The graph in Figure 5, plots the means for managerial information in each of the fourteen schools by the structural and discretionary dimensions. For purposes of comparison, the overall sample means for the structural dimension was 2.80 , and 2.66 for the discretionary dimension of managerial information. 
Figure 5. Individual school ef fects for the structural and discretionary behaviors of managerial information.

\section{Means}

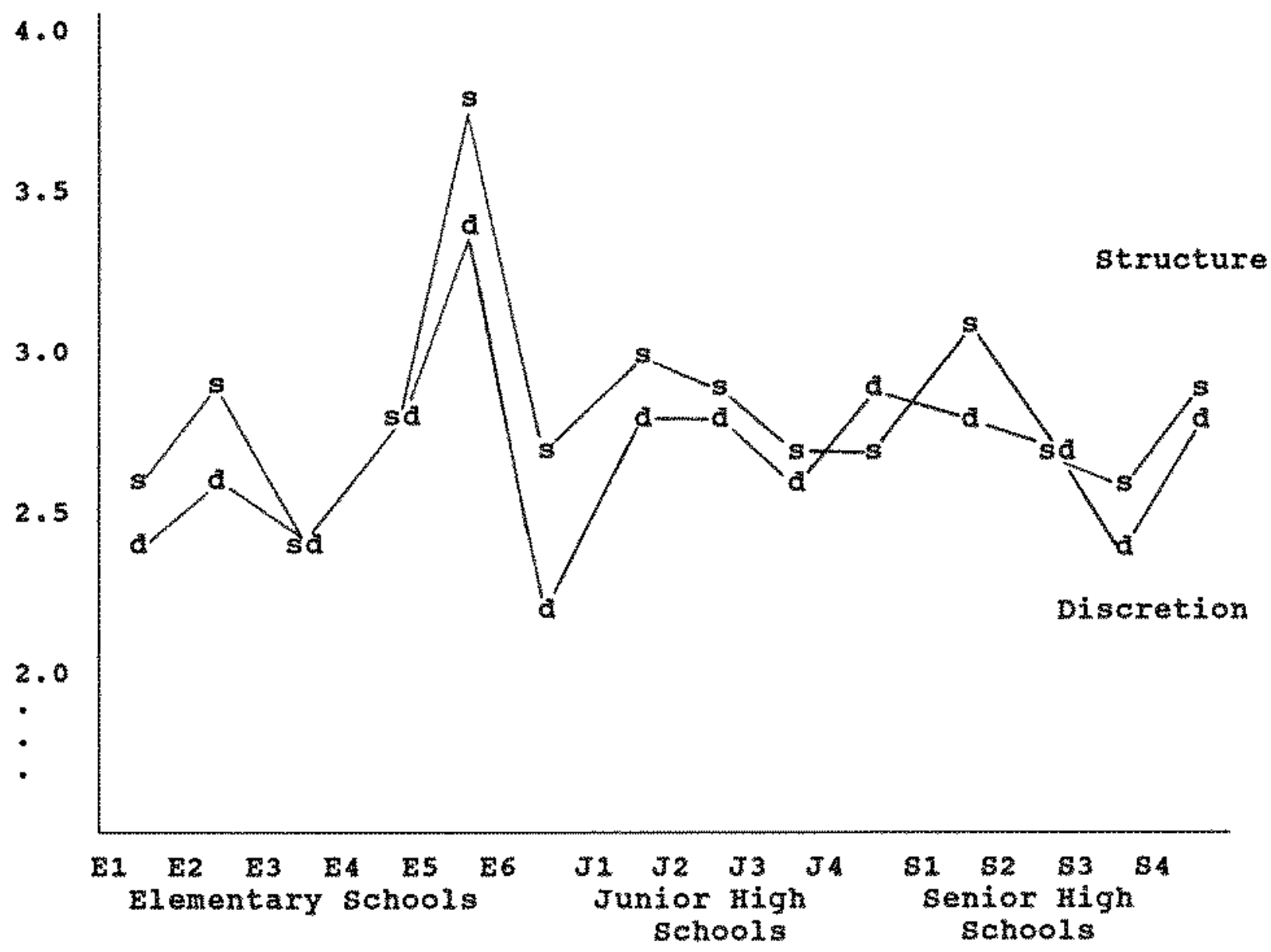

The structural and discretionary behaviors at 85 can be seen in Figure 5 to be considerably higher than the other 13 schools. The interaction effect can also be seen in the graph. The difference or interaction between the structural and discretionary dimensions within E6 (.5) [as wel1 as within E5 (*4)] was greater than the structural-discretionary differences within the other schools in the sample population. In most 
instances, managexial behaviors were perceived to be practiced more along the qualitative-discretionary dimension than with structural frequency. While that diference is statistically significant for all teachers within the sample population (see Table 37), the differences within school E6 were the most graphic.

on the other hand, within school differences revealed that at certain schools, primarily junior high schools, the managerial behaviors along the discretionary dimension were not perceived to be practiced to a greater extent. In Figure 5 , a higher level of teacher disagreement with the presence of discretionary information behaviors than structural information behaviors was found within I4. Similar findings were also recorded for managerial processes of standards within $J 3$ and for assessments within $I 1$ and $J 2$. These results were, of course, more prevalent for incentives, since individual teachers did not perceive significant dimensional differences for managerial behaviors of incentives.

Therefore, with the exception of the unique responses from teachers at $\mathbf{E 5}$, individual school effects may be said to have minimal significance.

\section{School Effectiveness}

The school sample population was divided into two groups, merit and matching. Only the school district's own criteria for merit designation were used, although two of the matching schools 
did receive lesser merit awards during one of the three years in which the current principal was employed. Univariate and multivariate tests of significance between merit and matching schools resulted in significant group differences on each of the managerial process variables. There were significant differences between merit and non-merit schools for each of the processes, but within-group differences (i.e., interactions) were not significant for the two dimensions of managerial behaviors (Table 40). In other words, the sMCQ instrument measured the differences within the two groups consistently. The direction of the mean scores clearly indicated that there was nigher teacher agreement about the occurrence of managerial activities at the merit-schools than at the matching schools. 
Table 40

Comparison of Merit versus Matohing schools by Managerial

Processes and Behaviors

Means

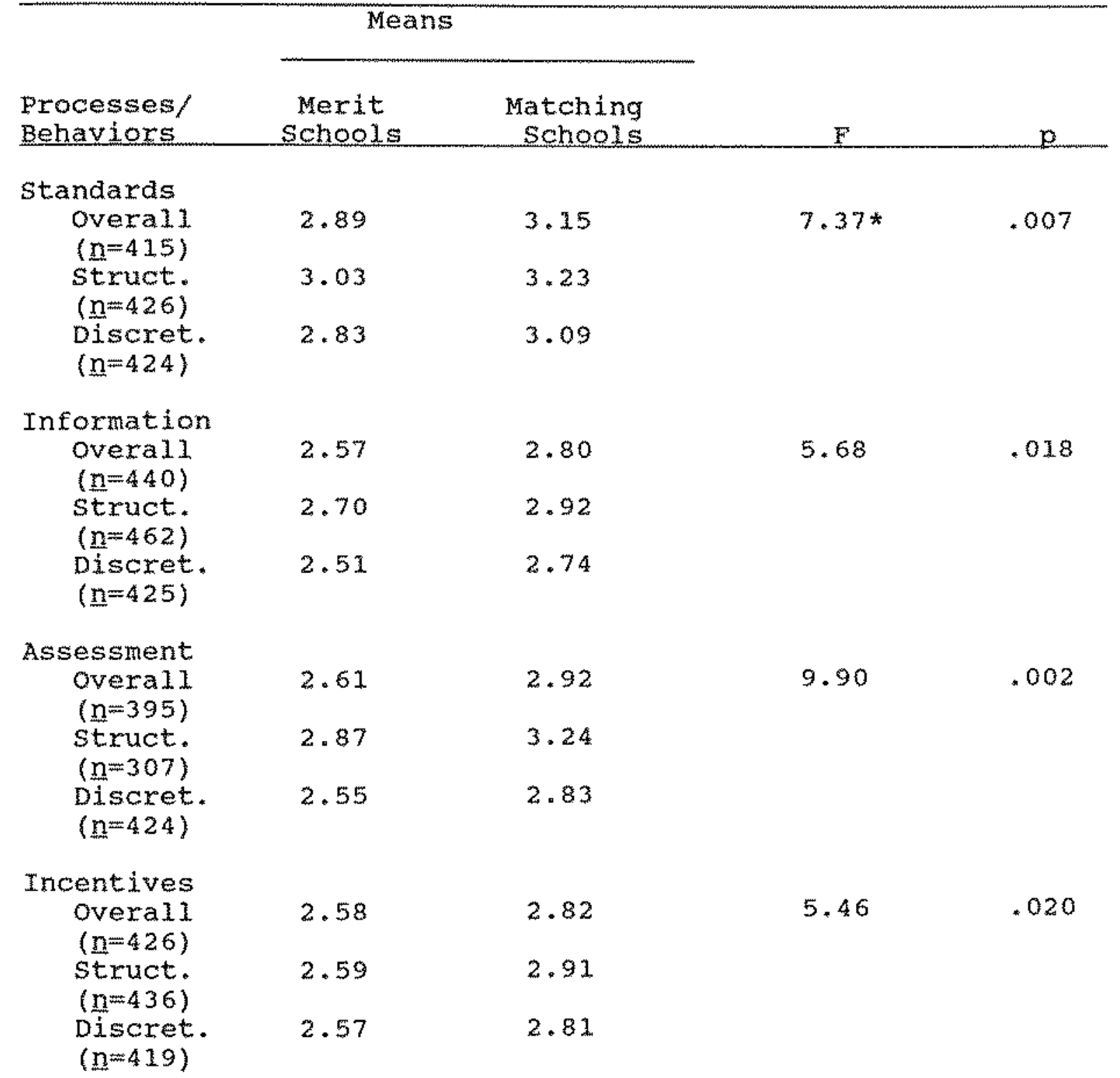

* Univariate ANOVA tests of significance

The absence of interaction effects would indicate that the SMCQ measured the difference between merit and matching schools 
in a consistent manner. Only when teacher tenure was added to the interaction analyses was there a significant interaction difference reported for the managerial process of information [F= 4.43, $\mathrm{df}=1,407, \mathrm{~g}=.0361$. Figure 6 demonstrates that the significant interaction difference occurred within merit-schools between experienced and less experienced teachers as measured by Tukey-kramer procedures at the .05 Level.

Figure 6. Interaction effect between experienced and less experienced teachers within merit and matching schools for the managerial process of information.

\section{Experienced}

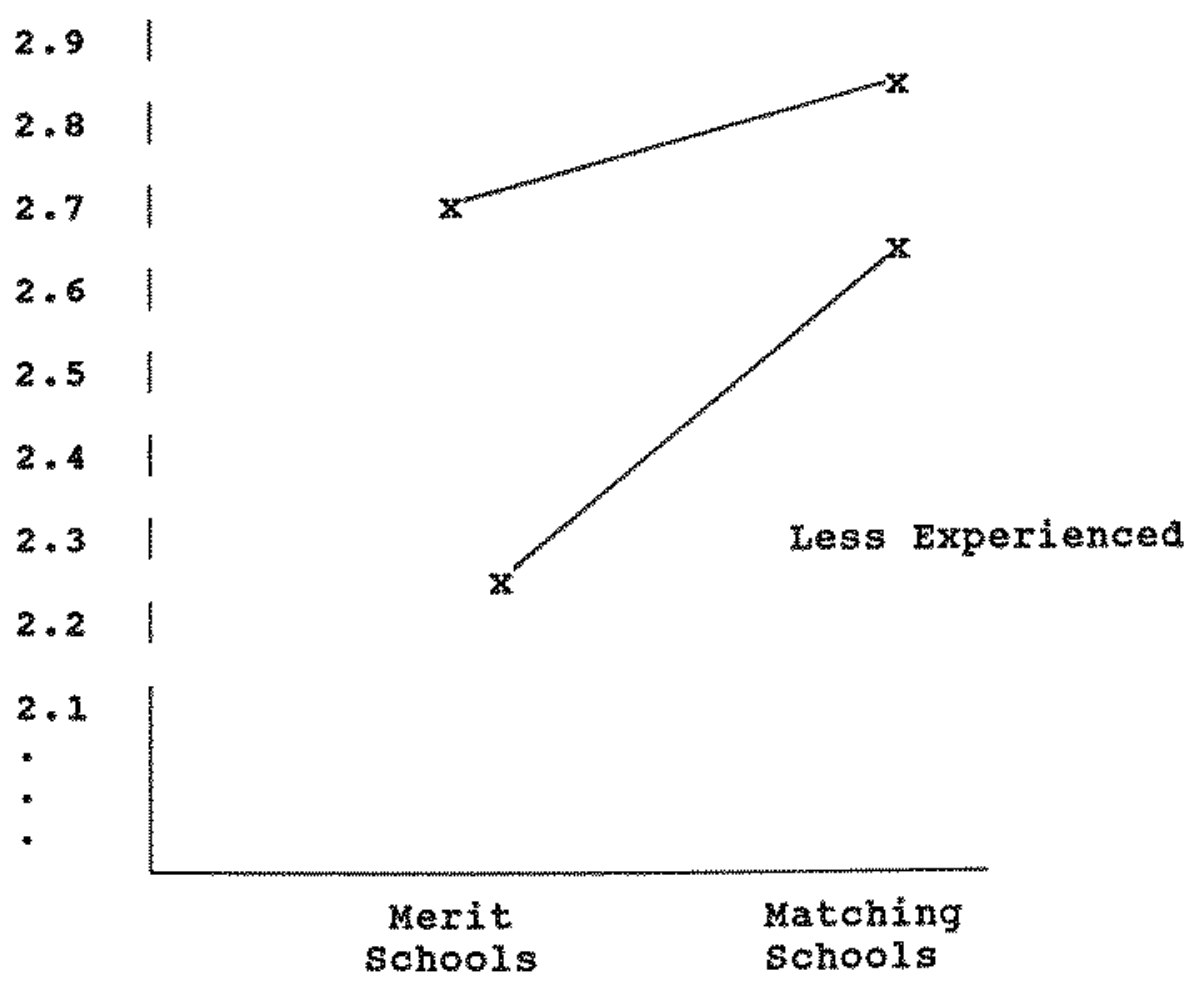


The multiple statistical operations performed on the sample population data were designed to test the data against both the hypothesized model of school managerial control and against the descriptive reality of school arganizations. In the final chapter, a summary of the study is presented along with conclusions and implications drawn from the substantive iterature reviews and data analyses. 


\section{CHAPTER SEVEN}

\section{Summary, Conclusions, and Implications}

\section{Summary}

Understanding organizational dynamics, such as school managerial control, is a search for operational language guided by theory and tested empirically. The operational definition of managerial control presented in this study reflected a synthesis of interdisciplinary concepts linked together by the systematic analysis of the organization's context and empirical measures.

A review of school organizational literature found that although control had initially been identified as a formal mechanism or structurally frequent behavior (Anderson \& Brown, 1971), research studies invariably refer to other mechanisms, less formal and less structural, but even more influential (cohen \& Miller, 1980). Similar results were reported in non-school organizations as wel1 (Mahoney \& Frost, 1977; Eisenhardt, 1985 ). Each time, these mediating variables were reported in the research on control as either residual findings or as implications for further research (Applewhite, 1965; Cohen \& Miller, 1980; Eisenhardt, 1985).

While organizational theory attributes both necessity and potency to the concept of managerial control (Etzioni, 1965 ; pfeffer, 1978a), empirical measures of control over the dominant school technology of curriculum and instruction are often found to be uncertain or weak (Deal \& Cellotti, 1980; Hannaway \& Sproul1, 1978-79; Sproul1, 1981; Rowan, 1982). If the reported 
empirical measures of control are valid, then either the theoretical importance of control has been overstated or the claims made by effective school and instructional leadership researchers concerning the emphasis on curxiculum and instruction cannot be reached. If the theoretical shift from authority, structure, and directives to cultural standards, information systens, critexion-based assessments, and incentives is to be empirically understood, then observable measures must be identified and validated.

Emerging from the reviews of social science theories of control was the inescapable conclusion that no adequate definition of organizational control yet existed. At no time, within any one discipline, did the theoretical construct of managerial control appear complete and fully developed. Many of the discussions remained at abstract levels, away from the level of action on which control was said to operate (Koontz, 1971; vickers, 1967). The overriding conclusion reached by Tannenbaum, et al. (1974) that organizational control was fundamentally hierarchical, regardless of the cultural context, has substantively linked organizational structure to control. But the causal relationships between structure and control were not found to be conclusive (Mahoney \& Frost, 1977). Other processes were involved. The first research objective of this study, therefore, was to identify the nature of these internal managerial dynamics.

Political analyses offered alternative open systems models 
based on the multidirectional concept of influence (Lexbinger, 1965) to replace authoritative power structures (Bacharach \& Lawler, 1982). Thus, two key processes were identified within political dynamics: information and evaluation (pfeffer, 1978a). Sociological definitions of control identified the role of norms and values in performance (Vickers, 1967). Based on both group and individual norms, the control process of standards of performance could be established.

Psychological analyses ultimately turned not only on individual standards, but also on the process of incentives (i.e., the distribution system for rewards and penalties) (Mitchel1, 1987: Mitchell \& Peters, 1988) which was deemed essential to individual motivation, learning, and subsequent behavior (Skinner, 1966). The findings from social-psychology were reviewed to establish specific qualities which contributed to personal rule acceptance (Schein, 1972) and implementation.

The synthesis of social science control theories, thus, led to the proposition that four processes were essential to managerial control: standards, information, assessment, and incentives. Having conceptualized an integrated model of managerial control based on social science theories, the second objective of this study was to measure managerial control within a specific organizational context. context is critical to control behaviors (Hallinger \& Murphy, 1987; Koontz, 1971: Tannenbaun, et al., 1974; Vickers, 2967). For this study, curricular and instructional tasks were chosen as the contextual 
focus. Caweiti and Adkisson (1986) have offered a curricular and instructional framework around four specific tasks: teacher evaluation, staff development, curricular development, and the selection of textbooks and instructional materials. A preliminary study (chapter Three) was conducted to identify and categorize school-building managerial activities related to each of the four managerial control processes. Findings from the preliminary study of specific managerial activities within the curricular and instructional context were then used to develop a measurement instrument of school managerial control.

The lexicon of structural control behaviors is well known throughout management theory. Among structural mechanisms are scheduling, monitoring, prescribing, programming, inspecting, supervising, testing, and checking. The frequency of principalteacher interactions for the hypothesized control processes was used to establish a measure of organizational structure. The preliminary study also revealed discretionary managerial behaviors for which qualitative measures were needed. The language of quality control was found to have a long history. Many qualitative terms such as responsiveness and sensitivity were suggested by Frank (1958-59). In 1967, Vickers had argued for a new, expansive language of control which incorporated growth, achievement, and development. More recent ciaims for a qualitative language have been voiced by patz \& Rowe (1977). Sergiovanni (1987), Weick (1985), and in the organizational coupling taxonomy proposed by Astuto \& Clark (1985). What is 
significant, therefore, is not so much reflected in language, but rather in research objectives and measurement methods. Thirty years ago, Frank's (1958-59) aim was to describe structural, bureaucratic properties, and the resulting dysfunctions in managerial responses. In Frank, the qualitative indicators were proposed only as alternative ideas to the dysfunctional bureaucratic behaviors. This pattern of research has continued during the decades of the sixties, seventies, and early eighties (Miles \& Vergin, 1966; Turcotte, 1974; Meyer, Scott, \& Deal, 1983).

In contrast, Astuto and Clark (1985) proposed qualitative indicators as relational measures between principals and teachers to explain their interactions more descriptively. It is, in part, upon the latter perspective which this study has been based. But, whereas Astuto and clark analyzed structural and qualitative variables alternately, one of the objectives here was to measure the two dimensions interactively.

Bolman and Deal (1984) suggested flipping lenses to bring different perspectives into focus: one structural, one human resource, one political, and one symbolic. The proposal here was to define processes of managerial control which incorporated each of these diverse perspectives. Thus, the essential attributes of managerial control activities should be structural-frequency and discretionary-qualities. Guided by substantive theory, a reciprocal model of managerial control emerged from a comprehensive review of behaviors and processes within a 
specific task context. Through this perspective, a three dimensional construct of managerial control, defined by processes, behaviors, and task context was matched successfully to the complexity of school organizational reality (Lortie, 1977; Weick, 1976; 1985)。

To meet the second research objective, a new instrument, the school Managerial Control Questionnaire (SMCQ), was pre-tested and administered to a large sample of school teachers from fourteen public schools within Dade County, Florida. Teacher responses ( $N=486$ ) were analyzed through unidimensional scaling and reliability techniques, and the latent, aggregate variables of control, hypothesized by the model, were tested using principal components analysis. The initial intexpretation confirmed the existence of four distinct managerial processes with both structural and discretionary qualities. Thirty-five of the original $48 \mathrm{sMCQ}$ items provided reliable and valid measures of these behaviors. Initial construct valiation was begun with post hoc statistical tests of significance to examine the effects of teacher tenure, levels of instruction, schools, and school effectiveness on the proposed model.

The study reflects a managerial research paradigm linking substantive theory with the organizational context and empirical measures (Figure 7). The investigative methods used also reflect different aspects of the paradigm: a synthesis of social science control theories, the systematic analysis of school managerial processes and activities, and the multiple testing and 
interpretation of the measures. The investigation has resulted in a model of school managerial control (see chapter four). The data findings suggest that further model testing is likely to lead to a valid theory of school managerial control.

Figure 7. Managerial research paradigm

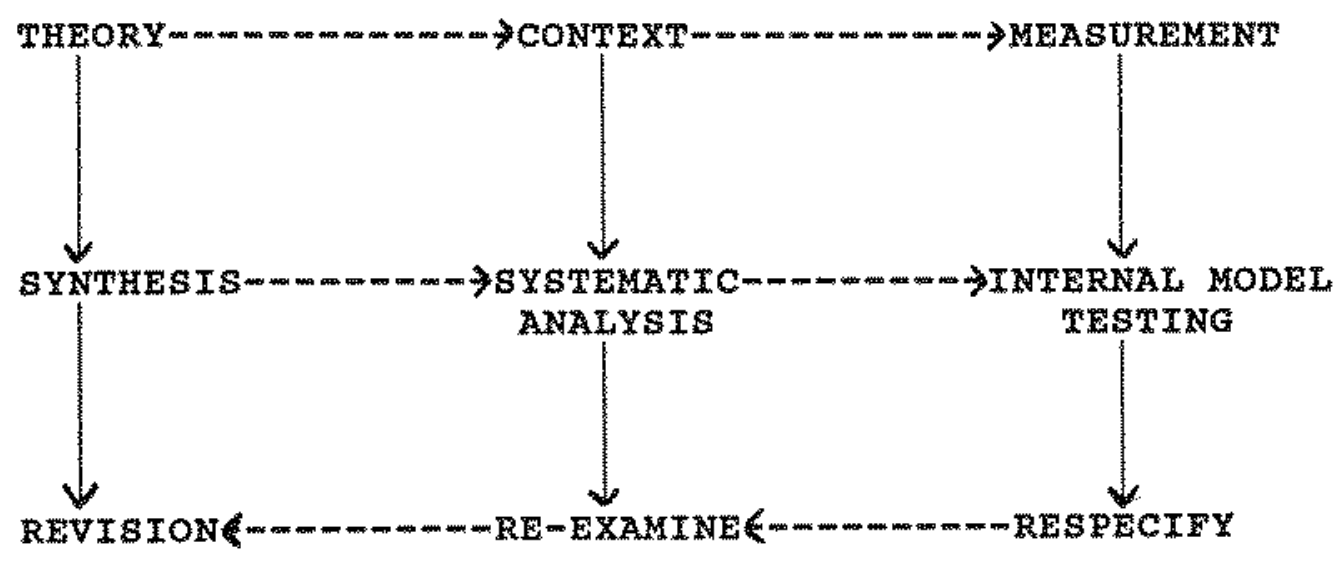




\section{Conclusions}

The findings in this study provided substantive and empirical support for the hypothesized model of school managerial control. The rational managerial control processes of standards, information, assessment, and incentives were each found to have distinct structural and discretionary behavioral indicators which were perceived by teachers across a variety of curricular and instructional tasks (see Tables 30 and 36). The data findings, however, did not delimit the two measures of managerial behaviors as narrowly as was originally hypothesized. That is, within each managerial control process, the structural-frequency measures were consistently associated with specific qualitative managerial behaviors, while other discretionary qualities formed distinct factors (see Tables 31 through 34). Thus, difficulty of standards, utility of information, fairness of assessment, and the equitable distribution of incentives were all somewhat independent and distinct from the frequency of managerial behaviors. The model depicted in Figure 8 suggests that the structural-frequency of managerial control behaviors encompass certain qualitative indicators, while those just cited form distinct factors underlying discretionary managerial control. 
Figure 8. Results from aggregate variable testing of school managerial control

Structural-frequency

Dimension

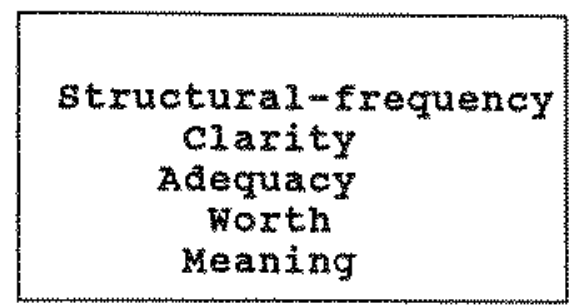

Discretionary

Dimension

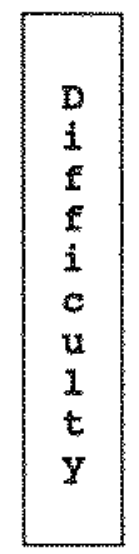

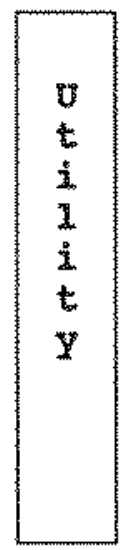

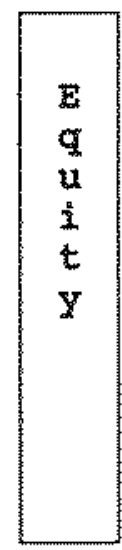

principal components analyses on the overall model of school managerial control (see Tables 30 and 36) confirmed the presence of each of the four managerial control processes. The correlations identified both information and incentives as the dominant managenial control processes within school buildings. Specifically, structural-frequency behaviors related to the process of information for each curricular and instructional task was highly correlated with adequacy of information (see Table 36). Both of the teacher satisfaction items were closely relatea to teacher perceptions of the equitable distribution of incentives. The structural-frequency of standards also was identified independently (see Table 36) as well as in association with the qualitative indicator of clarity (see Table 30 ). The 
fourth managerial control process, assessment, emerged only within the discretionary dimension of managerial behaviors.

In the revised model scale, the principal components analysis demonstrated that the lone frequency of assessment item in curxiculum development was correlated with the structuraifrequency of standards. The revised model also indicated that meaningfulness of incentives and difficulty of standards formed unique factors. One substantive difference between the aggregate variable model (see Figure 8 ) and the revised model in Figure 9 is the reversed roles played by the qualitative indicators of meaningfulness and equitable distribution. In the former, meaningfulness is associated with structural-frequency, while in the revised model, the items of meaningfulness are highly correlated within their own factor. Likewise, in the aggregate model, managerial activities for the equitable distribution are independent of structural behaviors, while in the revised model, equity is linked to structural-frequency. Given the fact that teachers did not perceive statistically significant differences between structural or discretionary behaviors of incentives, both results are tenable. In general, the results from the revised model testing were consistent with the findings from the aggregate variable tests.

The overall and revised models confirmed by principal components analyses (see Tables 30 and 36) indicate that information and incentives play the dominant roles in school managerial control. Figure 9 depicts three levels of school 
managerial control identified by the principal components analyses of the overall and revised models. Structural-frequency behaviors for information, incentives, and standards along with the discretionary qualities of assessment behaviors form the first structural level of school managerial control. A second integrative level reflects those qualitative perceptions inked to structural-frequency behaviors. The third level of school managerial control is completely qualitative and, therefore, reflects only independent discretionary managerial behaviors. The revised model in Figure 9 lists the managerial control processes in the ordex of empirical priority, as determined by the explained variance in the principal components analysis.

Figure 9. Three levels of school managerial control: structural, integrative, and discretionary under the managerial control processes

Information----Incentives-m--Standards----Assessment

Leve I I: (Structural) frequency frequency Erequency worth/ fairness

Level II: adequacy equatty clarity (Integrative) teacher satisfaction 
Many of the specific empirical findings of this study confirm results reported elsewhere. Among the most widely reported findings to be confirmed were (a) weak formal mechanisms of control for curriculum and instruction (Deal cellotti. 1980), especially for the tasks of staff development and the selection of textbooks and instructional materials: (b) weak formal evaluations (Dornbusch \& Scott, 1975; Meyer \& Rowan, 1977); (c) overall teacher agreement for the managerial control process of information (Eisenhardt, 1985; Sproul1, 1981; Sproull \& Zubrow, 1981); (d) controls tailored to specific curricular and instructional tasks, especially the selection of textbooks and instructional materials (Eye, Netzer, \& Krey, 1971; Koontz, 1971); (e) reliance upon informal and intrinsic rewards valued by teachers (Ames \& Ames, 1987; Mitchel1 \& Peters, 1988), and (f) mediating variables of effort (e. g., frequency behaviors) and rewards (e.g., incentives) in the relationship between performance and satisfaction (C. Greene, 1981). Yet, perhaps the most significant confirmation of all was the finding that discretionary managerial control behaviors were perceived for curricular and instructional [i.e., reciprocal-type] tasks (Thompson, 1967; Mahoney \& Frost, 1977), even within the structural-frequency dimension of school principal behaviors.

The interrelationship between structural and discretionary managerial behaviors should make it apparent why the sole reliance on single empirical measures has resulted in inconsistent and inaccurate findings about school management. 
Except for the managerial control process of incentives, teacher perceptions were more in agreement with the presence of discretionary qualities than with the structural-frequency of managerial behaviors, especially with respect to evaluations.

There were a number of managerial activities within the curricular and instructional domain of which teachers were not expressly aware. Among the items receiving the highest Don"t know teachex responses were (a) the use of teacher input [utility] in developing staff development programs, (b) the structural-frequency of evaluations for staff development, and (c) the structural-frequency of textbook selection evaluations. There were also a number of statistically significant differences found. Less experienced teachers were in greater agreement about the practices of managerial control behaviors for each of the control processes than were their more experienced colleagues. Based on mean scores, the largest differences between less experienced and more experienced teachers were found in managerial activities within the control processes of standards and assessment.

Less experienced teachers at merit-schools observed managerial information activities most positively of all groups of teachers. The perception on the part of new teachers at merit-schools may be that curricular and instructional information is provided more frequently as well as more clearly. Although C. Greene (1981) and others tend to reject satisfaction as a cause of performance, the "halo effect" upon joining a 
merit-school faculty should be considered as a possible explanation.

When instructional levels were considered in the data analysis, the only statistically significant interaction effect involved high school teachers who perceived structural and discretionary behaviors differently for the control process of standards. High school teachers reported a wider discrepancy between structural and discretionary managerial behaviors than did either junior high or elementary school teachers. With respect to standards, high school teachers also reported the lowest agreement on the presence of structural managerial activities. It may be as others have reported (child, 1977; Elmore, 1983; Peterson, 1984) that size and bureaucratic effects create a lesser behavioral impact on high school teachers regarding the control of standards than for teachers at other levels of instruction. Alternatively, it may be that their disagreement about structural managerial behaviors regarding high school organization standards reflects, a posteriori, a difference between what teachers view to be the mission of high schools from the actual managerial practices of high school administrators.

High school teachers expressed the most satisfaction with their jobs and with their school administrators. On the other hand, elementary school teachers were most in agreement with the occurrence of managerial control behaviors. Iunior high school teachers were not only the least satisfied with their school 
administrators, but they agreed least with the occurrence of managerial control behaviors. Junior high school teachers also had the highest percentage of "Don't know" responses and missing values. Although not statistically significant, teachers at junior high schools seemed to disagree about the existence of discretionary indicators as opposed to their colleagues at senior high schools or at elementary schools. This was particularly evident for the managerial process of assessment in which two of the four junior high schools ranked the structural-frequency of assessment more prevalent than were the discretionary qualities of assessment. Given the fact that the school district converted all of its junior high schools to midale schools one year after the data for this study were collected, it is likely that in the last year[s] of its junior high school program, neither assessments nor standards were communicated clearly or understood. Thus, junior high school teachers identified more with formally directed curricular and instructional policies. The patterns of managerial activities and their behavioral impact on teachers for each managerial control process revealed additional insights into what school-building administrators actually do, especially as it relates to task differences. The focus of discussion now shifts to a review of findings under each of the four managerial control processes.

\section{standards}

The expressive and challenging standards reported by the 
principals in the preliminary interview study (see chapter Three) were not strongly evident from the survey responses from teachers. Teachers were not able to discern challenging standards established by school building administrators. They clearly voiced their disagreement on items indicating moderately difficult or challenging standards. Although the principals spoke of high standards using phrases taken directly from effective school literature, the perception of difficulty was not translated into managerial control policies.

The principals had reported that within theix schools there existed criteria for outstanding classroom teaching which exceeded the district-adopted formal evaluation instrument, and which were understood by teachers. Principals had defined the formal instrument as measuring minimal competency. Generally, the within-school, discretionary criteria reflected qualitative aspects of classroom instruction, such as a "warm climate" and "learning as fun" philosophy. These standards were communicated in expressive language, rather than with instrumental detail (Etzioni, 1965). Perhaps, the lack of specificity or instrumental direction contributed to the perceived absence of challenge or difficulty imposed on curricular and instructional tasks.

While standards were comparatively weak for three of the tasks, they were almost non-existent for selection of texts and instructional materials. Here, the school district would seem to reflect the national norm. In 28 states, authority to select 
textbooks has been delegated to local districts. In Florida, however, this authority is retained by the state, although individual schools have discretionary funds to purchase texts not officially approved by the state. Yet when Tulley farx (1985) examined textbook adoption statutes they found "little evidence...[t]o support the expectation that the intent or purpose of state level textbook adoption is to control curriculum, instruction, or textbook quality." states have ignored content of curricular and instructional reforms (Murphy, Mesa, Hallinger, 1984). Thus, there would appear to be little managexial control of standards of texts, othex than perhaps from publishers. Murphy, Mesa, and Hallinger (1984) have advised that "communication between states and local districts and schools on textbook selection should focus on what is in the books and the instructional methodology to convey it rather than on book purchasing and warehousing." In developing the managerial control scale for the sMcQ, the task of textbook selection was rejected for the indicators of frequency and difficulty under the managerial process of standards.

The educational reform movement of the $1980^{\prime} \mathrm{s}$ has consolidated power at the state level. Teacher evaluation instruments, curriculum frameworks, and state-adopted textbooks are curricular policies currently established at the state level. Staff development pertaining to certification is also a statelevel function. Nevertheless, teacher perceptions of school reforms pertaining to effective schooling and teaching have not 
been successfully operationalized at the school level. If principals do not incorporate externally-directed standards into their managerial behaviors, the impact on teachers will continue to be minimal. What makes this finding so disturbing is that if educational reforms continue to push for significantly new policy directions for schools, then these external policies must become more successfully assimilated at the school-level by building administrators.

A central characteristic associated with effective schools has been administrative emphasis on instruction and curriculum. Based on the data, there appeared to be weak measures of teacher perceptions that building administrators contribute to the challenge of curricular and instructional work by establishing moderately difficult, challenging standards.

The frequency of managerial behaviors provided some indication of administrative emphasis. Several variations of principal components analyses linked the frequency of standards with the frequency of assessment. The strength of standards seemed to be greater for teacher evaluation and curriculum development than for either staff development or textbook selection. The formex tasks follow more formal structural procedures. Thus, the teacher evaluation instrument and curriculum frameworks provided less flexibility for managerial choice. Teachers were able to perceive this task difference. But the dichotomy of tasks raises the question of why builaing administrators do not assume greater control of school standards 
in areas in which state and district policy directives are less restrictive.

overal1, agreement on managerial activities relating to the entire process of standards was considerably less than for activities pertaining to the other managerial processes, particularly that of information. Teacher agreement was higher for the clarity of standards than for either frequency or difficulty in managing curricular and instructional tasks within schools.

By applying Thompson"s (1967) definition of reciprocal technology to curricular and instructional tasks, standards might be considered of lesser importance than othex managerial processes (Mahoney \& Frost, 1977), and, perhaps, even replaceable by the process of information. On the other hand, given the weak. structural control mechanisms of assessments coupled with the indistinct formal mechanisms of incentives, managing curricular and instructional standards within schools needs to improve.

\section{Information}

In spite of the admitted absence of formal, structural mechanisms for sharing curricular and instructional information (see Chapter Three), overall teacher perceptions of the structural-frequency of managerial behaviors under the process of information were very high. In addition, teachers agreed with the existence of utility of information (i.e., teacher input) in the selection of textbook and instructional materials and the 
adequacy of information for teacher evaluation. The indicators of frequency, adequacy, and utility were supported by teachers across all four curricular and instructional tasks. Ironically, the aggregate correlations for the utility of information in staff development were so low, and the Don"t xnow responses so high that this item was judged to be unreliable. The same decision to reject the utility of information in teacher evaluation was reached on the basis of low aggregate correlations and no significant factor score correlations in the overall model.

Task distinctions were not readily apparent for information. Nonetheless, the pattern of information frequency was the opposite of that reported under standards. That is, teachers perceived managerial frequency regarding staff development and selection of texts to a greater extent than for the tasks of teacher evaluation and curriculum development. Perhaps this finding suggests that building-level administrators rely upon external channels from the district or state to convey information for tasks in which formal mechanisms exist. If so, in terms of information adequacy, teachers were not affected by the lower structural-frequency.

Although, there was overall teacher agreement regarding building-level informational activities, it was clear that managerial behaviors of utility (i.e., teacher input) were lacking in teacher evaluation and staff development. The principal interview data indicated that in a number of different 
task axeas, principals consulted specifically with teachers whom they trusted.

Two significant interaction differences were also reported involving the managerial process of information. At two schools, (E5 and E6), teachers perceived a greater difference between the discretionary dimension of control behaviors and structure. The teachers at E5 disagreed more than teachers at the other 13 schools that discretionary managerial control behaviors occurred within their school. Thus, little significance should be given to this individual school effect. The difference, however, at E6 (a merit-school), suggests that managerial behaviors within the discretionary dimension were significantly more evident there than at the other schools in the sample. overald, less experienced teachers at all seven merit-schools identified more managerial behaviors involving information than did less experienced teachers at matching schools.

\section{Assessment}

Each of the curriculum-oriented principals in the prelininary interview study offered detailed, personal criteria on which both teachers and programs were assessed at their schools. These articulated criteria were distinct from any standardized testing and/or formal summative evaluations. The teacher survey data clearly confirmed the lack of formal, "public" assessments.

The public's preoccupation with standardized assessments was 
contrary to what principals and teachers themselves used to assess the worth of a curricular or instructional project. Yet, the within-school measures of assessment have remained hidden from public view. In most instances, programmatio assessment has tended to be informa1. The percentages of agreement and reliability data for practicaliy all of the structural-frequency indicators were lower than for the discretionary indicators of worth and fairness. Based on the percentages of teacher agreement on the discretionary indicators of assessment and the factor loadings of qualitative items, it is clear that teachers are aware of the informal evaluations conducted at the schoollevel. Since principals were able to articulate the withinschool assessment criteria, the reasons for their not making them more public (i.e., open to public testing) is a political question of implementation. The principals" views of managerial assessment indicated a bias towards informal or qualitative evaluations. Yet, the impact of qualitative managerial assessments, while critically important, has not been fully maximized.

\section{Incentives}

The interviews with principals noted both attitudes and managerial behaviors reflecting caution in the incentive distribution process of official and discretionary rewards to individual teachers, grade levels, and departments. Their justification, repeated at all schools, was that such behaviors 
would not inhibit the efforts of other teachers and divisions. The principals spoke of their reliance upon formal processes when it came to penalties and sanctions, in contrast to their initial use of informal behavior with respect to rewards. Although there have been unique structural Iimitations regarding the school building administrators" ability to distribute rewards and penalties (Lortie, 1969), the entire pattern of managerial activity for incentives is characterized by extremely cautious behaviors. This caution may explain in part an average teacher response of 16 percent Don"t know to the items within the variable equitable distribution. In other words, for curricular and instructional tasks, many teachers do not know whether incentives are distributed equitably by their building administrators.

Incentives were the only managerial control process in which the structural-frequency measures were congruent with the discretionary qualities. In practice, incentives dominated three of the eight factors in the revised model of school managerial control (see Table 36). Equitable distribution of incentives was linked with frequency to form one factor and with fairness to form a second factor. Both of these factors were related to teacher satisfaction. At the same time, the indicator of meaningfulness of incentives formed a separate unique factor. Thus, the managerial process of incentives must be considered as having a powerful influence on the construct of school managerial control in that teachers broady experienced these managerial 
behaviors. The strength of teacher identification was also measured by the cumulative percentages of teacher responses. For eight of the twelve items, over 40 percent of the teachers responded "Strongly Agree" [choices 1 or 2 on the Likert--type scale].

Consistent with the findings reported here, others have reported that subjective and phenomenological realities were independent of objective task characteristics (Blase, 1988; Dornbusch \& Scott, 1975). Thus, we found that teachers viewed standards applied to the task of stafl development to be more difficult than the standaras applied to the task of classroom teaching. Likewise, teacher evaluation, which is characterized by both a formal instrument and external directives, received lower teacher agreement concerning the equitable distribution of incentives than did other less formally structured tasks. Although further research is needed to establish the relationship between a scale of intensity as used in this study with a scale of importance, the phenomenlogical impact of managerial activities is readily apparent. Therefore, despite the low number of teachers who are actually rewarded or penalized by a teacher evaluation system, or no matter how tactful or cautious or objective a principal may be regarding tasks, rewards, and punishments (Dornbusch \& Scott, 1975), misunderstandings among teachers can and still arise within schools (Blase, 1988). Not surprisingly, the specific task of textbook and instructional materials' selection recorded the highest level of 
teacher agreement for meaningfulness of incentives. It would appear, therefore, that to a certain degree the absence of structural control resulted in higher teacher agreement concerning the quality of managerial behaviors, Given the dual perspective of managerial behaviors as structural and discretionary, qualitative indicators of controls should not be equated with either teacher autonomy or managerial weakness. 


\section{Implications For Further Research}

The implications for further research suggested by this study divide into three directions: (1) continued theory-building of the construct of managerial control, (2) further measurement validation with the present and subsequent sample populations, and (3) empirical hypothesis testing*

\section{Theory-building}

The present state of the art in control theory depicts an entangled web of control mechanisms (R. Campbell, et al., 1985; peterson, 1984; Peterson, Murphy, Hallingex, 1987), each with its own measures (Eisenhardt, 1985; Ouchi, 1978; Peterson, 1984). Conceptually, the web is as inchoate and impractical as were the idiosyncratic control definitions of previous decades (Cartwright, 1965; Lortie, 1969). Organizational theory-building still confronts an impasse of contingent situations and disciplinary biases with few practical guidelines for analyzing managerial processes and behaviors. It remains a matter of complexity, without control (Elmore, 1983). Missing is a philosophy of control, i.e., the systematic analysis from which to derive principles guiding administrative practice.

The managerial control model identified and measured in this study represents an initial step towards defining a theory of control suitable for managing school organizations. What began as a rational process model moving logically from standards to information to assessment to incentives (see Chapter Three, 
Figure 1) evolved into a descriptive picture of school managerial contral processes dominated by information and incentives with interactive structural and discretionary behaviors (see Figures 8 and 9). The principal components analysis assumed that these processes were statistically uncorrelated. Substantive theory suggests that the processes themselves are interrelated. therefore, measures between processes should be considered. Although standards, information, assessments, and incentives are viewed as latent, aggregate variables which can be applied to diverse situations, they are also measurable and heuristic. Blalock (1982) recommended that

the major orienting principles in each discipline be organized in terms of social processes that are sufficiently general in nature that they may be described and analyzed in terms of propositions that are not tied to particular timeand space bound entities... (p. 164).

Neither the substantive theory nor the measures, however. have been fully articulated. More theory development along the lines proposed by the managerial research paradign (see Figure 7) is still needed.

Many ways of knowing came into play in this research effort: phenomenological judgments were made as to the best evidence of what can arguably be described as the subjective reality of control (Dornbusch \& Scott, 1975; Heilbroner, 1975; Zaner, 1970): pragmatic choices of what to include and exclude were based on essential attributes, i.e., behavioral indicators which had practical implications (James, 1968). The thoughtful traditions of rationalism and empiricisn served as guideposts for 
establishing common needs (Heilbroner, 1975: Katz, 1965: tanger, 1983) and for testing whether those needs were being met by what participants actually did within school builaings (Miles, 1981). And, above a11, the theorymbilaing effort was symbolic, ever alert to new relationships, possibilities, and aesthetic interpretations (s. Langer, 1951; Vickers, 1967).

The underlying logical categories offered by Aristotle and Kant (i.e., quantity, guality, relation, and modality) served as the model for the concept of dimensionality. The categories of quantity and quality wexe defined as measures of managerial behavior. Quantity delimited structure, the first level of managerial control, while quality gave meaning through discretionary behaviors. The data findings, however, indicated that certain qualities were associated with structure, whereas other qualities formed separate and distinct factors in managerial control. The former have been labelled integrative or the second level of control. The latter were called purely discretionary, or third level control. Level two qualities may be viewed as alternative managerial behaviors for structuralfrequency. On the other hand, structural behaviors may be said to encompass certain qualitative meanings.

Possibly, the independent, aiscretionary qualities of managerial behaviors, such as difficulty, utility, fairness, equity, and or meaningfulness, reflect a measure of importance, rather than strength or intensity as measured by the Iikert scale items. That is, the items on the school Managerial control 
Questionnaire measured only the strength of agreement between teachers and building administrators; they did not attempt to measure how important or central to teacher job performance the specific managerial behavior was.

Alternative processes may also be projected as relating to control in just the same manner as the four proposed managerial processes. Among those already reported as residual findings from control research have been communication (Bidwell, 1965, p. 1014; Blau \& Scott, 1962, p. 183), socialization (Etzioni, 1965), improvement (Bossert, 1985; Patz Rowe, 1977), enabling and intention (Barth, 1987; R. Harrison, 1985, pp. 132ff), delegation and coordination (Blau \& Scott, 1962, p. 183; Bossert, et al., 1982; Cohen \& Miler, 1980; Wellisch, et al., 1978). At present, the judgment here is that these processes are less derivative from social science theories of control, and, therefore, are either collateral processes or not essential properties of control. Because of the defined parameters of managerial control as a reciprocal process within an organization, the alternative control process of staffing (Etzioni, 1965) was deliberately excluded from the analysis.

The selection of structural and discretionary behavioral. indicators was admittediy arbitrary. Therefore, others may be found to be more suitable and distinct. For example, it is likely that the indicator of "dependence" (Astuto \& Clark, 1985) belongs somewhere within the model; and, that the indicator of frequency could be more clearly distinguished from the attributes 
of stability, regularity, and consistency (Astuto \& Clark, 1985). Among the indicators used here, the definitions of clarity, adequacy, and worth need further refinement in their behavioral or contextual meanings. Out of the oxiginal 48 items, 35 were retained in the revised model. Perhaps the decision to reject items had as much to do with the contextual managerial activity as with the behavioral indicator itself. For example, item 1 , MI'TE, which defined meaningfulness of teacher evaluation incentives, was rejected. As written, the item inked "comments" made by school administrators to incentives. If instead of "comments," the item was rewritten to describe a managerial "action" performed by school administrators, then meaningfulness might be more accurately measured in relationship to the process of teacher evaluation incentives. The preliminary study reported over 150 different managerial activities. Therefore, it would be relatively simple to substitute alternative managerial activities for each of the rejected items, and then retest.

\section{Construct validation}

At this stage of theory development, the proposed model of school managerial control begins as a measurement model with no hypothesized causal relationships (Hoyle, in press, p. 4). The identification of the latent variables and their behavioral indicators was followed by empirical testing of the internal relationships among the variables. The next steps would be to employ other research designs and statistical methods to further 
establish the internal validity of the findings reported here. The high variance reported within the initial factors for each of the principal components analyses suggests that either (I) the construct has not been as clearly distinguished from among other highly correlated concepts, most likely satisfaction, or (2) there was considerable method variance found. Further research to control for satisfaction and the removal of method variance is recommended. In terms of construct validity, it is not feasible to rely solely on the results of a single study (Axmor, 1974, p.35).

Just as conceptual classification schemes differ, so, too, do the methods used to classify and interpret. It is even possible to reach different conclusions from the same data set using the same methods (Aldenderfer \& Blashfield, 1987, p.15). Unlike hypothetical-deductive research, construct validation is an on-going search for language, meanings, and measures. Quantitative research literature describes a variety of classification methods which theorists may employ singly or in conjunction.

Interview and survey data, unidimensional scaling, reliability tests of items, and principal components analyses were the procedures and methods used in this study. Further construct validation would require the continued search for convergent and discriminant validity (Sullivan \& Feldman, 1979 , 18f). In addition to replication studies which are strongly recommended, other research designs might utilize teacher 
interviews for more in-depth responses, structured observations (Mintzberg, 1971) instead of self-report data, and case studies to capture the unique cultural context of schools and principalteacher interactions.

Methodologically, the choices may be even more varied. In each instance, however, substantive theory and judgment play a considerable role in the use of such alternatives as discriminant analysis (Klecka, 1987), cluster analysis (Aldenderfer \& Bashfield, 1987), factor analysis (Kenney, 1979; Kim \& Muller, 1978), or covariance structural models (Herting, 1985; Hoyle, in press, Lennox, 1988; Long, 1983a; 1983b).

The advantages in having used principal components analysis in the initial stage of construct validation are well supported (Dunteman, 1989. p. 9: Heise, 1974: Lennox, 1988; Stevens, 1986, p. 338). The obvious disadvantage to principal components analysis was that measurement error (i.e., error variance) was part of the analysis because the total variance was used in the identification of construct factors (Lennox, 1988).

The primary advantage of a linear structural equation model, such as LISREL, is that it incorporates and corrects measurement error (Herting, 1985, p. 264 ; Long, 1983b, p. 16). By comparing the variances of the hypothesized model to the variances in the sample data (Hoyle, in press, p. 11), LISREL measures (a) covariation among dimensions, (b) exror covariances, (c) error variances of each indicator, and (d) covariation error between pairs of indicators (Herting, 1985, p. 297). Yet, every step of 
the analysis is somewhat of an art (Hoyle, in press, p. 22), and its use, especially in developing the dimensions of the construct, may not always be appropriate (Lennox, 1988).

The significance of theory-building and construct validation is associated directly with the practical consequences. To a large extent, the practical consequences of school managerial control must await the validation of the internal structure of empirical data before external validation can occur. The very same post hoc tests of significance of the effects of relevant criteria (e.g., teacher tenure, instructional levels, school effects, and school effectiveness) performed on valid and reliable items can be considered criteria for external validation.

\section{Hypotheses Testing}

This study focused on the curricular and instructional domain within school-buildings. The operational definition of managerial control extended across four specific tasks. Yet, curriculum and instruction is, obviously, only one managerial context of building administrative activity. similar studies may be designed within other school organizationai contexts, such as budgeting or school-based management activities.

While increased teacher participation in managerial decision-mating emerges from the proposed model of managerial control, participation alone is not a sufficient criterion for school improvement. It is clear from this study that single 
entity definitions of managerial concepts (e.9.. participation in decision-making) lead to neither good theory nor consistently good practice. The increased professionalization of teachers is not simply a matter of participation across diverse tasks. Rather, participation must be instituted across managerial processes and coupled with understanding and the freedom to grow. With respect to teacher development, the study found a significant difference regarding the practice of managerial behaviors between experienced and less experienced teachers. Experienced teachers were less in agreement about managerial control behaviors of curriculum and instruction than were less experienced teachers. It is likely that new teachers rely more on managerial directives and appreciate structural managerial behaviors more so than do tenured teachers. It would also appear that this reliance extended to all four managerial processes for less experienced teachers, while experienced teachers focused upon information and incentives. In their tife cycle Theory of Leadership, Hersey and Blanchard (1978) have suggested that control is primarily a function of the maturity of those being supervised. perhaps, the responses by experienced teachers reflect a more accurate view of school managerial control. Insights as to the reasons for these differences might contribute to policy discussions regarding principal and/or teacher staffing and transfers.

When merit and matching schools were compared, the more effective schools showed an overall significantly higher level of 
teacher agreement of the occurrence of managerial control behaviors. Thus, it may not be simply that experienced teachers become more autonomous from managerial activities, but rather that in effective schools managerial activities are qualitatively better. The significance of this finding should not be ignored. stephenson and Levine (1987) found no significant student academic achievement difference between merit and non-merit schools using the same definition of mexit schools as in this study. Although the two studies are not comparable, the implication here is that managerial practice does lead to significant differences in teacher performance.

Within the educational reform movement, the public emphasis on accountability has led to externally directed policies by state legislators and others external to schools. In practice, these policies operate within only the structural dimension of control. Yet, the findings indicate that qualitative aspects of managexial control behavior play at least as signicicant a role, if not more. The most logical way to integrate quality with structure would be to insure that school building managers have internalized these reform policies. Yet, a Rand corporation study (cited in wirt \& Kirst, 1982) of principals' job from 197580 [prior to the reform movement!] reported that principals felt "more constrained by rules, more subject to public scrutiny, and less in control of their schedules.... A majority of the principals reported that they now spend less time supervising instruction." (pp. 149-59). Increased centralization and 
bureaucratization of curriculum and instructional areas at the state and district levels have severely curtailed the principals" sphere of authority (Meyer, 1983).

Despite such trends, the findings here indicate that principals have an even broader discretionary avenue open to them along which to influence teachers. Not only are there discretionary behaviors within each of the four managerial contral processes, but even within their structural role, principals can and often do exercise quality control. The hypotheses presented at the end of the preliminary study, chapter Three (pp. 159-160), identified some of the discretionary behaviors practiced by curriculum-oriented principals. They included the use of effective school research language, use of personal school-level criteria for success, communication of trust in the performance of certain members of their staff and faculty, strategies to overcome structural constraints, and demonstration of administrative support and caring.

What the debate between leadership and managenent has chosen to ignore is that within the managerial role lie matters of substance, meaning, and necessity. Such is the nature of school control. Thus, the challenge facing school managers has always been, to paraphrase shakespeare, to make a virtue of managerial necessity. 


\section{References}

Abbott, M. (1975). Evaluating school administrators: The scope and nature of administrative performance. The evaluation of administrative performance: parameters, problems and practices [CEDR Monograph]. Bloomington, IN: Phi Delta Kappan Educational Report.

Adams, J. (1978). Towards an understanding of inequity. In $W$. Natemeyer (Ed.), Classics in organizational behavior (pp. 71-87). Oak Park, IL: Moore Publishing Co., Inc.

Aldenderfer, M. \& Blashfield, R. (1984). Cluster analysis. Beverly Hills, CA: Sage Publications.

Althauser, R. (1974). Inferring validity from the multitraitmultimethod matrix. In H. Costner (Ed.), Sociological methodology, 1973-74 (pp. 106-127). San Francisco: JosseyBass Publishers.

Alwin, D. F. (1974). Approaches to the interpretation of relationships in the multitrait-multimethod matrix. In H.L Costner (Ed.), Sociological methodology. 1973-1974 (pp. 74105). San Francisco: Jossey-Bass Publishers.

Ames, C. \& Ames, R. (1987). Systems of student and teacher motivation: Toward a qualitative definition. Journal of Educational Psychology, 26(4), 535-556.

Anderson, B. \& Brown, A. (1971). Who's a good principa1. In W. Hack, W. Gephart, J. Heck, \& J. Ramseyer (Eds.), Educational administration (pp. 193-199). Boston: Allyn \& Bacon, Inc.

Andrews, R. (1987) . On leadership and student achievement: A conversation with Richard Andrews. Educational Leadership, $45(1), 9-16$.

Apple, M. (1982). Education and power. Boston: Routledge \& Kegan Paul.

Applewhite, P. (1965). Organizational behavior. Englewood Cliffs, NJ: Prentice Mall.

Argyris, C. (1978). The individual and organization: Some problems of mutual adjustment. In $W$. Natemeyer (Ed.), Classics of organizational behavior ( $\mathrm{pp}, 253-266$ ). Oak park, Ill: Moore Publishing Co., Inc. (Reprinted from Argyris, c. (1957). Administrative science Quarterly, 2(1), $1-24$. 
Argyris, C, and Schon, D. (1982). Theory in practice: Increasing professional effectiveness. San Francisco: Jossey-Bass Publishers.

Armor, D. (1974), Theta reliability and factor scaling. In $H$. Costner (Ed.), Sociological methodology, 1973-1974 (pp. 1850). San Francisco: Jossey-Bass Publishers.

Ashton, P. (1984). Teacher efficacy: A motivational paradigm for effective teacher education. Journal of Teacher. Education, 35, 28-32.

Astuto, T. \& Clark, D. (1985). The strength of organizational coupling in the instructionally effective school. Urban Education, 19(4), 331-353.

Ayer, A.J. (1952). Language, truth and logic. New York: Dover Publications, Inc.

Bacharach, S. (Ed.). (1981). organizational behavior in schools and school districts. New York: Praeger.

Bacharach, S. \& Lawler, E. (1982). Power and politics in organizations. San Francisco: Jossey-Bass Publishers.

Bachman, J., Bowers, D*, \& Marcus, P. (1968). Basis of supervisory power: A comparative study in five organizational settings. In $A$. Tannenbaum (Ed.), control in organizations (Chapter 15) . New York: McGraw-Hill.

Bachman, J. \& Tannenbaum, A. (1968). The control-satisfaction relationship across varied areas of experience. In $A$. Tannenbaum (Ed.), Control in organizations (Chapter 16). New York: McGraw-Hill.

Bailite, J, (Trans.) (1967). Introduction. In G. Lichtheim (Ed.), The phenomenology of mind-G.W.F. Hege1. New York: Harper Torchbooks.

Baldridge, J. (1971), Eower and conflict in the university. New York: John Wiley \& Sons, Inc.

Baritz, L. (1974). The servants of power. Westport, CT: Greenwood Press, publishers.

Barnard, C. (1938). The functions of the executive. Cambridge, MA: Harvard University Press. 
Barth, R. (1987). The principal and the profession of teaching. In $W$. Greenfield (Ed.), Instructional leadership: concepts, issues, and controversies (pp. 249-270). Boston: Allyn \& Bacon, Inc.

Baumeister, R. \& Jones, E. (1978). When self-presentation is constrained by the subject's knowledge: Consistency and compensation. Journal of Personality \& Social Psychology, $36(6), 608-618$.

Berliner, D. (1984). Teacher eficacy: How can teachers make a difference? Instructor, 94(2), 12-13.

Berman, P. (1981). Educational change: an implementation paradigm. In $R$. Lehming \& $M$, Kane (Eds.), Improving schools: Using what we know (pp. 253-286). Beverly Hills, CA: Sage Publications.

Bidwell, $C$. (1965). The school as a formal organization. In J. March (Ed.), Handbook of organizations (pp. 972-1022). Chicago: Rand McNally.

Black, M. (1970). Rules and routines. Margins of precision: Logic and language. Ithaca, NY: Cornell university Press.

Blalock, H. (1984). Basic dilemmas in the social sciences. Beverly Hills, CA: Sage publications.

Blau, P. \& Scott, W. R. (1962). Formal organizations: A comparative approach. San Francisco: Chandler.

Bolman, L. \& Deal, T. (1984). Modern approaches to understanding and managing organizations. San Francisco: Jossey-Bass Publishers.

Bossert, S., Dwyer, D., Rowan, B., \& Lee, G. (1982). The instructional management role of the principal. Educational Administrative Quarterly, 18(3), 35-64.

Bossert, S. (1985). Effective elementary schools. In Reaching for excellence: An effective schools sourcebook (pp. 39-54). Washington, DC: National Institute of Education.

Bray, J. \& Maxwell, S. (1985). Multivariate analysis of variance. Beverly Hills, CA: Sage publications.

Brown, W. (1969). The organization and socio-technical controls. In W. Scott (Ed.), organization concepts and analysis ( $p$. 84). Belmont, CA: Dickenson Publishing Co., Inc. 
Bruner, J. (1962). The control of human behavior. on knowing: Essays for the left hand. Cambridge, MA: Harvard university Press.

Buber, M. (1967). Between man and man (p. 116). New York: MacMilian Co.

Burnell \& Reeve (1984). Persuasion as a political concept. British Journal of Political Science, 14(4), 393-410.

Burnstein, E. (1982). The notion of control in psychological theory. In J. Gibbs (Ed.), social control: Views from the social sciences (pp. 23-51). Beverly Hills, cA: Sage publications.

Cameron, K. \& Whetton, D. (1983). Organizational effectiveness: A comparison of multiple models. New York: Academic Press.

Campoe11, R., Cunningham, L., McPhee, R., \& Nystrand, R. (1985). The organization and control of American schools. Columbus, OH: Merrill Publishing $\mathrm{Co}$.

Campbe11, J., Dunnette, M., Lawler, E., \& Weick, K. (1978). Expectancy theory. In $w$. Natemeyer (Ed.), Classics of organizational behavior (pp. 107-112). Oak Park, IL: Moore Publishing Co.

Cartwright, D. (1965). Influence, leadership, control. In J. March (Ed.), Handbook of organizations (pp. 1-47). Chicago: Rand McNaliy Publishing Co.

Cawelti, G. (Speaker). (1987a). What behaviors constitute effective instructional leaders? (Cassette Recording No. 612-87526). Alexandria, Va.: Association for Supervision and Curriculum Development.

Cawelti, G. (1987b). Why instructional leaders are so scarce? Educational teadership, $45(1), 3$.

Cawelti, G. \& Adkisson, J. (1986, August). ASCD study documents changes needed in high school curriculum. ASCD curriculum Update. Alexandria, VA: Association for supervision and Curriculum Development.

Charters, W. (1981). The control of microeducational policy in elementary schools. In S. Bacharach (Ed.), organizational behavior in schools and school districts (pp. 277-312). New York: Praeger.

Child, J. (1977). Strategies of control and organizational behavior. In A. Patz A. Rowe, (Eds.), Management control and decision systems (pp. 34-58). New York:John Wiley \& Sons. 
Clark, D. \& Astuto, T. (1988). Paradoxical choice options in organizations. In D. Griffiths, R. Stout, E. Forsyth (Eds.), Leaders for America's schools: The report and papers of the National Commission on Excellence in Educational Administration (pP. 112-130). Berkeley, CA: McCutchan Pubisising Corp.

clark, R. (1988). Who decides? The basic policy issue. In L. Tanner (Ed.), Critical issues in curriculum (pp. 175-204). (NSSE Yearbook). Chicago: University of Chicago Press.

Coch, L. \& French, Ir. J. (1978). overcoming resistance to change. In W. Natemeyer, (Ed.). Classics of organizational behavior (pp. 300-318). Oak Park, IL: Moore Publishing co. Inc.

Cohen, M. (1985). Introduction to policy implications of effective school research. The Elementary school Journal, $85(3), 277-280$

Cohen, M., March, J. \& Olsen, J. (1972). A garbage can model of organizational choice. Administrative science ouarterly, $17(1), \quad 1-25$.

Cohen, E. \& Milier, R. (1980). Coordination and control of instruction in schools. Pacific Sociological Review, 23(4), $446-473$.

Cohen, E., Deal, T., Meyer, J. \& Scott, W.R. (1979) . Technology and teaming in the elementary school. Educational sociology, $52(1), 20-33$.

Converse, I. \& Presser, S. (1986). Survey questions: Handcrafting the standardized questionnaire. Beverly Hills, cA: Sage Publications.

Copleston, F. (1964). A history of philosophy: Volume 5: Modern philosophy: The British philosophers, part II. New York: Image Books.

Corcoran, T. (1985). Efective secondary schools. Reaching for excelience: An effective schools sourcebook (pp. 71-98). Washington, DC: The National Institute of Education.

Coser, L. (1982). The notion of control in sociological theory. In J. Gibbs (Ed.), Social control: Views from the social sciences (pp. 13-22). Beverly Hills, cA: Sage Publications.

Counts, G. (1971). The American road to culture: A social interpretation of education in the United states (Reprint edition). New York: Arno Press \& The New York wimes. (original copyright, 1930 , New York: John Day Co.). 
Crowson, R. \& Morris, V. (1985). Administrative control in large-city school systems: An investigation in Chicago. Educational Administrative Quarterly, 21(4), 331-350.

Darling-Hammond, L. \& Wise, A. (1985) State standards and school improvement. The Elementary School Journal, 85(3), 315-336.

Deal, T. cellotti. L. (1980). How much influence do (\& can) educational administrators have on classrooms? Phi Delta Kappan, 61(7), 471-473.

Deal, T. (1987). Effective school principals: counselors, engineers, pawnbrokers, poets... or instructional leaders? In W. Greenfield (Ed.), Instructional leadership: Concepts, issues \& controversies (pp. 230-245). Boston: Allyn \& Bacon, Inc.

Dembo, M. \& Gibson, S. (1984). Teacher efficacy: A construct validation. Journal of Educational Psychology, 76(4), 569582 .

Dornbusch, S. Scott, W. R. (1975). Evaluation and the exercise of authority: A theory of control applied to diverse organizations. San Francisco: Jossey-Bass publishers.

Doud, I. \& Montgomery, M. (1985). Setting standards for quality elementary schools. Principal, 64(3), 14-16.

Doyle, D. \& Hartle, T. (1985). Excellence in education: The states take charge. Washington, DC: American Enterprise Institute studies in Educational policy.

DuFour, R. (1986). Must principals choose between teacher morale and an effective school? NASSP Bulletin, 70(460), $33-36$.

Duke, D. (1982). Leadership functions and instructional effectiveness. NASSP Bulletin, 66(456), 1-12.

Dunn, W. (1985). Usable knowledge: A metatheory of policy research in the social sciences. In W. Bennis, $k$. Benne, \& R. Chin The planning of change (p. 242). New York: Holt, Rinehart and winston.

Dunteman, G. (1989). Principal components analysis. Newbury Park, CA: Sage Publications.

Dye, T. (1984). Understanding public policy. Englewood Clifes, NJ: Prentice Hall, Inc.

Edmonds, R. (1979). Effective schools for the urban poot. Educational Leadership, 37(1), $15-23$. 
Eisenhardt, K. (1985). Control: organizational and economic approaches. Manaqement science, 31(2), 134-149.

Ellett, C. (1987). Emerging teacher performance assessment practices: implications for the instructional supervision role of school principals. In W. Greenfield (Ed.), Instructional leadership: concepts, issues \& controversies (pp. 302-327). Boston: Allyn \& Bacon, Inc.

Elmore, R. (1987). Reform and the culture of authority in schools. Educational Administration Quarteriy, 23(4), 6078 .

Elmore, R. (1983). Complexity and control: What legislators and administrators can do about implementation. In $M$. Xudof, et a1. (Eds.), Educational policy and the law (pp. 658-675). Berkeley, CA: Mccutchan Publishing corp.

Erickson, F. (1988). Conceptions of school culture. Educational Administration Quarterly, 23(4), 11-24.

Etzioni, A. (1965). Organizational control structure. In J. March (Ed.), Handbook of organizations (pp. 650-677). Chicago: Rand McNally Publishing Co.

Eye, G., Netzer, L., \& Krey, R. (1971). Supervision of instruction. New York: Harper \& Row Publishers.

Fallon, B. (1979). Principals are instructional leaders - hit or myth? NASSP Bulletin, 63(423), 67-71.

Festinger, L. (1978). The motivating effect of cognitive dissonance. In $w$. Natemeyer (Ed.), Classics in organizational behavior (pp. 58-71). Oak Park, IL: Moore Publishing co. Inc.

Fielding, $N$ * \& Fielding, J. (1986). Linking data. Beverly Hills, CA: Sage publications.

Fioden, R., Porter, A., Alford, L., Freeman, D., Irwin, S., Schmidt, W., and Schwille, J. (1988). Instructional

leadership at the district level: A closer look at autonomy and control. Educational Administration Quarterly, 24 (2), $96-1.24$.

Florida Council on Educational Management. (1984-85). Training. selecting, appointing, assessing, certifying, compensating. educational managers for excellence. Tallahassee, FL: state of Florida, Department of Education.

Florida Education Digest. $(1987-88)$. Tallahassee, FL: State of Florida, Department of Education. 
Frank, A. (1958-59), Goal ambiguity and conflicting standards: An approach to the study of organizations. Human organization, 17(4), 8-13.

French, J. Raven, B. (1978). The bases of power. In W. Natemeyer (Ed.) . Classics of organizational behavior (pp. 198-209). Oak Park, Il: Moore Publishing Co. (Reprinted from Cartwright, D. (Ed.). (1959). Studies in social power (pp. 150-165). Institute for Social Research, University of Michigan*)

Fulian, M. \& Pomfret, A. (1977). Research on curriculum and instruction implementation. Review of Educational Research, $47(2), 335-397$.

Fullan, M. (1982). The meaning of educational change. New York: Teachers College Press.

Gevirtz, D. (1984). Business plan for America: An entrepreneur"s manifesto. New York: G.P. Putnam's Sons.

Gibbs, J. (Ed.). (1982). Law as a means of social control. Social control: Views from the social sciences (pp. $83-114$ ). Beverly Hills, CA: Sage Publications.

Goldman, P. (1983). A socio-historical perspective on performance assessment. In F. Landy, S. Zedeck, \& J. Cleveland (Eds.). performance measurement and theory (pp. 337-352). Hilisdale, NI: Lawrence Exlbaum Associates Publishers.

Goodlad, J. (1978). Educational leadership: Towards the third era. Educational Leadership, 35(4), 322-331.

Greene, C. (1981). Satisfaction-performance controversy. In D. Klingner (Ed.), Public personnel management (pp. 218-230). Palo Alto, CA: Mayfield Publishing Co.

Greene, M. (1973). And it still is news. In A. Gartner, C., Greer, \& F. Riessman (Eds.), After deschooling what? Ivan Illich, et al. (pp. 129-136). New York: Harper \& Row publishers.

Greenfield, W. (1987). Moral imagination and interpersonal competence: Antecedents to instructional leadership. In W. Greenfield (Ed.), Instructional leadership: Concepts. issues and controversies (pp. 56-76). Boston: Allyn \& Bacon, Inc.

Griffin, G. (1988). Leadership for curriculum improvement: The school administrators" role. In L. Tanner (Ed.), critical issues in curriculum (pp. 244-266). (NSSE Yearbook). Chicago: University of chicago Press. 
Hake1, M., Sorcher, M., Beer, M., \& Moses, J. (1985). Making it happen: Designing research with implementation in mind (pp. 44-60). Beverly Hills, CA: Sage publications.

Hall, Ir., E. (1965). Orientation and training in government for work overseas. Human organization, 15(1), 4-10.

Hallinger, P. \& Murphy, J. (1985). What's effective for whom? School context and student achievement. Planning \& changing, $16(3), 152-160$.

Hallinger, P. \& Murphy, J. (1986). Assessing the instructional management behavior of principals. The Elementary School Journal, 86(2), 217-247.

Hallinger, P. Murphy, J. (1987). Instructional leadership in the school context. In $W$. Greenfield (Ed.). Instructional leadership: Concepts, issues, and controversies (pp. 179m 203). Boston: Allyn \& Bacon, Ine.

Hamilton, E. \& Cairns, H. (Eds.). (1961). Plato: The collected dialogues. Princeton, NJ: Princeton University Press.

Hannaway, J. \& Sproul1, L. (1978-79). Who's running the show? Coordination and control in educational organizations. Administrator"s Notebook, $27(9)$.

Hanson, M. (1979). Educational administration and organizationa behavior (pp. 195-203). Boston: Allyn \& Bacon, Inc.

Hanson, M. (1981) . Organizational control in educational systems: A case study of governance in schools. In $S$. Bacharach (Ed.), organizational behavior in schools and school districts (pp. 245-276). New York: Praeger.

Harrison, M. (1987), Diagnosing organizations: Methods, models, and processes, Newbury Park, CA: Sage Publications.

Harrison, R. (1985). Strategies for a new age, In W. Bennis, K. Benne, \& R. Chin (Eds.), The plamning of change (pp. 128148). New York: Holt, Rinehart, \& Winston.

Heilbroner, R. (1975). An inquiry into the human prospect. New York: W. Worton \& Co., Ine.

Heise, D. (1974). Some issues in sociological measurement. In H. 16). Costner (Ed.), Sociological methodology, 1973-74 (pp. 1San Francisco: Jossey-Bass Publishers. 
Heise, D. (1985). Separating reliability and stability in testretest correlation. In H. Blalock (Ed.). CausaI models in pane 1 and experimental designs (pp. 117-143). New York: Aldine publishing co.

Hersey, P. Blanchard, K. (1978). Life cycle theory of leadership. In W Natemeyer (Ed.), classics of organizational behavior (pp. 216-226). Oak Park, IL: Moore Publishing Co., Inc.

Herting, J* (1985). Multiple indicator models using trSREL. In H. Blalock (Ed.), causal models in the social sciences (pp. $263-320)$. New York: Aldine Publishing co.

Herting, J. \& Costner, H. (1985). Respecification in multiple indicator models. In H. Blalock (Ed.), Causal models in the social sciences (pp. 321-394). New York: Aldine Publishing Co.

Herzberg, F, (1978). One more time: How do you motivate employees? In $W$. Natemeyer (Ed.), classics of organizational behavior (pp. 95-106). Oak Park, Ir: Moore Publishing Co., Inc.

Hills, R. J. (1963). The representative function. Administrative Science Quarterly, 8(1), 83-101.

Hobbes, T. (1958). Leviathan, Parts I and II. New York: BobbsMerrill Co. (original work published 1651).

Hofstede, G. (1978). The poverty of management control philosophy. Academy of Management Review, 3(3), 450-46I.

Holly, P. (1986). "Soaring like turkeys": the impossible dream? School organization, 6(3), 346-364.

House, E. (1981). Three perspectives on innovation: technological, political, and cultural. In R. Lehming \& M. Kane (Eds.), Improving schools: Using what we know (pp. 17-41). Beverly Hills, CA: Sage Publications.

House, R. \& Mitchell, T. (1974). Path-goal theory of leadership. Journal of Contemporary Business, 3, 81.97 .

Hoy, w. \& Miske1, C. (1982). Educational administration: Theory research, and practice. New York: Random House.

Hoyle, R. (in press). An introduction to the use of confirmatory factor analysis in the measurement of hypothetical conswructs. In R. Lennox (Ed.), Factor analysis and measurement in the social sciences (Chapter 5). 
Hughes, M., Price, R., \& Marrs, D. (1986). Linking theory construction and theory testing: Models with multiple indicators of latent variables. Academy of Management Review, 11(1), 128-144.

Husserl, E. (1964). The idea of phenomenology. (W. Alston \& G. Nakhnikian, Trans.). The Haque: Martinus Nijhoff.

Huxley, A. (1971). Words and their meanings. In C. Laird \& R. Gorrell (Eds.), Reading about language (pp. 161-164). New York: Harcourt Brace Jovanovich, Inc.

Illich, I. (1973). After deschooling, what? In A. Gartner, C. Greer, \& Feissman (Eds.), After deschooling, what? Ivan I11ich, et a1. (pp. 1-28). New York: Harper \& Row.

James, W. (1968). Pragmaticism and other essays. New York: washington Square Press, Inc.

James, L, Mulaik, $S$, \& Brett, J. (1982). Causal analysis: Assumptions, models and data. Beverly Hills, CA: Sage Publications.

Jaspers, K. (1955). Reason and Existenz (W. Earle, Trans.). New York: Noonday Press, Inc.

Jemison, D. (1984). The importance of boundaxy spanning roles in strategic decision-making. Journal of Management studies, $21(2), 131-152$.

Johnston, G. \& Venable, B. (1986). A study of teacher loyalty to the principal: Rule administration and hieraxchical influence of the principal. Educational Administration quarterly, 22(4), 4-27.

Johnston, B. (1985). Organizational structure and ideology in schooling. Educational Theory, 35(4), 333-344.

Katz, D. (1965). The functional approach to the study of attitudes. In 0 . Lerbinger \& A. Sullivan (Eas.), Information, influence and communication. New York: Basic Books.

Katz, D. \& Kahn, R. (1978). The social psychology of organizations. New York: John Wiley \& Sons.

Kenny, D. (1979), Correlation and causality. New York: John wiley \& Sons. 
Kerr, D. (1987). Authority and responsibility in public schooling. In J. Goodlad (Ed.), The ecology of school renewal (pp. 20-40). (NSSE Yearbook). Chicago: University of Chicago Press.

Kin, J. \& Muller, C. (1978). Introduction to factor analysis. Beverly Hills, CA: Sage publications.

Kixk, J. \& Miller, M, (1986), Reliability and validity in gualitative research. Beverly Hills, CA: Sage publications.

Kirst, M. (1984). The changing balance in state and local power to control education. Phi Delta Kappan, 66(3), 189-191.

Kirst, M. (1984). Who controls our schools? New York: W. Freeman \& $\mathrm{Co}$.

Klecka, w. (1980). Discriminant analysis. Beverly Hills, CA: Sage Publications.

Kleiman, C. (1988, June 18). Does hard work lead to a raise? Business News, Miami Herald. p. 2.

Koont $z$, H. (1971). Appraising managers as managers. New York: MCGraw-Hill.

Koontz, $H .(1978)$. The management theory jungle. In $W$. Natemeyer, (Ed.), Classics of organizational behavior (pp. 19-30). Oak Park, IL: Moore Publishing Company, Inc.

Krislov, S. (1982). The politics of control and the control of politics. In J. Gibbs (Ed.). Social control: Views from the soctal sciences (pp. 57-82). Beverly Hills, CA: Sage Publications.

Kruskal, J. \& Wish, M. (1978). Multidimensional scaling. Beverly Hills, CA: Sage publications.

Landy, F., Zedeck, S, \& Cleveland, J. (Eds.). (1983). Pexformance measurement and theory. Hillsale, NJ: Lawrence Erlbaum Associates Publishers.

Lang, K. (1965). Military organizations. In J. March (Ed.). Handbook of organizations (pp. 838-878). Chicago: Rand McNally.

Langer, S. (1951). Philosophy in a new key. New York: Mentor Books.

Langer, E. (1983). The psychology of control. Beverly wills, CA: Sage Fublications. 
Lawler, E. and Rhode, J. (1976). Information and control in organizations. Santa Monica, CA: Goodyear.

Leiberman, A. (1986). Collaborative research: Working with, not working on.... Educational Leadership, 43(5), 28-32.

Leiter, J. (1983). Perception of community dissatisfaction and school organizational structures. American Educational Research Journa1, 20(1), 45-61.

Lennox, R. (1988, April). Covariance structure analysis in social science research. Paper presented at Floxida International University, Miami, Florida

Lerbinger, 0. (1965). Influence: The generalized medium of public communication. In $O$. Lerbinger \& A. Sullivan (Eds.), Information, influence \& commication. New York: Basic Books.

Lightfoot, S. (1986), On goodness in schools: Themes of empowerment. Peabody Journal of Education, 63(3), 9-28. conference, New orleans, LA.

Hincoin, X. (Ed). (1985). Organizational theory and inguiry: The paradigm revolution. Beverly Hills, CA: Sage Publications.

Lindblom, C. (1959). The science of mudaling through. Public Administration Review, 19, 79-88.

Little, I. \& Bird, T. (1987). Instructional leadership 'close to the classroom; in secondary schools. In W. Greenfield (Ed.), Instructional leadership: Concepts, issues \& controversies (pp. 118-138). Boston: Allyn \& Bacon, Inc.

Locke, E. (1977). Toward a theory of task motivation and incentives. In A. Patz \& A. Rowe, A. (Eds.), Management control and decision system. New York: John wiley \& Sons.

Long, S. (1983a). Covariance structure models: An introduction to LISREL. Beverly Hills, CA: Sage Publications.

Long, I.S. (1983b) Confirmatory factor analysis. Beverly Hills, CA: Sage Publications.

Lorange, P. Morton, M. (1977). A framework for management control systems. In A. Patz \& A. Rowe (Eds.), Management control and decision systems (pp. 17-33). New York: John wiley \& Sons. 
Lortie, D. (1969). The balance of control and autonomy in elementary school teaching. In A. Etzioni (Ed.), The semiprofessions and their organizations (pp. 1-53). New York: Free Press.

Lortie, D. (1975) . Schoolteacher. Chicago: University of chicago Press.

Lortie, D. (1977). Two anomalies and three perspectives: Some observations on school organization. In R. Corwin \& Edelfelt (Eds.), Perspectives on organizations (pp. 20-38). Washington, DC: American Association of Colleges for Teacher Education.

Mahoney, T. \& Frost, P. (1977). The role of technology in models of organizational effectiveness. In A. Patz \& A. Rowe (Eds.). Management control and decision systems (pp. 305320). New York: John Wiley Sons.

Mann, D. (1975) * Policy decision-making in education. New York: Teachers College Press.

Mann, D. (Ed). (1978), Making change happen? New York: Teachers college Press.

Martin, W. \& Willower, D. (1981). The managerial behavior of high school principals. Educational Administration Quarteriy, 17 (1), $69-90$.

Marzano, R., et a1. (1988). Dimensions of thinking: A framework for curriculum and instruction. Alexandria, VA.: Association for Supervision and Curriculum Development.

Masland, A, (1984). Integrators and decision support systems in higher education Research in Higher Education, 20(2), $211-233$.

Maslow, A. (1978). A theory of human motivation. In W. Natemeyer (Ed.), classics of organizational behavior (pp. 42-57). Oak Park, IL: Moore Publishing Co.

May, C. \& Decker, R. (1988), Putting Herzberg's two factor theory of motivation in perspective. Planning and Changing, $19(3), 141-149$.

McDonne11, L. (1985). Implementing lowmcost school improvement strategies. The Elementary School Journal, 85(3), 423-438.

Mctver, J. \& Carmines, E. (1987). Unidimensional scaling. Beverly Hills, CA: Sage Publications. 
Mckeon, R. (Ed.). (1970). The basic works of Aristotle, New York: Random House.

Mclauglin, M. (1978). Implementation as mutual adaptation: change in ciassroom organizations. In D. Mann (Ed.), Making change happen? (pp. $19-31)$. New rork: Teachers college Press.

Mclaughin, M. (1983). State involvement in local educational quality. In A. Odden \& L. Webb (Eds.), School finance and school improvement, linkages for the $1980^{\prime} \mathrm{s}(\mathrm{pp} * 51-68)$. cambridge, MA: Ballinger Publishing $\mathrm{Co}$.

McManama, J. (1971). Systems analysis for effective school administration. West Nyack, NY: Parker Publishing Co.

Meier, R. (1982). Prospects for control theories and research. In J. Gibbs (Ea.). Social control: Views from the social sciences (pp* 265-276). Beverly Hills, CA: Sage Publications.

Meyer, J. (1983). Innovation and knowledge use in American public education. In $J$. Meyer \& W. R. Scott (Eds.), organizational environments: Ritual and rationality (po. 233-260. Beverly Hil1s, CA: Sage Publications.

Meyer, J. \& Rowan, B. (1977). Institutional organizations: Fomal structure as a myth and ceremony. American Journal of Sociologx, 83(2), 340-363.

Meyer, J. \& Scott, W.R. (EdS.). (1983)* Organizationa1 enviromments: Ritual and rationality. Beveriy Hilis, CA: Sage Publications.

Meyer, J., Scott, W.R. Q Dea1, T. (1983). Institutional and technical sources of organizational structure: explaining the structure of educational organizations. In J. Meyer, \& W.R. Scott (Eds.), Organizational environments: Rituals and rationality (pp. $45-67)$. Beverly Hil1s, CA: Sage Publications. (Reprinted from H. Stein (Ed.) . (1981). organization and human services. Temple University Press.)

Miles, M. (1981). Mapping the common properties of schools. In R. Lehming \& $M$. Kane (Eas.), Improving schools: Using what we know (pp. 42-114). Beverly Hills, CA: Sage Eublications.

Miles, R. \& Vergin, R. (1966). Behavioral properties of variance controls. California Management Review, $8(3), 57-65$.

Mintzberg, H. (1971). Managerial work: Analysis from observation. Management Science, 18(2), 97-100. 
Mintzbexg, H., Raisinghani, D. \& Theoret, A. (1976). The structure of "unstructured" decision processes. Administrative Science quarteriy, 21(2), 246-75.

Mitchell, D. (1987). Teaching incentives: Implications for school leadership. In W. Greenfield (Ed.). Instructional leadership: concepts, Issues, and controversies (pp. 204229). Boston: Allyn \& Bacon, Inc.

Mitche11, D. \& Peters, M, (1988). A stronger profession through appropriate teacher incentives. Educational Leadership, $46(3), 74-78$.

Mitche11, T. (1982). Motivation: New directions for theory, research and practice. Academy of Management Review, $2(1)$, $80-88$.

Morgan, G. (1980). Paradigms, metaphors, and puzzle solving in organizations. Administrative Science Quarterly, 25(4), 605622 .

Morxis, V., Crowson, R., Portex-Guthrie, C., \& Hurwitz, E. (1984). Principals in action: The reality of managing schools. Columbus, OH: Merrill.

Morris, I. \& Fitz-Gibbon, C. (1978). Evaluator's handbook. Beverly Hills, CA: Sage Publications.

Murphy, J., Mesa, R, Hallinger, P. (1984). A stronger state role in school reform. Educational Leadership, 42(2), 2026 .

Myers, M. S. (1981). Every emplovee a manager. New York: McGrawHi1l.

Nacoste, R. (1985). Selection procedures and responses to affirmative action. Law and Human Behavior, 2(3), $225-242$.

Nakhnikian, G. (1964). Introduction. In E. Husserl, The idea of phenomenology (pp. xi-xxii). The Haque: Martinus Nijhoff.

Odden, A. \& Odden, E. (1984). Educational reform, school improvement, and state policy. Educational Leadership, 42(2), 13-19.

Ogawa, R. \& Hart, A. W. (1985). The effect of principals on the instructional performance of schools. The Journal of Educational Administration, $23(1), 59-71$. 
Ouchi, W. (1978). Coupled versus uncoupled control in organizational hierarchies. In Meyer, M. \& Associates (Eds.), Environments \& organizations (pp. 264-289), San Francisco: Josseymass, Publishers.

Patterson, J., purkey, S., \& Parker, J. (1986). Productive school systems for a nonrational world. Alexandria, VA: Association for supervision and Curriculum Development.

Patz, A. \& Rowe, A. (1977). A new approach to management control and decision systems. In A. Patz \& A. Rowe (Eds.). Management control and decision systems (pp. 66-73). New York: John Wiley \& Sons.

Pellicer, L. (1982). Providing instructional leadership - a principal challenge. NASSP Bulletin, $66(456), 27-31$.

Perry, J. \& porter, I. (1982). Factors affecting the context for motivation in public organizations. Academy of Management Review, $7(1), 89-98$.

Peterson, K. (1984). Mechanisms of administrative control over managers in educational organizations. Administrative Science ouarterly, 29, 573-597.

Peterson, K. D. , Murphy, J. \& Hallinger, P. (1987). Superintendents' perceptions of the control and coordination of the technical core in effective school districts. Educational Administration Quarterly, 23(1), $79-95$.

pfeffer, J. (1978a). The micrompolitics of organizations. In Meyer, M. \& Associates (Eds,), Environments and organizations (pp. 29-50). San Francisco: Jossey-Bass Publishers.

Pfeffer, J. (1978b). Organizational design. Arlington Heights, IL: AHM Publishing Corp.

Pugh, D., Hickson, D., \& Hinings, C. (1985). Writers on organizations. Beverly Hills, CA: Sage publications.

Quality instruction incentives program. (1984-85). (1985-86). (1986-87). Miami, FL: Dade County Public Schools and United Teachers of Dade.

Quine, W. (1961). From a logical point of view. New York: Harper Torchbooks.

Rapoport, A. (1965). What is information? In O. Lerbinger \& A. Sullivan (Eds.), Information influence and communication (pp. 225-238). New York: Basic Books. 
Rossmillex, R. (1983). Resource allocation and achievement: A classroom analysis. In A. Odden \& $L_{*}$ Webb (Eds*), School Einance and school improvement linkages for the $1980^{\prime \prime}$ (pp. 171-192). Cambridge, MA: Ballinger publishing Co.

Rowan, B. (1985). The assessment of school effectiveness. In Reaching for excellence: An effective schools sourcebook (pp. 99-116). Washington, DC: National Instituce of Education.

Rowan, 8. (1982). Instructional management in historical perspective: Evidence on differentiation in school. districts. Educational Adninistration Quarteriy, 18(1), $43-59$.

Russe11, B. (1970). The problems of philosophy. New Yoxk: Oxford University press.

Russe11, B. (1966). Philosophical essays. New York: Simon * Schuster.

Ruthertord, w. (1985). School principals as effective leaders. Phi Delta Kapoan, 67(1), 31-34.

Ryle, G. (1969). The concept of mind. New York: Barnes \& Noble, Inc.

Schein, E. (1972). Organizational psychology (pp. 76-79). Englewood cliffs, NJ: Prentice Mall, Inc.

Schein, E., Schneier, I. \& Barker, C. (1961). Coercive persuasion: A socio-psychological analysis of the 'brainwashing" of American civilian prisoners by the chinese Communists. New York: W.W. Norton \& Co., Inc.

Schuman, H. \& presser, S. (1981). Questions and answers in attitude surveys: Experiments on question form, wordirg. and context. New York: Academic Press.

Scott, W.R. (1983). The organization of environments: network, cultural, and historical elements. organizational environments: Ritual and rationality (pp. 155-175). In I. Neyer \& W.R. Scott (Eds.), Beverly Hills, CA: Sage publications.

Scott, W. R. \& Meyer, J. W. (1983). The organization of societal sectors. In 3. Meyer \& W.R. Scott (Eas.), organizational enviconments: Ritual and rationality (pp. 129-154). Beverly Hils, CA: Sage Publications.

Scott, J. Scott, S. (Eds.). (1971). Social control and social change chicago: University of chicago Press. 
Sergiovanni, T. (1984). Leadership and excellence in schooling. Educationa1 Leadership, $41(5), 4-13$.

Sergiovanni, T* (1987). The theoretical basis for cultural

leadership. In L. Shieve \& M. Schoenheit (Eds.), Leadership: Examining the elusive (pp. 116-129). (ASCD Yearbook).

Alexandria, VA: Association for Supervision and Curriculum Development.

Shakespeare, w. The two gentlemen of Verona. Act IV, Scene I, Iine 62 .

Shrode, W. \& Brown, W. (1977). A study of optimality in recurrent decision-making of lower-level managers. In $A$. Patz \& $A$. Rowe (Eds.), Management control and decision systens (pp. 292-304). New York: John Wiley \& Sons.

sieber, S. (1981). Knowledge utilization in public education: Incentives and disincentives. In $R$. Jehing \& $M$. Kane (Eds.), Improving schools: Using what we know (pp. 115167). Beverly Hills, CA: Sage publications.

skinner, B.F. (1966). Freedom and the control of men. In $R$. Urlich, Stachnik, T. Mabry, J. (Eds.), Control of human behavior: Expanding the behavioral laboratory, volume 1 (pp. 11-20). Glenview, TL: Scott Foresman and co.

Simon, H. (1957). Administrative Behavior. New York: Macmillan.

Smith, C. Tannenbaum, A. (1963). Organizational control structure: A comparative analysis. Human Relations, 16(4), 299-316.

Smith, N* (Trans.). (1965). Immanuel Kant's Critique of pure reason. New York: St. Martin's Press.

Spector, P. (1981). Research Designs. (University Papers: No.23). Beverly Hils, CA: Sage Publications.

Sproul1, L. (1981). Managing education programs: A microbehavioral analysis. Human organizations, $40(2), 113-122$.

Sproul1, L. \& Zubrow, D. (1981). Performance information in school systems: Perspectives from organizational theory. Educational Administration Quartexly, 17(3), 61-79.

Staw, B. (1975). Attribution of the 'causes' of performance: A general altexnative interpretation of cross-sectional. research on organizations. organizational Behavior and Humar performance, $13(3), 414-431$. 
Stephenson, R. \& Levine, D. (1987). Are effective or meritorious schools meretricious? The Urban Review, 19(1), 25-34.

Stevens, I. (1986). Applied multivariate statistics for the social sciences. Hillsdale, NJ: Lawrence ErIbaum Associates, Publishers.

Sudman, S, \& Bradburn, N, (1983). Asking questions. San Francisco: Jossey-Bass Publishers.

Sullivan, J. \& Feldman, S. (1988). Multiple indicators: An introduction. Beverly Hills, CA: Sage Publications.

Tannenbaum, A. (1968). Control in organizations. New York: MoGraw-Hili.

Tannenbaum, A., et al. (1974). Hierarchy in orqanizations: An international comparison. San Francisco: Jossey Bass Publishers.

Thompson, J. (1967). Organizations in action. New York: McGrawHill.

Tully, M. Farr, R. (1985). The purpose of state level textbook adoption: What does the legislation reveal? Journal of Research and Development in Education, 18(2), 1-6.

Turcotte, W. (1974). Control systens, performance, and satisfaction in two state agencies. Administrative science Quarterly, 19(1), 60-73.

vickers, G. (1967). Towards a sociology of management. New York: Basic Books.

Vroom, V. (1984). Reflections on leadership and decision-making. Journal of General Management, $2(3), 18-36$.

Weick, K. (1985). Sources of order in underorganized systems: Themes in recent organizational theory. In $\mathrm{Y}$. Lincoln (Ed.), organizational theory and inquiry: The paradigm revolution (pp. 106-136). Beverly Hills, CA: Sage publications.

Weick, K. (1976). Educational organizations as loosely coupled systems. Administrative science Quarterly, 21(1), 1-19.

Wellisch, J., Macqueen, A, Carriere, R., Duck, G. (1978). School management and organization in successful schools. Sociology of Education, 51(3), 211-226. 
Wilson, B. Firestone, W. (1987). the principal and instruction: Combining bureaucratic and cultural inkages. Educational Leadership, 45(1), 18-24.

Wirt, F. \& Kirst, M. (1982), Schools in Conflict, Berkeley, CA: Mccutchan Publishing Corp.

Woodward, J. (1970). Management and technology. In J. Shafritz \& P. Whitbeck (Eds.), Classics of organizational theory (pp. 190-206. Oak Park, IL: Moore Publishing Co., Inc.

Zaner, R. (1970). The way of phenomenology. New York: Pegasus. 
Appendix A

School Distxict Approval to conduct Preliminary study with curriculummoriented Principals and staff 
OR. LEONARO ERATTON SUPEETNAENOENWF OF SCWOOLS

DR, RAY TURNER ASSISTART SUFE: RINTENDENT ERUCATIONAL ACCOUNTABHLITY $\{305\} \$ 76 \cdot 2500$

\section{DADE COUNTY PUBLIC SCHOOLS}

BOARD ADMINISTRATION BUILDING

OFFICE OF EDUCATIONAL ACCOUNTABILITY

I 50 NORTHEAST SECONO AVENUE

MIAMI, FLORIDA 33132

Recenber 18, 1986
DADE COUNTY SEHOOL BOA MP, PALIL L, CEJAS, CHAIRMA DF. MICHAEL KFOP, VICE.CHAIRN MP. S. HOLWES BRADDCEK DR, ROSA CASTRO FEIPEERG MS. JAEET R. ACALILEY MR, POEERT RENICK NR, WHLLIAMH. TURNER

Mr. Ira E. Bogotch

13225 S. W. 111 Terrace. Apt. 1

Miami, Florida 33186

Dear Mr. Bogotch:

The Research Review Comithee has approved your request to conduct the study, "ldentifying School Control Variables in Instructional Leadership," with the following provistons:

1. The agreement to participate (or not) in the study is at the discretion of the school principal(s):

2. principal and other school administrator participation in the study must be completely voluntary, and will not exceed one houm: (the time stated for the interview should be femestimated);

3. the data collection efforts for this phase of the study will be completed (in DCPS) by March 31, 1987, and must not interfere with countywide or school testing activities; and

4. precautions must be taken to assure the confidentiality of responses and anonymity of the respondents.

I have enclosed a copy of the readefs' comments pertaining to your study.

We would like to remind you to display the "RRC Approval Nuber" in the upper right corner of the first page of any correspondence to potential participants, and suggest that you provide principals of schools involved a copy of this letter.

Finally, please send a copy of the study abstract to the Research Review Chairperson when the study is completed; and the Comittee wishes you every success in your research activity.

Sincerely yours.

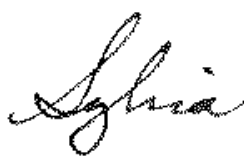

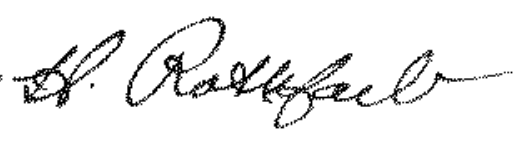

YOAR RESEARCH REVIEW APPROVAL NUMBER IS 118.

Sylvia H. Rothfarb, Pho.

Chairperson

Research Reyiew Commitee

Enclosures 
Appendix B

Interview Guide Used in the Preliminary study 
General Information: fame of the principal and school

number ot years in this postion and in previous position

size of the school, number of administrators temure of state

\section{Questions:}

1. If you were to alvide the job you do as princlpal into two categories, top administrator and instructional leader, what percentages do you think accurately reflect the the you devote to each?

2. What criteria do you think is used to judge your performance as a princlpal?

3. Dade county uses Tabs to evaluate teachers. In adaltion to TADs, do you have any specific goals for judging teacher pertormance?

4. Who does the TADs observations? How are they scheduled? How do you ensuxe consistency in the observations?

5. outside of a postive raps evaluation, do you reward outstanding teachers?

6. When TADs obsexvations reveal a problem, how do you inform the teacher and then monitor that teacher's improvement?

7. What kind of relationship does TADS create between teachers and administrators?

8. How would you improve the teacher evaluation process?

9. I would like to define state development as programs for professional growth. What kinds of staft development programs are avallable to teachers and adminstrators?

10. Is there a schedule of staff development opportuntules? (a schedule of regular meetings, announcoments?)

11. Are teachers given any xewaxds or recogntion for staf development participation?

12. Are recoras kept in this area?

13. What kind of follow-up or feedback 'sharing" is required? encouraged?

24. Would you recommend any changes in this axea?

15. Over the past year or two, what kunds of innovations have 
ocured at the schom? can you describe the process and paxticlpants?

16. Wexe any of the innovations evaluated? How and by whom?

17. In the regular school program, how are high standaras midition

13. Ane programs regulaty gvaluated?

19. Are outstanding programs $;$ ingled out for recognit on?

20. What do you do with lass successful programs?

21. The state and county have approved book 11sts. Do you rely solely on these sources for texts and instructional materials?

22. How would you describe the textbok selection process?

23. Do you keep records of the materials used/Ts this the same process used in changing texts/are these recoxds used in your evaluation of departmerts and the department heads/ how are matexlals evaluated? ldepending on the completeness of the answex to 22 , one of the above guestions was used as a follow wp.)

24. Are you satistied with the selection process?

Genexal Questions

25. To whom axe you most accountable?

26. If you could hire more personnel, what type ot peope would you choose?

27. In the foux areas aiscussed, how much control do you whink you really have? Would you want moke or less?

28. In terms of curxiculum and instruction, what impact do the following have:
a. school budget
b. collective baxgaining agreement
c. state curajculum laws
d. district policy
e. community and parents

29. If I were to walk around the school and ask various people what they thought your goals for the sohool were, what would I hear? 


\section{Appendix C}

School District Approval to Conduct Teacher Survey study at 14 schools 
Please send a copy of the study abstract to the Research Review Comnittee
when the study is complete. when the study is complete. The Comititee wishes you every success in your
research activity. Sincerely yours,

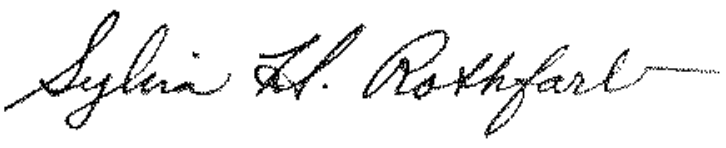

YOUR RESEARCH REVIEW

APPROVAL NUMBER IS 153 .

Dr. Sylvia H. Rothearb

Chairperson

Research Review Comittee

$S H R / p w$ 
Appendix D

Cover Letter and school Managerial control questionnaire 


\section{Florida International Universily}

The State Universily of Flonila at Mitmi

Division of Educational Pollcy and Human Fascure Development

May, 1988

Dear Teachex:

A1 Daje County peincipass axe judged on 19 managertal competencies based on data obtained from the rlorida council on Educational Management. Less emphasis has beengiven to the views of teachers. As a result, school administration research Eindings tend to refiect a decidediy managerial perspective. strong evidence, however, supports the importance of teachers" input in building and maintaining successtul schools.

Your participation is reguested in a research suty that takes an in-depth look at one ot the principals competencies thxough the eyes of teachers. It asks specifically for your views concerning the quality of youx school's administration in accomplishing cuxricular and instructional tasks only.

The attached questionaire takes about 15 minutes to complete. Your responses w112 be completely anonymous. Not eyen your school wil be lientified. The number in the upper right hand corner of the questionaire will permit the researcher to determine the percentage of responses from any one school. No name is attached to any number.

I have arranged with your school administration for assistance in the collection of the questionaire. Simply as a matter of convenience, an "inmbox" will be placed in the office tor you to drop off the completed questionaire. I would prefer that you put the questionaize into the envelope provided and seal it. I will personally come to your school on Monday. May 16 to pick them up. If you wish, you may mail the questionaire to me care of $F^{2}, U$. College of Education.

I. would also be happy to send you a summey of the Eindings if you leave a note in the envelope with your name and address on a separate piece of paper.

I sincerely thank you for your cooperation.
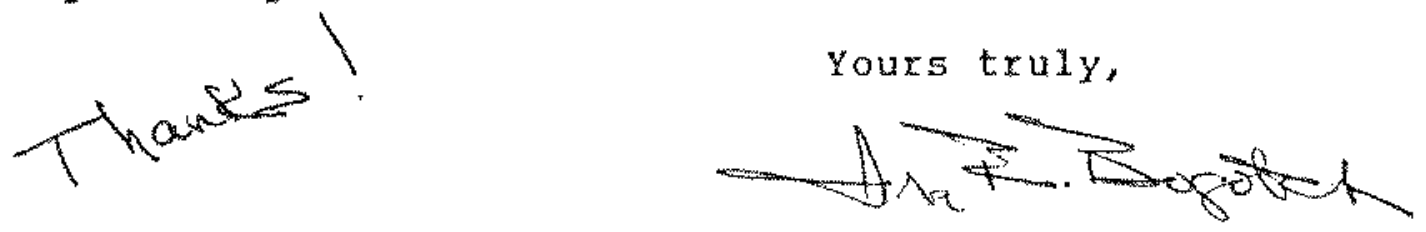

Ixa Ell iot Bogotoh 
School Curricular \& Instructional Management Instrument

No.

Please respond to the following statements about your current principal and school administration. The response choices range frorn:

strongly

disagree

6 disagree

s.

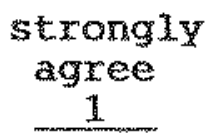

$\operatorname{don}^{5} \mathrm{t}$

know

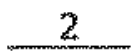

0

1. Classroom observation coments from school administrators about my teaching motivate me to incorporate new teaching behaviors and ideas into my classes

2. The principal does not favor one grade level or department over another when it comes to distributing resources and money for textbooks and instructional materials

3. The principal or administrative staff frequently responds to my ideas for curxicular improvement

4. The process of evaluating teachers occurs at my school more often than just when I am being observed for TADS

5. The principal or other school administrator makes it clear how state and county curricular requirements are to apply to my school, my students, and to the courses I teach

6. The principal or other school administrator frequently reviews good teaching practices with teachers

7. I consider the information I receive from my school administrators regarding teacher evaluation to be adequate

8. The information I obtain from state meetings and inservice activities held at my school give me an adequate understanding of how to do my job well.

9. Providing me with released time and hiring substitutes to cover classes are meaningful ways in which my school administration shows its support of my efforts to improve my courses

10. All grade levels, departments and programs at my school are evaluated on an equitable basis

11. In my opinion, the principal or other school administrator states clearly the classroom teaching behaviors that she/he values most

12. The principal frequent $1 y$ finds ways to meet my requests for more and bettex instructional materials and books

13. The procedures used at my school for selecting textbooks and instructional materials give a tair assessment to the alternative choices 
27. The principal does not favor one grade level or department over another when it comes to distributing resources and money for program development and curricular improvement

28. My school administration provides me with adequate information to participate in curricular planning and innovative projects

29. Time and effort devoted to classroom observations, both formal. and informal, have been worthwhile to me as a teacher

30. The formal and informal assessments by my school administrators of the courses I teach have been worthwhile both for me and for my students

31. The teaching behaviors that my principal would most like to see in the classroom are more ditulcult than those in TaDs

32. The principal expects the academic course requirements for my students to be higher than state and county standards

33. Each year, the principal or other school administrator sets inservice and professional growth guidelines for me and the other teachers

34. Information is regularly available to me at my school regarding the publication of new textbooks and instructional materials

35. In my opinion, the principal equitably rewards teachers whose performance is well-above-average and treats fairly teachers whose performance need improvement

36. All teachers who participate in staf development activities receive the similar kinds of recognition and rewards from the principal and other school administrators

37. My school administration frequenty sends me information regarding staff development opportunities and activities

38. The principal uses the information from classroom visits and observations to generally improve the caliber of teaching at my school

39. The information I receive through my school administration regarding published materials is adequate for deciding on terts and instructional materials

40. The criteria used by the principal and other school administrators to evaluate classroom teachers are fair 
Appendix

Survey Follow-up Letters and sample Memos 
May, 1988

Dear weachex:

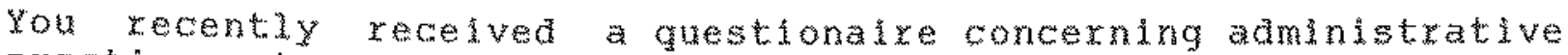
pracilces at your school. The puxpose of the study ls to measure teacher perceptions of curricular and lnstuctional management. and theresore, 1 goes beyond the traditional admingtwative point or vis.

of course. the value of the study is aependent upon the number of teachers who respond from each school. To those of you who have sent in your questomeires, thank you. I you have not yet completed the guescionatze and wish to do so, please fill It out, seal di in the envelope provided, and return th to the school secretaxy. I will return to your school latex in the week to pick up your questonnate. Alternatively, you may send the guestionaixe directly to the college of aducation.

once again, it thank you sor your support.

Sircereng,

Ixa Eliot Bogoten 
TO:

Faculty

FroM:

Vice-Principal

SUDJECT:

FTU Survey

DATE:

May A, 1988

Our school has been selected to participate in a county-wde study of Dade County Administrators. We would appreciate fifteen minutes of your time to complete the attached questionaire. Thank you

Please return the questionaire to a box by Mrs. desk by Tuesday, May 10, 1988 


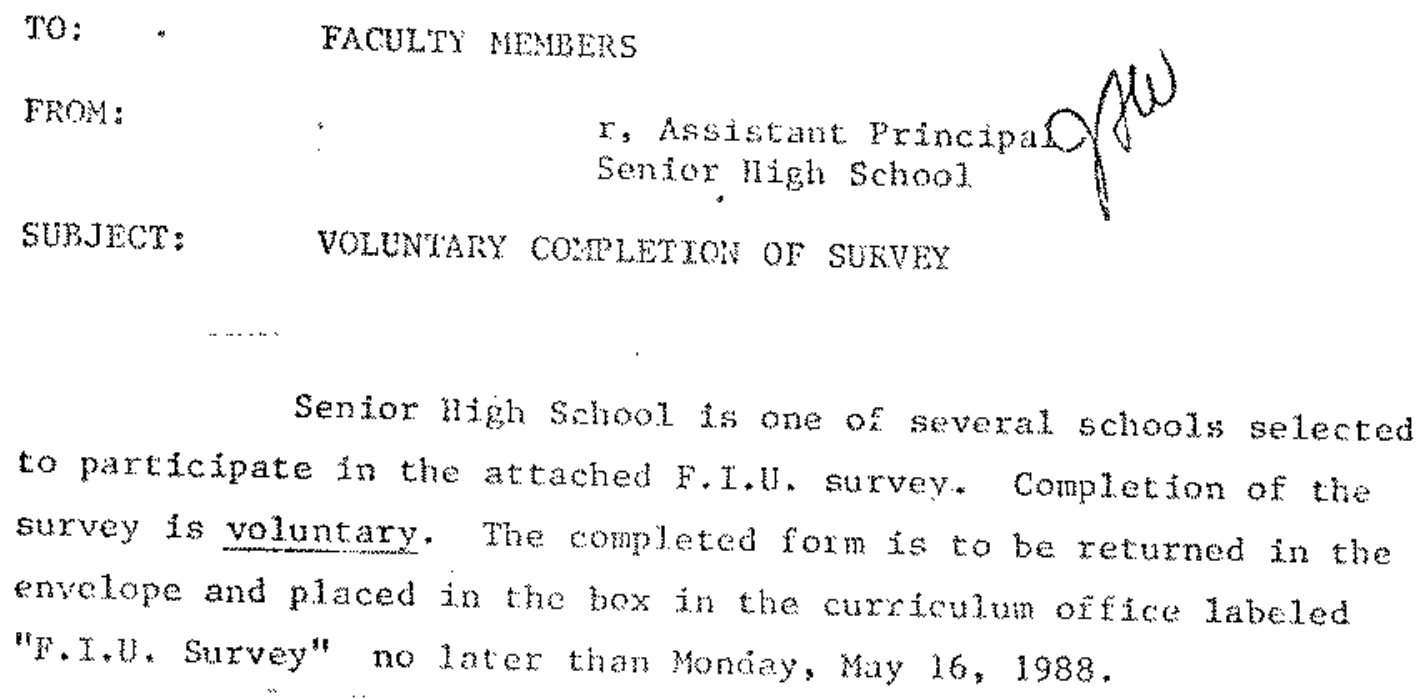

Senior high sinool is one of severat schools selected to participate in the attached F. I.l. survey. Completion of the survey is voluntary. The completed form is to be returned in the ervelope and piaced in the box in the cuxpiculun orfice labeled "W. I. Survey" no later than Monday, May $16,1988$.

ISW/er 